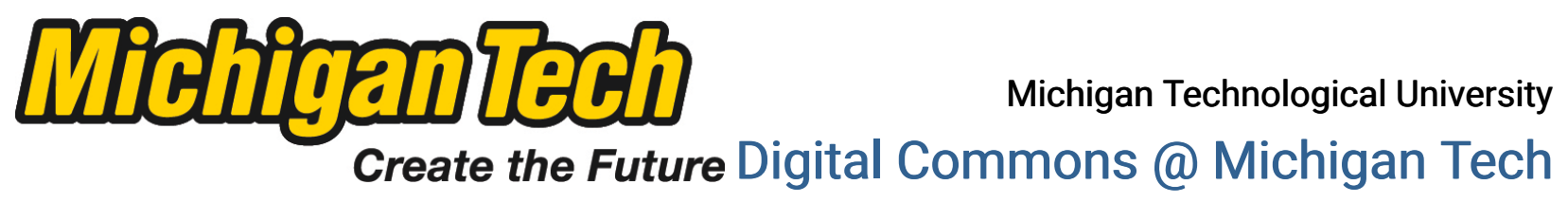

Dissertations, Master's Theses and Master's Reports - Open

2015

\title{
PERFORMANCE-BASED ENGINEERING FOR EVALUATION AND RETROFITTING NON-DUCTILE REINFORCED CONCRETE BUILDINGS INCORPORATING AFTERSHOCK HAZARD
}

Ruilong Han

Michigan Technological University

Follow this and additional works at: https://digitalcommons.mtu.edu/etds

Part of the Civil Engineering Commons

Copyright 2015 Ruilong Han

\section{Recommended Citation}

Han, Ruilong, "PERFORMANCE-BASED ENGINEERING FOR EVALUATION AND RETROFITTING NONDUCTILE REINFORCED CONCRETE BUILDINGS INCORPORATING AFTERSHOCK HAZARD", Dissertation, Michigan Technological University, 2015.

https://doi.org/10.37099/mtu.dc.etds/969

Follow this and additional works at: https://digitalcommons.mtu.edu/etds

Part of the Civil Engineering Commons 


\title{
PERFORMANCE-BASED ENGINEERING FOR EVALUATION AND RETROFITTING NON-DUCTILE REINFORCED CONCRETE BUILDINGS INCORPORATING AFTERSHOCK HAZARD
}

\author{
By \\ Ruilong Han \\ A DISSERTATION \\ Submitted in partial fulfillment of the requirements for the degree of \\ DOCTOR OF PHILOSOPHY \\ In Civil Engineering
}

MICHIGAN TECHNOLOGICAL UNIVERSITY

2015

C2015 Ruilong Han 

This dissertation has been approved in partial fulfillment of the requirements for the Degree of DOCTOR OF PHILOSOPHY in Civil Engineering.

Department of Civil and Environmental Engineering

Dissertation Advisor: $\quad$ Yue $\mathrm{Li}$

Committee Member: William M. Bulleit

Committee Member: Raymond A. Swartz

Committee Member: $\quad$ Ibrahim Miskioglu

Department Chair: $\quad$ David Hand 

This dissertation is dedicated to my parents, Chunshan Han and Huirong Xia, and my wife, Dan Wei, for their endless love and unconditional support. 



\section{Table of Contents}

List of Figures........................................................................................................................................ xi

List of Tables ..........................................................................................................................................

Preface...................................................................................................................

Acknowledgements ...................................................................................................................... xix

List of Abbreviations .................................................................................................................... xxi

Abstract........................................................................................................................................ xxiii

1. Introduction .................................................................................................................1

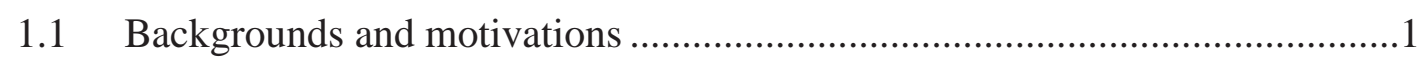

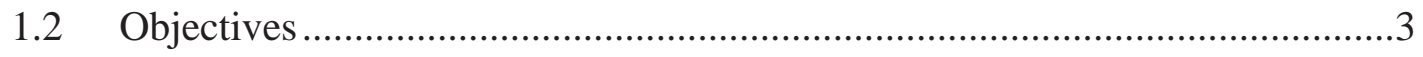

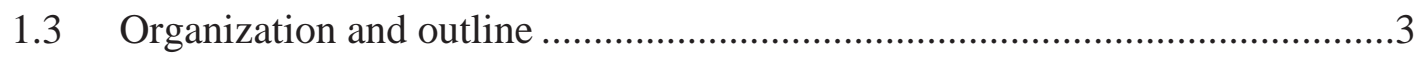

2. Simulation of Aftershock Ground Motions for Seismic Risk Assessment.................7

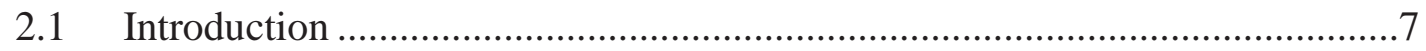

2.2 Mainshock-aftershock sequences ...............................................................10

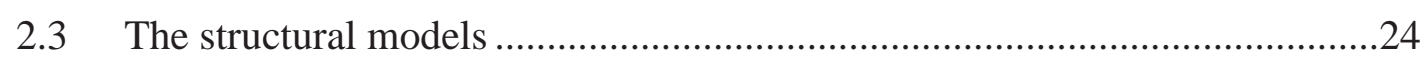

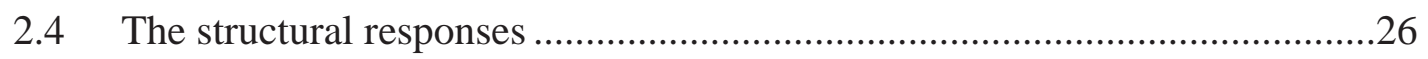

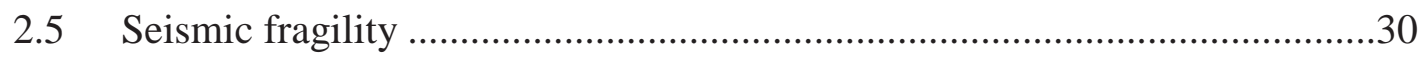

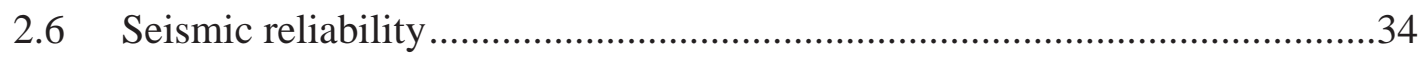

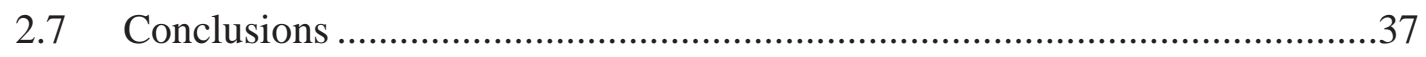

3. Seismic Performance Assessment with Consideration of Aftershock Hazard and

Post-Quake Decisions.....................................................................................................................39

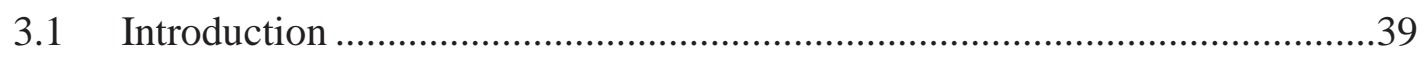

3.2 Post-quake decisions and aftershocks ........................................................

3.3 General equations for seismic performance assessment ................................43

3.4 Case study: seismic performance of RC frame buildings subjected to

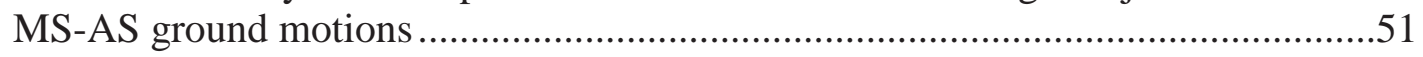

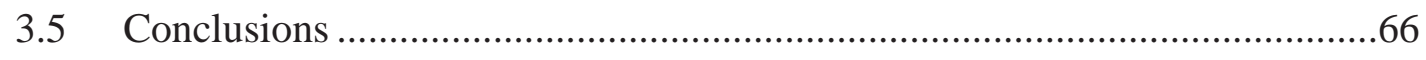

4. Impact of Aftershocks and Uncertainties on the Seismic Evaluation of NonDuctile Reinforced Concrete Frame Buildings ......................................................................67 


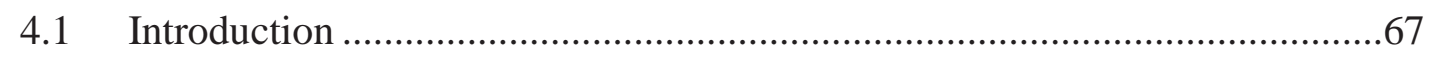

4.2 Post-quake decisions and their interaction with aftershocks..........................68

4.3 Building models and mainshock-aftershock sequences ..................................70

4.4 The influence of aftershocks on the seismic direct loss, downtime, and

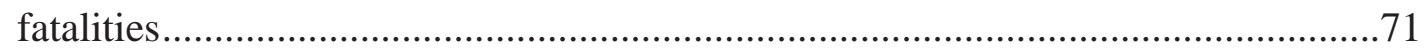

4.5 The uncertainties in decision-making and their influences ............................79

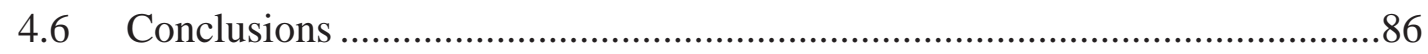

5. Seismic Risk of Base Isolated Non-ductile Reinforced Concrete Buildings Considering Uncertainties and Mainshock-Aftershock Sequences................................89

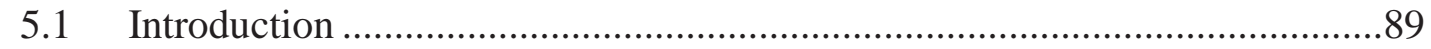

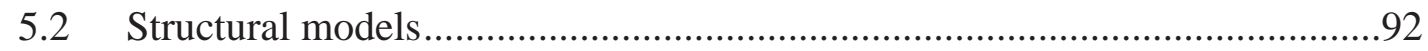

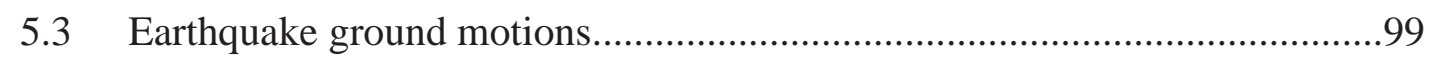

5.4 Seismic fragilities of building components ……………............................100

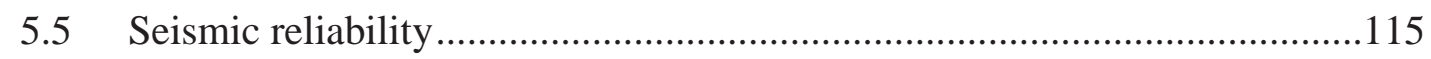

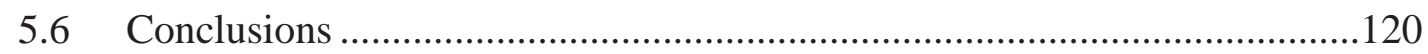

6. Seismic Performance Assessment and Cost-Benefit Analysis of Non-Ductile Reinforced Concrete Buildings Retrofitted with Base Isolation: Considering Mainshock-Aftershock Hazards ...........................................................................................121

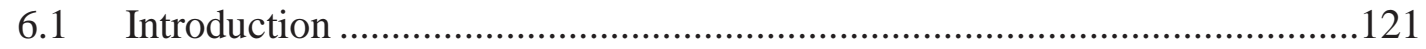

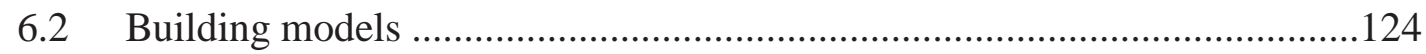

6.3 The mainshock-aftershock earthquake sequences.......................................129

6.4 Seismic performance assessment and cost-benefit analysis .........................134

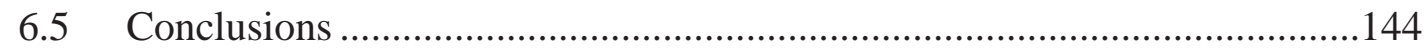

7. Influence of Aftershocks and Base Isolation on the Robustness of Older Reinforced Concrete Buildings................................................................................................145

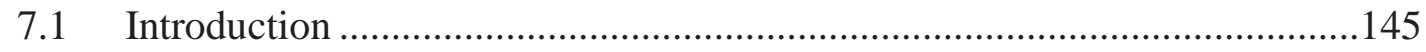

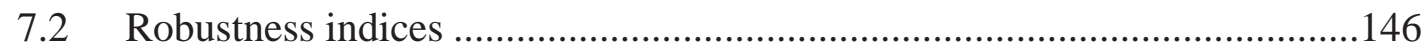

7.3 Building models, mainshock-aftershock ground motions, and loss

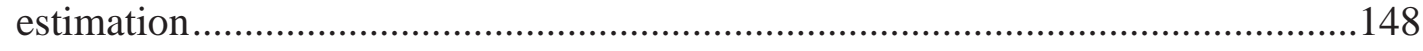

7.4 Seismic losses and robustness indices ........................................................149

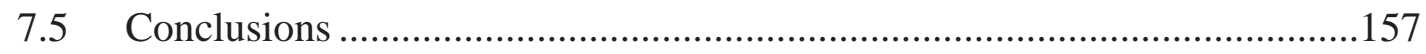

8. Summary, Conclusions, and Future Work...................................................................159

8.1 Summary and Conclusions ……………………………………..............159

viii 
8.2 Future work 160

Bibliography .163

Appendix A: Permission to Publish Chapter 2 ...........................................................175

Appendix B: Document showing that Figure 2.2 is in the public domain .177

Appendix C: Permission to Publish Chapter 5 .183 



\section{List of Figures}

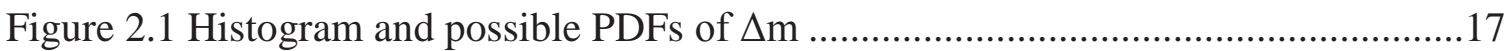

Figure 2.2 USGS map of earthquakes and faults (USGS 2013) ..................................19

Figure 2.3 Geometric relation for deriving the distance from site to rupture plane .........20

Figure 2.4 Time histories of the recorded and the synthesized MS-AS sequence of the

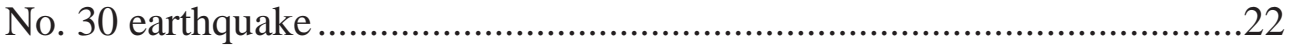

Figure 2.5 Response spectra $(\zeta=5 \%)$ of the suites of mainshocks, recorded, and synthesized aftershocks.....................................................................23

Figure 2.6 Plan, elevations, and reinforcement details of the two buildings ...................25

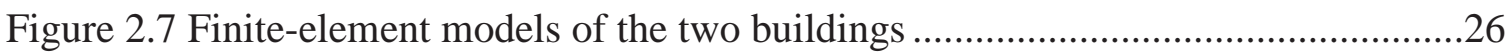

Figure 2.8 Some structural responses of the two buildings .......................................27

Figure 2.9 Some structural responses time histories of the two buildings......................29

Figure 2.10 Seismic demands on the components of the two buildings ..........................31

Figure 2.11 Fragility curves of different components for the buildings under various

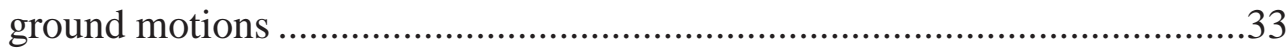

Figure 2.12 Seismic hazard curves for the two buildings in St. Louis, MO .....................35

Figure 2.13 Annual and 50-year PE for the components of the two buildings.................36

Figure 3.1 Flowcharts of performance assessment procedures with and without consideration of aftershock hazard .......................................................42

Figure 3.2 Gantt charts of different repair schemes.....................................................46

Figure 3.3 The population (relative to its peak value) model for office buildings used in FEMA P-58 (FEMA 2012a) ....................................................................50

Figure 3.4 The schematic plots of the two buildings and models.................................52

Figure 3.5 The $S_{a}\left(\mathrm{~T}_{1}\right)$ of the mainshocks, the aftershocks, and the number of aftershocks

Figure 3.6 A MS-AS sequence of Chi-Chi earthquake from station CHY036. .57 
Figure 3.7 The normalized direct loss (DL) of the two buildings 62

Figure 3.8 The normalized downtime (DT) of the two buildings ................................62

Figure 3.9 The normalized fatalities $(\mathrm{Fa})$ of the two buildings ....................................62

Figure 3.10 The normalized total loss (TL) of the two buildings .................................64

Figure 4.1 The assumed repair scheme for the three-story building (schematic) ..............73

Figure 4.2 The histograms of the performance metrics of the buildings under the MS-

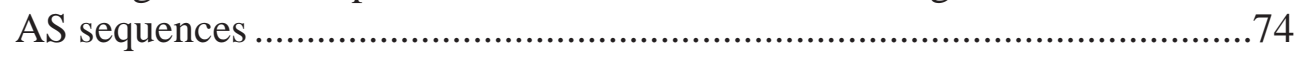

Figure 4.3 Pie charts of the normalized direct loss (NDL) of the two buildings ..............75

Figure 4.4 Pie charts of the normalized downtime (ND) of the two buildings.................76

Figure 4.5 Pie charts of the normalized fatalities (NF) of the two buildings....................76

Figure 4.6 Pie charts of the normalized total loss (NTL) of the two buildings .................76

Figure 4.7 The results of sensitivity study on the three-story building .........................85

Figure 4.8 The results of sensitivity study on the six-story building .............................86

Figure 5.1 The layout of the un-retrofitted building (unit: $\mathrm{mm}$ ) ................................93

Figure 5.2 The finite element model of the un-retrofitted building ...............................94

Figure 5.3 Comparison of the IDA curves of the model in this paper and the reference model using the same earthquake record ................................................95

Figure 5.4 The bilinear force-displacement model for seismic isolation bearings ...........96

Figure 5.5 The target spectra and spectra of the scaled ground motions for BSE-1 and BSE-2 levels ................................................................................97

Figure 5.6 The layout and details of the base isolated building..................................99

Figure 5.7 Acceleration time histories of some MS-AS sequences ..............................100

Figure 5.8 The parametric analysis for the peak inter story drift ratio (PIDR) of the two

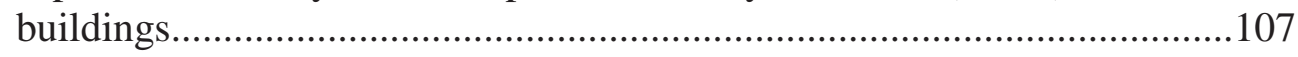

Figure 5.9 The parametric analysis for the peak floor acceleration (PFA) of the two

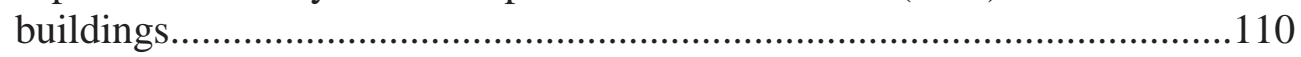


Figure 5.10 The parametric analysis for the peak shear strain (PSS) of the isolated building.....

Figure 5.11 The fragility curves of the building components under Mainshocks and MS-AS sequences

Figure 5.12 The annual and 50-year probabilities of exceedance (PE) at ED and CD levels of the building components under Mainshocks and MS-AS sequences

Figure 6.1 The PIDR of the three-story isolated building at Los Angeles under design ground motions

Figure 6.2 Elevation view of the isolated buildings

Figure 6.3 The seismic hazard curves of St. Louis and Los Angeles

Figure 6.4 The basic procedure of synthesizing aftershock ground motions

Figure 6.5 Examples of an aftershock response spectra set and a MS-AS sequence

Figure 6.6 The histogram and the fitted PDF of the occurrence time of the largest aftershock.

Figure 6.7 The CDFs of the annual direct loss, downtime, fatalities, and total loss of all the buildings.

Figure 6.8 Comparison between retrofit costs and NPVs of different years computed using mean annual avoided direct and total loss.

Figure 7.1 The mean results of the buildings at each intensity level (notation in the legend: $\mathrm{U}=$ an un-retrofitted building; $\mathrm{I}=\mathrm{an}$ isolated building; $3=\mathrm{a}$ threestory building; $6=$ a six-story building; $M=$ under mainshocks; $S=$ under MS-AS sequences)

Figure 7.2 The normalized repair/replacement cost and total financial loss of the buildings at each intensity level (notation in the legend: $U=$ an unretrofitted building; $\mathrm{I}=$ an isolated building; $3=\mathrm{a}$ three-story building; $6=\mathrm{a}$ six-story building; $M=$ under mainshocks; $S=$ under MS-AS sequences)....152

Figure 7.3 The $L_{\text {repair }}$ and $L_{\text {replace }}$ of the buildings at each intensity level (notation in the legend: $3=a$ three-story building; $6=a$ six-story building; $M=$ under mainshocks; $\mathrm{S}=$ under MS-AS sequences)

Figure 7.4 The RI of the buildings at each intensity level (notation in the legend: $3=a$ three-story building; $6=a$ six-story building; $M=$ under mainshocks; $\mathrm{S}=$ under MS-AS sequences). 



\section{List of Tables}

Table 2.1 List of recorded ground motions selected in Chapter 2 ..................................12

Table 2.2 Result of goodness-of-fit tests for the three distributions ..............................17

Table 2.3 The statistical results of the buildings under the two types of aftershocks........28

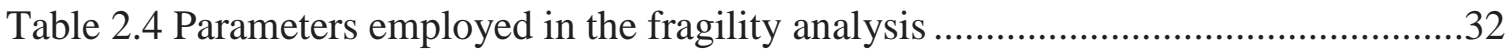

Table 3.1 The fragility groups and relevant information ............................................54

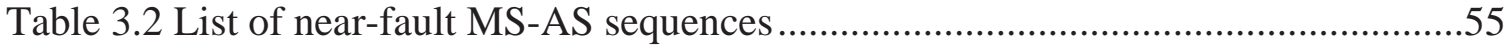

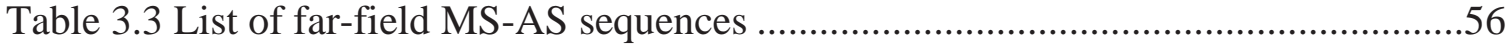

Table 3.4 The story and total values of the two buildings ..........................................59

Table 3.5 The quantities of different component units for the two buildings...................60

Table 3.6 The statistical results of the seismic performance metrics ............................62

Table 3.7 The average percentages of different losses relative to the total loss ...............64

Table 3.8 The statistical parameters of the normalized total loss .................................64

Table 3.9 The statistical parameters of the normalized results .....................................66

Table 4.1 The average contribution of different loss to the total loss of each building.....74

Table 4.2 The parameters of MS-AS sequences that strongly related to the normalized

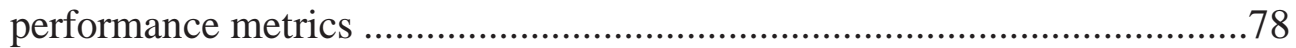

Table 4.3 The target $S_{a \text {, M }}$ of different earthquake groups and information of the scale

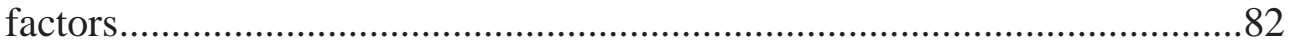

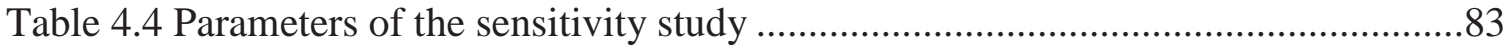

Table 5.1 Ground motions used for design...........................................................97

Table 5.2 Structural capacity $C$ of each component at various damage states ..............103

Table 5.3 System property modification factor $\left(\lambda_{\mathrm{M}}\right)$ of aging and temperature ..............104

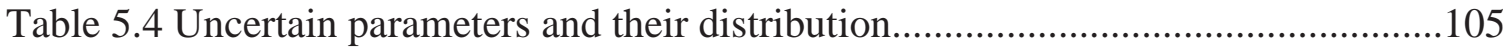


Table $5.5 S_{a}\left(\mathrm{~T}_{1}\right)$ of the two buildings at different hazard levels

Table 5.6 The annual and 50-year probabilities of exceedance (PE) oft SD and MD levels of the building components under Mainshocks and MS-AS sequences

Table 5.7 The upper and lower bound probabilities of exceedance (PE) at ED and CD levels for the structural system of the isolated building under Mainshocks and MS-AS sequences .

Table 6.1 Details about the LRBs and added beams .................................................126

Table 6.2 The average PIDR of each building under the design ground motions ...........126

Table 6.3 Cost of retrofit with base isolation.........................................................127

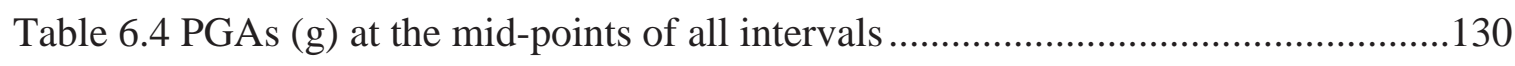

Table 6.5 The annual seismic performance metrics with consideration of aftershocks normalized by the corresponding results without consideration of aftershocks

Table 6.6 The expected annual seismic performance metrics ...................................139

Table 6.7 The break-even time (in years) for the buildings in Los Angeles .................143

Table 7. 1 The Annual loss and corresponding RI...............................................156 


\section{Preface}

A version of Chapter 2 has been published as Assessment of Seismic Performance of Buildings with Incorporation of Aftershocks in the Journal of Performance of Constructed Facilities (http://dx.doi.org/10.1061/(ASCE)CF.1943-5509.0000596). The author performed modeling, data collection, analysis, and writing with the indispensable help from Dr. Yue Li and Dr. John van de Lindt.

A version of Chapter 3 has been submitted to the ASCE-ASME Journal of Risk and Uncertainty in Engineering Systems, Part A: Civil Engineering with title of Seismic Loss Estimation with Consideration of Aftershock Hazard and Post-Quake Decisions, and is in review. The author developed the assessment procedure and relevant equations, performed the case study and summarized conclusions. Dr. Yue Li and Dr. John van de Lindt offered valuable suggestions throughout the procedure.

A version of Chapter 4 has been accepted by Engineering Structures. The modeling, analysis, and results presenting of the manuscript titled with Impact of Aftershocks and Uncertainties on the Seismic Evaluation of Non-Ductile Reinforced Concrete Frame Buildings was also finished by the author, with the valuable comments from Dr. Yue Li and Dr. John van de Lindt.

Chapter 5, Seismic Risk of Base Isolated Non-Ductile Reinforced Concrete Buildings Considering Uncertainties and Mainshock-Aftershock Sequences, has been published in Structural Safety (Volume 50, pp 39-56). The modeling, design, analysis, and paper writing was finished by the author. Dr. Yue Li and Dr. John van de Lindt provided many valuable advices and improved the quality of this paper.

A version of Chapter 6, Seismic Performance Assessment and Cost-Benefit Analysis of Non-Ductile Reinforced Concrete Buildings Retrofitted with Base Isolation: Considering Mainshock-Aftershock Hazards, will be submitted to a journal. The numerical simulation, analysis, and result presentation was finished by the author under the instruction from Dr. Yue Li and Dr. John van de Lindt.

A version of Chapter 7 is based on another manuscript that was also finished by the author. The analysis, discussion, and paper writing was finished by the author with the 
advices from Dr. Yue Li and Dr. John van de Lindt. The manuscript will be submitted to a journal. 


\section{Acknowledgements}

First and foremost I would like to express my sincere gratitude to my advisor, Dr. Yue Li who had offered me continuous mentorship, guidance, inspiration and instruction, which greatly helped my completion of graduate school and research. His support and encouragement through my doctoral research is indispensable, for which I am forever indebted. His high standard for professionalism, work ethics and integrity has shaped me into a scholar who I am today.

I am also grateful to Dr. van de Lindt at Colorado State University. He spent substantial amount of time on developing and training me into a better scholar and researcher. His guidance and inspiration contributed to my academic success and completion of this dissertation. His academic competence guaranteed timely progress of my research. I would also like to acknowledge my committee members, Dr. William Bulleit, Dr. Raymond Swartz, and Dr. Ibrahim Miskioglu for their valuable input and persistent guidance. Without their constructive suggestions and enlightening insight, my academic success would not be possible. I also owe thanks to Dr. Qingli Dai, Dr. Tess Ahlborn, and Dr. Zhen Liu for their advice about both life and research throughout my graduate studies.

During three years graduate study at Michigan Technological University, I am fortune enough to not only earn mentorship but also friendship. I am thankful to my colleagues and friends, Bing Han, Chao Zhang, Abdullahi Salman, Ruiqiang Song, Ji Zhang, Ting Bao, Yadong Dong and many others for their consistent help and support. Because of them, life in a different country became much more wonderful. Good time of being together may come to an end, but the precious moment that we share will never fade in my memory.

This research could not be completed without the financial support of National Science Foundation (NSF) CMMI Division of Civil, Mechanical, and Manufacturing Innovation (Grant No. CMMI-1100423). This support is prerequisite for the smooth progress of the Chapter 2 6. The financial support from the Finishing Fellowship of the Graduate School of Michigan Technological University is also greatly appreciated. Without this support, the study in Chapter 7 would be very difficult to complete. 
Finally, I would like to thank my parents, Chunshan Han and Huirong Xia for their selfless love and constant support. I attribute all my success in doctoral study to the moral, intellectual and physical education that I received from them. Although they are thousands miles away from here, I strongly feel love and warmth from them. I also owe my sincere thanks to my wife, Dan Wei, who has been providing advices and unconditional supports to both my research and life. The nine-hour-driving distance between our universities has never taken our hearts apart from each other. I am so lucky that she is in my world and makes my life more beautiful. 


\section{List of Abbreviations}

\begin{tabular}{|c|c|}
\hline APSHA & Aftershock probabilistic seismic hazard analysis \\
\hline ASNSC & Acceleration sensitive non-structural components \\
\hline CEUS & Central and Eastern United States \\
\hline $\mathrm{CD}$ & Collapse damage \\
\hline $\mathrm{CDF}$ & Cumulative distribution function \\
\hline DS & Damage state \\
\hline $\mathrm{ED}$ & Extensive damage \\
\hline EDP & Engineering demand parameter \\
\hline IDA & Incremental dynamic analysis \\
\hline IDR & Inter story drift ratio \\
\hline IM & Intensity measure \\
\hline LHS & Latin hypercube sampling \\
\hline LRB & Lead-rubber bearing \\
\hline MCS & Monte Carlo simulation \\
\hline MD & Moderate damage \\
\hline MDOF & Multiple-degree-of-freedom \\
\hline MEP & Mechanical, electronic and plumbing \\
\hline MS-AS & Mainshock-aftershock \\
\hline NPV & Net present value \\
\hline NTHA & Non-linear time history analysis \\
\hline PBEE & Performance-based earthquake engineering \\
\hline PDF & Probabilistic distribution function \\
\hline $\mathrm{PE}$ & Probability of exceedance \\
\hline PFA & Peak floor acceleration \\
\hline PGA & Peak ground acceleration \\
\hline PIDR & Peak inter story drift ratio \\
\hline PSS & Peak shear strain \\
\hline
\end{tabular}


$\mathrm{RC}$

Reinforced concrete

RI

Robustness index

RIDR

Residual inter story drift ratio

SD

Slight damage

SDOF

Single-degree-of-freedom

SDSNC

Structural and deformation sensitive non-structural components

UHS

Uniform hazard spectrum

WUS

Western United States

xxii 


\section{Abstract}

Performance-based engineering (PBE) provides a probabilistic tool for assessing the seismic risk and performance of buildings. Only the mainshock hazard has been included in the current PBE framework, although the concern on aftershock hazard has been increased recently. This study develops methodologies to incorporate aftershock hazard into a PBE framework, and assesses the seismic risk and performance of non-ductile reinforced concrete $(\mathrm{RC})$ frame buildings under mainshock and aftershock hazards. A seismic retrofit strategy for these buildings, base isolation, is also evaluated using the developed methodologies.

A methodology for synthesizing aftershock ground motions is proposed and validated to resolve the challenge imposed by limited aftershock records. Seismic risks for two nonductile RC frame buildings representing low-rise and mid-rise buildings are examined. Results show that aftershocks can increase structural responses and seismic risk. Based on the state-of-the-art mainshock-based performance assessment methodologies, a new assessment methodology is developed with incorporation of aftershock hazard. The interactive effects between a variety of post-quake decisions and aftershocks are also considered. The proposed methodology is utilized to estimate the direct loss, downtime, and fatalities for two RC frame buildings under MS-AS sequences. Results suggest that aftershocks can cause significant additional seismic loss. The characteristics of MS-AS sequences that may be the cause of the aftershock-induced additional consequence in terms of loss, downtime, and fatalities are discussed and identified through a statistical analysis. The important sources of uncertainty of post-quake decisions are also investigated though a sensitivity study.

A comparative study is also performed for a $\mathrm{RC}$ frame building before and after being retrofitted with base isolation to determine the risk mitigation due to base isolation. The seismic risk is found to be effectively reduced by base isolation. The effect of various sources of uncertainties in the base isolation system are investigated through a sensitive study using mainshock-aftershock (MS-AS) ground motions at a variety of intensity levels. The most important uncertainty sources are identified. Life-cycle cost-benefit analysis is also performed for the two RC frame buildings to evaluate the economical

effectiveness of adopting base isolation as a seismic retrofit strategy with consideration of mainshock and aftershocks. It is revealed that the benefit from base isolation can 
outweigh the additional cost for buildings in regions with high seismicity, and that the benefit is more significant when aftershocks are considered. The influence of aftershocks and base isolation on the structural robustness is investigated. Limitations and future works are also presented. 


\section{Introduction}

\subsection{Backgrounds and motivations}

Reinforced concrete (RC) frame buildings that were constructed prior to modern seismic design codes tend to exhibit non-ductile behavior under seismic excitation, which leads to substantial casualties and economic loss during earthquakes. This type of buildings includes the typical RC frame buildings built before the mid-1970s in Western United States (WUS) (Liel and Deierlein 2008) and those built before the late 1990s in Central and Eastern United States (CEUS) (Celik and Ellingwood 2009). These buildings also have higher seismic damage probability and expected repair cost for the damage induced by earthquakes than their counterparts which were built per modern codes (Goulet, et al. 2007; Haselton, et al. 2010).

Additionally, many recent major earthquakes have strong aftershocks following a mainshock, such as the 1994 Northridge earthquake (Hauksson, et al. 1995), the 2008 Wenchuan earthquake (Huang, et al, 2008), and the 2011 Tohoku earthquake (Asano, et al. 2011). Recent research found that aftershocks shortly following a mainshock may have large magnitude, high peak ground acceleration (PGA), and different frequency content from those of the mainshock (Ruiz-García and Negrete-Manriquez 2011). Therefore, aftershocks have the potential to incur additional damage to the buildings that conventionally only designed for earthquake mainshock hazard. The situation that a building suffered more severe damage during aftershocks was observed many times. For example, during the 1999 Turkey Kocaeli earthquake, a building sustained only minor damage after the mainshock of magnitude 7.4 but then collapsed during an aftershock of magnitude 5.9 about a month later (USGS 2000). During the 1999 Taiwan earthquake, a gas station also collapsed after an aftershock instead of the mainshock (Lew, et al. 2000). In the 2002 Italy earthquake, the mainshock caused slight damage to the beam-column joint of a reinforced concrete $(\mathrm{RC})$ frame building but was reported to have developed into a much more severely damaged condition due to an aftershock (Yeo and Cornell 2005). Because these non-ductile RC frame buildings are highly vulnerable to earthquakes, approaches to mitigate their seismic risk must be determined and applied.

Among all the potential seismic retrofit methods, base isolation is a relatively new approach to "isolate" the superstructure from the earthquake ground motion, which has 
unique advantages in greatly reducing both the deformation and acceleration of the superstructure. When base isolation is utilized for retrofitting an existing building, the parts connecting the superstructure and the footings are removed and replaced by a base isolation system, whereas the superstructure needs little structural retrofit work (Mokha, et al. 1996; De Luca, et al. 2001). By selecting proper lateral stiffness of the isolation layer, the fundamental period of the building can be shifted to a spectral range with smaller spectral accelerations, and therefore the base shear and consequently the structural responses can be reduced. The retrofit work will induce minimal interruption for the superstructure occupancy and operation, which is an important advantage for stake holders and decision makers.

Many studies have revealed that the responses of the isolated structure are significantly smaller compared with the fixed base structure (Karim and Yamazaki 2007; Sayani and Ryan 2009; Zhang and Huo 2009). Most of previous studies compared the seismic demands (e.g. inter story drift ratio, floor acceleration, and base shear) for the two types of building structures, and a limited number of investigations examined the seismic risk of isolated bridges or nuclear plants based on probabilistic methods to incorporate the uncertainties in seismic demands, structural capacity, and seismic hazard. However, there is a lack of investigation on the seismic risk mitigation and performance improvement of civil buildings by adopting base isolation from a probabilistic view. And yet the uncertainties related to base isolation and other methods still need to be investigated.

Performance-based earthquake engineering (PBEE) provides a powerful tool for analyzing the seismic performance of buildings with explicit consideration of all the uncertainties, and thus is suitable to be applied for the assessment of base isolated nonductile RC frame buildings. PBEE also offers the stakeholders probabilistic explanation about the performance of building systems, such as monetary loss, downtime, and fatalities, to help them better understand the cost and benefit of the retrofit method and consequently make better informed decisions. Nevertheless, the current PBEE only considers the earthquake mainshock hazard, and therefore it is important to incorporate the aftershock hazard into the present PBEE framework.

The motivations of this study come from: (1) previous studies on base isolation mostly utilized deterministic methods, but the uncertainties and seismic performance of base isolated RC frame buildings have not been well investigated based on PBEE. And (2) the conventional PBEE method cannot consider aftershock hazard, which may cause 
underestimation in the results, so a method that can incorporate the aftershock hazard into PBEE framework with sufficient convenience and adequate accuracy is necessary to be developed.

\subsection{Objectives}

The aim of this study is to develop methodologies to incorporate aftershock hazard into a PBEE framework, and use the improved framework to assess the seismic risk and performance of non-ductile RC frame buildings that are retrofitted using base isolation with consideration of aftershock hazard. The specific objectives include follows.

1. Develop a methodology that is applicable to simulate aftershock ground motions, and examine the impact of aftershocks on the seismic risk of non-ductile RC buildings.

2. Develop a methodology for assessing multiple seismic performance metrics with incorporation of aftershock hazard based on current mainshock-based seismic performance assessment methodologies. Investigate the differences in seismic performance of non-ductile RC frame buildings due to aftershocks.

3. Examine the impact of aftershocks and post-quake decisions on the seismic performance of non-ductile RC frame buildings. Identify the characteristics of mainshock-aftershock (MS-AS) sequences that may be related to the ability to cause consequences that are different from the consequences due to mainshocks.

4. Investigate the influence due to the uncertainties of a base isolation system with the consideration of aftershocks, and examine the seismic risk mitigation by applying base isolation on non-ductile RC frame buildings.

5. Investigate the life cycle cost and benefit of retrofitting non-ductile RC frame buildings with base isolation, considering mainshock and aftershock hazard.

6. Examine the influence of aftershocks and base isolation on the robustness of nonductile RC frame buildings.

\subsection{Organization and outline}


The material contained in each of the chapters from Chapter 2 7 is from a single paper that has either been published by a journal, submitted to a journal, or will be submitted to a journal. Chapters 2 7 are summarized as follows.

Chapter 2 proposes a methodology to synthesize aftershocks based on the information of the mainshocks, which is able to incorporate the uncertainties of ground motions and can be utilized for generating aftershock ground motions for seismic risk analysis. The proposed method is illustrated by application to risk analysis for two nonductile RC frame buildings, and is validated by comparing with the results obtained using recorded MS-AS sequences. The results calculated when only mainshocks are considered are also studied to investigate the MS-AS effects. The study shows that the synthesized MS-AS sequences using the proposed method can yield results statistically close to the recorded sequences. The results also reveal that only considering the mainshock will underestimate the seismic risk.

Chapter 3 discusses the effects of aftershocks and post-quake decisions on seismic performance. An assessment procedure in accordance with other PBEE based methods, but also with the ability to consider aftershocks, is proposed. A framework is developed according to the procedure. An illustrative case study is also presented using two non-ductile RC frame buildings. A total of 18 near-fault and 60 far-field recorded MS-AS sequences are employed in the example. The case study shows that MS-AS sequences can result in significantly more serious consequences than when only the mainshock is considered. Also, using only one aftershock instead of multiple aftershocks is found to be an acceptable balance between computational effort and accuracy.

Chapter 4 assesses the seismic performance of two non-ductile RC frame buildings with consideration of aftershocks and various post-quake decisions. The assessment investigates the direct loss, downtime, fatalities, and total loss of the buildings with incorporation of the interaction between the aftershocks and post-quake decisions. A total of 60 recorded MS-AS sequences are utilized in the analysis. The different results between the methods with and without the consideration of aftershocks are compared. The characteristics of MS-AS sequences that may be the cause of the difference are discussed and identified. Important uncertainty sources of the postquake decisions are also investigated through a sensitivity study. 
Chapter 5 performs seismic risk assessment for an old non-ductile RC frame building before and after retrofit with base isolation. Various sources of uncertainty such as structural uncertainties, ground motions uncertainties and modeling uncertainties are discussed and propagated in the analysis procedure. A sensitivity study is also conducted to determine which structural parameters have the most significant impact on the seismic demands of both the un-retrofitted and base isolated building. A suite of recorded mainshock and aftershock ground motions is utilized to investigate the influence of considering aftershocks on the performance of these types of buildings. The study reveals that base isolation can greatly reduce the seismic risk for higher damage levels, as one would expect. More importantly, the results also indicate that neglecting aftershocks can cause considerable underestimation of the seismic risk.

Chapter 6 performs seismic performance assessment and cost-benefit analysis on two non-ductile RC frame building before and after being numerically retrofitted with base isolation, so that whether base isolation is economical when the benefits and costs are compared can be determined. Locations of the buildings are assumed to be Los Angeles, CA and Saint Louis, MO to represent regions with higher and lower seismicity, respectively. Aftershock ground motions are generated to examine the influence of aftershock hazard. Direct loss, downtime, fatalities, and total loss for each of the buildings are investigated. Results suggest that base isolation can reduce the seismic loss, downtime, and fatalities effectively, but the benefits only outweigh the costs for buildings in Los Angeles and not in Saint Louis. The effect on the results caused by indirect losses from downtime and fatalities is quantified and shown to be substantial. Aftershock hazard is also found to have relatively significant impact on the results.

Chapter 7 presents robustness assessment for two non-ductile RC buildings before and after being retrofitted with base isolation, using the results of loss estimation. Aftershock hazard is also included in this study. The influence of aftershocks and base isolation on the seismic loss and robustness is investigated. Results show that the seismic loss increases significantly due to aftershocks and decreases greatly due to base isolation. However, their influences on the robustness are complicated. The advantage and limitation of the adopted robustness measure is also discussed. 



\section{Simulation of Aftershock Ground Motions for Seismic Risk Assessment ${ }^{1}$}

\subsection{Introduction}

Constructed facilities in seismically prone areas are not only damaged by mainshock earthquakes but may be damaged by one or more aftershocks. Though advanced computational models have been achieved for seismic analysis and design methods for several decades, current design approaches only consider the effect of mainshocks on structures. However, many earthquakes have strong aftershocks that follow the mainshock, such as the 1994 Northridge earthquake (Hauksson and Jones 1995), the 1999 Chi-Chi Earthquake (Kao and Chen 2000), the 2008 Wenchuan Earthquake (Huang, et al. 2008), the 2010 Darfield and 2011 Christchurch Earthquake (Smyrou, et al. 2011), and the 2011 Tohoku Earthquake (Asano, et al. 2011). Observations during earthquakes over the past several decades also revealed that structures that experience mainshocks are more vulnerable to damage from aftershocks. For example, following the 1985 Mexico City earthquake, dozens of damaged RC buildings were determined to be incapable to withstand aftershocks, and consequently they had to be demolished to prevent potential future loss (Rosenblueth and Meli 1996).

A few studies have been completed that investigated the structural responses and other effects induced by aftershocks. Some of them focused on simulating the nonlinear behavior of single-degree-of-freedom (SDOF) systems (Mahin 1980; Aschheim and Black 1999; Amadio, et al. 2003; Sunasaka and Kiremidjian 1993; Nazari, et al. 2013). For example, Mahin (1980) investigated the ductility factor, $\mu$ (defined as the maximum deformation of elastoplastic system normalized relative to the yield deformation of the system) of an elastoplastic SDOF system under the MS-AS sequences of the 1972 Managua Earthquake. Aschheim and Black (1999) utilized a hysteretic pinching model of SDOF system to simulate the effect of mainshocks, but they only accounted for the effect of stiffness degradation. Amadio, et al. (2003) also studied the nonlinear responses of SDOF systems, but focused on only three ground motions.

\footnotetext{
${ }^{1}$ The material contained in this chapter was previously published in Journal of Performance of Constructed Facilities and is re-used herein with permission from ASCE. The permission is presented in Appendix A.
} 
Since employing the SDOF systems to represent multiple-story building is idealized and not necessarily accurate, in recent years, research has been mostly focused on the response of multiple-degree-of-freedom (MDOF) systems. Lee and Foutch (2004), as well as Li and Ellingwood (2007) investigated the responses of two steel momentresisting frames in the Los Angeles area when artificial MS-AS sequences were applied. Li and Ellingwood (2007) utilized the method that Sunasaka and Kiremidjian (1993) developed to determine scale factors, which were later employed to scale the ground motions as aftershock ground motions. They also proposed a methodology to randomize the combination of designated mainshocks and scaled aftershocks so that the stochastic characteristics of MS-AS sequences can be simulated. They found that replicating the mainshock as the aftershock would yield different results than results obtained using the randomized method, and using the repeated mainshock as the aftershock would overestimated the maximum inter story drift demands. Hazigiorgious and Liolios (2010) conducted multiple parametric analyses on the inelastic response of 8 low-rise and midrise RC frames (including 4 with regular and 4 with irregular structural configurations) under 5 recorded and 40 synthesized MS-AS sequences. Their conclusions suggested that the MS-AS sequences require more displacement ductility demands than only mainshocks requires. Ruiz-García and Negrete-Manriquez (2011) investigated the maximum and residual drift demands of three steel frame buildings under 64 recorded MS-AS sequences obtained from the 1994 Northridge Earthquake and the 1980 Mammoth Lakes Earthquake. They found that the frequency characteristics of the mainshocks and aftershocks, including predominant period and bandwidth, have only weak statistical correlations. Yin and Li (2011) proposed a method for loss estimation of light-frame wood buildings utilizing scaled ground motions as aftershocks. The magnitude and time interval were calculated based on the modified Omori's Law (Utsu 1961). The results of the loss estimation for an illustrative light-frame building showed that aftershocks and downtime cost are the most important part of total seismic loss. More recently, Jeon, et al. (2012) studied the maximum inter story drift of a non-ductile $\mathrm{RC}$ frame building utilizing cyclic pushover loading to simulate the mainshock induced structural damage, then use nonlinear time history analysis (NTHA) as aftershocks. Their methodology also incorporated uncertainty of both ground motions and structural capacities. They concluded that the seismic demands during aftershocks would increase as the sustained damage caused by mainshocks increase.

It should be noted that for those limited studies about the effect of MS-AS sequence, no consensus has been achieved with regards to how MS-AS should be simulated. Yeo and 
Cornell (2009a) proposed a framework on aftershock probabilistic seismic hazard analysis (APSHA), and investigated the time-dependent occurrence rate of aftershocks, simulation of site-to-source distance and the parametric influence on aftershock hazards. The issue of how to simulate aftershock accelerograms for structural analysis was not discussed. Ruiz-García and Negrete-Manriquez (2011) suggested that the best way to simulate MS-AS is to use the recorded aftershock data. However, this is unfeasible for many situations, since there is limited number of earthquakes aftershock records. Even for recent earthquakes which were well recorded, only some of the seismic stations have recorded all the aftershocks. Consequently, it would be difficult to find enough aftershock records to conduct seismic analysis for a building if it is located at a certain area where only mainshocks and insufficient aftershocks were recorded. Therefore, it is necessary to find a method to simulate the aftershocks based on the mainshocks or the building's site location.

Damage indices establish the connection between a building's seismic response and damage states, which makes them important parameters for seismic analysis. The damage indices employed by the aforementioned studies are all deformation-related, such as peak and residual inter story drift, which have been proved to be a good indicator for damage of structural components (FEMA 2000a). Nonetheless, seismic damage also affects nonstructural components. The damage to nonstructural components can cause economic loss, suspension of building function and loss of life (Whittaker and Soong 2003; ATC 2008; FEMA 2012b). It may be surprising but research showed that cost of structural components for public buildings only accounts for $8-18 \%$ of total costs of the buildings, whereas the nonstructural components (including contents) account for $82-92 \%$ of the total cost (Whittaker and Soong 2003), which indicates that the economic loss can be mainly from damage to nonstructural components in an earthquake. Therefore, considering the seismic damage to nonstructural components is essential for a comprehensive seismic risk assessment. Damage to some types of nonstructural components such as plaster partitions, masonry infill and glass is deformation sensitive and can be well represented by displacement-related indices (Whittaker and Soong 2003), other components such as electronics, mechanical equipment, plumbing systems are vulnerable to inertial forces that induce sliding, swinging or overturning, an rely on acceleration-related indices such as the peak acceleration at each floor which can be selected to represent their damage states (Whittaker and Soong 2003). 
The main purposes of this chapter is to find a general methodology that can be employed for seismic risk analysis including the synthesized MS-AS effects, and to further understand the seismic response of MDOF systems under MS-AS sequences. To achieve those objectives, 32 recorded MS-AS sequences from the Western United States are utilized. Then a method to synthesize aftershock ground motions based on the mainshock records and information is proposed. Monte Carlo Simulation (MCS) with Latin hypercube sampling (LHS) is employed to simulate the uncertainties of aftershock ground motions. The MCS with LHS approach utilizes a stratified sampling scheme which provides comparable results but requires much less computational effort than the ordinary MCS (McKay, et al. 2000; Celik and Ellingwood 2010), thereby reducing the computational effort in the present study. To compare the effects of both the recorded MS-AS sequences and the recorded-mainshock-synthesized-aftershock sequences (hereafter referred as synthesized MS-AS sequences), NTHA using both suites of sequences is conducted in a "back-to-back" analysis in OpenSees (Mazzoni, et al., 2006) on two analytical models, which are based on two non-ductile RC frame buildings and validated by being compared with the models employed in the reference (Celik and Ellingwood 2009). Responses parameters including peak inter story drift ratio (PIDR) and peak floor acceleration (PFA) are investigated and compared. Risk assessment using result from both suites of ground motion is then conducted. The proposed method of synthesizing aftershocks based on mainshocks can also be applied beyond the scope of risk analysis.

\subsection{Mainshock-aftershock sequences}

As mentioned previously, recorded MS-AS sequences can yield accurate structural responses (Ruiz-García and Negrete-Manriquez 2011). Therefore, a suite of recorded MS-AS sequences are selected and employed as ground motions for comparison. A mainshock generally is followed by a number of aftershocks, which means the most accurate way to consider the MS-AS effect is to employ all the aftershock ground motions according to their time sequence. However, this would be too time consuming, let alone the records of entire aftershock sequences in a same seismic station are rare. Lee and Foutch (2004) found that the repeated identical earthquake only caused slightly more damage to structures than the one same earthquake did. So, for the purpose of the

preliminary study, using only a single "largest" aftershock from the aftershock sequence in a MS-AS sequence will yield results with sufficient accuracy. The same method is also employed in the research of Li and Ellingwood (2007). However, an explanation of how 
to determine the "largest" aftershock is still needed, because there are various parameters that are used to define the intensity of a ground motion, such as the magnitude $(M)$, peak ground acceleration (PGA) and spectral acceleration $\left(S_{a}\right)$. Although for the response of a specific structure, the spectral acceleration at fundamental period $\left(S_{a}\left(\mathrm{~T}_{1}, \zeta\right)\right)$ is most relevant, the magnitude of an aftershock $\left(M_{\mathrm{a}}\right)$ is most easy to obtain. Additionally, since $M_{\mathrm{a}}$ is related to the mechanism of the earthquake, it is also one of the most predicable parameter for aftershocks (Sunasaka and Kiremidjian 1993; Utsu 1961; Båth 1965).Therefore, the "largest" aftershock is considered as the one with the largest magnitude in the aftershock sequences.

\subsubsection{The recorded MS-AS sequences}

The 32 recorded MS-AS ground motions are obtained from strong motion databases including the Center for Engineering Strong Motion Data (CESMD) (CESMD 2013) and the Pacific Earthquake Engineering NGA Database (PEER NGA) (PEER Ground Motion Database 2013). The total number of sequences is big enough to yield reliable results (Haselton, et al. 2012). Each sequence consists of a mainshock motion, a three min time interval and a following aftershock motion. The structure is in static condition before subjecting to the aftershock. The aftershocks that are selected in this study mostly occurred within a week after the mainshock occurred, which suggests the building would not have been repaired when the aftershock occurred because there is not enough time. Therefore using the back-to-back earthquake records is felt to be realistic.

The criteria for selecting MS-AS records include: (1) that the earthquake and recorded stations are located in Western United States; (2) the aftershock records is the one with largest magnitude in the aftershock sequence; (3) the minimum aftershock magnitude of interest is taken as 5.0 (Yeo and Cornell 2005; Yin and Li 2010); (4) the site-to-source distances are larger than $10 \mathrm{~km}$ so that they can be classified as far-field ground motions (FEMA 2009b); and (5) the site conditions should be similar in the site classification (ASCE 2010).. Those earthquakes include the 1979 Imperial Valley Earthquake, the 1980 Livermore Earthquake, the1980 Mammoth Lakes Earthquake, the 1983 Coalinga Earthquake, the 1986 Chalfant Valley Earthquake, the 1987 Whittier Narrows Earthquake, the 1992 Petrolia Earthquake and the 1994 Northridge Earthquake. The moment magnitudes of the mainshocks $\left(M_{\mathrm{m}}\right)$ range from 5.80 to 7.20 , and the magnitudes of aftershocks $\left(M_{\mathrm{a}}\right)$ vary from 5.01 to 6.70 . The average shear wave velocity in the upper 30 meters $\left(V_{\mathrm{S} 30}\right)$ of each station mostly lies between $200 \mathrm{~m} / \mathrm{s}$ and $400 \mathrm{~m} / \mathrm{s}$, which implies 
their site conditions are similar and can be classified as soil when employing the attenuation equation proposed by Abrahamson and Silva (1997). The details of all the MS-AS sequences are presented in Table 2.1.

Table 2.1 List of recorded ground motions selected in Chapter 2

\begin{tabular}{|c|c|c|c|c|c|}
\hline No. & Earthquake & Magnitude & Record Name & Station Name & Database \\
\hline \multirow[t]{2}{*}{1} & \multirow[t]{2}{*}{ Coalinga } & 6.36 & NGA_no_368_H-PVY045.AT2 & \multirow{2}{*}{\begin{tabular}{l}
\multicolumn{2}{l}{ PLEASANT } \\
VALLEY \\
YARD
\end{tabular}} & \multirow{2}{*}{$\begin{array}{l}\text { PEER } \\
\text { NGA }\end{array}$} \\
\hline & & 5.09 & NGA_no_383_A-PVY045.AT2 & & \\
\hline \multirow[t]{2}{*}{2} & \multirow[t]{2}{*}{ Coalinga } & 6.36 & NGA_no_368_H-PVY135.AT2 & \multirow{2}{*}{$\begin{array}{l}\text { PLEASANT } \\
\text { VALLEY P.P. } \\
\text { YARD }\end{array}$} & \multirow{2}{*}{$\begin{array}{l}\text { PEER } \\
\text { NGA }\end{array}$} \\
\hline & & 5.09 & NGA_no_383_A-PVY135.AT2 & & \\
\hline \multirow[t]{2}{*}{3} & \multirow{2}{*}{$\begin{array}{l}\text { Chalfant } \\
\text { Valley }\end{array}$} & 6.19 & ChalfantValley86_CE54171P.V2 & \multirow[t]{2}{*}{ NO. 54171} & \multirow[t]{2}{*}{ CESMD } \\
\hline & & 5.44 & ChalfantValley86C_CE54171P.V2 & & \\
\hline \multirow[t]{2}{*}{4} & \multirow{2}{*}{$\begin{array}{l}\text { Chalfant } \\
\text { Valley }\end{array}$} & 6.19 & ChalfantValley86_CE54428P.V2 & \multirow{2}{*}{ NO.54428 } & \multirow{2}{*}{ CESMD } \\
\hline & & 5.44 & ChalfantValley86B_CE54428P.V2 & & \\
\hline \multirow[t]{2}{*}{5} & \multirow{2}{*}{$\begin{array}{l}\text { Chalfant } \\
\text { Valley }\end{array}$} & 6.19 & ChalfantValley86_CE54424P.V2 & \multirow[t]{2}{*}{ NO.54424 } & \multirow[t]{2}{*}{ CESMD } \\
\hline & & 5.44 & ChalfantValley86B_CE54424P.V2 & & \\
\hline \multirow[t]{2}{*}{6} & \multirow{2}{*}{$\begin{array}{l}\text { Imperial } \\
\text { Valley }\end{array}$} & 6.53 & NGA_no_162_H-CXO315.AT2 & \multirow{2}{*}{$\begin{array}{l}\text { CALEXICO } \\
\text { STA }\end{array}$} & \multirow{2}{*}{$\begin{array}{l}\text { PEER } \\
\text { NGA }\end{array}$} \\
\hline & & 5.01 & NGA_no_195_A-CXO315.AT2 & & \\
\hline \multirow[t]{2}{*}{7} & \multirow{2}{*}{$\begin{array}{l}\text { Imperial } \\
\text { Valley }\end{array}$} & 6.53 & NGA_no_174_H-E11140.AT2 & \multirow{2}{*}{$\begin{array}{l}\text { EL CENTRO ARRAY } \\
11\end{array}$} & \multirow{2}{*}{$\begin{array}{l}\text { PEER } \\
\text { NGA }\end{array}$} \\
\hline & & 5.01 & NGA_no_199_A-E11140.AT2 & & \\
\hline \multirow[t]{2}{*}{8} & \multirow{2}{*}{$\begin{array}{l}\text { Imperial } \\
\text { Valley }\end{array}$} & 6.53 & NGA_no_178_H-E03230.AT2 & \multirow{2}{*}{$\begin{array}{l}\text { EL CENTRO ARRAY } \\
3\end{array}$} & PEER \\
\hline & & 5.01 & NGA_no_201_A-E03230.AT2 & & NGA \\
\hline 9 & Imperial & 6.53 & NGA_no_172_H-E01230.AT2 & EL CENTRO ARRAY & PEER \\
\hline & Val & 5.01 & NGA_no_197_A-E01230.AT2 & 1 & NGA \\
\hline 10 & Imperial & 6.53 & NGA_no_169_H-DLT262.AT2 & DELTA & PEER \\
\hline & Valley & 5.01 & NGA_no_196_A-DLT262.AT2 & & NGA \\
\hline 11 & Livermore & 5.80 & Livermore80A_CE57187P.V2 & NO.57187 & CESMD \\
\hline & & 5.42 & Livermore80B_CE57187P.V2 & & \\
\hline 12 & Livermore & 5.80 & Livermore80A_CE67070P.V2 & NO. 67070 & CESMD \\
\hline & & 5.42 & Livermore80B_CE67070P.V2 & & \\
\hline 13 & Livermore & 5.80 & NGA_no_212_A-DVD246.AT2 & DEL VALLE DAM & PEER \\
\hline & & 5.42 & NGA_no_219_B-DVD246.AT2 & & NC \\
\hline 14 & Livermore & 5.80 & NGA_no_214_A-KOD180.AT2 & RAMON & PEER \\
\hline & & 5.42 & NGA_no_223_B-KOD180.AT2 & $\mathrm{KO}$ & $\mathrm{NC}$ \\
\hline 15 & Livermore & 5.80 & NGA_no_215_A-SRM070.AT2 & SAN RAMON & PEER \\
\hline & & 5.42 & NGA_no_224_B-SRM070.AT2 & & NGA \\
\hline
\end{tabular}


Table 2.1 (continued)

\begin{tabular}{|c|c|c|c|c|c|}
\hline No. & Earthquake & Magnitude & Record Name & Station Name & Database \\
\hline \multirow[t]{2}{*}{16} & \multirow[t]{2}{*}{ Livermore } & 5.80 & NGA_no_213_A-FRE075.AT2 & \multirow{2}{*}{$\begin{array}{l}\text { FREMONT } \\
\text { MISSION } \\
\text { S.J. }\end{array}$} & \multirow{2}{*}{$\begin{array}{l}\text { PEER } \\
\text { NGA }\end{array}$} \\
\hline & & 5.42 & NGA_no_220_B-FRE075.AT2 & & \\
\hline \multirow[t]{2}{*}{17} & \multirow[t]{2}{*}{ Livermore } & 5.80 & NGA_no_210_A-A3E236.AT2 & \multirow{2}{*}{$\begin{array}{l}\text { HAYWARD } \\
\text { CSUH } \\
\text { STADIUM }\end{array}$} & \multirow{2}{*}{$\begin{array}{l}\text { PEER } \\
\text { NGA }\end{array}$} \\
\hline & & 5.42 & NGA_no_217_B-A3E236.AT2 & & \\
\hline \multirow[t]{2}{*}{18} & \multirow{2}{*}{$\begin{array}{l}\text { Mammoth } \\
\text { Lakes }\end{array}$} & 6.06 & NGA_no_231_I-LUL090.AT2 & \multirow{2}{*}{$\begin{array}{l}\text { LONG } \\
\text { VALLEY } \\
\text { DAM UPR L }\end{array}$} & \multirow{2}{*}{$\begin{array}{l}\text { PEER } \\
\text { NGA }\end{array}$} \\
\hline & & 5.94 & NGA_no_250_L-LUL090.AT2 & & \\
\hline \multirow[t]{2}{*}{19} & \multirow{2}{*}{$\begin{array}{l}\text { Mammoth } \\
\text { Lakes }\end{array}$} & 6.06 & NGA_no_231_I-LUL090.AT2 & \multirow{2}{*}{$\begin{array}{l}\text { LONG } \\
\text { VALLEY } \\
\text { DAM UPR L }\end{array}$} & \multirow{2}{*}{$\begin{array}{l}\text { PEER } \\
\text { NGA }\end{array}$} \\
\hline & & 5.70 & NGA_no_243_B-LUL090.AT2 & & \\
\hline \multirow[t]{2}{*}{20} & \multirow{2}{*}{$\begin{array}{l}\text { Mammoth } \\
\text { Lakes }\end{array}$} & 6.06 & NGA_no_231_I-LUL090.AT2 & \multirow{2}{*}{$\begin{array}{l}\text { LONG } \\
\text { VALLEY } \\
\text { DAM UPR L }\end{array}$} & \multirow{2}{*}{$\begin{array}{l}\text { PEER } \\
\text { NGA }\end{array}$} \\
\hline & & 5.69 & NGA_no_234_J-LUL090.AT2 & & \\
\hline \multirow[t]{2}{*}{21} & \multirow[t]{2}{*}{ Northridge } & 6.69 & NGA_no_963_ORR090.AT2 & \multirow{2}{*}{$\begin{array}{l}\text { CASTAIC - } \\
\text { OLD RIDGE } \\
\text { ROUTE }\end{array}$} & \multirow{2}{*}{$\begin{array}{l}\text { PEER } \\
\text { NGA }\end{array}$} \\
\hline & & 5.93 & NGA_no_1676_CASTA090.AT2 & & \\
\hline \multirow[t]{2}{*}{22} & \multirow[t]{2}{*}{ Northridge } & 6.69 & NGA_no_1039_MRP090.AT2 & \multirow[t]{2}{*}{ MOORPARK } & \multirow{2}{*}{$\begin{array}{l}\text { PEER } \\
\text { NGA }\end{array}$} \\
\hline & & 5.93 & NGA_no_1681_MPARK090.AT2 & & \\
\hline \multirow[t]{2}{*}{23} & Northridge & 6.69 & NGA_no_1005_TEM090.AT2 & LOS & PEER \\
\hline & & 5.28 & NGA_no_1712_TEMPL090.AT2 & $\begin{array}{l}\text { ANGELES - } \\
\text { TEMPLE \& }\end{array}$ & NGA \\
\hline 24 & Northridge & 6.69 & NGA_no_971_ELI180.AT2 & ELIZABETH & PEER \\
\hline & & 5.93 & NGA_no_1677_ELIZL180.AT2 & LAKE & NGA \\
\hline 25 & Northridge & 6.69 & NGA_no_945_ANA180.AT2 & ANAVERDE & PEER \\
\hline & & 5.93 & NGA_no_1675_ANAVE180.AT2 & $\begin{array}{l}\text { VALLEY } \\
\text { CITY }\end{array}$ & NGA \\
\hline 26 & Northridge & 6.69 & NGA_no_990_LAC180.AT2 & LOS & PEER \\
\hline & & 5.93 & NGA_no_1678_CTYTE180.AT2 & $\begin{array}{l}\text { ANGELES - } \\
\text { CITY }\end{array}$ & NGA \\
\hline 27 & Northridge & 6.69 & NGA_no_1007_UNI095.AT2 & LA-UNIV. & PEER \\
\hline & & 5.93 & NGA_no_1680_UNIHP090.AT2 & $\begin{array}{l}\text { HOSPITAL } \\
\text { GR }\end{array}$ & NGA \\
\hline 28 & Petrolia & 7.20 & Petrolia_25Apr1992_CE89530P.V2 & NO. 89530 & CESMD \\
\hline & & 6.70 & PetroliaAftershock2_26Apr1992_CE89530P.V2 & & \\
\hline 29 & Petrolia & 7.20 & Petrolia_25Apr1992_CE89156P.V2 & NO. 89156 & CESMD \\
\hline & & 6.50 & PetroliaAftershock1_26Apr1992_CE89156P.V2 & & \\
\hline 30 & Petrolia & 7.20 & Petrolia_25Apr1992_CE89509P.V2 & NO. 89509 & CESMD \\
\hline & & 6.50 & PetroliaAftershock1_26Apr1992_CE89509P.V2 & & \\
\hline 31 & Whittier & 5.99 & NGA_no_615_A-DWN270.AT2 & DOWNEY & PEER \\
\hline & Narrows & 5.27 & NGA_no_709_B-DWN270.AT2 & & NG \\
\hline 32 & Whittier & 5.99 & NGA_no_663_A-MTW000.AT2 & MT WILSON & PEER \\
\hline & $\mathrm{N}$ & 5.27 & NGA_no_715_B-MTW000.AT2 & & \\
\hline
\end{tabular}


The MS-AS sequences 18, 19, and 20 have the same mainshock but different aftershocks. The aftershock of sequence 18 has the largest magnitude in the aftershock sequences. The aftershock magnitudes of sequences 19 and 20 are only slightly smaller than that of sequence 18, and may also cause large structural response during the aftershocks. Considering limited available MS-AS records, the sequences 19 and 20 are also employed in this study. The magnitudes shown in Table 2.1 are acquired from the USGS (2014).

\subsubsection{The synthesized MS-AS sequences}

For the aforementioned reasons, finding a method to synthesize aftershocks is important for incorporating aftershocks in seismic risk. This paper proposes a methodology to synthesize aftershocks stochastically utilizing LHS with the information from mainshocks, site conditions and rupture mechanism of faults. The basic procedure includes:

1. Select the proper attenuation equations for $S_{a}$ and durations. The employed attenuation equations will determine the parameters that are required in the following steps. The selection of equations depends on the information available and the complexity and the accuracy of the equations.

2. Determine the probability distribution of magnitudes and use LHS to select the value for each aftershock. That is, for each distribution, divide the range of magnitude into $N$ successive but not overlapped sub-ranges ( $N$ is the total number of mainshocks) and ensure each sub-range corresponding to a same probability of occurrence. Number all the sub-ranges in ascending order from 1 to $N$ for the magnitude of each aftershock. Then randomly assign a unique number to every aftershock, and pick a random value of magnitude from the sub-range with this unique number for each aftershock.

3. Determine the probability distribution of other parameters that will be used in the attenuation equations, such as site-to-source distance, fault type and so on. Then follow the same numbering and sampling method to pick the stochastic value for each parameter of each aftershock. 
4. With the attenuation equations and the parameters obtained during previous steps, develop the duration and a set of $S_{a}$ at various periods for each aftershock. Each duration and $S_{a}$ calculated with the equations would have a median value and a standard deviation, with which a probability distribution can be determined for duration or $S_{a}$ at every period of each aftershock. Then use the same method of numbering and sampling to select the random values of $S_{a}$ and duration for every aftershock.

5. The target response spectra can be established with those $S_{a}$ value. For each aftershock, with the target response spectra and duration obtained in last step, an artificial ground motion can be synthesized. Assemble each synthesized aftershock motion behind the corresponding mainshock record and a blank time interval, a suite of synthesized back-to-back MS-AS sequences is then completed. These MSAS sequences can be employed for seismic analysis and risk assessment.

6. The application of the above numbering and sampling method for all the parameters will ensure all the parameter of all the aftershocks follows the procedure of LHS, which requires significantly less computation than classic Monte Carlo simulation but can yield comparable results (McKay, et al. 2000; Celik and Ellingwood 2010; Yin and Li 2011). In this way, the uncertainty of ground motion can be simulated. In order to illustrate this method and to examine its result, a suite of $32 \mathrm{MS}-\mathrm{AS}$ sequences are generated based on the 32 mainshocks of the previous recorded MS-AS sequences with this method. The detail steps are presented below.

\subsubsection{Attenuation models}

There are a variety of attenuation equations that can be applied for calculating $S_{a}$ at different values (e.g. Abrahamson and Silva 1997, 2008; Boore et.al 1997; Campbell and Bozorgnia 2003) or earthquake durations (e.g. Kamiyama 1984; Abrahamson and Silva 1996; Kempton and Stewart 2006). In this paper, the attenuation relationships proposed by Abrahamson and Silva (1997 and 1996) will be employed for $S_{a}$ and durations, as shown below:

$$
\ln S_{a}=f_{1}\left(m, r_{\text {rup }}\right)+F \cdot f_{3}(m)+H W \cdot f_{4}\left(m, r_{\text {rup }}\right)+S \cdot f_{5}\left(P G A_{\text {rock }}\right)
$$




$$
\ln \left(D_{0.05-\mathrm{I}}\right)=\ln \left[\frac{\left(\frac{\Delta \sigma(m)}{10^{1.5 m+16.05}}\right)^{-1 / 3}}{4.9 \times 10^{6} \beta}+S \cdot c_{1}+c_{2}\left(r_{\text {rup }}-r_{c}\right)\right]+\ln \left(\frac{D_{0.05-\mathrm{I}}}{D_{0.05-0.75}}\right)
$$

where $S_{a}$ is the spectral acceleration in $\mathrm{g}$; the $D_{0.05-\mathrm{I}}$ is the Arias duration in sec, typically $\mathrm{I}=0.95 ; m$ is the moment magnitude of the earthquake; the $r_{r u p}$ is the closest distance from site to the rupture plane in $\mathrm{km} ; P G A_{\text {rock }}$ is the expected PGA on rock in $\mathrm{g} ; F, H W$ and $S$ are parameters of fault type, hanging wall sites and site condition respectively. $f_{1}$ to $f_{4}$ are regression functions; $\Delta \sigma$ and $\ln \left(D_{0.05-\mathrm{I}} / D_{0.05-0.75}\right)$ are regression functions about $m$ and I, respectively; $r_{c}=10 \mathrm{~km} ; c_{1}, c_{2}$ and $\beta$ are constants obtained from regression analysis. If $r_{\text {rup }}<r_{c}, c_{2}=0$.

Those two equations are selected in this study because they are simple enough so that the available information is adequate to conduct the calculation. Additionally, these two expressions have been utilized extensively and are felt to be able to yield accurate results (Power, et al. 2008; Kempton and Stewart 2006). The results of Eq. 2.1 and Eq. 2.2 are the median value. In Abrahamson and Silva's studies (1996, 1997), regression equations for predicting corresponding standard deviations were also provided. For Eq. 2.1, regression coefficients were given for $S_{a}$ at a series of periods (from $0.01 \mathrm{~s}$ to $5 \mathrm{~s}$ ), which make it possible to establish a response spectrum based on the attenuation model. Arias duration, which is a type of significant duration, describes the duration when most energy of the ground motion is dissipated (Kempton and Stewart 2006). A typical measure of Arias duration is the time interval between 5\%-95\% of the Arias intensity (an integral of ground acceleration to represent the energy), which is employed in this study to substitute for the duration of aftershocks.

\subsubsection{Maximum magnitudes of aftershocks}

As discussed previously, in this study, only the maximum aftershocks in term of magnitude are considered. Therefore, a method to determine the maximum magnitudes of the aftershocks based on the information of mainshock must be proposed.

There have been a number of research efforts related to the magnitude of aftershocks (e.g. Utsu 1961; Båth 1965; Helmstetter and Sornette 2003; Shcherbakov, et al. 2004). Because only the largest aftershock will be considered in this study, Båth's law (Båth $1965)$, which indicates the average of magnitude difference $(\Delta m)$ between a mainshock 
and its largest aftershock is a constant about 1.2, is used in this paper. Also, it has been observed that the $\Delta m$ varies between 0 and 3 for different MS-AS sequences (Helmstetter and Sornette 2003). Therefore, $\Delta m$ follows a distribution that satisfies at least three criteria: (1) the mean of the distribution is approximately 1.2 ; (2) $\mathrm{P}(\Delta m \leq 0)=0$; and (3) $\mathrm{P}(\Delta m \geq 3) \approx 0$. To determine the distribution, $\Delta m, 50$ earthquake sequences are collected from USGS (2014), and histogram is shown in Figure 2.1(a). Probability density functions (PDF) of three possible distributions (lognormal, gamma and beta) are also presented in Figure 2.1(b).
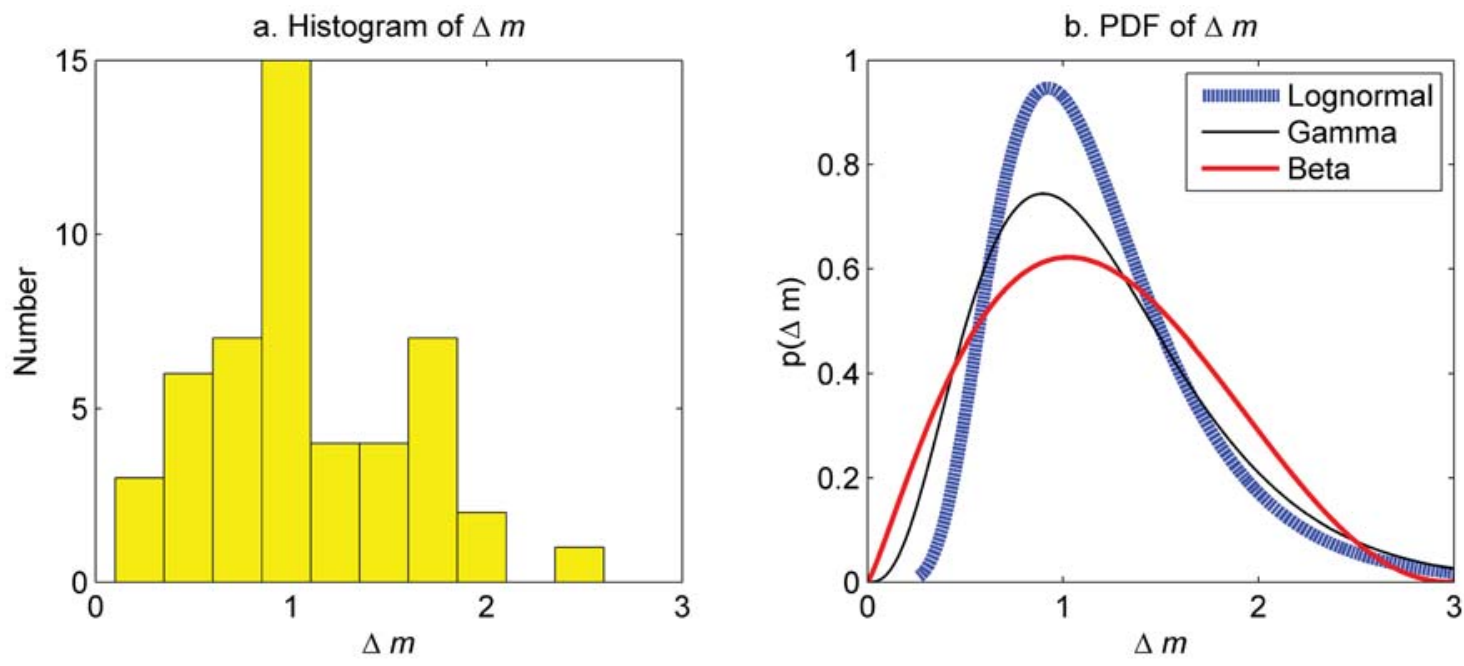

Figure 2.1 Histogram and possible PDFs of $\Delta \mathrm{m}$

Chi-square tests for the three distributions are performed to determine which one fit the data best. And the results are shown in Table 2.2.

Table 2.2 Result of goodness-of-fit tests for the three distributions

\begin{tabular}{lll}
\hline Distribution & $\sum\left(\mathrm{n}_{\mathrm{i}}-\mathrm{e}_{\mathrm{i}}\right)^{2} / \mathrm{e}_{\mathrm{i}}$ & The critical value $C_{0.95,9}$ \\
\hline Lognormal & 194.63 & 16.919 \\
Gamma & 14.022 & 16.919 \\
Beta & 11.134 & 16.919 \\
\hline
\end{tabular}

It can be observed from Table 2.2 that the gamma distribution and the beta distribution are both suitable for describe the $\Delta m$ at the $5 \%$ significance level, and the beta distribution fit the data best. Therefore the estimated beta distribution is employed in this study. The PDF of this beta distribution is presented below. 


$$
p(\Delta m)= \begin{cases}\frac{1}{B(2.2,3.3)} \cdot \frac{\Delta m^{1.2}(3-\Delta m)^{2.3}}{3^{4.5}} & 0 \leq \Delta m \leq 3 \\ 0 & \text { otherwise }\end{cases}
$$

With the distribution of $\Delta m$ determined, the maximum magnitude of each aftershock can be obtained using the aforementioned numbering and sampling method.

\subsubsection{Site-to-Source Distances}

Different attenuation relationships employ different measures of site-to-source distance (Abrahamson and Silva 1997; Boore et.al 1997; Campbell and Bozorgnia 2003), such as Joyner-Boore distance, DistanceSeis and distance to rupture plane. As shown in Eq. 2.1, the closest distance to the rupture plane is used in this paper.

There are many hypotheses about where the aftershocks may occur. The simplest way is to assume that the aftershocks occur exactly at the same location as the mainshock, but this assumption will obviously cause bias (e.g. Goda 2012). Another two theories assume the epicenters of aftershocks are uniformly distributed along the rupture length of the fault of mainshock (e.g. Sunasaka and Kiremidjian 1993; Yeo and Cornell 2009a) or uniformly distributed in a circular area, the center of which is the epicenter of the mainshock (e.g, Kumitani and Takada 2008). Figure 2.2 shows the USGS earthquake and fault maps (USGS 2014) of 1980 Mammoth Lakes Earthquake sequences and 1983 Coalinga Earthquake sequences, in which the shaded circle indicate the epicenters of the mainshocks, white circles denote the epicenter of aftershocks, and the straight lines are the active faults. 


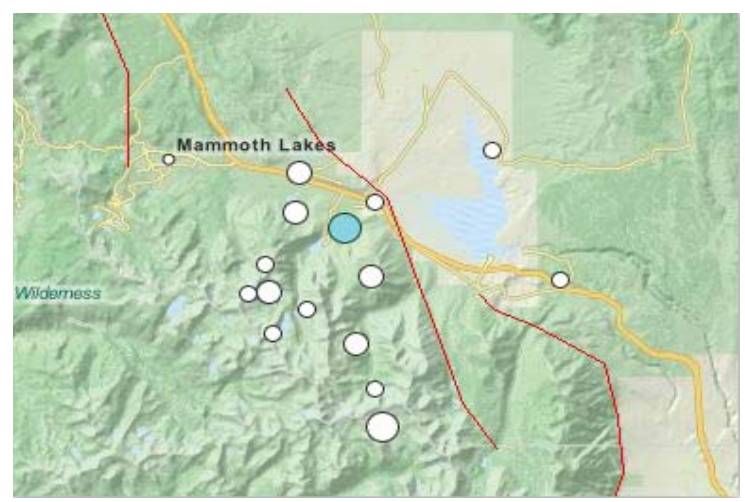

(a) 1980 Mammoth Lakes earthquake

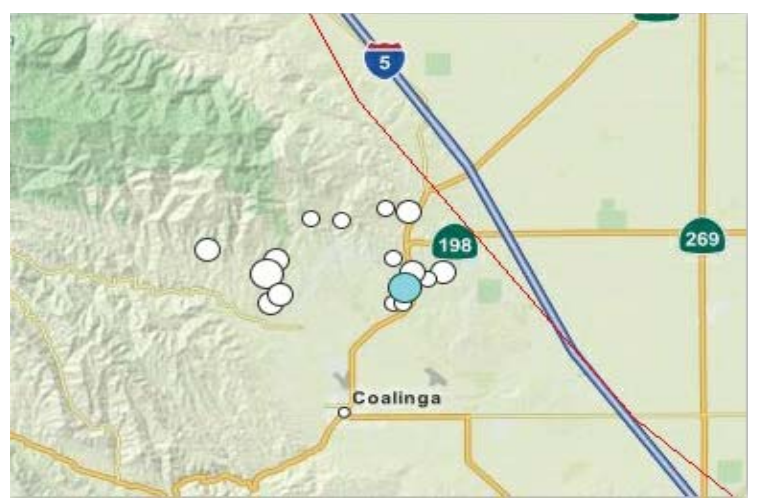

(b) 1983 Coalinga earthquake

Figure 2.2 USGS map of earthquakes and faults [images courtesy of USGS (2013)] (See Appendix B for documentation that this material is in the public domain.)

From examining the available data, such as those scattered locations of most aftershocks with respect to the mainshock in Figure 2.2, the assumption that the epicenter of the aftershock is uniformly distributed in a circular region around the epicenter of the mainshock is considered as a starting point for current study. The area of the circular region can be determined with the equation below (Kumitani and Takada 2008).

$$
\log _{10} A=M_{\mathrm{m}}-3.7
$$

where $A$ denotes the area of the circular region in $\mathrm{km}^{2} ; M_{\mathrm{m}}$ is the magnitude of mainshock. Assume the depth of hypocenters of aftershocks and the mainshock are same, and assume the rupture plane of aftershocks and the mainshock are parallel, the distance from site to rupture plane can be derived from the geometric relations, as illustrated in Figure 2.3. 


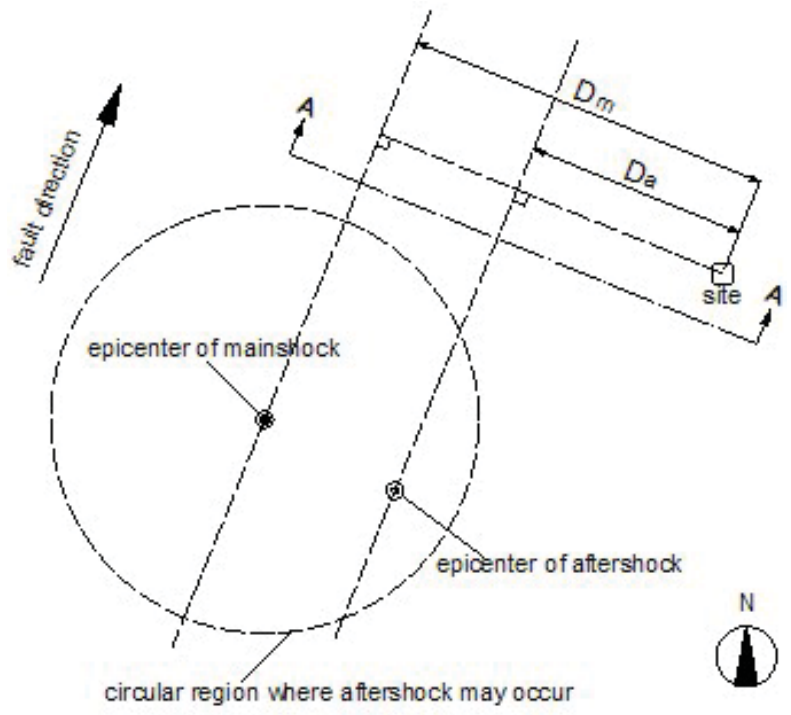

a. Plane View

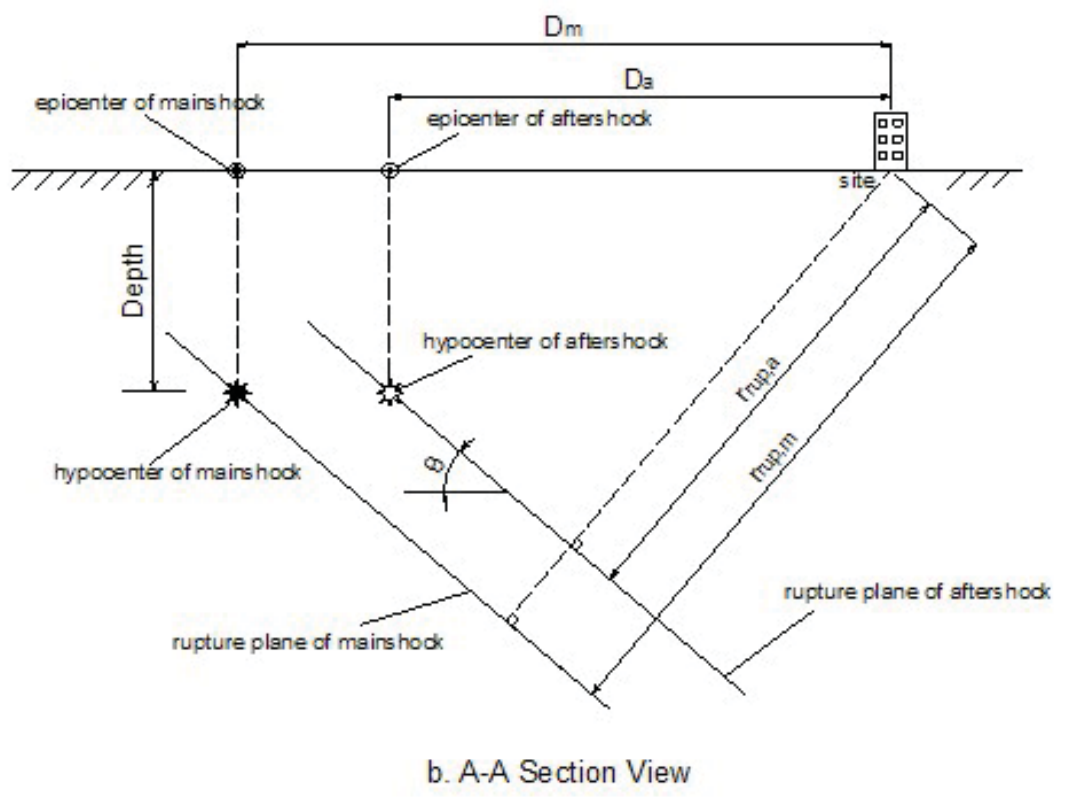

Figure 2.3 Geometric relation for deriving the distance from site to rupture plane

In Figure 2.3, $D_{\mathrm{m}}$ and $D_{\mathrm{a}}$ are the distances from site to the lines which lie along the fault direction and pass the epicenter of mainshock and aftershock, respectively; Depth means the depth of hypocenter; $\theta$ is the incline angle of rupture planes; $r_{\text {rup,m }}$ and $r_{\text {rup,a }}$ are the distances from site to the rupture plane of mainshock and aftershock, respectively. The $D_{\mathrm{m}}$ can be calculated with the location of station and the epicenter, and the fault direction, which are all available at the database of PEER NGA (2014), CESMD (2013) and USGS (2014). $D_{\text {a }}$ can also be obtained in the same way once the epicenter of aftershock is 
determined. The $r_{\text {rup,m }}$ and the depth of the hypocenters can also be found in those databases. Therefore, $r_{\text {rup,a }}$ can be calculated according to the geometric relations, and is presented as the following equations.

$$
\begin{aligned}
r_{\text {rup }, \mathrm{a}} & =r_{\text {rup }, \mathrm{m}}-\left(D_{\mathrm{m}}-D_{\mathrm{a}}\right) \sin \theta \\
\text { and } \quad \theta & =\arctan \frac{D_{\mathrm{m}}}{D e p t h}-\arccos \frac{r_{\text {rup, } \mathrm{m}}}{\sqrt{D_{\mathrm{m}}{ }^{2}+D_{\text {epth }}^{2}}}
\end{aligned}
$$

The procedure of generating the $r_{\text {rup,a }}$ for each aftershock is similar as the previous step. Since the epicenters of aftershocks are uniformly distributed in the circles around their mainshock epicenter, each circular area is divided into 32 parts with equal area by a set of paralleled straight lines that are along the fault direction. Then all the parts of each circle are numbered from 1 to 32 according to their distances to the site. For the each of the 32 aftershocks, pick a part with a different number, and randomly locate a point in this part as the epicenter. Then the $r_{\text {rup,a }}$ can be determined for each aftershocks utilizing Eq. 2.5.

\subsubsection{Target Response Spectra, Durations and Synthesized Aftershocks}

For synthesizing aftershocks, it is essential to obtain the target response spectra which can represent the frequency contents of ground motions. Previous studies sometimes employed mainshock ground motions that were scaled with a single parameter as aftershocks (e.g. Li and Ellingwood 2007; Yin and Li 2011), based on the intuition that the frequency content of a aftershock should have some stochastic dependence with the mainshock, which has been proved to be yet incorrect recently (Ruiz-García and NegreteManriquez 2011). Another study utilized design spectra as target spectra to synthesize aftershocks (Hatzigeorgious and Liolios 2010), but this will yield conservative results due to the low probability of the spectral value at all periods occurring simultaneously (Naeim, et al. 2004). This paper employs the attenuation relationship to calculate the median and standard deviation of $S_{a}$ at various periods, and develops the target response spectra based on that. Utilizing an attenuation equation to develop the response spectrum is typically considered as a reasonable approach describing the frequency content of an earthquake ground motion (Rathje, et al. 1998).

The median and standard deviation of $S_{a}$ of each period for the aftershocks are calculated from Eq. 2.1. Since there is no research on the distribution of the calculated $S_{a}$, lognormal distribution is hypothesized and determined with the median and standard deviation at 
each period. Then the $S_{a}$ at each period of each aftershock is stochastically generated in the same way as the magnitudes of the aftershocks are selected.

Durations of aftershocks can also be generated in the same way with the medians and standard deviation that are calculated with Eq. 2.2. The lognormal distribution was assumed since no study has been conducted on the distribution of durations calculated by Eq. 2.2.With the target spectrum and duration determined for each aftershock, the acceleration-time histories can be synthesized based on the theory that earthquake ground motion can be expressed as the combination of a series of sinusoidal waves (Gasparini and Vanmarcke 1976). The synthesized aftershocks are assembled after the corresponding mainshocks, with a 3 min time interval between each mainshock and aftershock. A typical synthesized MS-AS sequence and the recorded MS-AS sequence with the same mainshock are presented in Figure 2.4.
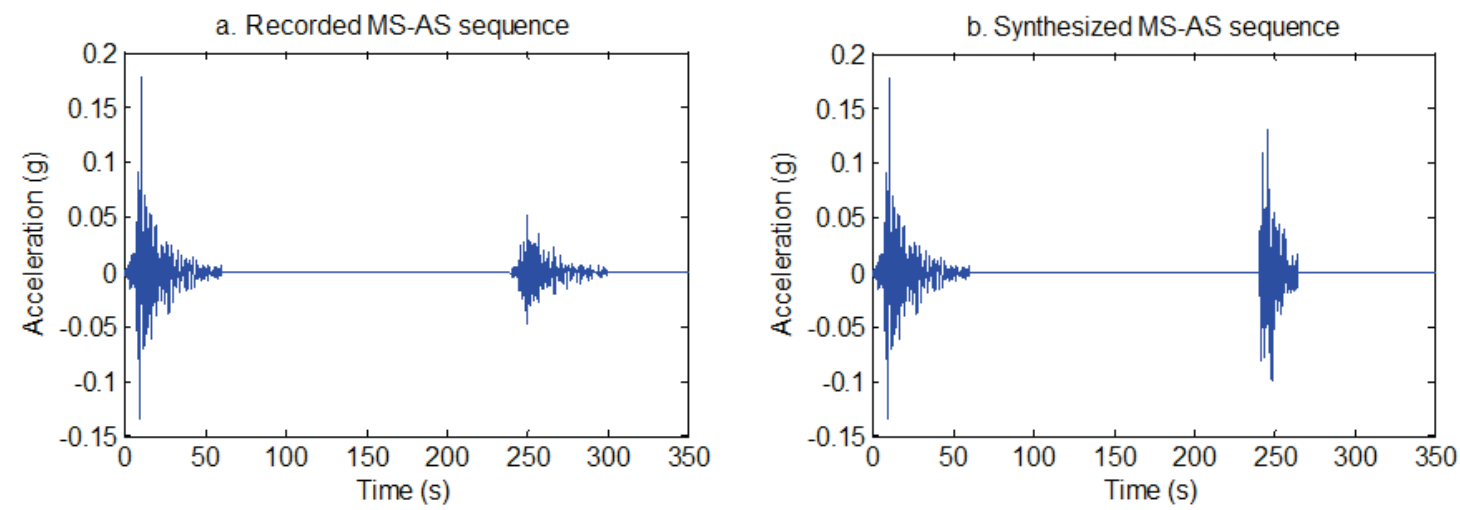

Figure 2.4 Time histories of the recorded and the synthesized MS-AS sequence of the No. 30 earthquake

It can be observed that the recorded and synthesized aftershocks are dissimilar. This is normal because the LHS method that is applied herein to determine the synthesized aftershock is a stochastic method which only guarantees the statistical results of the suite sequences comparable with those of the recorded suite. For the results of a specific synthesized MS-AS sequence, it is generally not comparable with its counterpart of recorded sequence. The response spectra $(\zeta=5 \%)$ of the mainshocks, the recorded and synthesized aftershocks are presented in the Figure 2.5. The median response spectrum calculated with Eq. 2.1 and the stochastically generated target response spectrum of an aftershock (NO. 3 of Table 2.1) are also shown in Figure 2.5 as an illustration (damping ratio, $\zeta$, equals $5 \%$ for both the spectra) of how the target spectrum for an aftershock differs from the median attenuation spectrum. 
As shown in Figure 2.5, the envelope shapes and the peak values of the two suites of aftershocks are similar. The median response spectra of the two suites also have similar shapes, except that the spectral values of the synthesized aftershocks at periods less than $1 \mathrm{sec}$ generally are slightly smaller than those of the recorded aftershocks. This difference may happen due to the error of the attenuation model and assumed distribution of $S_{a}$ and $r_{\text {rup,a }}$, the error of synthesizing method, and the error of sampling. Possible cause also includes the limited records that are employed.
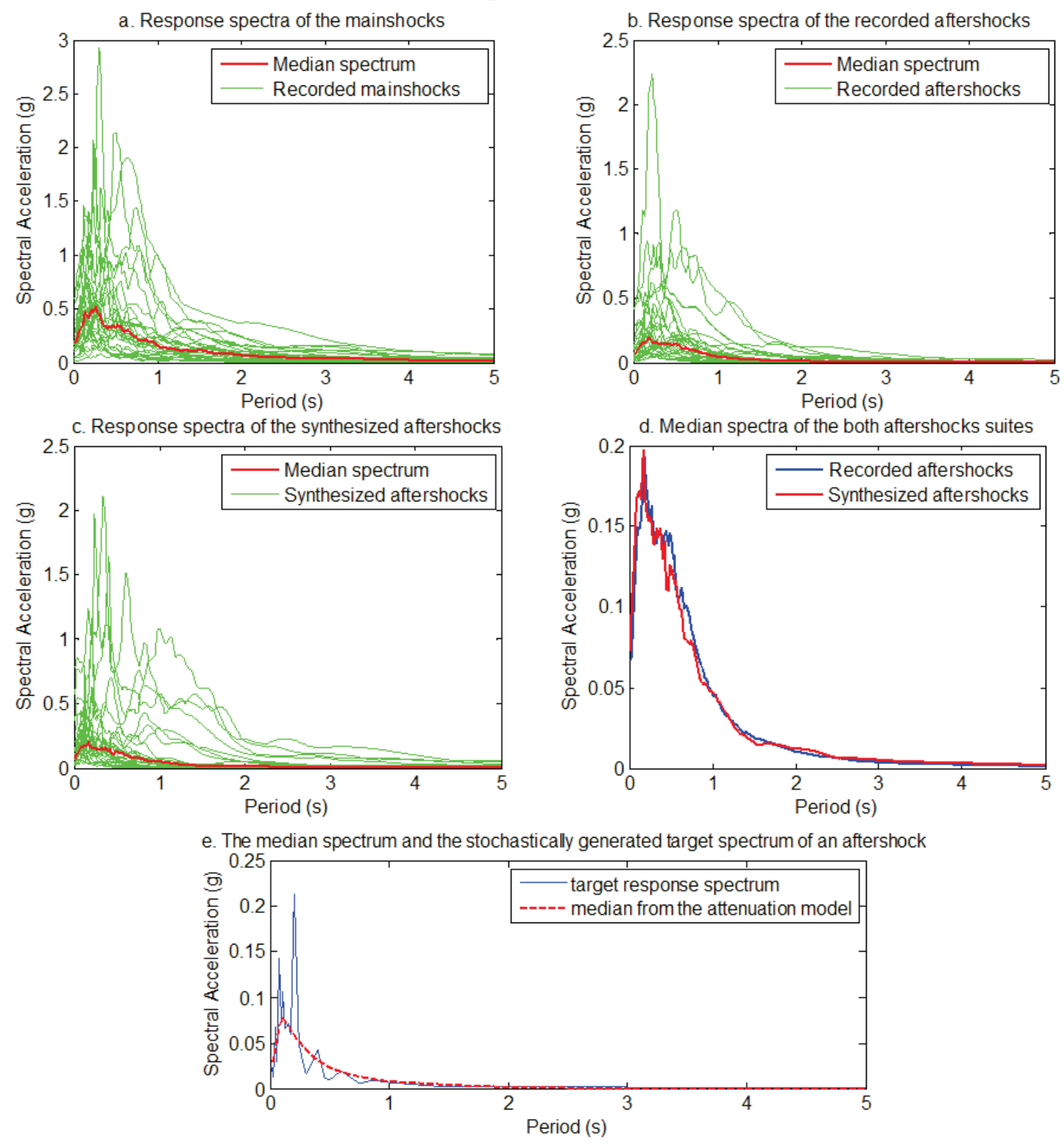

Figure 2.5 Response spectra $(\zeta=5 \%)$ of the suites of mainshocks, recorded, and synthesized aftershocks 


\subsection{The structural models}

Two non-ductile RC frame building in the United States are considered in this paper, with a three-bay-three-story and a three-bay-six-story building to represent low-rise and mid-rise RC buildings, respectively. The prototype buildings were studied by Celik and Ellingwood (2009) and other studies (Kwon and Elnashai 2006; Celik and Ellingwood 2010), and can be representative for the typical pre-1975 RC frame office buildings in United States (Celik and Ellingwood 2009; Liel and Deierlein 2008).Those buildings are known to be vulnerable to seismic load because of the non-seismic detailing, such as inadequate transverse reinforcement, weak columns, short embedment length and poor beam-column joint confinement. The two buildings have the same and symmetric floor layouts at each level, and the layouts of beam reinforcement at each floor are identical. The column sections of the three-story building and those of the 4-6 floor of the six-story building are same. The specific compressive strength of the concrete of both buildings is $28 \mathrm{MPa}$ (4 ksi), and the design yield strength of the rebars is $280 \mathrm{MPa}$ (40 ksi). The elevations, plan and reinforcement details are presented in Figure 2.6.

Two-dimensional finite-element models for the interior frame of each building are developed in OpenSees (Mazzoni, et al., 2006), which is able to account for the geometric and material nonlinear behaviors. The structural modeling uncertainties such as the uncertainty in material strength and damping ratio are not considered in this study and could be investigated in the future. It is believed that the uncertainties are overshadowed by the uncertainty of seismic ground motions (Celik and Ellingwood 2009).The details of finite-element models for both buildings are illustrated in Figure 2.7. The displacement-based beam-column elements are selected for modeling the beams and columns of the frames. To account for nonlinear behavior and reinforcement layouts, the fiber sections are employed for beams and columns. The beam-column joint models are built based on Celik and Ellingwood's study on non-ductile RC frames (Celik and Ellingwood 2008). The nodes are placed so that both the deforming shape and rebar layout can both be simulated. The final models are determined after validating trial analyses with experimental data, and the structural dynamic characteristics are consistent with the models employed by Celik and Ellingwood in studies on the same buildings (Celik and Ellingwood 2009, 2010). The analytical models are presented in Figure 2.7. 


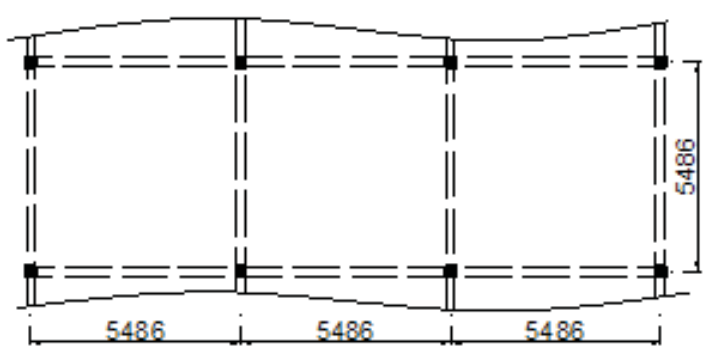

(a) Plan of a typical interior frame
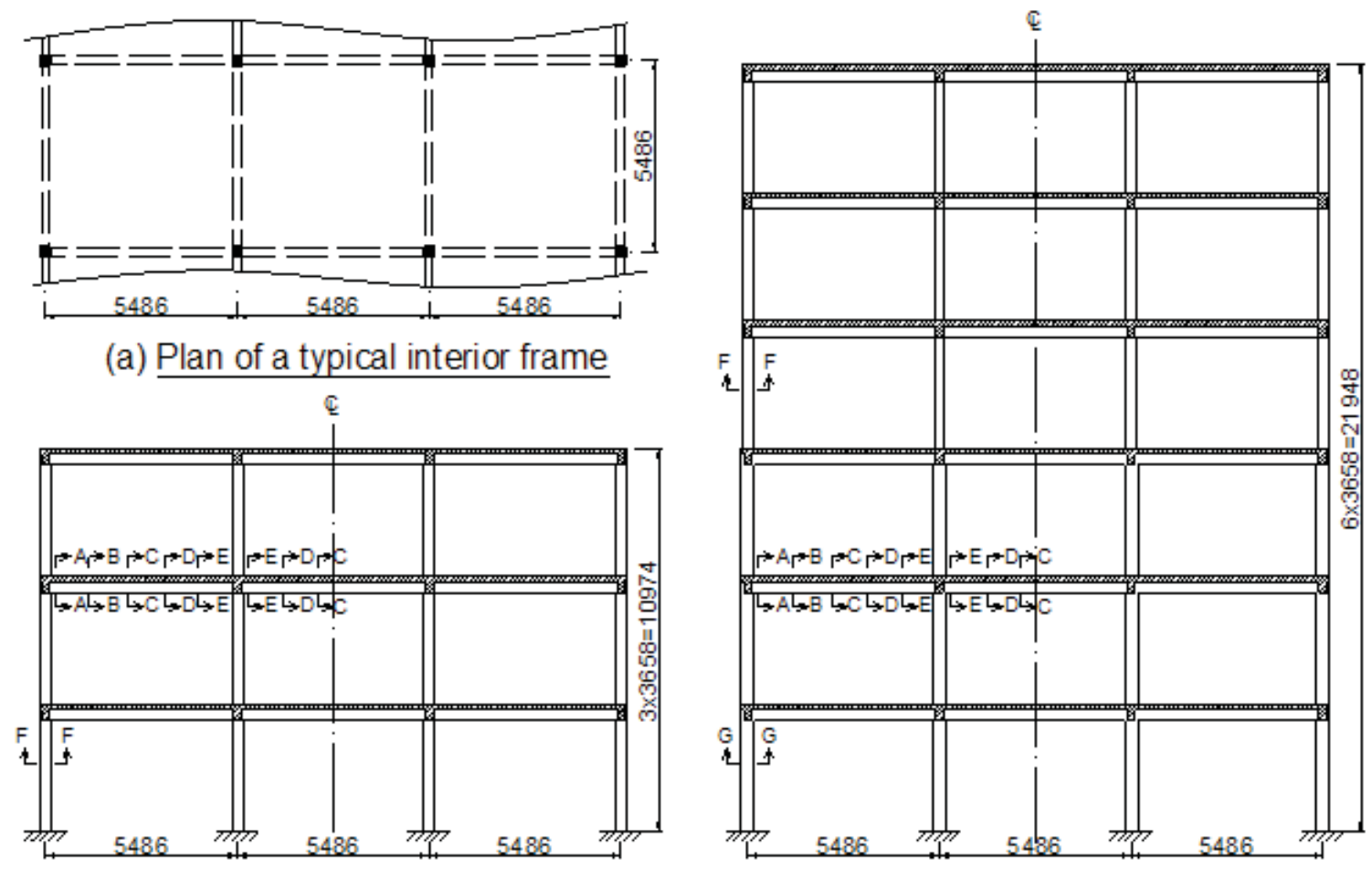

(b) Elevation of the 3-story building

(c) Elevation of the 6-story building
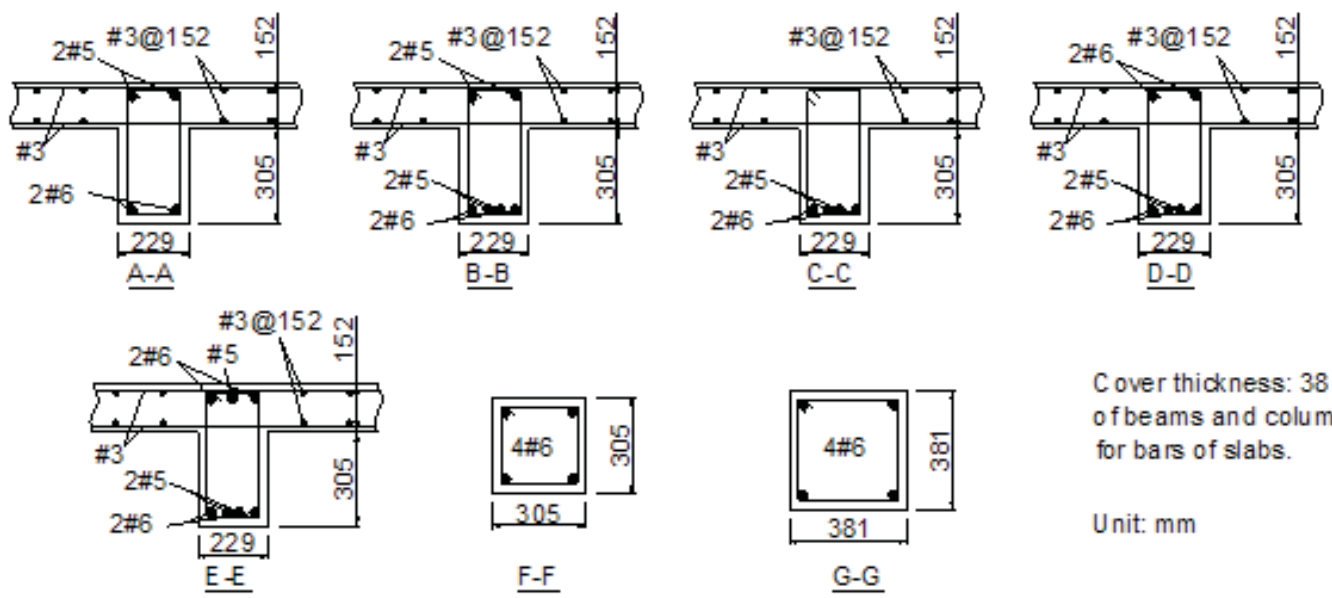

Cover thickness: $38 \mathrm{~mm}$ for bars of beams and columns, $19 \mathrm{~mm}$ for bars of slabs.

Unit: mm

(d) Reinforcment details

Figure 2.6 Plan, elevations, and reinforcement details of the two buildings

The concrete stress-strain relationship is simulated using the modified Kent and Park model (Park, et al. 1982), whereas the steel material is computed with a $0.5 \%$ strain hardening bilinear model. Both the compressive strength of concrete and the yield strength of steel are increased by $25 \%$ of their nominal value to account for the in situ strength and the increase of strength under the dynamic loading (Aslani and Miranda 
2005b). The core concrete has only $3 \%$ increased stress due to the limited confine provided by irredundant transverse reinforcement (Celik and Ellingwood 2009).

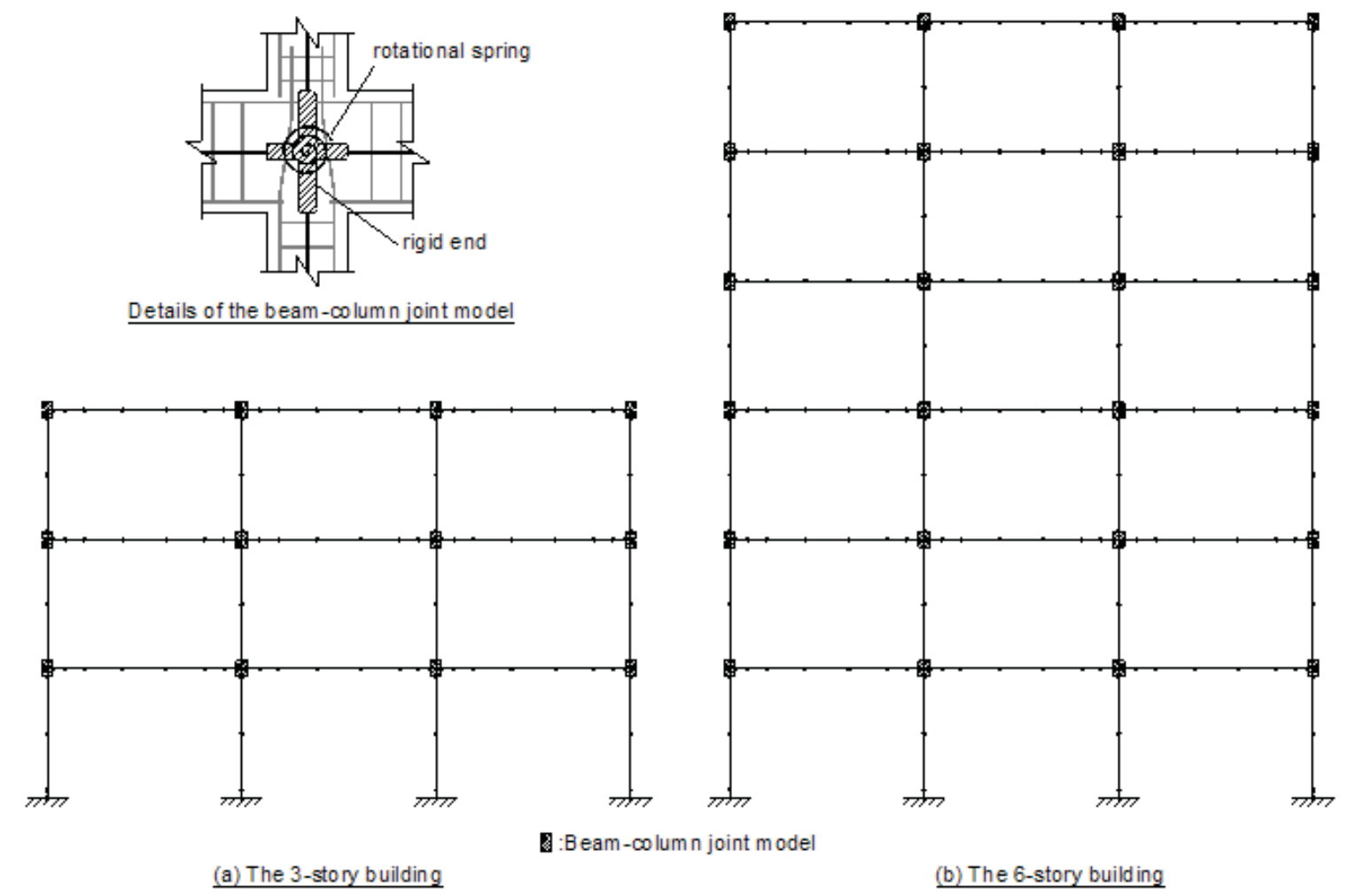

Figure 2.7 Finite-element models of the two buildings

The uniformly distributed load on each beam is $40 \mathrm{kN} / \mathrm{m}$. The mass of the building is equivalent to lumped masses of $15,700 \mathrm{~kg}$ at each beam column joint, according to the load combination $1.0 \mathrm{D}+0.25 \mathrm{~L}$. The hysteretic damping of the both models are automatically calculated when the materials go into nonlinear range in the analyses, and damping ratio of 5\% is adopted for viscous damping which is only valid when the models behaved elastically. The fundamental periods of the three-story and six-story building are $1.14 \mathrm{~s}$ and $1.92 \mathrm{~s}$ respectively, and the effective masses of first mode are 0.90 and 0.77 respectively. Therefore, the buildings are flexible and first mode dominant.

\subsection{The structural responses}

Structural responses of the two models are obtained via NTHA using the two suites of MS-AS sequences. The peak inter story drift ratio (PIDR) of each floor and the peak floor 
acceleration (PFA) at each level are investigated to consider the damage of structural and non-structural components (including deformation and acceleration sensitive components). Some typical results of the two buildings during only the mainshocks and the entire recorded or synthesized sequences are shown in Figure 2.8.
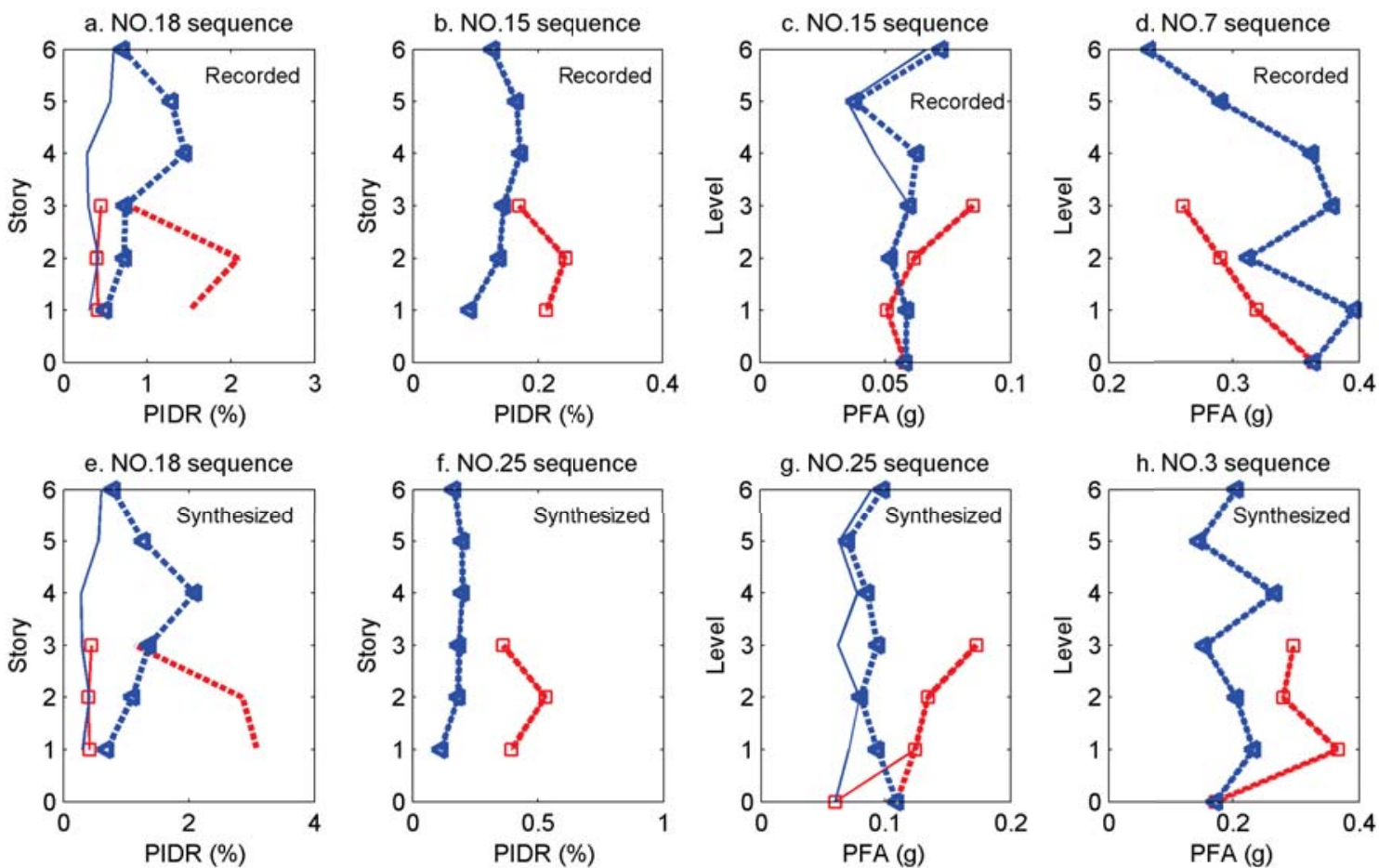

—-3-story, mainshock only ........ 3-story, MS-AS

6-story, mainshock only $\cdots \cdots 6$-story, MS-AS

Figure 2.8 Some structural responses of the two buildings

The results of the recorded sequences and those of the synthesized sequences show the similar trends. From the vertical distribution of PIDR illustrated in Figure 2.8(a), (b), (e) and (f), it can be inferred that the $2^{\text {nd }}$ story of the three-story building and the $4^{\text {th }}$ story of the six-story building are weak stories. It is obviously that larger structural responses can occur during the aftershocks other than the mainshocks, as shown in Figure 2.8(a), (c), (e) and $(\mathrm{g})$, indicating that only consider mainshocks may underestimate the seismic damage. However, it is also true that the most common cases are like Figure 2.8(b), (d), (f) and (h), which show that the largest responses are observed during the mainshocks. Notice Figure 2.8(b) and (c) as well as Figure 2.8 (f) and (g) are obtained from the same sequences, which indicate that larger PFA can occur during aftershocks when largest PIDR occurs during mainshocks. To further understand the structural responses, the response time histories are also investigated. There are several types of responses time 
histories when the two models are subjected to the MS-AS sequences, as shown in Figure 2.9 .

Figure 2.9(a) to (c) illustrate three types of inter story drift ratio (IDR) response observed in this study. Figure 2.9(a) shows that the PIDR during the mainshock is larger than that during the aftershock, which is the most common case in the analysis. Occasionally, situations like Figure 2.9(b) also occur, indicating that the aftershocks may be more intense than the mainshock. There are two main reasons why this "abnormal" phenomenon happens. On one hand, the site-to-source distance of the aftershock may be smaller than that of the mainshock, leading to a stronger ground motion at the site. On the other hand, the energy content of the mainshock and the aftershock may be different, causing the larger spectral acceleration at the fundamental period of the building occurs during the aftershock. The third situation, as shown in Figure 2.9(c), is rare yet also observed in this study. The aftershock in this case is not as intense as the mainshock, but the mainshock has taken significant damage to the building. Consequently, during the following aftershock, the impaired structural capacity together with the large residual displacements caused even bigger displacements to the building, although the aftershock is less intense. The large deformation shown in Figure 2.9(c) occurs very early because the peak intensity of the corresponding ground motion comes very early. Figure 2.9(d) demonstrates the most usual case, which is the PFA during the mainshock is larger than that during the aftershock. Since floor acceleration (FA) responses do not have residual values and cannot show impaired structural capacity, there is only one situation illustrating the larger PFA can sometimes occur during aftershocks, as presented in Figure 2.9(e). Though those figures only show the structural responses when recorded MS-AS sequences are applied because results from actual motion records are most convincible, similar phenomena are also observed from the synthesized MS-AS sequences. In order to validate the method of synthesizing the MS-AS sequences, the statistical results of the structural responses of the two buildings during the recorded and synthesized aftershocks are listed in Table 2.3.

Table 2.3 The statistical results of the buildings under the two types of aftershocks

\begin{tabular}{|c|c|c|c|c|c|c|}
\hline Building & Parameter & & Median & Mean & $\begin{array}{l}\text { Standard } \\
\text { deviation }\end{array}$ & $\begin{array}{l}\text { Number of sequences of which the } \\
\text { aftershock causes larger responses }\end{array}$ \\
\hline \multirow{4}{*}{$\begin{array}{l}\text { Three- } \\
\text { story }\end{array}$} & PIDR & Recorded & 0.20 & 0.43 & 0.71 & 3 \\
\hline & $(\%)$ & Synthesized & 0.18 & 0.63 & 0.95 & 6 \\
\hline & PFA (g) & Recorded & 0.11 & 0.16 & 0.16 & 6 \\
\hline & & Synthesized & 0.11 & 0.17 & 0.18 & 6 \\
\hline \multirow[t]{2}{*}{ Six-story } & PIDR & Recorded & 0.17 & 0.47 & 0.93 & 4 \\
\hline & $(\%)$ & Synthesized & 0.19 & 0.58 & 0.95 & 6 \\
\hline
\end{tabular}




\begin{tabular}{|c|c|c|c|c|c|}
\hline PFA (g) & $\begin{array}{l}\text { Recorded } \\
\text { Synthesized }\end{array}$ & $\begin{array}{l}0.10 \\
0.11\end{array}$ & $\begin{array}{l}0.15 \\
0.17\end{array}$ & $\begin{array}{l}0.16 \\
0.18\end{array}$ & $\begin{array}{l}8 \\
8\end{array}$ \\
\hline
\end{tabular}
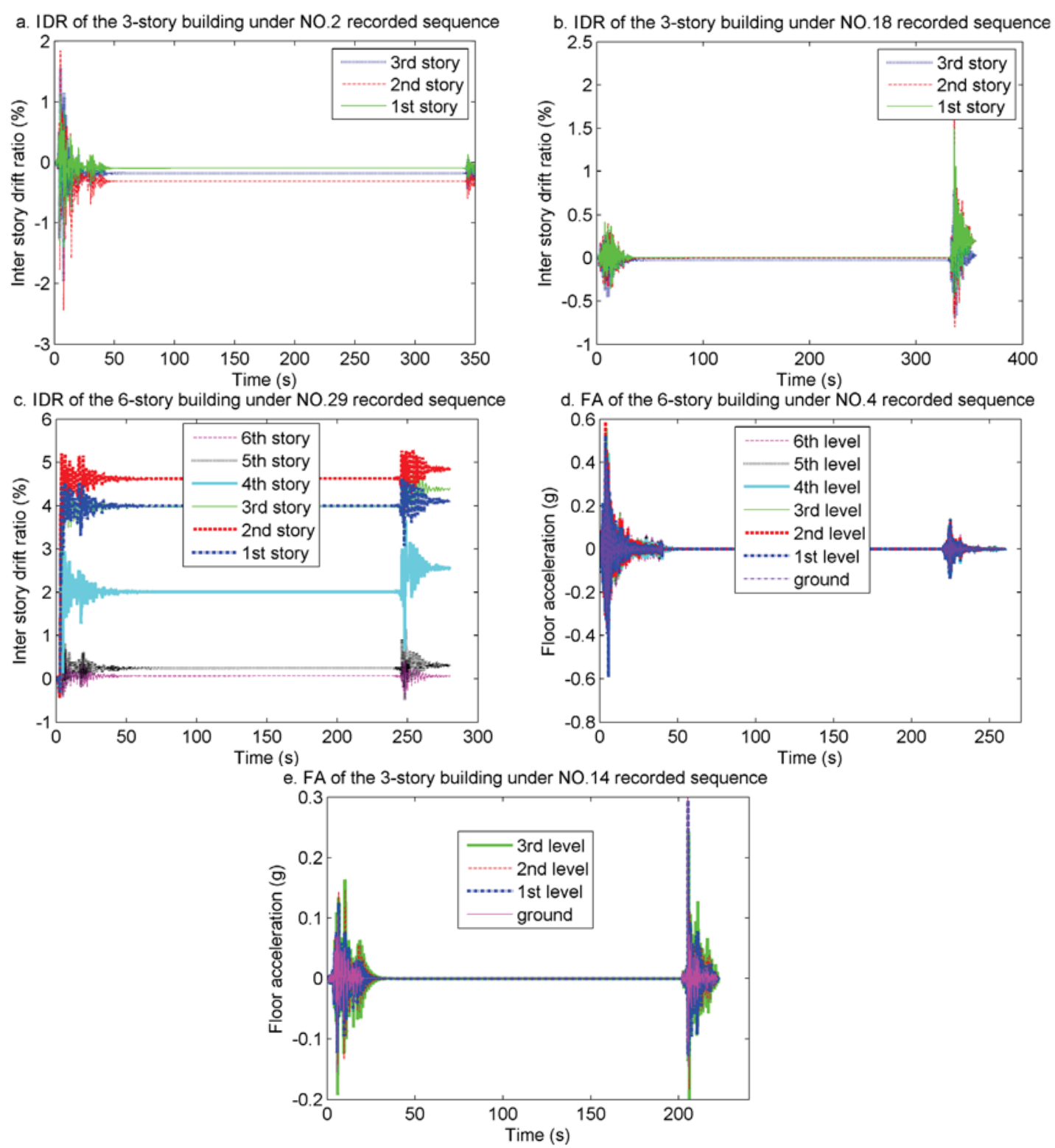

Figure 2.9 Some structural responses time histories of the two buildings

The data presented in Table 2.3 suggest that the results yielded by the recorded and synthesized MS-AS sequences are close from the viewpoint of statistics. Notice that the results obtained from the synthesized sequences for the six-story building, which has a longer fundamental period, are closer to those of the recorded sequences than those of the three-story building. These phenomena are consistent with the median response spectra shown in Figure 2.5(d), and imply that this method to synthesize aftershock will yield 
more accurate result when the structural fundamental period is relatively long. Unlike the median results, the means and standard deviations of the synthesized aftershocks are generally larger, indicating that the results of synthesized sequences have larger variation. Generally speaking, considering the uncertainty of sampling method, the synthesis method proposed in this study can generate aftershock ground motions that are able to yield similar results as the actual aftershocks.

\subsection{Seismic fragility}

Seismic fragilities are an important component of the seismic risk assessment, which estimates the performance and safety of a building under certain seismic scenarios. Seismic fragility is defined as the conditional probability that given certain seismic intensity $(\mathrm{SI})$, the structural demand $(D)$ exceeds the capacity of structures $(C)$.Seismic fragility can be well expressed as a lognormal cumulative distribution function as follow.

$$
P(C<D \mid \mathrm{SI}=x)=1-\Phi\left[\frac{\ln (C / D)}{\sqrt{\beta_{D \mid \mathrm{SI}}^{2}+\beta_{\mathrm{C}}^{2}+\beta_{\mathrm{M}}^{2}}}\right]
$$

where $\Phi[\cdot]$ is the standard Guassian distribution function; $C$ is the median value of structural capacity at certain performance levels; $D$ is the median value of structural demand; $\beta_{D \mid S I}$ and $\beta_{\mathrm{C}}$ are parameters describing aleatoric uncertainties of structural demand and structural capacity, respectively; $\beta_{\mathrm{M}}$ is the parameter represent the modeling (epistemic) uncertainty. The structural demand, which is obtained by time history analyses using the MS-AS sequences, can be related to SI, using the following equation (Cornell, et al. 2002).

$$
D=a(\mathrm{SI})^{b}
$$

where $a$ and $b$ are constants that can be obtained by taking logarithm at both side and making regression in analysis. The structural seismic fragility can then be obtained using Eq. 2.6 and 2.7. For the study on MS-AS effect, aftershock fragility (Jeon, et al. 2012) or the entire sequence fragility may be investigated based on different purposes. For most buildings which have not suffered earthquake mainshocks, develop the seismic fragility curves for the entire MS-AS sequences may be more helpful. Thus the sequence fragility is the focus of this study. Fragility curves based on mainshocks, recorded, and synthesized MS-AS sequences are developed and compared to investigate the MS-AS 
effects and to verify the accuracy of synthesized sequences when employed for fragility analysis.

Measurements and limit states need to be determined before fragility curves can be developed using Eq. 2.6 and 2.7. For structural and deformation sensitive non-structural components (SDSNC), PIDR is selected as the seismic demand (damage index), whereas the PFA is selected as the seismic demand of the acceleration sensitive non-structural components (ASNSC). $S_{a}\left(\mathrm{~T}_{1}, \zeta=5 \%\right)$ is used for measuring the seismic intensity. The Figure 2.10 illustrates the seismic demands on the SDSNC and ASNSC for the mainshocks, recorded sequences and synthesized sequences.
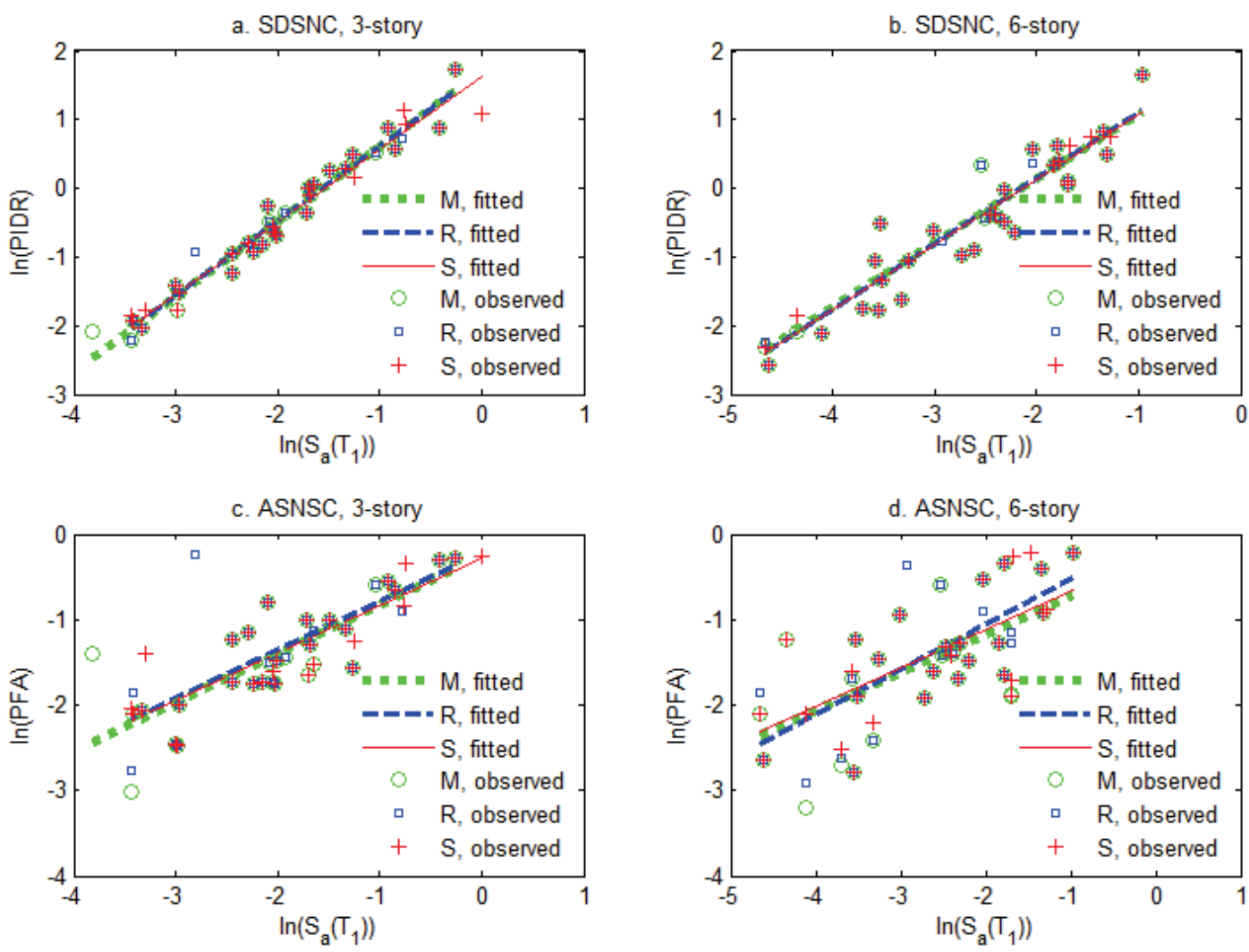

Note: $M=$ Mainshocks; $R=$ Recorded MS-AS sequences; $S=$ Synthesized MS-AS sequences

Figure 2.10 Seismic demands on the components of the two buildings

Four damage states (slight, moderate, extensive and collapse damage) are employed in this study. Generally, damage of nonstructural components will not lead to the collapse of a building, so the non-structural components in this paper are only considered for slight, 
moderate and extensive damage states. The PIDR at slight damage (SD) state is defined as the PIDR at the elastic limit state, and is calculated using nonlinear pushover analysis with up-side-down triangular load pattern. The PIDR at moderate damage (MD) level and extensive damage (ED) level are assumed to be $0.8 \%$ and $2 \%$ respectively, following HAZUS-MH (FEMA 2009a). The PIDR corresponding to the collapse damage (CD) state is obtained from incremental dynamic analysis (IDA) (Vamvatsikos and Cornell 2002) with each suite of ground motions using the 20\% slope criterion (FEMA 2000b). The $\beta_{\mathrm{C}}$ of $\mathrm{SD}, \mathrm{MD}$ and $\mathrm{ED}$ levels are assumed to be 0.25 , and the $\beta_{\mathrm{C}}$ of $\mathrm{CD}$ level is designated to be the logarithmic standard deviation of the IDA calculated structural capacity. A uniform PFA at each damage state is difficult to define because the damage of acceleration sensitive non-structural components is related to many factors such as the failure mechanism and anchorage. But for the purposes of quantitative analysis, these components can be categorized into two types according to Elenas and Meskouris (2001). One type is mechanical, electronic and plumbing (MEP) systems and the other is the contents such as furniture and equipment. The PFA of these two types of components at each damage level are set following Elenas and Meskouris (2001), as shown in Table 2.4. The $\beta_{\mathrm{C}}$ of all damage levels are set to be 0.25 , and the modeling uncertainty $\beta_{\mathrm{M}}$ is assumed to be 0.2 (Celik and Ellingwood 2010) in this study. All the parameters used in the fragility analysis are presented in Table 2.4.

Table 2.4 Parameters employed in the fragility analysis

\begin{tabular}{|c|c|c|c|c|c|c|c|c|c|c|c|c|c|c|c|c|c|c|c|}
\hline \multirow[t]{3}{*}{ Parameters } & & \multicolumn{6}{|c|}{ SDSNC } & \multicolumn{6}{|c|}{ MEP } & \multicolumn{6}{|c|}{ Contents } \\
\hline & & \multicolumn{3}{|c|}{ three-story } & \multicolumn{3}{|c|}{ six-story } & \multicolumn{3}{|c|}{ three-story } & \multicolumn{3}{|c|}{ six-story } & \multicolumn{3}{|c|}{ three-story } & \multicolumn{3}{|c|}{ six-story } \\
\hline & & $\mathrm{M}$ & $\mathrm{R}$ & $\mathrm{S}$ & M & $\mathrm{R}$ & S & M & $\mathrm{R}$ & $\mathrm{S}$ & M & $\mathrm{R}$ & S & M & $\mathrm{R}$ & S & M & $\mathrm{R}$ & $\mathrm{S}$ \\
\hline \multicolumn{20}{|l|}{ Demand } \\
\hline$a$ & & 5.48 & 5.48 & 5.08 & 7.45 & 7.83 & 7.53 & 0.78 & 0.81 & 0.7 & 0.75 & 1.00 & 0.81 & 0.78 & 0.81 & 0.7 & 0.75 & 1.00 & 0.81 \\
\hline$b$ & & 1.09 & 1.09 & 1.06 & 0.93 & 0.96 & 0.95 & 0.57 & 0.57 & 0.5 & 0.44 & 0.53 & 0.45 & 0.57 & 0.57 & 70.5 & 50.44 & 0.53 & 0.45 \\
\hline$\beta_{D \mid \mathrm{SI}}$ & & 0.19 & 0.19 & 0.21 & 0.41 & 0.39 & 0.36 & 0.39 & 0.43 & 0.3 & 0.59 & 0.5 & 0.53 & 0.39 & 0.43 & 30.3 & 30.59 & 0.53 & 0.53 \\
\hline \multicolumn{20}{|l|}{ Capacity } \\
\hline \multirow[t]{4}{*}{ C } & SD & 0.2 & & & 0.3 & & & $0.5 \mathrm{~g}$ & & & & & & $0.2 \mathrm{~g}$ & & & & & \\
\hline & MD & 0.8 & & & & & & $1.2 \mathrm{~g}$ & & & & & & $0.8 \mathrm{~g}$ & & & & & \\
\hline & ED & 2 & & & & & & $1.7 \mathrm{~g}$ & & & & & & 1.25 & & & & & \\
\hline & $\mathrm{CD}$ & 5.32 & 4.84 & 4.90 & 4.23 & 4.26 & 4.21 & _ & & & & & & - & & & & & \\
\hline \multirow[t]{4}{*}{${ }^{\beta_{\mathrm{C}}}$} & $\mathrm{SD}$ & 0.25 & & & & & & 0.25 & & & & & & 0.25 & & & & & \\
\hline & MD & 0.25 & & & & & & 0.25 & & & & & & 0.25 & & & & & \\
\hline & ED & 0.25 & & & & & & 0.25 & & & & & & 0.25 & & & & & \\
\hline & $\mathrm{CD}$ & 0.26 & 0.27 & 0.31 & 0.30 & 0.28 & 0.25 & _ & & & & & & _ & & & & & \\
\hline Modeling & & & & & & & & & & & & & & & & & & & \\
\hline & & 0.2 & & & & & & 0.2 & & & & & & 0.2 & & & & & \\
\hline
\end{tabular}

Note: M=Mainshocks; R=Recorded sequences; $\mathrm{S}=$ Synthesized sequences. 
The fragility curves of the components for each building under various ground motions are obtained with the parameters listed in Table 2.4, and are illustrated in Figure 2.11.
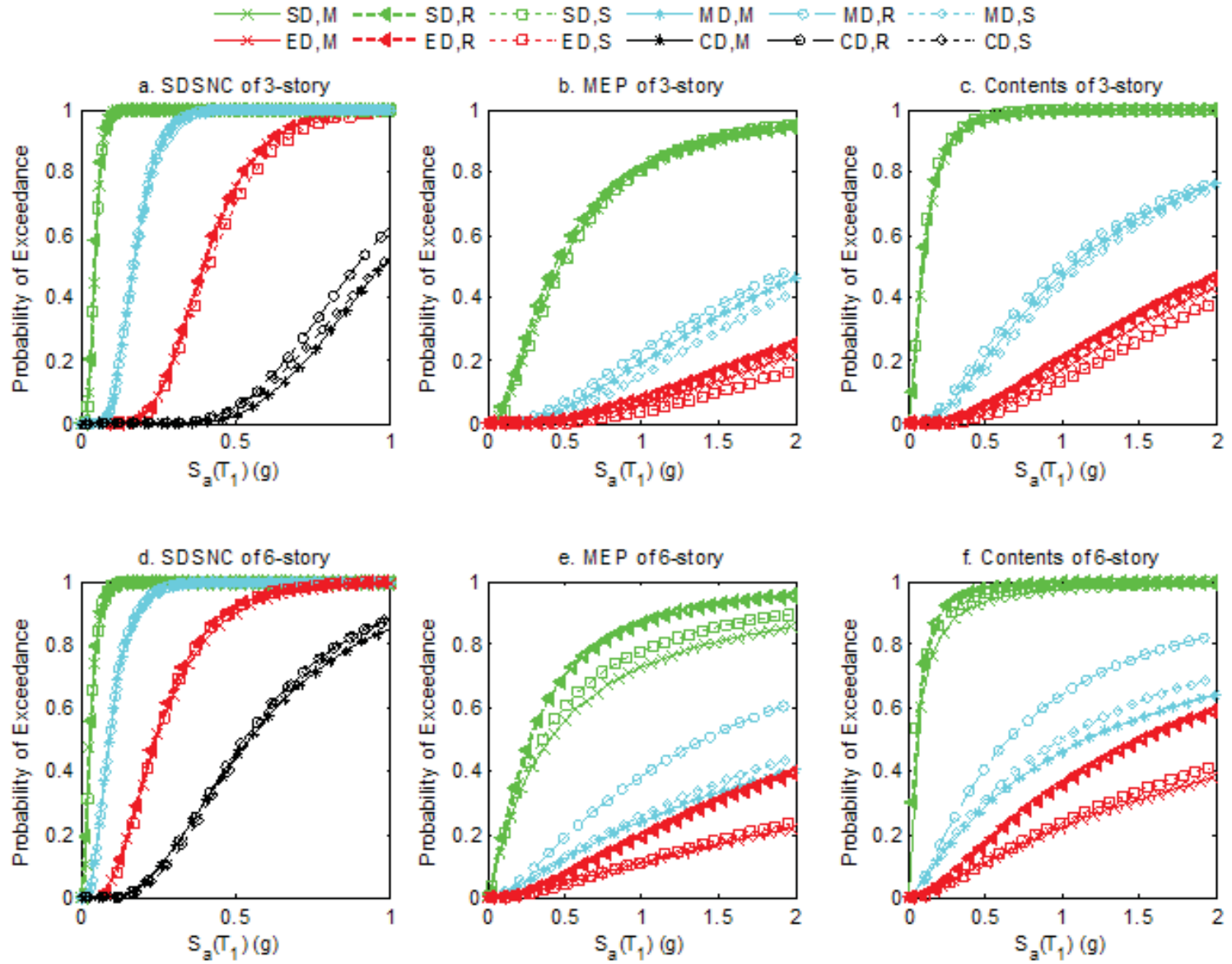

Figure 2.11 Fragility curves of different components for the buildings under various ground motions

As depicted in Figure 2.11, the fragility curves of the SDSNC are close for mainshocks, recorded sequences, and synthesized sequences, indicating that the difference in seismic fragility between only considering mainshocks and mainshock-aftershock sequences could be limited. While for ASNSC, the differences between considering aftershocks or not are significant. By comparing the fragilities under only mainshocks and the recorded sequences, a general trend can be concluded that the exclusive consideration of mainshocks leads to underestimation of the seismic fragility. This trend is also observed for the six-story building by comparison between mainshocks and synthesized sequences, whereas for the three-story building, no such general rule can be observed. This suggests 
that the synthesized sequences are more suitable for seismic fragility analysis of buildings with longer fundamental periods, which is consistent with the results listed in Table 2.3. When the two buildings are compared, it can be concluded that the six-story building has higher fragility. The fragility curves under only mainshocks for the two buildings are quite similar as those of the same two building in Celik and Ellingwood's study using ground motions from Central and Eastern United States (CEUS) (Celik and Ellingwood 2009), indicating that the seismic fragilities of buildings are relatively independent to the suites of ground motions. Consequently, the fragility curves shown in this part can also be used in seismic reliability analysis for other areas such as CEUS.

\subsection{Seismic reliability}

The seismic reliability analysis deals with the uncertainties of seismic demand and structural capacity, and evaluates the reliability of structural system under a spectrum of earthquakes. The seismic risk of a building exceeding certain performance levels or damage states can be expressed as follow.

$$
P(C<D)=\int P(C<D \mid \mathrm{SI}=x) \cdot d H(x)
$$

where the $P(C<D \mid \mathrm{SI}=x)$ is the seismic fragility calculated previously, and the relevant notations are the same as aforementioned; $H(x)$ is the seismic hazard which describes the probability that SI exceeds $x$ and can be expressed as Eq. 2.9 when $S_{a}$ is employed as SI (Cornell, et al. 2002).

$$
H(x)=P\left(S_{a} \geq x\right)=k_{0} \cdot x^{-k}
$$

in which $k_{0}$ and $k$ are constants varying by different regions and site conditions. Using Eq. 2.9 will significantly reduce the computational effort (Cornell, et al. 2002). However, the hazard curve defined by Eq. 2.9 is a straight line on a log-log plot, which may lead to an overestimation of earthquake hazard within the extremely low and high intensity regions of the hazard curve (USGS 2014). However, for the purpose of the risk assessment, adoption of Eq. 2.9 will still yield sufficiently accurate results (Cornell, et al. 2002; Yun and Foutch 2000). With Eq. 2.6-2.9, the Eq. 2.8 can be rewritten as follow.

$$
P(C<D)=H\left(S_{a}^{C}\right) \exp \left[\frac{k^{2}}{2 b^{2}}\left(\beta_{D \mid \mathrm{SI}}^{2}+\beta_{\mathrm{C}}^{2}+\beta_{\mathrm{M}}^{2}\right)\right]
$$




$$
\text { and } \quad S_{a}^{C}=(C / a)^{1 / b}
$$

Assume that the buildings are located in St. Louis, MO, and the site condition is Site Class D according to the shear wave velocities (ASCE 2010). USGS provides 5\% damped $S_{a}$ at various periods (from $0.1 \mathrm{~s}$ to $2 \mathrm{~s}$ ) at $2 \%, 5 \%$ and $10 \%$ probability of exceedance (PE) in 50 years (USGS 2013) for Site Class B. Uniform hazard spectra (UHS) are then constructed with site coefficients according to ASCE-7/10 (ASCE 2010) and $S_{a}\left(\mathrm{~T}_{1}\right)$ for the two buildings at different PE in 50 years are calculated. For the threestory building, the $S_{a}\left(\mathrm{~T}_{1}\right)$ at $2 \%, 5 \%$ and $10 \%$ PE in 50 years are $0.29 \mathrm{~g}, 0.19 \mathrm{~g}$ and $0.11 \mathrm{~g}$ respectively, whereas the $S_{a}\left(\mathrm{~T}_{1}\right)$ of the six-story building at $2 \%, 5 \%$ and $10 \% \mathrm{PE}$ in 50 years are $0.17 \mathrm{~g}, 0.11 \mathrm{~g}$ and $0.06 \mathrm{~g}$. Seismic curves for the two $S_{a}\left(\mathrm{~T}_{1}\right)$ at St. Louis can then be obtained, as shown in the log-log plot (Figure 2.12). For the three-story building $\left(\mathrm{T}_{1}=1.14 \mathrm{~s}\right)$, the constants in Eq. 2.9 are $k_{0}=5.99 \times 10^{-5}$ and $k=1.61$, and for the six-story building $\left(\mathrm{T}_{1}=1.92 \mathrm{~s}\right), k_{0}=2.58 \times 10^{-5}$ and $k=1.61$.

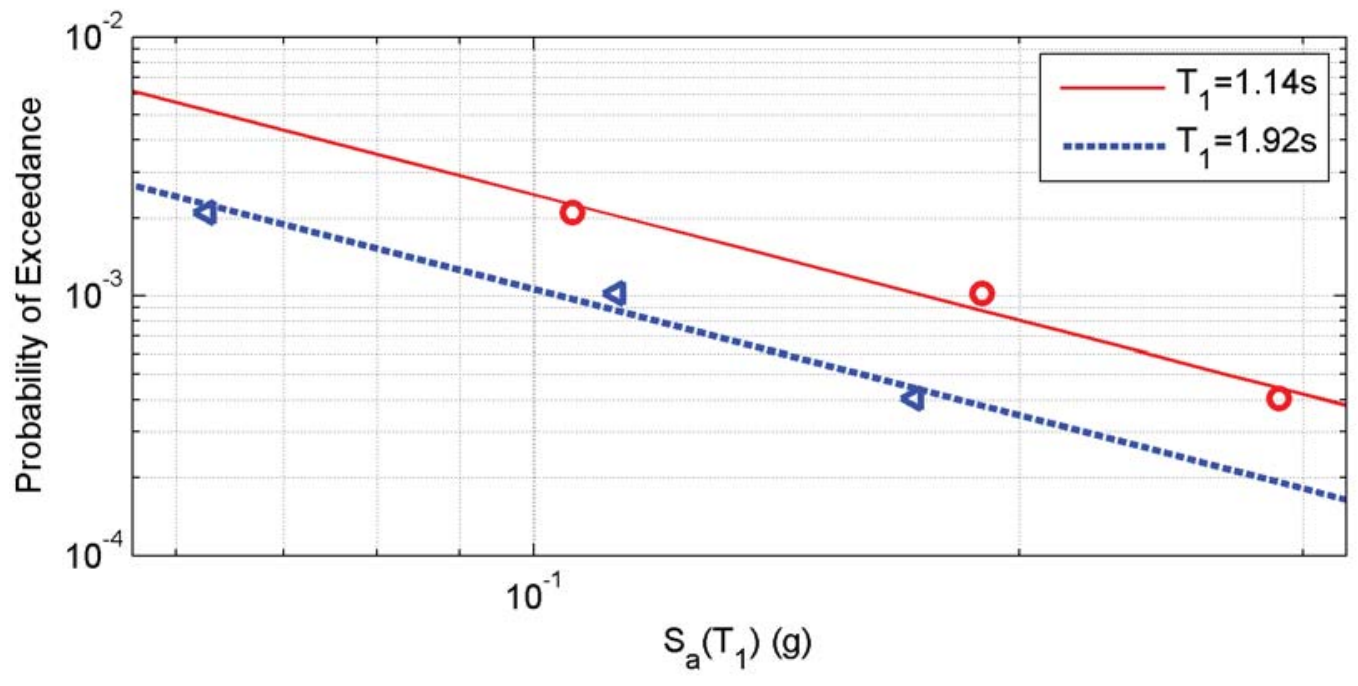

Figure 2.12 Seismic hazard curves for the two buildings in St. Louis, MO

The annual and 50 years probability of the components for the two buildings exceeding the corresponding damage states $(\mathrm{SD}, \mathrm{MD}, \mathrm{ED}$ and $\mathrm{CD})$ are calculated using the previous equations. The results are depicted in Figure 2.13. 

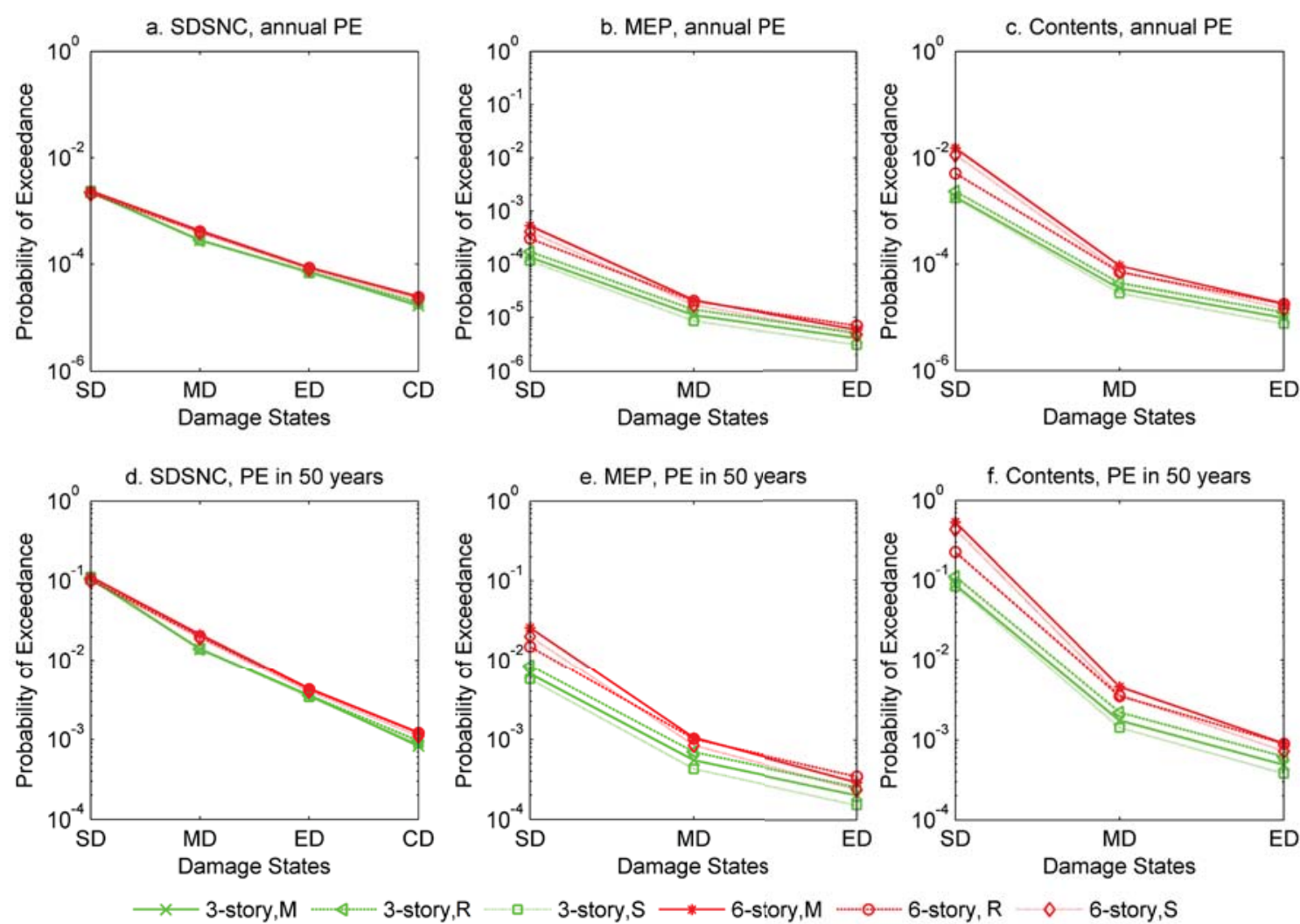

Figure 2.13 Annual and 50-year PE for the components of the two buildings

It is obvious that all the components of the two buildings have relatively high annual and 50 years $\mathrm{PE}$ in all the damage levels (especially for SD, MD and ED), indicating their insufficient structural capacity and high seismic vulnerability. Their capacity need to be reinforced otherwise significant economic loss and casualties may occur. This result is similar to a previous study on the same buildings subjected to ground motions of CEUS (Celik and Ellingwood 2009). For SDSNC, the PE calculated with mainshocks, recorded and synthesized sequences are close, implying the underestimation when only account for mainshock is marginal. But for MEP and contents, the differences between the PE under different ground motions are significant but are in a haphazard way. The reason why no general trend can be observed even for the PE for mainshocks and the recorded sequences may be caused by the uncertainties in the damage of ASNSC are large, as also demonstrated in Figure 2.11. 


\subsection{Conclusions}

A method for synthesizing aftershocks based on mainshocks was proposed and applied in the risk analysis of two non-ductile RC frame buildings. The results of using both recorded and synthesized sequences were compared to validate this synthesis method. The results obtained from only mainshocks were also investigated to study the effects of MS-AS sequences. The results showed that the methodology of synthesizing aftershocks proposed in this paper can statistically achieve results close to those employing recorded MS-AS sequences, especially for buildings with longer fundamental periods, and is therefore felt to be applicable for conducting seismic risk analysis. To further improve the accuracy of this synthesis method, future effort may focus on the probabilistic distribution of the parameters utilized in the attenuation relationships. By comparing the results for only mainshocks and MS-AS sequences, it has been observed that aftershocks may cause larger structural responses than the mainshocks for two reasons. One case is when the structural capacities have been severely compromised by the mainshocks. The other is aftershocks have more intense ground motion (e.g. higher $S_{a}$ or PGA) at a particular site, resulting from shorter site-to-source distances of the aftershocks or a change in the energy content for the aftershock which has a more detrimental effect on the structure. However, fragility and reliability analysis reveals that the underestimation of seismic risk induced by exclusive consideration of the mainshocks is limited, and could even be overshadowed by the uncertainties of some components. The investigation on the two non-ductile RC frame buildings showed that both structural and non-structural components of this type of buildings are vulnerable to seismic risk, which is consistent with the previous studies (Celik and Ellingwood 2009; Liel and Deierlein 2008). The

large uncertainties of the damage to ASNSC suggest that the methods to incorporate the damage of ASNSC in risk analysis need further investigation. 



\section{Seismic Performance Assessment with Consideration of Aftershock Hazard and Post-Quake Decisions ${ }^{2}$}

\subsection{Introduction}

Although earthquake mainshocks generally have larger magnitudes and are more destructive than the numerous following aftershocks, it has been observed that the aftershocks sometimes can cause additional damage to buildings. For example, in the 1999 Turkey earthquake, a residential building which survived the mainshock of magnitude 7.4 completely collapsed during an aftershock of magnitude 5.9 occurred about one month later (USGS 2000). During the 1999 Taiwan earthquake, a gas station also collapsed after an aftershock instead of the mainshock (Lew, et al. 2000). In the 2002 Italy earthquake, the mainshock caused slight damage to the beam-column joint of a reinforced concrete (RC) frame building but was reported to have developed into a much more severely damaged condition due to an aftershock (Yeo and Cornell 2005). However, current seismic performance assessment methodologies generally only consider the mainshock hazard, which raises the need for assessment methodologies with the ability to explicitly incorporate aftershock hazard as well.

Many studies revealed that aftershocks may increase the structural response and seismic risks of buildings. Li and Ellingwood (2007) studied the structural damages of two steel frame buildings using simple probabilistic methods and concluded that aftershocks can increase the structural responses. Ruiz-García and Negrete-Manriquez (2011) concluded that the aftershocks could increase the residual drifts by investigating the drift demands of several steel frame buildings under a group of mainshock-aftershock (MS-AS) ground motions. Nazari, et al. (2013) investigated the damage fragilities of woodframe buildings subjected to MS-AS ground motions and found out that aftershocks can increase the probability of exceedance for different damage levels. Chapter 2 of this study also finds that the structural responses and seismic risk could be underestimated if aftershocks are not considered. These studies mainly focused on the structural response or the seismic fragility, but did not investigate the impact of aftershocks on the seismic performance of buildings, such as the direct loss, downtime and fatalities.

\footnotetext{
2 The material contained in this chapter has been submitted to ASCE-ASME Journal of Risk and Uncertainty in Engineering Systems, Part A: Civil Engineering.
} 
Direct loss (repair/replacement cost), downtime and fatalities are important, especially for stakeholders and decision makers. They have been adopted as the performance metrics in the latest seismic performance assessment methodologies of performance-based earthquake engineering (PBEE), such as the FEMA P-58 (FEMA 2012a), although aftershocks are still not considered in these methodologies. Yeo and Cornell (2005) developed a conceptual framework to estimate the direct loss and downtime loss of buildings caused by both mainshock and aftershock hazard using PBEE method. Yin and $\mathrm{Li}$ (2011) also proposed a Monte Carlo based methodology to simulate the direct loss and downtime loss of buildings under MS-AS sequences. However, as highlighted by their developers (Yeo and Cornell 2005; Yin and $\mathrm{Li}$ 2011), these frameworks and methodologies are still at their early stages and more investigations are necessary.

For example, the post-quake decisions such as whether to evacuate people after an earthquake and whether to repair or rebuild the building have not been adequately discussed. However, these decisions along with the aftershocks both influence the seismic direct loss, downtime, and fatalities. Additionally, the methods applied to compute direct loss and downtime over-simplified compared to the assembly-based methods, which can account for details of the buildings and has been widely utilized in seismic performance assessment for mainshocks (e.g. Porter, et al. 2001, Mitrani-Reiser 2007, and FEMA 2012a). Furthermore, the fatalities caused by aftershock hazard were not considered in the previous methodologies. The purpose of this study is to develop a procedure to incorporate the aftershock hazard and the influence of various post-quake decisions into performance-based seismic performance assessment and loss estimation thereby allowing the direct loss, downtime, and fatalities to be estimated using a method with similar complexity and accuracy to other current PBEE based assessment methodologies. Another question of interest is whether considering only the largest aftershock will yield similar results when one considers multiple aftershocks, since using multiple aftershock records is difficult due to a dearth of available aftershock records with multiple aftershocks. This question will also be examined through a case study in this paper.

\subsection{Post-quake decisions and aftershocks}

In current PBEE based seismic performance assessment methodologies which only account for the mainshocks, many post-quake decisions have impact on the estimation of 
building performance. For example, different tags of the building assigned after the postquake evaluation have significant impact on the nonoperational time (i.e. downtime) of a building (Mitrani-Reiser 2007). The decision as to whether to repair the building or to demolish and rebuild also results in significant difference in direct loss and downtime. Furthermore, under what condition the building will be considered as uninhabitable and people will be evacuated from the building also influences on the downtime. To incorporate these post-quake decisions in the assessment, current assessment methods which only consider mainshocks are generally performed as depicted by the flowchart at the right part of Figure 3.1. After the mainshock, if the building has collapsed, the debris will be cleaned and the building replaced. If the building survived the mainshock, people inside the building will be evacuated if significant damages are found to have occurred, which will result in downtime before the safety evaluation. If the building does not collapse, it will go through a safety evaluation process, the details of which will be discussed later in this paper. After the safety evaluation, the building will be assigned with a different posting, including "inspected", "restricted use", and "unsafe" (ATC 2005), which are also commonly known as "green tag", "yellow tag", and "red tag" respectively (Mitrani-Reiser 2007; Yeo and Cornell 2005). The criteria of different tagging and their influence on the seismic performance will also be discussed later. After the safety evaluation, the building will be determined to be repairable or not, and the repair cost will be estimated if it is repairable. If the building is not repairable or if the repair cost is too high (i.e. higher than the financial threshold of the owner), the building will be demolished and rebuilt.

Similar procedures can be applied for assessing the impact of aftershocks. Due to the number of aftershocks considered, it will require significant computational effort as the assessment procedure needs to be repeated for each aftershock that caused more severe damage, but it can be realized easily with computer aided programming. For example, there are actually multiple aftershocks before the safety evaluation. Collapse of building and evacuation of occupants might be trigged by each shock. Additionally, aftershocks after the safety evaluation may increase the damage, and consequently elongate the downtime and increase the repair cost. If more aftershocks occur after the structural components of the building have been repaired, the building can be treated as a new building subjected to another earthquake sequence, which may be true for some aftershocks occur months after the mainshock. Note that it is important to identify which nonstructural components have been repaired by the time of the aftershock in such a 
scenario. The procedure of assessment considering mainshock and aftershocks is also illustrated in the left flowchart of Figure 3.1.

Considering both mainshock and aftershock hazards

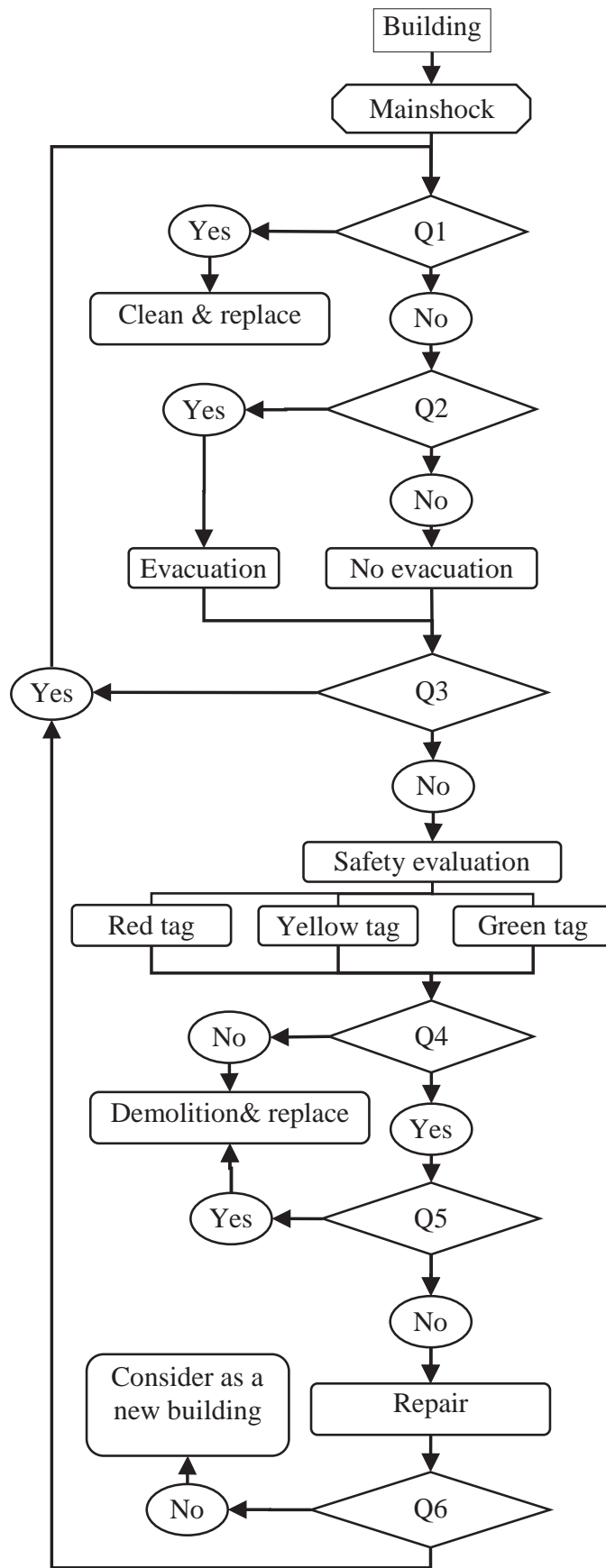

Considering only mainshock hazard
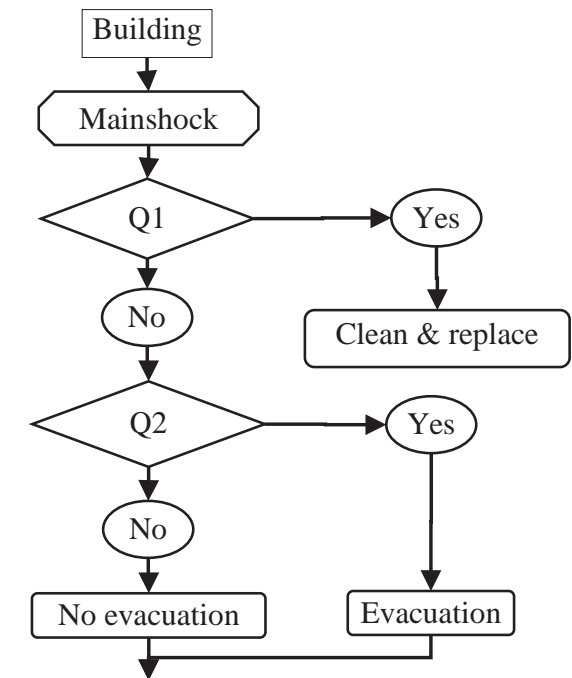

Safety evaluation

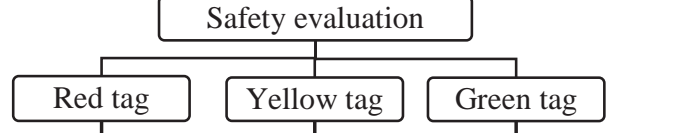

Q1: Has the building collapsed?

Q2: Is the damage significant enough to trigger evacuation?

Q3: Is there any more aftershocks occur before safety evaluation?

Q4: Is the building repairable?

Q5: Is the repair cost higher than the owner's threshold?

Q6: Is there any more aftershocks occur before the structure has been repaired?

Figure 3.1 Flowcharts of performance assessment procedures with and without consideration of aftershock hazard 
An assumption adopted in this study is that more severe damage occurs only when a larger structural response occurs. For example, if the peak inter story drifts of a reinforced concrete (RC) column during a mainshock and three following aftershocks are $1.0 \%, 0.5 \%, 0.6 \%$, and $1.1 \%$, only the last aftershock is assumed to have caused additional damage to the mainshock damaged RC column. This assumption might neglect the failure due to low-cycle fatigue, but it can balance the accuracy and simplicity, and has been adopted in previous studies (Yeo and Cornell 2005; Yin and Li 2011).

\subsection{General equations for seismic performance assessment}

All the performance metrics can be calculated according to the flowchart. In this section, some general equations derived using probabilistic theories and based on the flowchart in Figure 3.1 are presented for performance assessment regarding the mean of direct loss, downtime, and fatalities. The loss exceedance rate of a building under a specific earthquake hazard level can be obtained with the results from a group of earthquake ground motions at the hazard level, which, however, will not be discussion in this paper. These equations are general to account for the interaction between aftershocks and postquake events, and the detail equations to calculate the variables in the equations are not presented if they have been extensively investigated. However, references that contain the detailed equations are presented, and the case study in the next section also shows an example of calculating all the variables.

\subsubsection{Direct loss (repair/replacement cost)}

For a building under a specific MS-AS sequence, the mean direct loss, which is generally defined as the cost to repair or replace the building to its intact state, is disaggregated as follow.

$$
E(L)=E(L \mid M)+\sum_{i=1}^{m+n} E\left(L \mid A_{i}\right)
$$

where $L$ is the direct loss; $E(L \mid M)$ is the mean of direct loss caused by the mainshock; whereas $E\left(L \mid A_{i}\right)$ is the mean of direct loss caused by the $i$ th aftershock which caused more damage; $n$ is the number of aftershocks that caused more damage than the predecessors and occurred before the safety evaluation; $m$ is the number of aftershocks 
that caused more damage than the predecessors and occurred after the safety evaluation but before the building structure has been repaired. As illustrated in Figure 3.1, typically right after an earthquake, there is limited resource to examine whether the building is repairable or not. Therefore, the reparability is not considered for the mainshock and the first $n-1$ aftershocks. The aftershocks that occur after the repair of the structure is completed should be treated as a new MS-AS sequence and Eq. 3.1 can be utilized again to calculate the direct loss. It is notable that in such scenario, some nonstructural components may not have been repaired, and the repair cost shall not be double counted. The mean of direct losses due to the mainshock and an aftershock are presented in Eq. $3.2 \sim 3.4$.

$$
\begin{aligned}
& E(L \mid M)=E(L \mid C, M) \cdot P(C \mid M)+E(L \mid N C, M) \cdot P(N C \mid M) \\
& \text { where } E(L \mid N C, M)=0 \quad \text { if } n>0
\end{aligned}
$$

when $i \leq n-1$ :

$$
\begin{aligned}
& E\left(L \mid A_{i}\right)=\left\{\begin{array}{l}
P(N C \mid M) \cdot \prod_{j=1}^{i-1}\left[P\left(N C \mid A_{j}\right)\right] \\
\cdot\left[E\left(L \mid C, A_{i}\right) \cdot P\left(C \mid A_{i}\right)+E\left(L \mid N C, A_{i}\right) \cdot P\left(N C \mid A_{i}\right)\right]
\end{array}\right\} \\
& E\left(L \mid N C, A_{i}\right)=0 \quad \text { if } i<n-1
\end{aligned}
$$

when $n \leq i \leq n+m$ :

$$
\begin{aligned}
& E\left(L \mid A_{i}\right)=P(N C \mid M) \cdot \prod_{j=1}^{n-1}\left[P\left(N C \mid A_{j}\right)\right] \cdot \prod_{k=n}^{i-1}\left[P\left(R \mid N C, A_{k}\right) \cdot P\left(N C \mid A_{k}\right)\right] \\
& \left.\qquad \begin{array}{l}
E\left(L \mid C, A_{i}\right) \cdot P\left(C \mid A_{i}\right) \\
+E\left(L \mid N R, N C, A_{i}\right) \cdot P\left(N R \mid N C, A_{i}\right) \cdot P\left(N C \mid A_{i}\right) \\
+E\left(L \mid R, N C, A_{i}\right) \cdot P\left(R \mid N C, A_{i}\right) \cdot P\left(N C \mid A_{i}\right)
\end{array}\right] \\
& E\left(L \mid R, N C, A_{i}\right)=0 \quad \text { if } i<n+m
\end{aligned}
$$

\subsubsection{Downtime}

Downtime is the time period between when the occupants are evacuated and the building resumes occupancy or function, including the necessary time to prepare, to finance, and to finish the repair work. The economic loss due to downtime can be substantial 
sometimes. The length of this time period is highly uncertain because it depends on many human factors such as the available labor, materials, and capital (Comerio and Blecher 2010). Comerio (2006) categorized downtime into two types, namely the "rational downtime" and the "irrational downtime". Both the two types of downtimes can be as long as years. The rational downtime refers to the repair time, which is less uncertain and can be predicted (FEMA 2012a; Mitrani-Reiser 2007). Commonly, the rational downtime is considered as the maximum repair time of all the stories for parallel repaired buildings and as the total repair time of all the stories for serially repaired buildings (as illustrated in Figure 3.2). The repair time of a story is assumed to be the summation of the repair time of all the components in that story. However, the irrational downtime, which is the downtime before repair starts, is highly affected by the labor, economic, and regulatory uncertainties (Comerio and Blecher 2010). Despite that the irrational downtime is difficult to predict, some rudimentary models have been proposed to roughly calculate it. Comerio (2006) related the total downtime with the percentage of the repaired or demolished components using historical data. Mitrani-Reiser (2007) developed a model, which is also adopted in this study, to simulate it based on the result of the rapid evaluation of the building. The rapid evaluation (the first post-quake evaluation), which is the first step of the aforementioned safety evaluation required by ATC-20 (ATC 2005), generally is performed a few days after the mainshock by examining the exterior damage quickly. The building will be tagged green, yellow, or red after the rapid evaluation, indicating inspected, restricted use, and unsafe, respectively. The green tagged buildings have only suffered minor damage and do not need much time to prepare for the repair (short irrational downtime). The red tagged buildings generally have obvious damage and require substantial time to prepare for things such as capital and labor for the following work (long irrational downtime). The yellow tagged buildings typically are at some intermediate damage states and will need detailed evaluations or even engineering evaluations to follow up (moderate irrational time). Statistical data indicates that the irrational downtime for the buildings with yellow tags after rapid evaluation is somewhere between that of the buildings with green and red tags (Mitrani-Reiser 2007). 


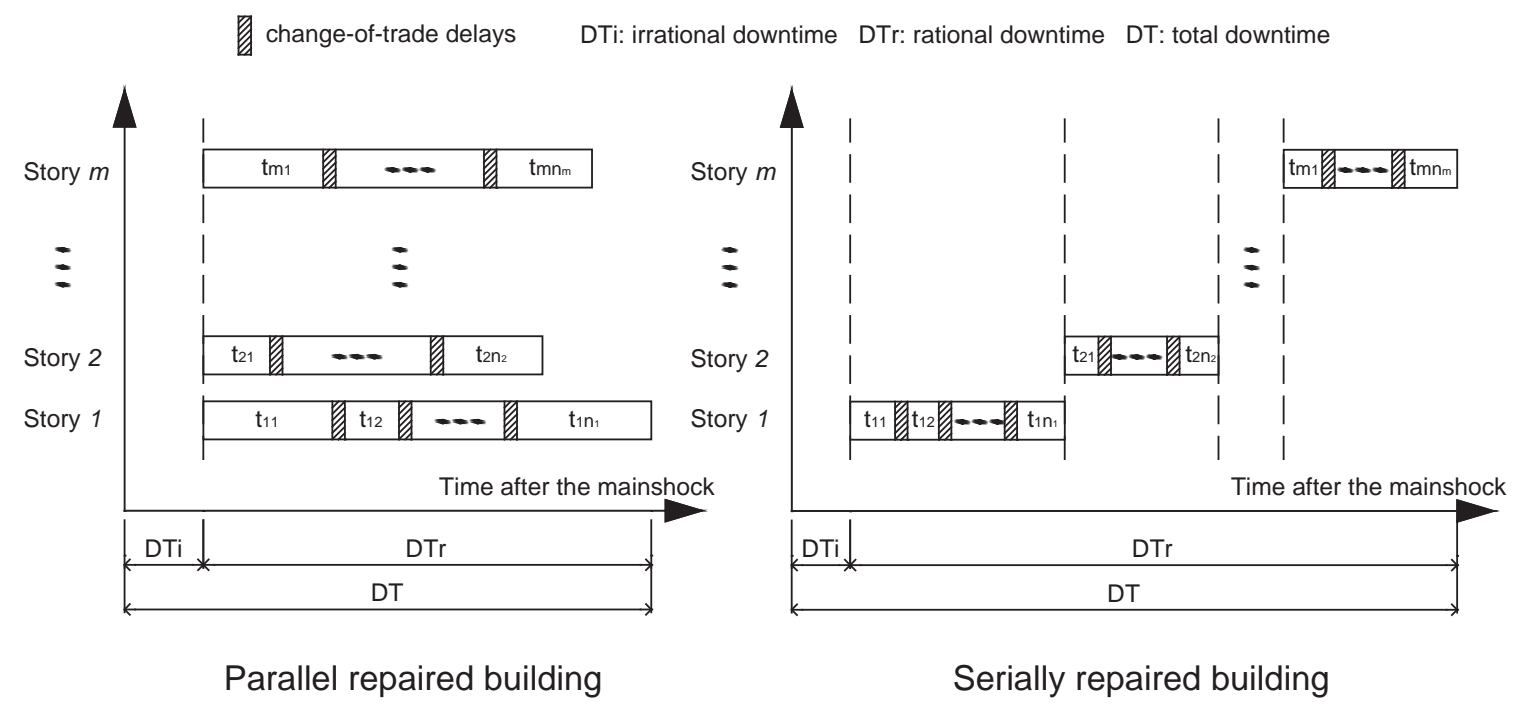

Figure 3.2 Gantt charts of different repair schemes

Another event that can affect the irrational downtime is the decision of evacuation before the rapid evaluation, which has been rarely investigated in previous studies. In present performance assessment procedure, downtime is assumed to start right after the mainshock, implying the assumption that the occupants are evacuated after the mainshock. However, there are generally a few days between the mainshock and the rapid evaluation. If no obvious damage occurs, people inside the building will probably keep their daily life and hence yield no downtime, otherwise they will likely evacuate and cause downtime. It should be noted that besides the damage of structural components, the damage of nonstructural components such as drywall partitions and ceilings may also cause people to decide to evacuate, although experts performing safety evaluation make their judgments mostly based on the damage of structural components (ATC 2005; FEMA 2012a).

Consideration of only the mainshocks may result in underestimation for both the irrational and the rational downtime. First of all, the aftershocks before the rapid evaluation will trigger a higher probability of evacuation and induce more irrational downtime consequently. Secondly, the probability of the building suffering additional damage due to the aftershocks will not only result in a higher probability to of receiving a yellow or red tag and hence increase the preparation time before repair, but will also more likely require a longer repair time. Thirdly, if more aftershocks occur after the building has been repaired, more downtime is likely. 
$E\left(D T_{\text {pre }}\right)$, the mean of the downtime caused by the mainshock and the aftershocks before the rapid evaluation can be written as Eq. 3.5 and further expanded to Eq. 3.6 and 3.7 .

$$
\begin{gathered}
E\left(D T_{\text {pre }}\right)=E\left(D T_{\text {pre }} \mid M\right)+\sum_{i=1}^{n} E\left(D T_{\text {pre }} \mid A_{i}\right) \\
E\left(D T_{\text {pre }} \mid M\right)=\left[\begin{array}{l}
P(C \mid M) \cdot E(D T \mid C) \\
+P(N C \mid M) \cdot P(E v \mid N C, M) \cdot E(D T \mid e @ M)
\end{array}\right] \\
E\left(D T_{p r e} \mid A_{i}\right)=\left\{\begin{array}{l}
P(N C \mid M) \cdot \prod_{j=1}^{i-1}\left[P\left(N C \mid A_{j}\right)\right] \cdot P\left(C \mid A_{i}\right) \cdot E(D T \mid C) \\
+P(N C \mid M) \cdot P(N E v \mid N C, M) \\
\cdot \prod_{j=1}^{i-1}\left[P\left(N C \mid A_{j}\right) \cdot P\left(N E v \mid N C, A_{j}\right)\right] \\
\cdot P\left(N C \mid A_{i}\right) \cdot P\left(E v \mid N C, A_{i}\right) \cdot E\left(D T \mid e @ A_{i}\right)
\end{array}\right\}
\end{gathered}
$$

where the $E\left(D T_{\text {pre }} \mid M\right)$ and $E\left(D T_{\text {pre }} \mid A_{i}\right)$ are the downtime caused by the mainshock and the $i$ th aftershock respectively; $E(D T \mid C)$ is the expected downtime when the building is collapsed; $E v$ and $N E v$ denote evacuation and no evacuation respectively; $P(E v \mid N C, M)$ and $P\left(E v \mid N C, A_{i}\right)$ are the probability that evacuation occurs given the building has not collapsed after the mainshock or in an aftershock, respectively; $E(D T \mid e @ M)$ and $E\left(D T \mid e @ A_{i}\right)$ are the expected time between the time that evacuation occurs after the mainshock or the $i$ th aftershock and the time that the safety evaluation is performed. It should be noted that the evacuation will have influence on the actual downtime that causes indirect loss, but it does not have impact on the time when the repair work will be finished. The time when the repair work will be finished is useful to determine the number of aftershocks that may occur before the repair of the building is completed.

After the safety evaluation, the inspectors will decide whether the building is repairable or not. Also, the repair cost will be estimated to determine whether it has exceeded the threshold value and consequently a decision made as to whether to repair or rebuild. These tasks are performed simultaneously with other preparation work, so they are assumed to induce no additional downtime. Unlike the safety evaluations after the mainshock, such evaluations after aftershocks are performed only for buildings with 
additional damage reported as a result of the aftershock (ATC 2005). It is likely that the human resource shortage for building inspection which may follow the mainshock will not present following the aftershock (ATC 2005). Therefore, it is also assumed that after each aftershock that results in a larger structural response, such as floor acceleration, peak inter story drift ratio, or residual inter story drift ratio, a safety evaluation will be performed immediately. The preparation time and the repair time are updated after each aftershock that induces a larger structural response. The expected downtime after the first evaluation, $E\left(D T_{\text {post }}\right)$, can be calculated using Eq. 3.8 3.11. The total expected downtime is the sum of expected downtime before and after the first evaluation, as expressed in Eq. 3.12.

$$
\begin{gathered}
E\left(D T_{\text {post }}\right)=P(N C \mid M) \cdot \prod_{i=1}^{n}\left[P\left(N C \mid A_{i}\right)\right] \cdot E\left(D T_{\text {post }} \mid N C, A_{n}\right) \\
E\left(D T_{\text {post }} \mid N C, A_{n}\right)=\left[\begin{array}{l}
P\left(N R \mid N C, A_{n}\right) \cdot E(D T \mid N R) \\
+P\left(R \mid N C, A_{n}\right) \cdot E\left(D T \mid R, N C, A_{n}\right)
\end{array}\right]
\end{gathered}
$$

when $i=n, n+1, \ldots, n+m+1$ :

$$
E\left(D T \mid R, N C, A_{i}\right)=\left[\begin{array}{l}
P\left(C \mid A_{i}\right) \cdot E(D T \mid C) \\
+P\left(N C \mid A_{i}\right) \cdot P\left(N R \mid N C, A_{i}\right) \cdot E(D T \mid N R) \\
+P\left(N C \mid A_{i}\right) \cdot P\left(R \mid N C, A_{i}\right) \cdot E\left(D T \mid R, N C, A_{i+1}\right)
\end{array}\right]
$$

when $i=n+m$ :

$$
\begin{aligned}
E\left(D T \mid R, N C, A_{i}\right)=\left\{\begin{array}{l}
P\left(C \mid A_{i}\right) \cdot E(D T \mid C) \\
+P\left(N C \mid A_{i}\right) \cdot P\left(N R \mid N C, A_{i}\right) \cdot E(D T \mid N R) \\
+P\left(N C \mid A_{i}\right) \cdot P\left(R \mid N C, A_{i}\right) \\
{\left[\begin{array}{l}
P\left(T_{g} \mid R, N C, A_{i}\right) \cdot E\left(D T \mid T_{g}\right) \\
+P\left(T_{y} \mid R, N C, A_{i}\right) \cdot E\left(D T \mid T_{y}\right) \\
+P\left(T_{r} \mid R, N C, A_{i}\right) \cdot E\left(D T \mid T_{r}\right) \\
+E\left(D T_{R} \mid R, N C, A_{i}\right)
\end{array}\right]} \\
E(D T)=E\left(D T_{\text {post }}\right)+E\left(D T_{\text {pre }}\right)
\end{array}\right\}
\end{aligned}
$$


where $E\left(D T_{\text {post }} \mid N C, A_{n}\right)$ is the mean downtime after the first evaluation conditioned on not collapse after the $n$th aftershock; $E(D T)$ is the total expected downtime; $E(D T \mid N R)$ is the mean replace time of the building if it is not repairable; $E\left(D T \mid R, N C, A_{i}\right)$ is the expected total downtime if the building has not collapsed and is repairable after the $i$ th aftershock; $P\left(T_{g} \mid R, N C, A_{i}\right), P\left(T_{y} \mid R, N C, A_{i}\right), \quad$ and $P\left(T_{r} \mid R, N C, A_{i}\right)$ are the probability that the building is tagged green, yellow, and red, respectively, after the evaluation following the $i$ th aftershock, given non-collapse and that it is repairable; $E\left(D T \mid T_{g}\right), E\left(D T \mid T_{y}\right)$, and $E\left(D T \mid T_{r}\right)$ are the expected preparation time before repair given green, yellow, and red tag, respectively; $E\left(D T_{R} \mid R, N C, A_{i}\right)$ is the repair time for the building, conditioned on the damage after the $i$ th aftershock if it is non-collapse and repairable. The three color tags are collectively exhaustive and mutually exclusive events. The repair time of the building can be calculated using assembly based or component based method which has been explained thoroughly by many studies (e.g. Porter and Kiremidjian 2001, Mitrani-Reiser 2007, Porter, et al., 2011, and FEMA 2012a), so it will not be reiterated here. It should be stressed that after each aftershock, the repair cost, $E\left(L \mid R, N C, A_{i}\right)$, is estimated and compared with the threshold value. If the repair cost exceed the threshold after the $i$ th aftershock, the building is assumed to be replaced, and $E\left(D T \mid R, N C, A_{i}\right)$ is equal to $E(D T \mid N R)$ plus the time between the mainshock and the $i$ th aftershock. However, the aftershocks that follow are not considered in downtime estimation when replacement occurs, unless there are some more after the building has been replaced.

\subsubsection{Fatalities}

Reducing the number of fatalities resulting from an earthquake is perhaps the most important factor that should be considered in design. Conventional fatality estimation only considers the fatalities caused from the mainshock, which may again result in an inaccurate number since it is possible occupants will stay in the building after a mainshock, causing potential fatalities in aftershocks that followed. It is assumed herein that from the time of safety evaluation to the time that the building has been repaired or replaced, there are no occupants in the building (some engineers and works others may be inside the building during the construction, but this is neglected in this analysis). Therefore, the only time period that may have fatalities in the present analysis is the time between the mainshock and the safety evaluation. Once the building has been repaired or 
replaced, people will re-enter the building, and if more aftershocks occur, then additional fatalities are possible statistically.

In order to estimate the fatalities, the population distribution in the building must be determined first. Different building types such as residential buildings, commercial buildings, and industrial buildings have different population makeup and population densities (Mitrani-Reiser 2007; FEMA 2012a). This can also vary significantly by time of day. Different population-time models have been developed (Coburm, et al. 1992; FEMA 2012a), such as the model adopted by FEMA P-58 for office buildings (FEMA 2012a), which is depicted in Figure 3.3.

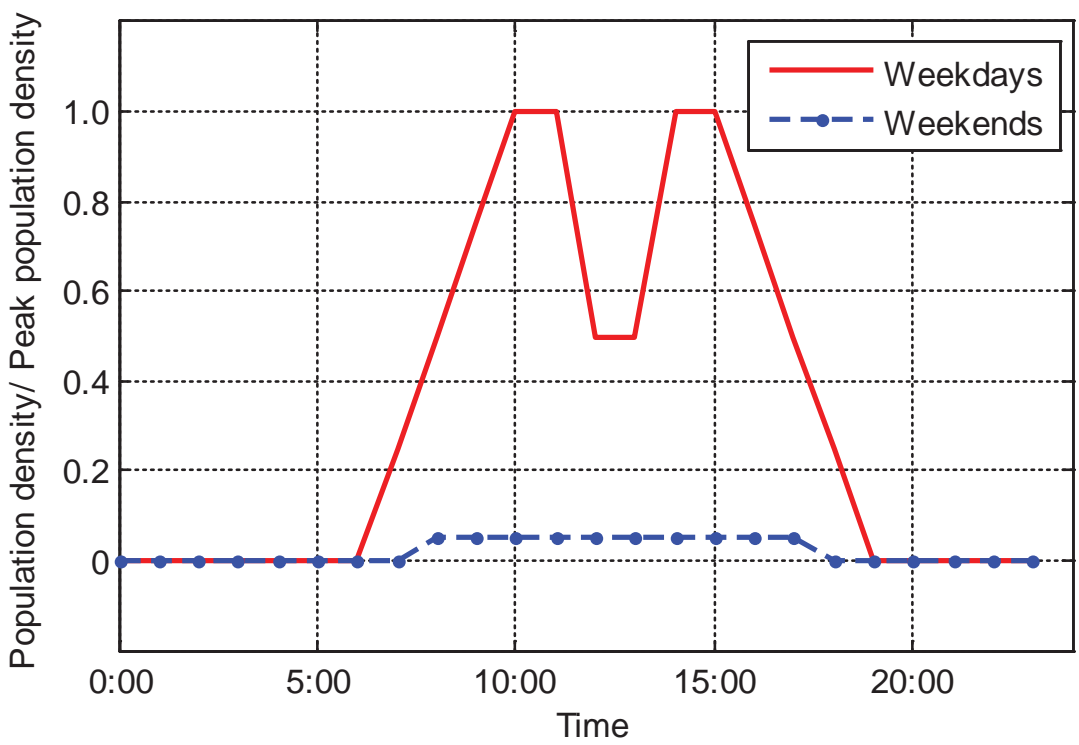

Figure 3.3 The population (relative to its peak value) model for office buildings used in FEMA P-58 (FEMA 2012a)

As introduced previously, after a shock, if people are not evacuated from the building, the subsequent shocks would have the potential to cause additional fatalities. Therefore the potential for fatalities is related to the evacuation decision, which is also indicated by the equations to calculate the fatalities expressed mathematically as follows.

$$
\begin{gathered}
E(F a)=E(F a \mid M)+\sum_{i=1}^{n} E\left(F a \mid A_{i}\right) \\
E(F a \mid M)=P(C \mid M) \cdot E(F a \mid C)+P(N C \mid M) \cdot E(F a \mid N C, M)
\end{gathered}
$$




$$
E\left(F a \mid A_{i}\right)=\left\{\begin{array}{l}
P(N C \mid M) \\
\cdot \prod_{j=1}^{i-1}\left[P\left(N C \mid A_{j}\right) \cdot P\left(N E v \mid N C, A_{j}\right)\right] \\
\cdot\left[P\left(C \mid A_{i}\right) \cdot E(F a \mid C)+P\left(N C \mid A_{i}\right) \cdot E\left(F a \mid N C, A_{i}\right)\right]
\end{array}\right\}
$$

where the $E(F a), E(F a \mid M)$, and $E\left(F a \mid A_{i}\right)$ are the mean total fatalities, mean fatalities caused by the mainshock, and mean fatalities caused by the ith aftershock respectively; $E(F a \mid C)$ is the expected fatalities if the building has collapsed; $E(F a \mid N C, M)$ and $E\left(F a \mid N C, A_{i}\right)$ are the mean fatalities when the building has not collapsed after the mainshock and the $i$ th aftershock, respectively.

\subsection{Case study: seismic performance of RC frame buildings subjected to MS-AS ground motions}

Seismic performance assessment is performed on two RC frame buildings under recorded MS-AS sequences using the method proposed in the previous section. Direct loss, downtime, and fatalities are examined, and then the total economic loss is also discussed. 9 sets of near-fault MS-AS sequences and 30 sets of far-field MS-AS sequence are selected to offer $78 \mathrm{MS}$-AS scenarios (each set includes two orthogonal horizontal components). This case study also illustrates how to apply Eq. 3.1 3.15 in practice. Though this example adopts some specific methods to calculate the variables in Eq. 3.1 3.13 such as mean repair cost and mean repair time, other methods can also be used.

\subsubsection{Structural models}

A three-bay three-story and a three-bay six-story non-ductile RC frame office buildings that are introduced in Chapter 2 are utilized for this case study, representing typical lowrise and mid-rise RC frame buildings in the United States. The elevations and the plan of the two buildings are presented in Figure 3.4. Other details such as member sections and layout of reinforcements can also be found in other articles (Kwon and Elnashai 2006; Celik and Ellingwood 2009; Celik and Ellingwood 2010). A two-dimensional frame is extracted from each building to perform the analysis. The prototype buildings are threebay-by-four-bay in plan, but they are modified to be a three-bay-by-three-bay in plan (as shown in Figure 3.4) in this study so that analyzing one two-dimensional model can provide the performance of each orthogonal direction for each building. 
Planar finite element models are built for the two two-dimensional frame using OpenSees (Mazzoni, et al. 2006) to incorporate the nonlinearity in both the geometry and material. The nodes are placed at specific locations (as illustrated in Figure 3.4) so that both the reinforcement layout and the structural deformed shape could be simulated. More information about the buildings and the finite-element models are available in Chapter 2.

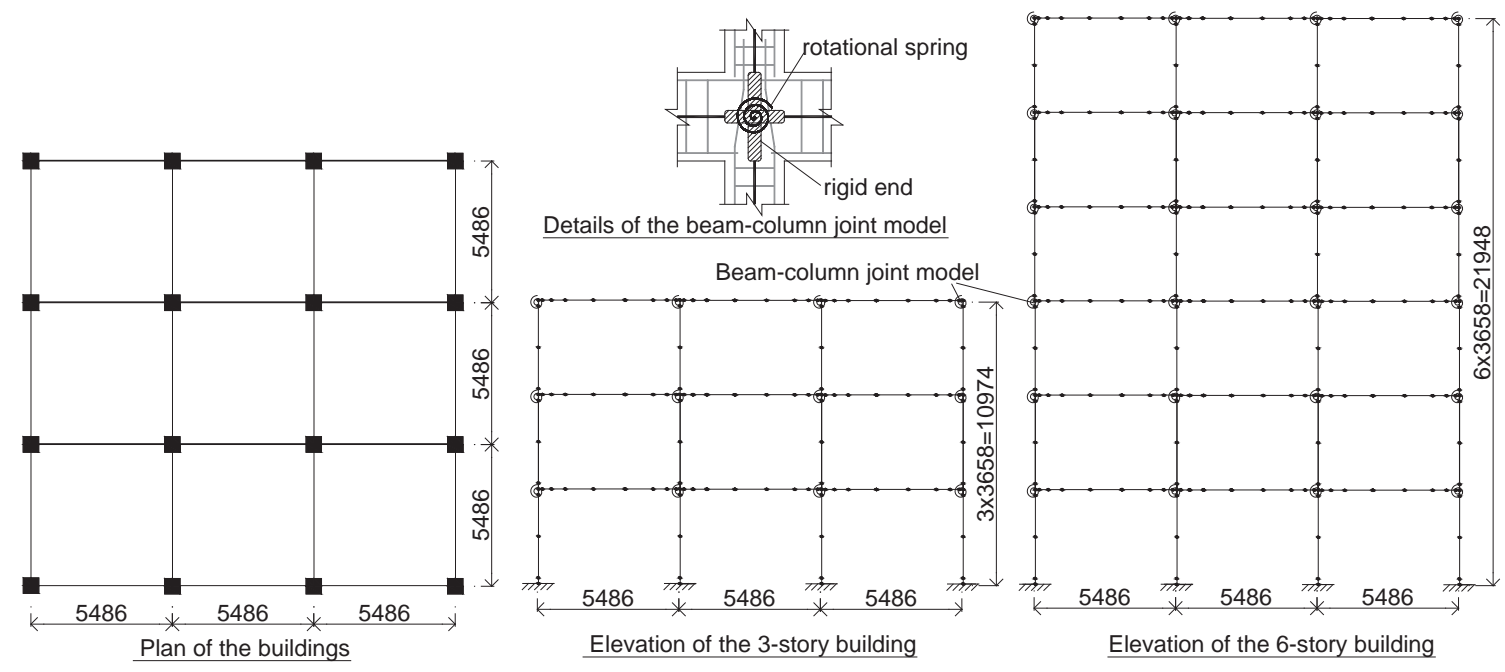

Figure 3.4 The schematic plots of the two buildings and models

\subsubsection{Building performance models}

As defined in FEMA P-58 (FEMA 2012a), a building performance model is "an organized collection of all data necessary to define the building assets at risk". In addition to the structural information that is presented in last section, fragility groups, performance groups and population models are all part of the building performance model. These data provide essential information to compute the seismic performance. Although the results are more accurate if more detailed information is used, many simplifications are employed in the models herein because the main purpose of this case study is to illustrate the previously proposed methods.

A fragility group includes all the components in a building with similar construction characteristics, potential damage mode, probability of initializing the damage mode, and the potential consequences of damage. Different damage modes of the components are usually termed as different damage states (DS). For example, the RC columns of a same fragility group may have 4 DSs, which are DS1 light cracking, DS2 severe cracking, DS3 
shear failure, and DS4 loss of vertical carrying capacity (Aslani and Miranda 2005a). The seismic fragility describes the probability of exceeding certain DS given an engineering demand parameter (EDP) value, such as the peak inter story drift ratio (PIDR), peak floor acceleration (PFA), and peak ground acceleration (PGA). The potential consequences of damage include repair method, repair cost, and repair time when the component is at a specific DS. Therefore, all the components in a fragility group are of the same type, have the same DSs, fragility functions, and potential consequences.

The fragility groups for the two buildings are listed in Table 3.1. Components that have insignificant contributions to the direct loss, downtime, and fatalities are not considered. The slabs are considered as rugged components which means they are not vulnerable to damage. Therefore they do not contribute to the repair cost and repair time unless the building is collapsed as a whole. The DSs, EDP associated with the DSs, fragility function parameters, repair methods and expected repair time per unit for each DS, and the references are also presented in Table 3.1. The fragility functions are selected based on the type of the components. Detail descriptions about the DSs are available in the references shown in the last column of Table 3.1. If component-based or assembly-based methods are applied when computing the direct loss, repair cost data associated with different DSs is also essential. However, the method to estimate the direct loss adopted here is the story-based method proposed by Ramirez and Miranda (2009) to convert the EDP of each story directly to the direct loss for that story. The repair time data are shown in Table 3.1. The story-based method will be introduced later.

The fragility groups shown in Table 3.1 are sub-categorized into performance groups based on where their EDP values are identical under earthquakes. For example, the columns at each story always have the same PIDR and thus they are in a same performance group. Generally, for each fragility group, the components within a same story are considered as in a same performance group, except that the elevators are only assumed to have one performance group because of their EDP is PGA. The number of components in each performance group is presented in Table 3.5, and the calculation of the quantities will be presented later. The fragility unit of measure associated with components in performance groups is selected as the same units shown in Table 3.1. The damage of the units in a performance group is assumed to be uncorrelated, because even if two components experienced the same EDP value, they may still have incurred different DSs. Components in different performance groups are also presumed to be uncorrelated. 
Table 3.1 The fragility groups and relevant information

\begin{tabular}{|c|c|c|c|c|c|c|c|c|}
\hline \multirow[t]{2}{*}{$\begin{array}{l}\text { Fragility } \\
\text { groups }\end{array}$} & \multirow[t]{2}{*}{ DS } & \multirow[t]{2}{*}{ EDP } & \multicolumn{2}{|c|}{$\begin{array}{l}\text { Fragility function } \\
\text { parameters }\end{array}$} & \multirow[t]{2}{*}{$\begin{array}{l}\text { Repair } \\
\text { method }\end{array}$} & \multirow{2}{*}{$\begin{array}{l}\text { Mean } \\
\text { repair } \\
\text { hours }\end{array}$} & \multirow[t]{2}{*}{ Unit } & \multirow[t]{2}{*}{ Reference } \\
\hline & & & Median & Dispersion & & & & \\
\hline \multirow[t]{4}{*}{ Columns } & Light & PIDR & $0.35 \%$ & 0.33 & Epoxy & 36.0 & Each & Aslani and \\
\hline & Moderate & & $1.00 \%$ & 0.44 & Jacket & 150.0 & Each & Miranda 2005a; \\
\hline & Severe & & $2.60 \%$ & 0.55 & Replace & 220.0 & Each & Mitrani-Reiser \\
\hline & Collapse & & $6.80 \%$ & 0.38 & Replace & 220.0 & Each & 2007 \\
\hline \multirow[t]{4}{*}{ Beams } & Light & PIDR & $1.20 \%$ & 0.45 & Epoxy & 44.0 & Each & Pagni and \\
\hline & Moderate & & $2.20 \%$ & 0.33 & Jacket & 190.0 & Each & Lowes 2006; \\
\hline & Severe & & $3.00 \%$ & 0.30 & Replace & 240.0 & Each & Mitrani-Reiser \\
\hline & Collapse & & $3.60 \%$ & 0.26 & Replace & 240.0 & Each & 2007 \\
\hline Drywall & Visible & PIDR & $0.39 \%$ & 0.17 & Patch & 1.0 & $64 \mathrm{ft}^{2}$ & Porter, et al. \\
\hline partitions & Significant & & $0.85 \%$ & 0.23 & Replace & 4.0 & $64 \mathrm{ft}^{2}$ & 2001; Mitrani- \\
\hline Drywall & Visible & PIDR & $0.39 \%$ & 0.17 & Patch & 1.0 & $64 \mathrm{ft}^{2}$ & Reiser 2007 \\
\hline finish & Significant & & $0.85 \%$ & 0.23 & Replace & 7.0 & $64 \mathrm{ft}^{2}$ & \\
\hline Exterior & Crack & PIDR & $4.00 \%$ & 0.36 & Replace & 11.5 & Pane & \\
\hline glazing & Fallout & & $4.60 \%$ & 0.33 & Replace & 11.5 & Pane & \\
\hline Ceilings & Collapse & PFA & $1.28 \mathrm{~g}$ & 0.55 & Replace & 0.20 & $250 \mathrm{ft}^{2}$ & $\begin{array}{l}\text { Mitrani-Reiser } \\
\text { 2007; Ramirez } \\
\text { and Miranda } \\
2009\end{array}$ \\
\hline Sprinklers & Fracture & PFA & $32.0 \mathrm{~g}$ & 1.4 & Replace & 15.0 & $12 \mathrm{ft}$ & $\begin{array}{l}\text { Porter, et al. } \\
\text { 2001; Mitrani- } \\
\text { Reiser } 2007\end{array}$ \\
\hline Elevators & Failure & PGA & $0.41 \mathrm{~g}$ & 0.28 & Repair & 60.0 & Each & $\begin{array}{l}\text { Mitrani-Reiser } \\
\text { 2007; Porter } \\
2007\end{array}$ \\
\hline
\end{tabular}

The population model provides essential information for the computation of possible fatalities. Since the occupancy of the buildings is commercial office, the population model developed by FEMA P-58 (FEMA 2012a) (shown in Figure 3.3) is applied. The peak population density is 0.043 persons $/ \mathrm{m}^{2}$ ( 4 persons $/ 1,000 \mathrm{ft}^{2}$ ). So for these two buildings, the peak population on a typical floor is 12 . Besides, the peak population at the $1^{\text {st }}$ floor is assumed to be $8,2 / 3$ of that of a typical floor, because the $1^{\text {st }}$ floor usually has some non-office areas (e.g. mail room and lobby area) (Mitrani-Reiser 2007). Additionally, it is commonly assumed that $50 \%$ of the people in $1^{\text {st }}$ floor can escape during the ground shaking (Coburm, et al. 1992; Mitrani-Reiser 2007; Yeo and Cornell 2003), and consequently the peak population at the $1^{\text {st }}$ story for fatality calculation is presume to be 4 .

\subsubsection{Mainshock-aftershock sequences and ground motions}

Only recorded ground motions are utilized here because there has not been consensus about how to simulate the aftershock ground motions, and using the recorded aftershocks 
is felt to be the best available option (Ruiz-Garcia and Negrete-Manriquez 2011). Most selected aftershocks occurred within days after a mainshock, but some MS-AS sequences also have aftershocks recorded after one or two months after the mainshock. Nine sets of near-fault sequences are separated from thirty sets of far-field sequences because they have different characteristics (Mavroeidis and Papageorgiou 2003). The categorization of near-fault and far-field ground motion adopts the criteria from FEMA P-695 (FEMA 2009b). To investigate the effect of multiple aftershocks, records from the stations with at least two aftershocks are selected. Although the number of aftershocks in each sequence is still significantly smaller than the actual number of the aftershocks that occurred in these earthquakes, it is the best approximation that can be achieved with the available records. In addition, it should be noted that the aftershock records in each sequence are the intense aftershocks, thereby enabling examination of all damage states for the buildings (Li and Ellingwood 2007; Lee and Foutch 2004). Compared to previous studies which used only one aftershock (such as Han, et al. 2014a,b; Lee and Foutch 2004; Li and Ellingwood 2007; Yin and Li 2011), more accurate results can be expected by using multiple aftershocks. There are 78 mainshocks and 360 aftershocks in total. Their records are obtained from the Pacific Earthquake Engineering Research Center Next Generation Attenuation database (PEER NGA) (PEER 2014) and the National Research Institute for Earth Science and Disaster Prevention (NIED) strong-motion seismograph Kyoshin networks of Japan (K-NET) (K-NET 2014). All the stations that record the ground motions have their specific site condition information available. The records are from the 1980 Mammoth Lakes earthquake, the 1983 Coalinga earthquake, the 1986 Chalfant Valley earthquake, the 1994 Northridge earthquake, the 1999 Chi-Chi earthquake, and the 2011 Tohoku earthquake. The lists of the near-fault and far-field earthquakes are shown in Table 3.2 and 3.3, respectively.

Table 3.2 List of near-fault MS-AS sequences

\begin{tabular}{lcclll}
\hline Earthquake & Year & $\mathrm{M}_{\mathrm{w}}$ & Station & $\begin{array}{l}\text { No. of } \\
\text { aftershocks }\end{array}$ & Database \\
\hline $\begin{array}{l}\text { Chalfant Valley } \\
\text { Chi-Chi, Taiwan }\end{array}$ & 1986 & 6.19 & Zack Brothers Ranch & 2 & PEER NGA \\
& 1999 & 7.62 & TCU051 & 5 & PEER NGA \\
& & & TCU065 & 3 & PEER NGA \\
& & & TCU067 & 5 & PEER NGA \\
Coalinga & 1983 & 6.36 & TCU120 & 4 & PEER NGA \\
Mammoth Lakes & 1980 & 6.06 & Convict Creek & 2 & PEER NGA \\
Northridge & 1994 & 6.69 & Arleta - Nordhoff Fire Sta & 2 & PEER NGA \\
& & & Newhall - Fire Sta & 3 & PEER NGA \\
\hline
\end{tabular}


Table 3.3 List of far-field MS-AS sequences

\begin{tabular}{|c|c|c|c|c|c|}
\hline Earthquake & Year & $\mathrm{M}_{\mathrm{m}}$ & Station & $\begin{array}{l}\text { No. of } \\
\text { aftershocks }\end{array}$ & Database \\
\hline Chalfant Valley & 1986 & 6.19 & Bishop - LADWP South St & 2 & PEER NGA \\
\hline \multirow[t]{11}{*}{ Chi-Chi, Taiwan } & 1999 & 7.62 & CHY024 & 5 & PEER NGA \\
\hline & & & CHY025 & 5 & PEER NGA \\
\hline & & & CHY036 & 4 & PEER NGA \\
\hline & & & CHY082 & 5 & PEER NGA \\
\hline & & & CHY101 & 4 & PEER NGA \\
\hline & & & HWA011 & 5 & PEER NGA \\
\hline & & & HWA037 & 5 & PEER NGA \\
\hline & & & HWA041 & 5 & PEER NGA \\
\hline & & & HWA043 & 5 & PEER NGA \\
\hline & & & HWA045 & 5 & PEER NGA \\
\hline & & & KAU088 & 4 & PEER NGA \\
\hline Mammoth Lakes & 1980 & 6.06 & Long Valley Dam (Upr L Abut) & 5 & PEER NGA \\
\hline \multirow[t]{11}{*}{ Northridge } & 1994 & 6.69 & Anaverde Valley - City R & 4 & PEER NGA \\
\hline & & & Castaic - Old Ridge Route & 5 & PEER NGA \\
\hline & & & Elizabeth Lake & 5 & PEER NGA \\
\hline & & & Inglewood - Union Oil & 2 & PEER NGA \\
\hline & & & LA - 116th St School & 2 & PEER NGA \\
\hline & & & LA - Baldwin Hills & 2 & PEER NGA \\
\hline & & & LA - Century City CC North & 2 & PEER NGA \\
\hline & & & LA - Hollywood Stor FF & 2 & PEER NGA \\
\hline & & & Moorpark - Fire Sta & 2 & PEER NGA \\
\hline & & & Palmdale - Hwy 14 \& Palmdale & 2 & PEER NGA \\
\hline & & & Santa Monica City Hall & 2 & PEER NGA \\
\hline \multirow[t]{6}{*}{ Tohoku, Japan } & 2011 & 9.00 & FKS017 & 9 & K-NET \\
\hline & & & FKSH20 & 8 & K-NET \\
\hline & & & IBR013 & 10 & K-NET \\
\hline & & & MYG007 & 13 & K-NET \\
\hline & & & MYG013 & 13 & K-NET \\
\hline & & & TCGH16 & 7 & K-NET \\
\hline
\end{tabular}

The ground motions are selected in such a way that small, moderate, and large earthquakes are all represented. For each building under each ground motion suite, the $S_{a}\left(\mathrm{~T}_{1}\right)$, spectral acceleration at fundamental period, of the mainshocks, the maximum $S_{a}\left(\mathrm{~T}_{1}\right)$ of all the corresponding aftershocks, and the number of aftershocks are presented in Figure 3.5. The figure shows that the selected MS-AS sequences cover a wide range of scenarios. The $S_{a}\left(\mathrm{~T}_{1}=1.14 \mathrm{~s}\right)$ ranges from $0.17 \mathrm{~g}$ to $1.38 \mathrm{~g}$ and from $0.04 \mathrm{~g}$ to $1.03 \mathrm{~g}$ for the near-fault and far-field mainshocks, respectively, whereas the $S_{a}\left(\mathrm{~T}_{1}=1.92 \mathrm{~s}\right)$ ranges from $0.08 \mathrm{~g}$ to $0.80 \mathrm{~g}$ and from $0.03 \mathrm{~g}$ to $1.02 \mathrm{~g}$ for the near-fault and far-field mainshocks, respectively. The $S_{a}\left(\mathrm{~T}_{1}\right)$ of the aftershocks are generally much smaller than that of the corresponding mainshock, even for the maximum $S_{a}\left(\mathrm{~T}_{1}\right)$ of all the aftershocks. The time histories of the mainshocks and corresponding aftershocks are combined in chronological order to form back-to-back MS-AS sequences. The occurring time of each aftershock is documented in the records. Figure 3.6 shows an example of the time history of a MS-AS sequence. 
a. Near-fault ground motions, $\mathrm{Sa}(\mathrm{T}=1.14 \mathrm{~s})$

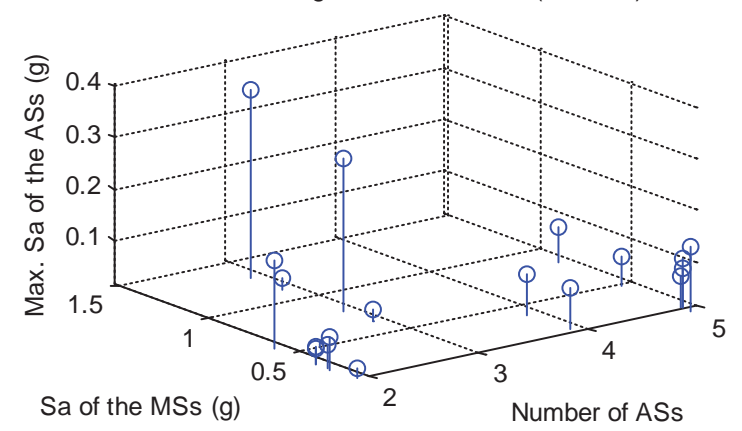

c. Far-field ground motions, $\mathrm{Sa}(\mathrm{T}=1.14 \mathrm{~s})$

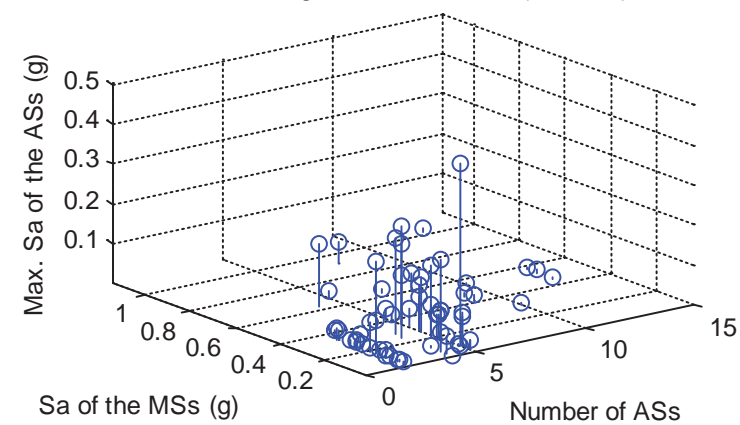

b. Near-fault ground motions, $\mathrm{Sa}(\mathrm{T}=1.92 \mathrm{~s})$

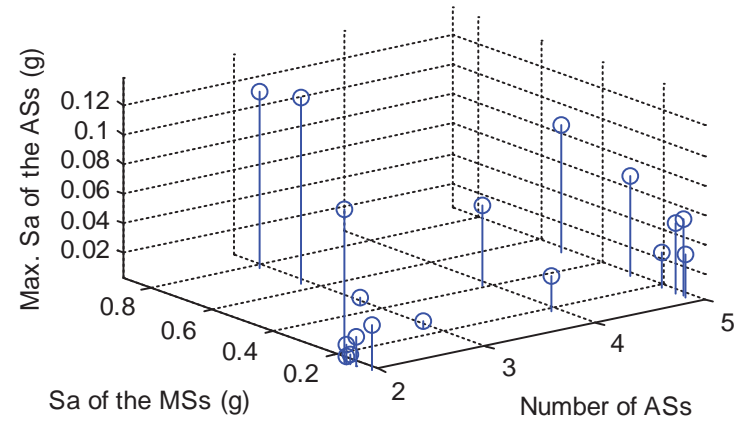

d. Far-field ground motions, $\mathrm{Sa}(\mathrm{T}=1.92 \mathrm{~s})$

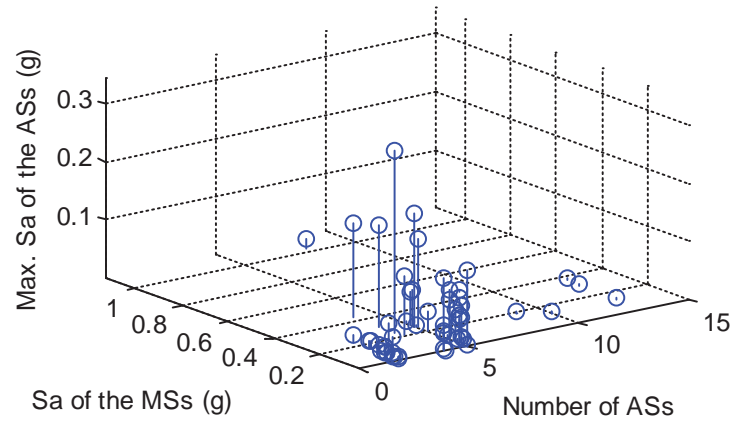

Figure 3.5 The $S_{a}\left(\mathrm{~T}_{1}\right)$ of the mainshocks, the aftershocks, and the number of aftershocks

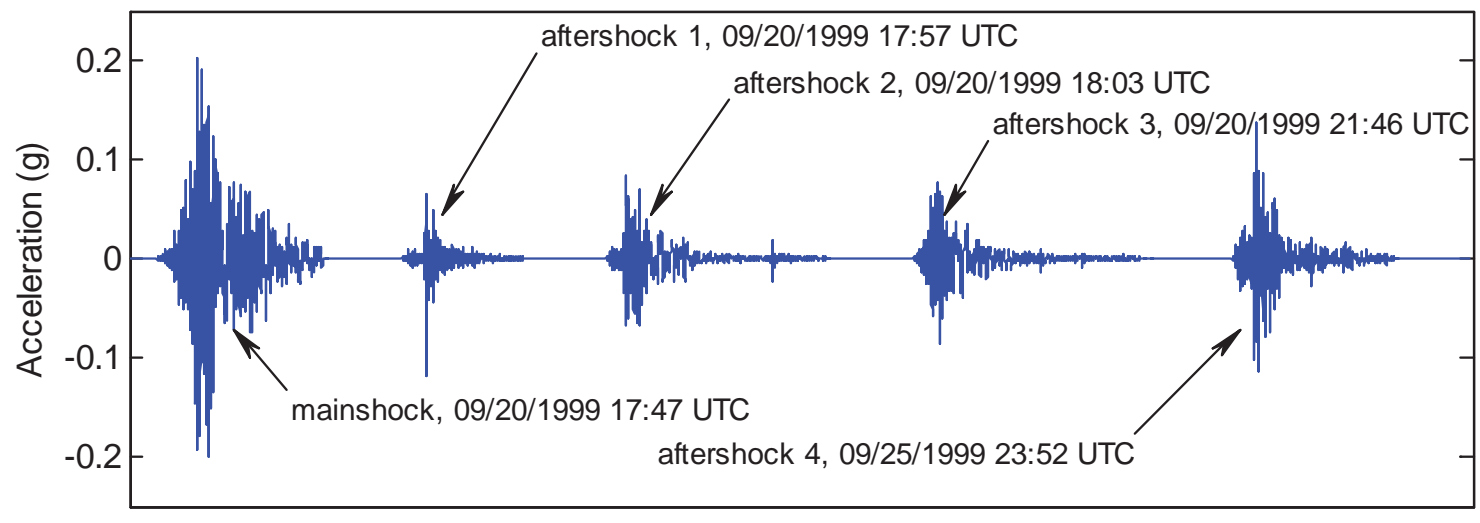

Time

Figure 3.6 A MS-AS sequence of Chi-Chi earthquake from station CHY036

\subsubsection{Seismic performance evaluation and loss estimation}

Nonlinear time history analysis (NTHA) is executed with the finite element models and the MS-AS sequences. The EDP values are recorded for every mainshock and aftershock. 
The residual inter story drift ratio (RIDR) after each shock is also recorded when the building came to rest, because the RIDR is related to the reparability of the building (FEMA 2012a). The NTHA fails to converge in some scenarios in which the ground motions are intense, indicating building collapse. For these cases, the collapse probability is 1 and replacement is assumed in the performance assessment model. Before the assessment starts, the collapse fragility and the repair fragility must first be defined. They are the probability that the building collapses or cannot be repaired given an EDP value. Both the two fragilities are usually expressed by a lognormal cumulative distribution function defined with the median and dispersion (Ramirez and Miranda 2009; FEMA 2012a). The median peak inter story drift ratio (PIDR) and dispersion of the collapse fragility for the two buildings are obtained using incremental dynamic analysis (IDA) (Vamvtsikos and Cornell 2002) under a group of ground motions (details can be found in Chapter 2). The median PIDR of the collapse fragility are 5.0\% and $4.2 \%$ respectively for the three-story and six-story building, whereas the dispersions for the two buildings are both 0.36 . The median RIDR for the reparability and the dispersion are $1.0 \%$ and 0.3 respectively (FEMA 2012a).

The story-based direct loss estimation method proposed by Ramirez and Miranda (2009) is adopted to compute the direct loss after each shock. This method directly converts the EDP values at each story to the direct loss in form of the percentage of the total story value. The detailed design of the architectural layouts for the buildings is unnecessary if the story-based method is used, and the computational effort is significantly reduced from that of conventional component-based methods. The EDP-direct loss function is developed based on their investigation on RC frame buildings with various occupancy, height, and seismic design, which ensured that this rapid method can be applied to this study. The total value of buildings and the value of each story should be computed as a prerequisite. Based on the available data for low-rise and mid-rise RC frame office buildings (Ramirez and Miranda 2009; RS Means 2014), the unit costs for the three-story and six-story buildings are assumed to be $\$ 1,853.7 / \mathrm{m}^{2}\left(\$ 172.2 / \mathrm{ft}^{2}\right)$ and $\$ 2,147.7 / \mathrm{m}^{2}$ $\left(\$ 199.5 / \mathrm{ft}^{2}\right)$. The story values vary because the $1^{\text {st }}$ story, middle stories, and the top story usually have different nonstructural components configuration. For example, the $1^{\text {st }}$ story usually uses more expensive decoration material for the entrance and the lobby; the middle stories generally have more office and have more contents; whereas the HVAC system are mainly located at the top story. With the data from the references (Ramirez and Miranda 2009; RS Means 2014), the total building costs and the story values are estimated and are presented in Table 3.4. The replacement costs of the scenario that the 
building collapse and the scenario that the building need to be demolished and replaced are both assumed to equal to the total value listed in Table 3.4.

Table 3.4 The story and total values of the two buildings

\begin{tabular}{lllll}
\hline Building & $1^{\text {st }}$ story value & Middle story value & Top story value & Total value \\
\hline Three-story & $\$ 512,000$ & $\$ 503,000$ & $\$ 491,000$ & $\$ 1,506,000$ \\
Six-story & $\$ 576,000$ & $\$ 590,000$ & $\$ 555,000$ & $\$ 3,491,000$ \\
\hline
\end{tabular}

The direct loss after each shock is calculated with this information. However, as discussed previously, the direct loss of a MS-AS sequence is interactive with the downtime because the number of aftershocks depends on the downtime and conversely the high repair cost after a shock will lead to the decision for replacement and change the downtime. The total replacement time when the building collapses or needs to be demolished and rebuilt is assumed to be 33 months for the three-story building and 47 months for the six-story building (Mitrani-Reiser 2007). The rapid evaluations is assumed to have performed 3 days after the mainshock for the near-fault ground motions and 10 days after the mainshock for the far-field ground motions, because the buildings located near the epicenter have higher priority for rapid evaluation (ATC 2005). The repair of green tagged building is presumed to be started right after the rapid evaluation, whereas the preparation time for yellow and red tagged building is designated to be 30 days and 180 days respectively, follow the recommendation of Mitrani-Reiser (2007).

Based on the requirements for the rapid evaluation from ATC-20 (ATC 2005) and FEMA P-58 (FEMA 2012a), different tags are placed according to the exterior structural components, overall residual drift, and fire protection system. Therefore, a non-collapsed building is considered to have a green tag when all the three conditions were met: 1 ). the damage of exterior beams and columns are all no worse than light damage; 2).no significant RIDR for the stories (equivalent to the building is repairable using the repair fragility); and 3).the sprinklers do not fracture. A non-collapsed building is considered to have red tag if at least one of the three scenarios occurred: 1). the damage of any exterior beams and columns reached or exceeds the severe damage state; 2). significant RIDR is found on any story (equivalent to the building is not repairable using the repair fragility); and 3). any of the sprinklers unit incurres fracture. If the building is neither tagged red nor green, it will be tagged yellow. The probability of different tags can be calculated accordingly. 
In addition to structural damage, the decision to evacuate can also be triggered by the obvious damage to nonstructural components. The decision to evacuate is assumed when any of the six conditions occurred after a shock: 1). the damage of any beams or columns reaches or exceeds the moderate damage state; 2). significant RIDR is found on any story (equivalent to the building is not repairable using the repair fragility); 3). the crack of drywall partitions reaches the significant damage state; 4). any of the sprinklers units incurs fracture; 5). any ceiling unit collapses; and 6). any exterior glazing unit reaches the crack damage state.

The quantities of different component units in the performance groups are necessary for calculating the probabilities of different tags and probabilities of evacuation. They are also essential for computing the repair time. So, the quantities of component units are estimated. The nonstructural component units are estimated based on their typical unit value, their percentages of the total story value, and the total story values (Ramirez and Miranda 2009; RS Means 2014). The quantities of various components for the two buildings are shown in Table 3.5. The mean repair time of different component units is calculated using the total probability theorem with the probability of various damage states and the corresponding mean repair hours shown in Table 3.1. It is assumed that the working time of each day is 15 hours ( 8 hours for daytime crew and 7 hours for nighttime crew), and the building stories is assumed to be repaired in parallel (as shown in Figure 3.2). The change-of-trade time is taken as 2 days (Mitrani-Reiser 2007). Then, both the direct loss and downtime can be computed. It should be stressed that the repair time for elevators is only considered in the $1^{\text {st }}$ story since the repair work for elevators mostly takes place in the $1^{\text {st }}$ story (Mitrani-Reiser 2007).

Table 3.5 The quantities of different component units for the two buildings

\begin{tabular}{|c|c|c|c|c|c|c|}
\hline \multirow[t]{2}{*}{ Component } & \multicolumn{3}{|c|}{$\begin{array}{l}\text { Quantities of components, the three-story } \\
\text { building }\end{array}$} & \multicolumn{3}{|c|}{$\begin{array}{l}\text { Quantities of components, the six-story } \\
\text { building }\end{array}$} \\
\hline & $1^{\text {st }}$ story & $2^{\text {nd }}$ story & $3^{\text {rd }}$ story & $1^{\text {st }}$ story & $2^{\text {nd }} \sim 5^{\text {th }}$ story & Top story \\
\hline Columns & 16 & 16 & 16 & 16 & 16 & 16 \\
\hline Beams & 24 & 24 & 24 & 24 & 24 & 24 \\
\hline Drywall partition & 81 & 79 & 61 & 83 & 85 & 67 \\
\hline Exterior glazing & 70 & 60 & 60 & 77 & 68 & 67 \\
\hline Ceilings & 11 & 11 & 11 & 11 & 11 & 11 \\
\hline Sprinklers & 27 & 27 & 27 & 27 & 27 & 27 \\
\hline Elevators & 1 & - & - & 2 & - & - \\
\hline
\end{tabular}

Since the fatalities in earthquakes are typically caused by building collapse or partial collapse (Coburm, et al. 1992; FEMA 2012a), only the collapse or partial collapse of a building is considered to be able to induce fatalities in this study. Partial collapse is 
assumed to occur when any beam or column reaches the collapse damage state shown in Table 3.1. Fatalities caused by the nonstructural components are neglected because previous research showed that fatal injuries are seldom caused by nonstructural components (Durkin and Thiel 1992). The total population when the earthquake occurs must be estimated. The peak population of each story has been introduced previously, with which the mean population at any time of any day is calculated. The mean population was calculated using the Eq. 3.16.

$$
N=N_{P} \cdot\left(\frac{251}{365} \cdot \int_{0}^{24} \frac{P_{p, w d}(t)}{24} \cdot \mathrm{d} t+\frac{114}{365} \cdot \int_{0}^{24} \frac{P_{p, w e}(t)}{24} \cdot \mathrm{d} t\right)
$$

where $N$ is the mean population at any time of any day; $N_{p}$ is the peak occupancy (refer as peak population in FEMA P-58) (FEMA 2012a); $P_{p, w d}(t)$ and $P_{p, w e}(t)$ are the population models respectively for weekdays and weekends as shown in Figure 3.3. The number of weekdays is assumed to be 251 for a typical year with 365 days, considering all the weekends and 10 U.S. national holidays (Mitrani-Reiser 2007). The probability of fatalities occurring conditioned on structural damage states is usually modeled as a binomial distribution (Krawinkler 2005; Mitrani-Reiser 2007; Rojahn and Sharpe 1985), and therefore the calculated $N$ should be rounded to an integer number. The fatality rates for the binomial distribution are assumed to be 0.131 and 0.015 for complete collapse and partial collapse, respectively, according to a previous fatality model for non-ductile RC frames (Krawinkler 2005). The mean fatality caused by each shock can then be computed.

\subsubsection{Results and discussions}

The mean direct loss, downtime, and fatalities are calculated for both the MS-AS sequences and the mainshocks. The mean, median, and coefficient of variation (COV) of the three metrics under the MS-AS sequences are presented in Table 3.6. It can be seen that the three-story building generally has less direct loss, downtime, and fatalities than the six-story building. The near-fault ground motions generally cause more direct loss, downtime, and fatalities than the far-field ground motions because the near-fault ground motions are typically more intense. The performance metrics obtained using each sequence are normalized by the results calculated using the corresponding mainshocks to determine how much difference it will be if aftershocks are also considered. The results are shown in Figure 3.7 3.9. 
Table 3.6 The statistical results of the seismic performance metrics

\begin{tabular}{|c|c|c|c|c|c|c|c|c|c|c|c|c|}
\hline \multirow[t]{3}{*}{ Parameters } & \multicolumn{6}{|c|}{ The three-story building } & \multicolumn{6}{|c|}{ The six-story building } \\
\hline & \multicolumn{2}{|c|}{ Direct loss $(\$)$} & \multicolumn{2}{|c|}{$\begin{array}{l}\text { Downtime } \\
\text { (days) }\end{array}$} & \multicolumn{2}{|c|}{ Fatalities } & \multicolumn{2}{|c|}{ Direct loss (\$) } & \multicolumn{2}{|c|}{$\begin{array}{l}\text { Downtime } \\
\text { (days) }\end{array}$} & \multicolumn{2}{|c|}{ Fatalities } \\
\hline & $\mathrm{FF}^{1}$ & $\mathrm{NF}^{2}$ & FF & NF & $\mathrm{FF}$ & NF & FF & $\mathrm{NF}$ & $\mathrm{FF}$ & NF & FF & $\mathrm{NF}$ \\
\hline Mean & 422000 & 792000 & 408 & 653 & 0.10 & 0.26 & 761000 & 1570000 & 421 & 774 & 0.21 & 0.69 \\
\hline Median & 249000 & 455000 & 379 & 547 & 0.09 & 0.11 & 311000 & 752000 & 297 & 529 & 0.12 & 0.24 \\
\hline $\mathrm{COV}$ & 1.16 & 0.75 & 0.76 & 0.45 & 1.53 & 1.21 & 1.32 & 0.86 & 0.94 & 0.59 & 1.52 & 1.09 \\
\hline
\end{tabular}

Note: ${ }^{1}$. FF=Far-field MS-AS sequences; ${ }^{2}$. NF=Near-fault MS-AS sequences.
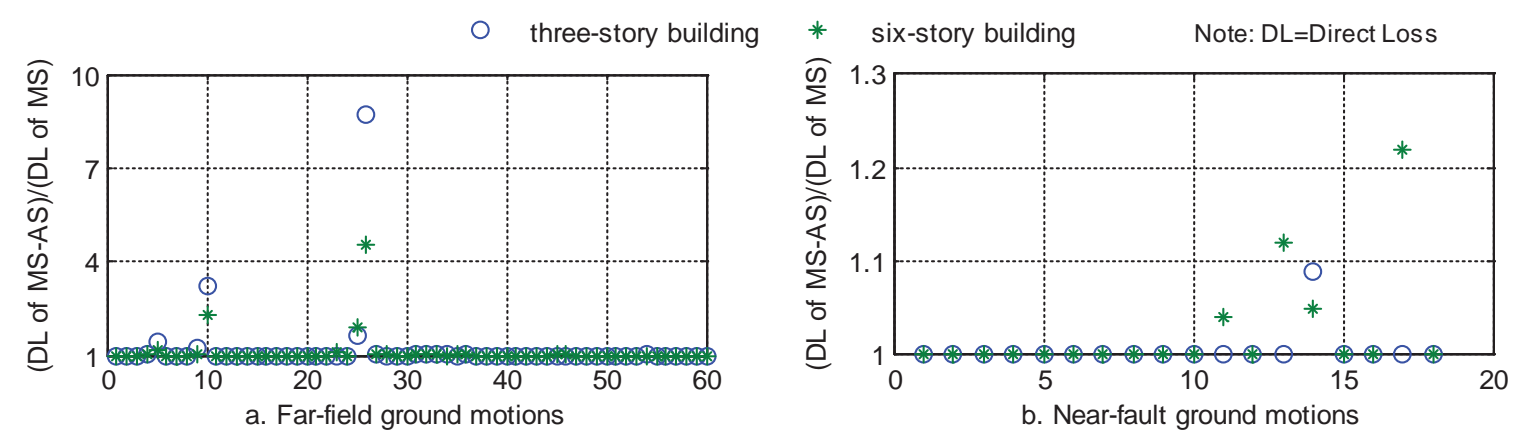

Figure 3.7 The normalized direct loss (DL) of the two buildings
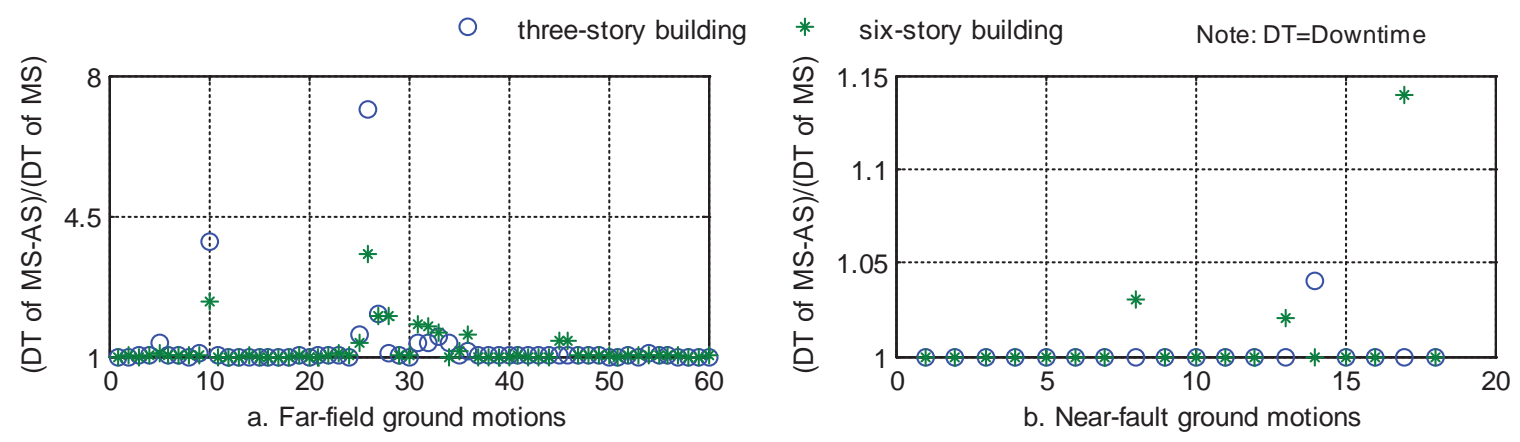

Figure 3.8 The normalized downtime (DT) of the two buildings
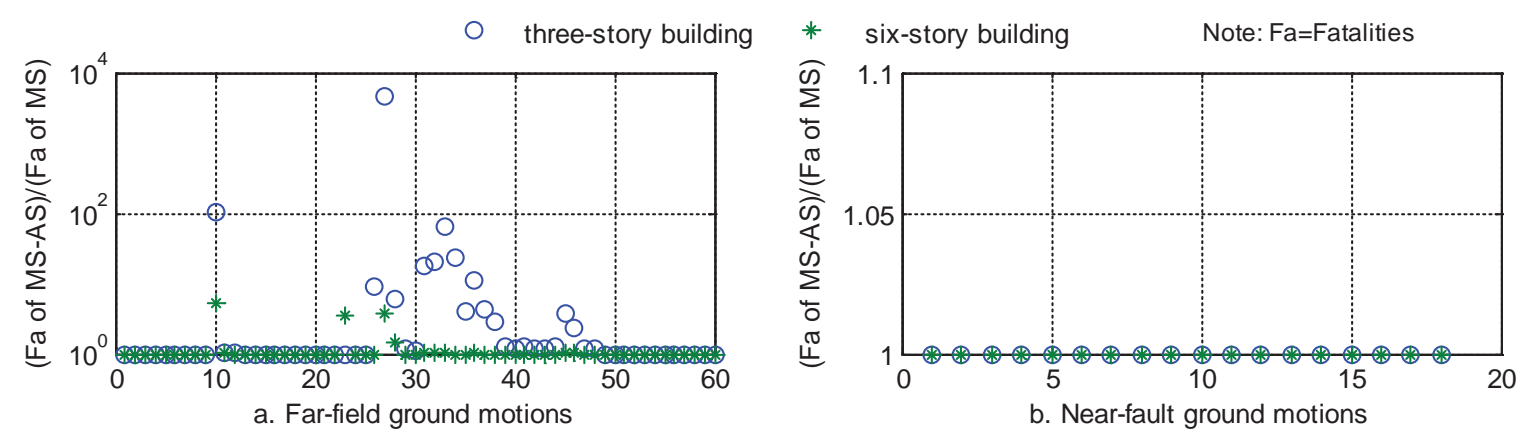

Figure 3.9 The normalized fatalities $(\mathrm{Fa})$ of the two buildings 
It can be seen that for the direct loss, most MS-AS scenarios cause similar results as the mainshocks do. The far-field ground motions show greater uncertainty as the normalized value was equal to 8.74 for the three-story building and 4.57 for the six-story building. For the downtime, slightly more far-field MS-AS scenarios cause larger results than the mainshocks did, but for most scenarios the sequence and the mainshock still have similar results. However, the difference between the near-fault MS-AS and mainshock are still limited. The smaller differences in the results of the near-fault ground motions is probably because the near-fault mainshocks are so intense and that the intensities of aftershocks are not high enough to cause more damage. For the fatalities, many of the farfield MS-AS sequences cause significantly larger results than the mainshocks, especially for the three-story building, whereas the fatalities caused by the near-fault MS-AS are identical to that caused by the corresponding mainshocks. It is also notable that the differences between the results caused by the MS-AS and mainshocks are generally less significant for the six-story building, indicating that the influence of aftershock may vary for different buildings. It is interesting to observe that the aftershocks affects more commonly and significantly for the fatalities than for the direct loss and downtime. An explanation is that for some MS-AS, of which the mainshocks are not intense enough to trigger evacuation, so occupants will choose to stay in the buildings during the next aftershock. Consequently the aftershocks will cause additional fatalities, no matter whether the aftershock is more intense than the mainshock. It should be noted that, although for some sequences the additional fatalities caused by aftershocks are greatly higher compared with the fatalities due to mainshocks, the actual value is still small. This is because the fatalities due to these mainshocks are extremely small.

To further investigate the influence of aftershocks on seismic performance, the direct loss, downtime, and the fatalities are converted to a single monetary term, total economic loss. The total loss includes the direct loss and the indirect loss which includes downtime and fatalities. The downtime loss is assumed to be $\$ 461 /$ day for the three-story building and $\$ 921 /$ day for the six-story building, according to the average lease rate data and an annual inflation rate of $3.5 \%$, which is used to convert the cost to present (Yeo and Cornell 2009b). Although assuming a price for human life has always been controversial, the value of a statistical life has been used in many cost-benefit analyses (Mitrani-Reiser 2007; Li 2010). For the purposes of this study and illustration, the value of a statistical life is assumed to be $\$ 4.16$ million based on the annual inflation rate and the data from previous studies (Mitrani-Reiser 2007; Mrozek and Taylor 2002). The indirect loss is found to contribute significantly to the total loss. The average percentages of different 
losses divided by the total loss are shown in Table 3.7. Near-fault ground motions generally cause more loss related to fatalities for the two non-ductile RC buildings. It has also been observed in other studies that downtime loss takes up a large part of the total loss (Mitrani-Reiser 2007; Yin and Li 2011), and the fatality loss is also found to be significant for non-code conforming RC frames (Mitrani-Reiser 2007). Therefore, the results of this case study are felt to be well in line with other study results.

Table 3.7 The average percentages of different losses relative to the total loss

\begin{tabular}{lllll}
\hline Parameters & \multicolumn{2}{l}{ The three-story building } & \multicolumn{2}{l}{ The six-story building } \\
& FF & NF & FF & NF \\
\hline Direct loss/ Total loss & $37.8 \%$ & $38.6 \%$ & $36.6 \%$ & $31.5 \%$ \\
Downtime loss/ Total loss & $23.8 \%$ & $18.4 \%$ & $30.8 \%$ & $18.2 \%$ \\
Fatality loss/ Total loss & $38.4 \%$ & $43.0 \%$ & $32.8 \%$ & $50.3 \%$ \\
\hline
\end{tabular}

Note: ${ }^{1}$. FF=Far-field MS-AS sequences; ${ }^{2}$. NF=Near-fault MS-AS sequences.

The total loss caused by each MS-AS sequence is also normalized by the loss induced by the corresponding mainshocks, and the results are presented in Figure 3.10. For the farfield ground motions, it is clear that significant underestimation in the total loss would be incurred if only the mainshock hazard is considered, especially for the three-story building. Such underestimation is less significant for the near-fault ground motions though. The statistical parameters of the normalized total loss are listed in Table 3.8.
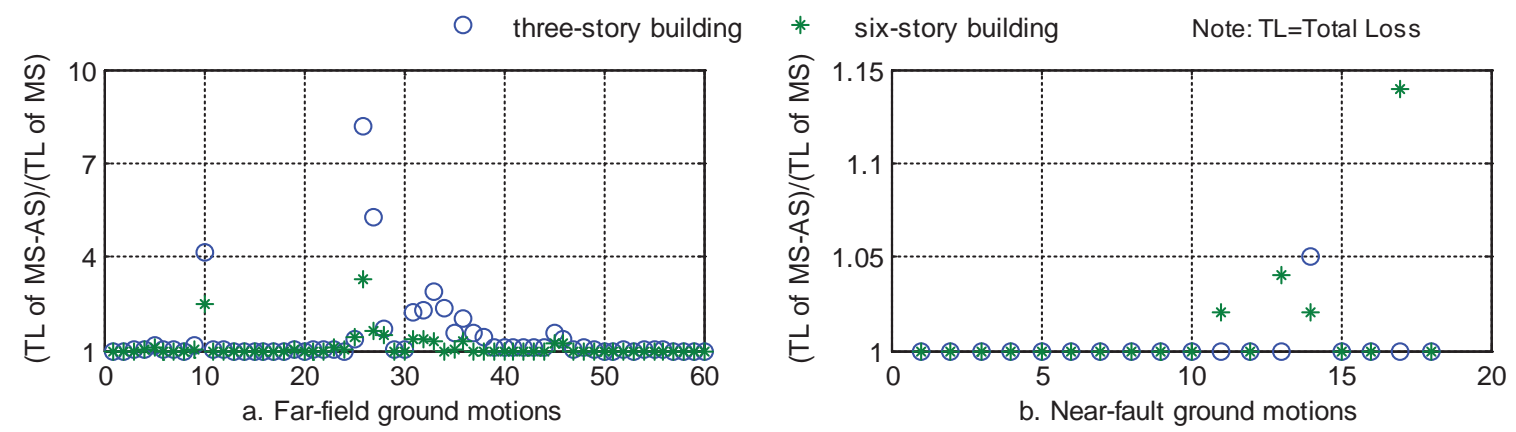

Figure 3.10 The normalized total loss (TL) of the two buildings

Table 3.8 The statistical parameters of the normalized total loss

\begin{tabular}{|c|c|c|c|c|}
\hline \multirow[t]{2}{*}{ Parameters } & \multicolumn{2}{|c|}{ The three-story building } & \multicolumn{2}{|c|}{ The six-story building } \\
\hline & FF & $\mathrm{NF}$ & $\mathrm{FF}$ & NF \\
\hline Mean & 1.44 & 1.00 & 1.12 & 1.01 \\
\hline Median & 1.01 & 1.00 & 1.00 & 1.00 \\
\hline $\mathrm{COV}$ & 0.81 & 0.01 & 0.33 & 0.03 \\
\hline
\end{tabular}

Note: ${ }^{1}$. FF=Far-field MS-AS sequences; ${ }^{2}$. NF=Near-fault MS-AS sequences. 
From Table 3.8, it can be concluded that the influence of aftershock hazard for near-fault MS-AS is negligible, but this could potentially be because the sampling size of the nearfault ground motions is not large enough. The statistical parameters for the far-field MSAS reflect the fact that most MS-AS sequences cause similar total loss as the mainshocks do yet some MS-AS sequences cause much larger total loss than the corresponding mainshock do, which significantly increased the mean value.

Accounting for multiple aftershocks in the performance assessment requires significantly more time and computational effort than the traditional seismic performance assessment, and most previous studies on the MS-AS considered only one aftershock for each sequence to reduce the necessary effort (Yin and Li 2011; Ruiz-Garcia and NegreteManriquez 2011; Nazari, et al. 2013). Therefore, it would be interesting to investigate whether using only one aftershock will yield similar results to using multiple aftershocks. For this purpose, the aftershock with the largest magnitude of all the aftershocks in each MS-AS sequence are selected and combined with the corresponding mainshock using the aforementioned back-to-back approach to form a mainshock-one-aftershock (MS-1-AS) sequence. It should be noted that the aftershock with largest magnitude is not necessarily equivalent to the aftershock with the largest $S_{a}\left(\mathrm{~T}_{1}\right)$. The assessment is performed again using the MS-1-AS sequences, then the computed direct loss, downtime, fatalities, and the total loss are normalized by those calculated using the sequences with multiple aftershocks. The statistical results are presented in Table 3.9.

The very small COV and the mean and median values that are close to one in Table 3.9 is because most results obtained from MS-AS and from MS-1-AS are the same, suggesting good agreement between the result induced by only one aftershock and that induced by multiple aftershocks. Except for that of the fatalities of the three-story building under farfield ground motions, which indicates some differences between considering MS-AS and MS-1-AS. However, generally speaking, the seismic performance evaluations obtained with the two types of sequences are close to each other, indicating using only one aftershock with the largest magnitude in performance assessment would be an acceptable balance between computational effort and accuracy. 
Table 3.9 The statistical parameters of the normalized results

\begin{tabular}{llllllllll}
\hline Parameters & & \multicolumn{2}{l}{ Direct loss } & \multicolumn{2}{l}{ Downtime } & \multicolumn{2}{c}{ Fatalities } & \multicolumn{2}{c}{ Total loss } \\
& & $\mathrm{FF}^{1}$ & $\mathrm{NF}^{2}$ & $\mathrm{FF}$ & $\mathrm{NF}$ & $\mathrm{FF}$ & $\mathrm{NF}$ & $\mathrm{FF}$ & $\mathrm{NF}$ \\
\hline The three- & Mean & 1.00 & 1.00 & 0.97 & 1.00 & 0.81 & 1.00 & 0.90 & 1.00 \\
story building & Median & 1.00 & 1.00 & 1.00 & 1.00 & 1.00 & 1.00 & 1.00 & 1.00 \\
& COV & 0.01 & 0.02 & 0.10 & 0.01 & 0.42 & 0.00 & 0.23 & 0.01 \\
The six-story & Mean & 0.99 & 0.98 & 0.94 & 0.99 & 0.98 & 1.00 & 0.96 & 0.99 \\
building & Median & 1.00 & 1.00 & 1.00 & 1.00 & 1.00 & 1.00 & 1.00 & 1.00 \\
& COV & 0.02 & 0.05 & 0.15 & 0.03 & 0.11 & 0.00 & 0.09 & 0.03 \\
\hline
\end{tabular}

Note: ${ }^{1}$. FF=Far-field MS-AS sequences; ${ }^{2}$. NF=Near-fault MS-AS sequences.

\subsection{Conclusions}

There has been a lack of research on the influence of post-quake decisions and aftershock hazard on the seismic performance of buildings, thus post-quake decisions, and the interactions these have with aftershock hazard were examined in this paper. Basic equations reflecting those interactions were developed for seismic performance evaluation in terms of direct loss, downtime, and fatalities. An illustrative performance assessment for two non-ductile RC frame buildings was used to illustrate the proposed assessment procedure as well as to investigate the influence of aftershocks on seismic performance. The influence of aftershocks was found to be insignificant for most MS-AS scenarios, but some far-field MS-AS sequences were found to have caused much more serious consequences than the mainshocks. For the far-field ground motions, neglecting aftershock hazard would lead to significant underestimation in the mean value of the seismic performance. However, no such conclusion could be made for the near-fault ground motions. It was also confirmed that using only one aftershock with the greatest magnitude will yield a similar result in seismic performance assessment using multiple aftershocks, but much less computational effort is required.

It should be noted that the discussions summarized from the case study are for low-rise and mid-rise non-ductile RC buildings only. The influence of aftershocks on the seismic performance of other types of structures still needs to be investigated. The study can also be improved by collecting more MS-AS sequences. The case studies showed an example of using the proposed procedure with some specific loss, downtime and fatality estimation methods, but other methods can also be adopted to perform assessment following the proposed procedure. Although the case study was a scenario-based assessment, the proposed procedure is also applicable to intensity-based and time-based assessment. 


\section{Impact of Aftershocks and Uncertainties on the Seismic Evaluation of Non-Ductile Reinforced Concrete Frame Buildings ${ }^{3}$}

\subsection{Introduction}

Current seismic performance assessment methods allow the estimation of the direct loss (repair cost), downtime (nonoperational time), and fatalities of buildings with consideration of mainshocks. However, a number of earthquake aftershocks can occur following the strike of a mainshock, many of which also have large magnitudes and intense ground motions (Asano, et al. 2011; Hauksson, et al. 1995; Kao and Chen 2000; Smyrou, et al. 2011). They have also been reported to have caused additional damage to buildings that survived a mainshock (Lew, et al. 2000; USGS 2000; Yeo and Cornell 2005). Thus, based on this evidence, it can be surmised that aftershocks can increase the direct loss, downtime, and fatalities of buildings during an earthquake sequence.

Previous preliminary studies on aftershocks revealed that the additional building damage and loss due to aftershocks can be significant (Nazari, et al. 2013; Yeo and Cornell 2009b; Yin and Li 2011). However, many of these studies used simplified methods and building performance models with limited ability to represent the actual seismic performance of buildings. In addition, they generally focused the direct loss without insight investigation of downtime and fatalities, which are also of great interest to engineers and building owners (FEMA 2012a). Finally, they did not incorporate post-quake decisions which may have a substantial influence on the seismic performance of buildings and have been considered in many current mainshock based assessment methodologies (FEMA 2012a; Mitrani-Reiser 2007; Ramirez and Miranda 2009). The post-quake decisions mainly include: 1). whether the building is collapsed; 2). whether occupants will be evacuated; 3). which kind of placard will be tagged to the building after the safety evaluation; 4). whether the building is repairable; 5). whether the repair cost is too high that the owner decides to replace it instead.

\footnotetext{
${ }^{3}$ The material contained in this chapter has accepted by Engineering Structures.
} 
This study examines the influence of aftershock hazard and post-quake decisions on the seismic performance of two non-ductile reinforced concrete (RC) frame buildings in term of direct loss, downtime, and fatalities, which are extensively recognized as the major metrics of seismic performance (FEMA 2012a; Mitrani-Reiser 2007). The detailed building models and analysis methods are employed in a manner consistent with the contemporary mainshock based assessment methodologies (FEMA 2012a; Mitrani-Reiser 2007; Ramirez and Miranda 2009). The characteristics of mainshock-aftershock (MS-AS) sequences, which have the potential to cause additional direct loss, downtime, and fatalities, have been identified. A sensitivity study is also performed to examine the influence of the uncertainties for the post-quake decisions on the seismic performance metrics.

\subsection{Post-quake decisions and their interaction with aftershocks}

Post-quake decisions depend on human factors as well as the post-quake condition of the building. All these post-quake decisions play an important role in the mainshock-based seismic performance assessment except the decision of whether the occupants will be evacuated, since evacuation will have no impact on the seismic performance if no following aftershocks are considered (FEMA 2012a; Mitrani-Reiser 2007; Ramirez and Miranda 2009). When aftershock hazard is considered, these post-quake decisions may become more important because they have an interactive influence with aftershocks, as introduced in the following paragraphs.

Figure 3.1 in Chapter 3 presents the procedure for the post-quake decisions when only a mainshock is considered (the right part) and when the mainshock and aftershocks are all considered (the left part). For the scenario without aftershocks, the building is initially determined to have either collapsed or survived after the mainshock. If the building has collapsed, the debris will be cleared and a replacement building is assumed to be built. If the building survives the mainshock, occupants will make the decision whether to evacuate based on the building damage condition. Then structural experts will perform a safety evaluation of the building, leaving a placard indicating "inspected", "restricted use", or "unsafe" (also known as green, yellow, or red tagged) (ATC 2005; MitraniReiser 2007). The preparation time for repair (part of downtime) increases in order of green tagged building, yellow tagged building, and red tagged building (Mitrani-Reiser 2007). Another conclusion made during the safety evaluation is whether the building is technically repairable or has to be demolished and replaced. After that, if the building is 
considered as technically repairable, the repair cost will be estimated to see whether it exceed the threshold value of the building owner. If the repair cost is too high, the owner will be prone to replace the damaged building instead of repairing it. This is the event procedure adopted by current mainshock based seismic assessment methodologies, with additional details presented in (FEMA 2012a; Mitrani-Reiser 2007).

When aftershocks are included in the scenario, a similar procedure applies following each shock, except that some post-quake decisions will not repeat after each aftershock. After a mainshock, if the building does not collapse, it may experience aftershocks before the safety evaluation. The building may collapse from any of the successive aftershocks, with the consideration of an aftershock conditioned on the obvious constraint that the building does not collapse from the previous shock (either the mainshock or an aftershock). Likewise, whether occupants will be evacuated is considered after each aftershock, conditioned on that no evacuation occurred after the previous shock. The first safety evaluation usually is conducted at least several days after the mainshock occurrence, because there will typically be a shortage of inspectors compared to the overwhelming quantity of buildings to be evaluated right after the disaster (ATC 2005). However, the shortage of inspectors will no longer be a problem during the aftershocks that occur after the first safety evaluation. Therefore, it is assumed that a safety evaluation will be performed on the building right after each aftershock. Whether an aftershock, which occurs after the first evaluation, should be considered is conditioned on the building not collapsing and is determined as repairable (with acceptable repair cost) after the previous shock. Once the repair of the building structural components is completed, the building can be treated as an intact building and the following aftershocks can be treated as a new MS-AS sequence. It should be noted that in such a situation, the nonstructural components that have not been repaired should be carefully considered to avoid double counting the repair cost and repair time.

The post-quake decisions and the aftershocks may have significant influence on the seismic direct loss, downtime, and fatalities. Each aftershock has the potential to cause additional damage to the building and hence increase the possibility of collapse, evacuation, and being irreparable. Building collapse can cause a substantial raise in the direct loss, downtime, and fatalities. Evacuation may cause some downtime but can also reduce the potential fatalities for the following aftershocks. Demolishing and replacing the building also induces more direct loss and downtime than repairing it. The aftershocks increase the possibility of changing the decisions, whereas changing the 
decisions increases the downtime and consequently may take more aftershocks into consideration. This is the interaction between the post-quake decisions and the aftershocks.

\subsection{Building models and mainshock-aftershock sequences}

The two non-ductile RC frame buildings that has been presented in Chapter 2 and 3 are used in this study. Information such as the prototype buildings, structural models, building components, fragility groups and associated repair cost and time, occupancy models has been introduced in Chapter 2 or Chapter 3, and therefore is not reiterated in this chapter.

Since the impact of aftershocks are found to be marginal for the near-fault ground motions in Chapter 3, this chapter only utilizes the 60 far-field mainshock-aftershock (MS-AS) sequences that are used in Chapter 3 for investigation. The ground motion suite covers wide range of intensities and aftershock numbers, and hence is able to simulate small to major earthquake events with varieties of aftershock numbers. The mainshock spectral acceleration at the fundamental period, $S_{a}\left(\mathrm{~T}_{1}\right)$, of the three-story building $\left(\mathrm{T}_{1}=\right.$ $1.14 \mathrm{~s})$ and the six-story building $\left(\mathrm{T}_{1}=1.92 \mathrm{~s}\right)$ varies from $0.040 \mathrm{~g}$ to $1.032 \mathrm{~g}$ and $0.029 \mathrm{~g}$ to $1.025 \mathrm{~g}$, respectively, whereas the maximum aftershock $S_{a}\left(\mathrm{~T}_{1}\right)$ for each sequence ranges from $0.002 \mathrm{~g}$ to $0.456 \mathrm{~g}$ and $0.001 \mathrm{~g}$ to $0.312 \mathrm{~g}$ respectively for the three-story and six-story building. The number of aftershocks ranges from 2 to 13 . Although the numbers of aftershocks are still less than actual situations, it is the best approximation could be achieved with available data. The mainshock and aftershock ground motions are combined chronologically with a 30 second interval that has zero acceleration between each shock to simulate the peace time between two shocks. Such a time interval was found to be sufficient for the buildings to end any free vibration following forced excitation. An illustrative example of the acceleration record for a sequence is shown in Figure 3.6. Then back-to-back nonlinear time-history analysis (NTHA) can be performed using the MS-AS sequences. Such NTHA can account for the structural damage sustained during all the shocks that occurs prior to any point in time. The $30 \mathrm{sec}$ interval is only utilized in the NTHA. However, the actual inter-arrival time between two shocks has great uncertainty and can be as long as weeks. Therefore, the real inter-arrival times that were recorded along with the ground motions are utilized in the performance assessment. 


\subsection{The influence of aftershocks on the seismic direct loss, downtime, and fatalities}

\subsubsection{Computation of building seismic performance metrics}

The seismic direct loss, downtime, and fatalities of the two buildings under each of the 60 MS-AS sequences are calculated following the procedure described in Figure 3.1. Only the mean values of these three performance metrics are computed in this study. The assumptions and methods that are used in this chapter are identical as those in Chapter 3, but some key assumptions that are related to the topic of this chapter are still introduced in the following paragraphs.

The criteria for making the post-quake decisions should be outlined before the performance assessment is implemented. The buildings are considered as collapsed when the NTHA fails to converge when unreasonably large deformation occurred (Celik and Ellingwood 2009). Otherwise the probability of collapse after a shock is calculated through the collapse fragility with the peak inter-story drift ratio (PIDR) of the building during the shock. The medians and dispersions of the collapse fragility functions for the two buildings is obtained via incremental dynamic analysis (IDA) (Vamvatsikos and Cornell 2002) using the structural models and a suite of ground motions. More information of the collapse fragility can be found in Chapter 2 and Chapter 3. The median and dispersion of the collapse fragility for the three-story building are $5.0 \%$ and 0.36 respectively, whereas those for the six story building are $4.2 \%$ and 0.36 respectively. Similarly, the probability that the building is not repairable is also expressed as a lognormal fragility function using the residual inter story drift ratio (RIDR) after a shock (FEMA 2012a). The median RIDR and dispersion of the repair fragility is taken as $1.0 \%$ and 0.3 respectively, according to the FEMA P-58 (FEMA 2012a).

Whether occupants will decide to evacuate is difficult to predict because it depends on both the damage level of the building and their psychological endurance. In this study, the evacuation is assumed to occur when any of following situation happened: 1). any beam or column has damage not less than the moderate damage state (defined in Table 3.1); 2). any story has significant RIDR; 3). any unit of drywall partition reaches a significant damage state; 4). any unit of the sprinklers is fractured; 5). any ceiling unit has collapsed; and 6). any exterior glazing unit has cracked or has more serious damage. The 
probability of having significant RIDR is assumed to be the same as when the building is not repairable using the repair fragility.

The safety evaluation result directly impact the preparation time for repair. The actual decision of tagging depends on both the damage condition and the judgment of the examiner. However, in this study, the criteria for different taggings are simplified to depend on the damage of the exterior structural components, residual drift, and fire protection system according to the FEMA P-58 (FEMA 2012a) and ATC-20 (ATC 2005). A green tag is assumed to be placed when all the following three conditions are achieved: 1). there is no damage exceeding the light damage state for all the exterior beams and columns; 2). there is no significant RIDR found at any story; and 3). there is no fracture for any sprinkler unit. The red tag is assigned if any of these three scenarios occurred: 1). the damage of any exterior beam or column reaches or exceeds the severe damage state; 2). significant RIDR occurs on at least on story; and 3). fracture is found on any sprinkler unit. When the building does not satisfy criteria of either the green tag or red tag, it is tagged yellow. The probability of different tagging is calculated following these criteria.

The direct loss refers to the repair or replacement cost. Repair cost is computed using the story-based method as introduced previously. The replacement cost is assumed to be equal to the total value of the building. The repair cost threshold of the owners above which they would prefer to replace the building is assumed to be $40 \%$ of the total building value according to FEMA P-58 (FEMA 2012a).

As introduced in Chapter 3, the total downtime equals the irrational downtime plus the rational downtime. Irrational downtime relies on the required repair method and cost, labor, economic, and regulatory, so it is complicated to simulate. For the purpose of this study, the simplified post-quake tag-irrational downtime model proposed by MitraniReiser (2007) is adopted, same as in Chapter 3. The rational downtime indicates the repair time, which is equal to the summation of the repair time for each story when the stories are repaired sequentially or equal to the maximum story repair time when the stories are repaired in parallel. The repair time for a story is the summation of repair time for all the component units, which depends on the damage states of the components themselves, and the change-of-trade time. The change-of-trade time means the time interval between the subsequent repair work on different components, such as the time after the repair of the sprinklers finished but before the beginning of repair on the drywall 
partitions. The repair time can change after any aftershock, and therefore it is calculated after each aftershock. It is assumed that the repair scheme of the buildings is parallel and the change-of-trade time is 2 days. Figure 4.1 shows a schematic Gantt chart of the threestory building using the assumed repair scheme in this study. Methods for estimating the fatalities and other unmentioned information that is necessary for the performance assessment are the available in Chapter 3.

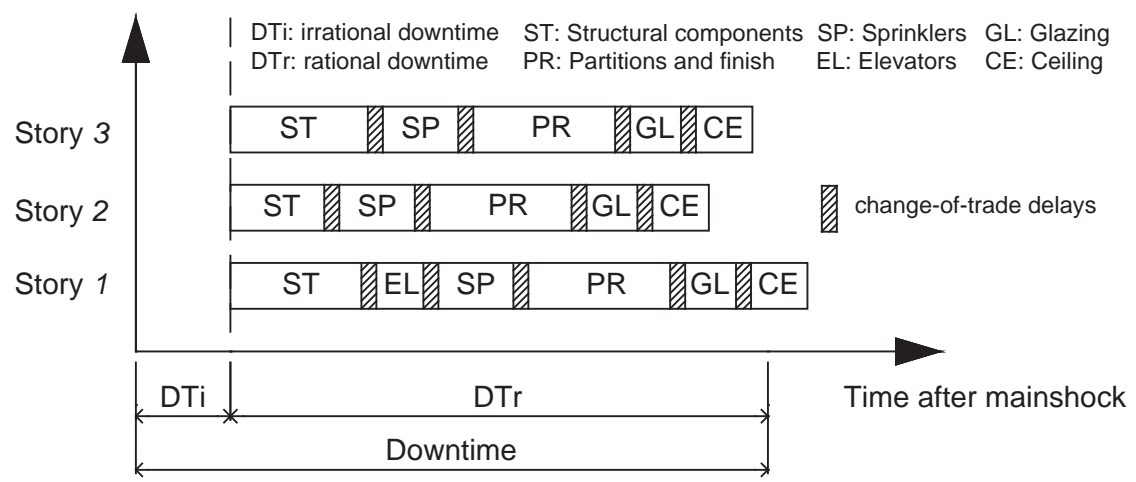

Figure 4.1 The assumed repair scheme for the three-story building (schematic)

\subsubsection{The assessment results and discussions}

The direct loss, downtime, and fatatilities are computed for each building under each MSAS sequence. To evaluate the comprehensive performance, the three metrics are all converted in monetory form and summed up as the total loss. Although it is controverisal to assume a "price" for human life, the statistical value of life has been utilized in previous studies for research purpose (Li 2010; Mitrani-Reiser 2007). It is assumed that the statistical value of a human life is $\$ 4.16$ million based on a 3.5\% annual inflation rate (Yeo and Cornell 2009b) and the data from references (Mitrani-Reiser 2007; Mrozek and Taylor 2002). Such value and the fatality calculated using the methods described in the previous section may have significant uncertainty, which need further investigation. The loss due to downtime is assumed to be $\$ 461 /$ day for the three-story building and $\$ 921 /$ day for the six-story building, based on the average lease rate data and the annual inflation rate of 3.5\% (Mitrani-Reiser 2007). The direct loss, downtime, fatalities, and the total loss of the two buildings for the 60 MS-AS sequences are presented in form of histograms as shown in Figure 4.2. 

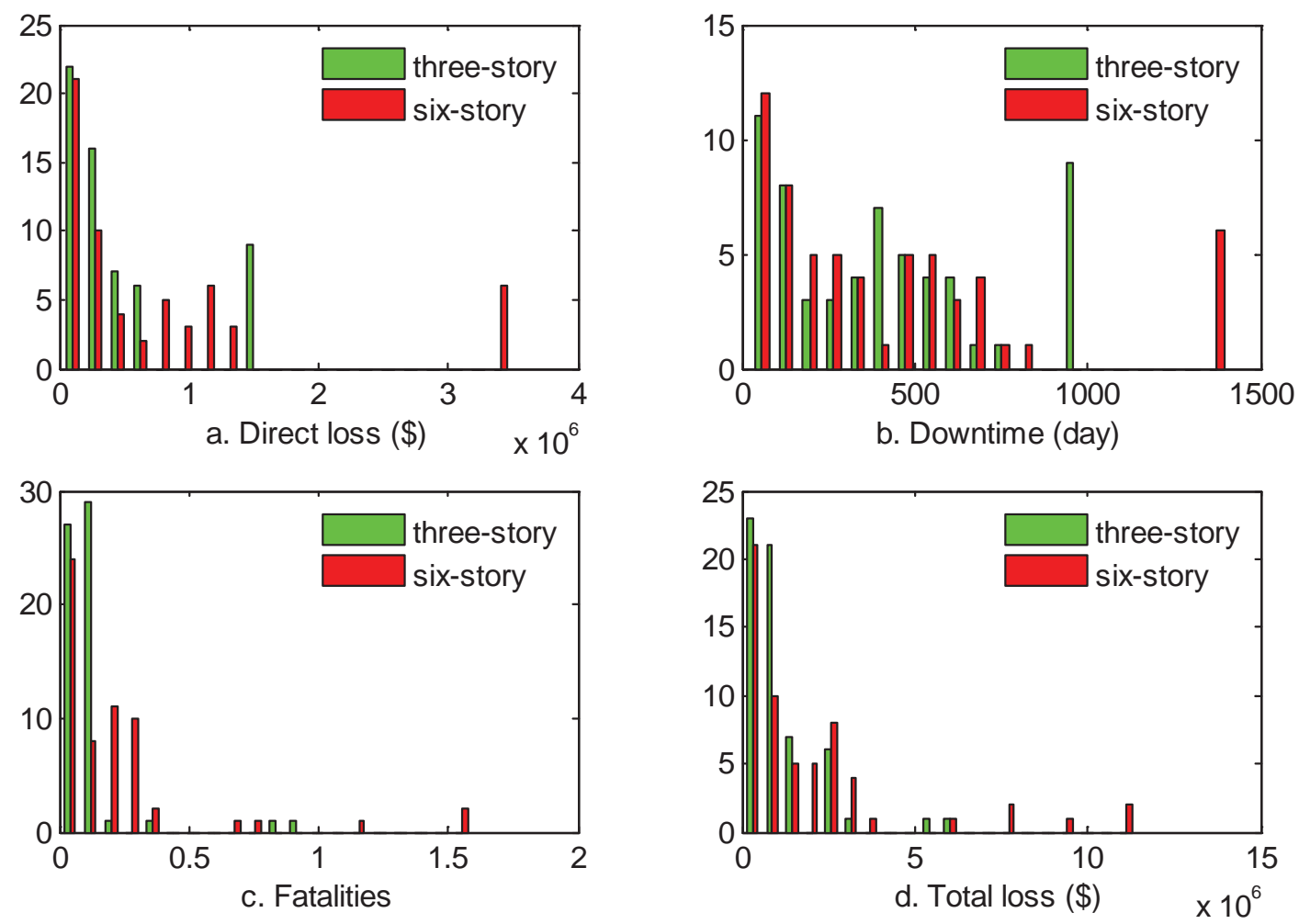

Figure 4.2 The histograms of the performance metrics of the buildings under the MS-AS sequences

It can be observed that the value of these performance metrics vary in a wide range. There are obvious gaps between the bar at the right end and the bar next to it for each building in the histograms of direct loss and downtime, which is because the estimated repair cost exceeded the threshold value and the owners decide to replace the building. Therefore, the cases of which the direct loss and downtime should be at the gap area all move to the right end. However, this phenomenon is not significant for fatalities and total loss. It is also notable that the total losses of the buildings are much higher than the direct losses, indicating that the indirect loss contributes significantly to the total loss. The average percentages for different losses normalized by the total loss are shown in Table 4.1.

Table 4.1 The average contribution of different loss to the total loss of each building

\begin{tabular}{llll}
\hline Building & Direct loss/ Total loss & Downtime loss/ Total loss & Fatality loss/ Total loss \\
\hline Three-story & $37.8 \%$ & $23.8 \%$ & $38.4 \%$ \\
Six-story & $36.6 \%$ & $30.8 \%$ & $32.8 \%$ \\
\hline
\end{tabular}


The results in Table 4.1 also suggest that the indirect loss caused by the downtime and fatalities are even greater than the direct losses. The downtime losses considered in this study are still conservative because only the loss of the lease is considered. Clearly, losses due to fatalities contribute significantly to the total loss, which may be because of the high collapse risk of non-ductile RC frame buildings (Liel, et al. 2010). For ductile $\mathrm{RC}$ frame buildings, which have lower collapse risk, the contribution of fatality loss to the total loss is expected to be lower.

It is also of interest to see how different is the mainshock-aftershock analysis results are when compared with the results obtained with conventinal mainshock based assessment method. Therefore, the direct loss, downtime, fatalities, and total loss caused by each MS-AS sequence are normalized respectively by those caused by the corresponding mainshock. If the normalized value is larger than 1, it means the MS-AS caused more serious consequences than the mainshock. The results of various performance metrices of the two buildings induced by all the 60 MS-AS sequences are expressed using the pie charts, as shown in Figure 4.3 4.6.

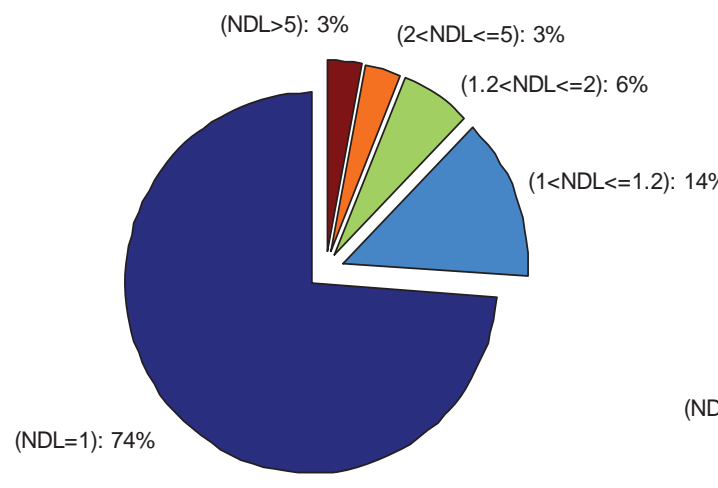

a. The three-story building

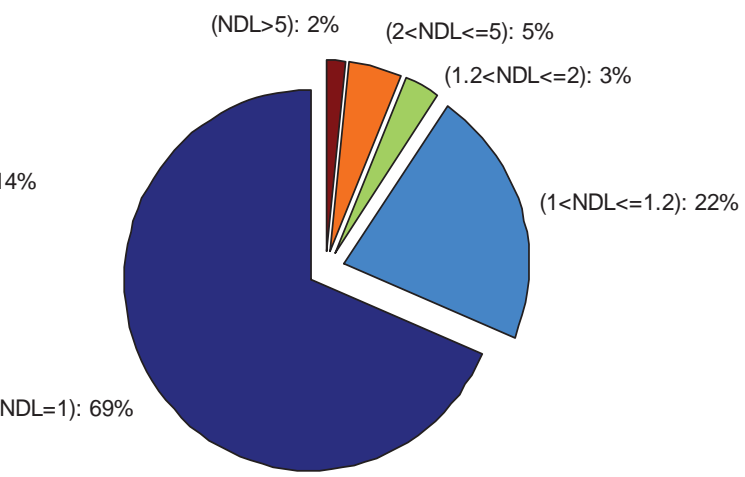

b. The six-story building

Figure 4.3 Pie charts of the normalized direct loss (NDL) of the two buildings 


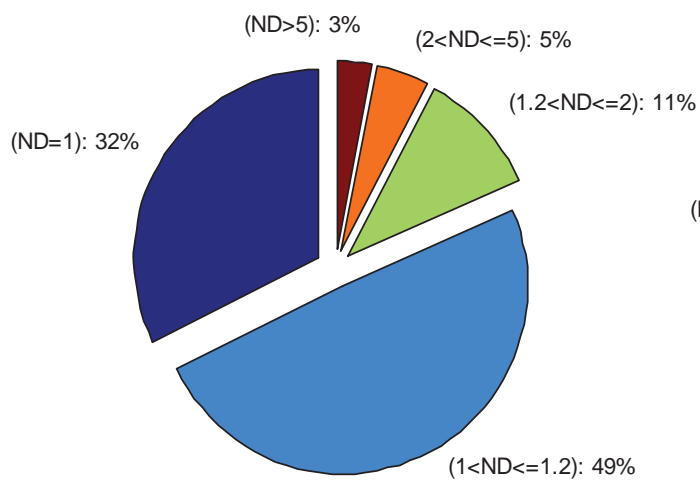

a. The three-story building

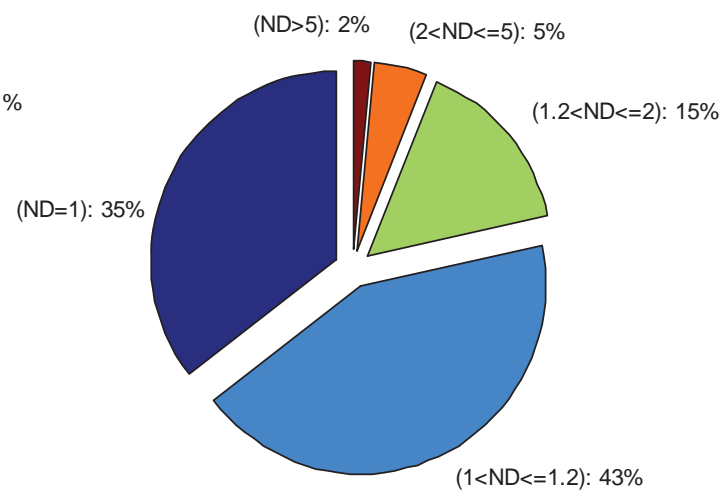

b. The six-story building

Figure 4.4 Pie charts of the normalized downtime (ND) of the two buildings

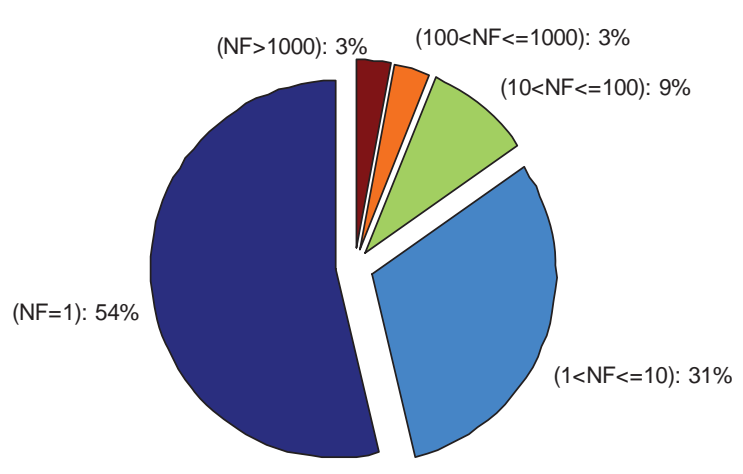

a. The three-story building

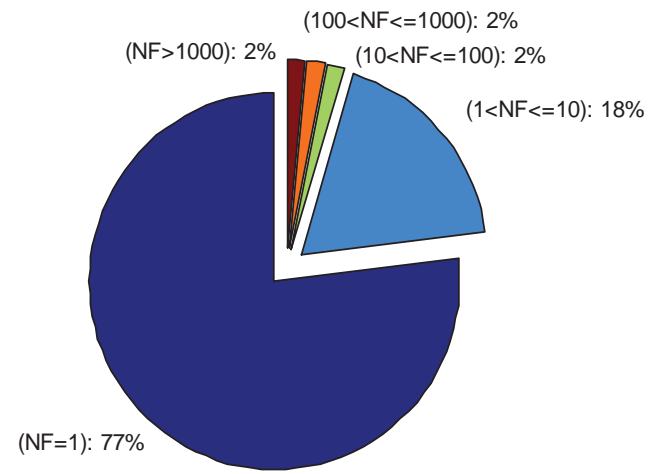

b. The six-story building

Figure 4.5 Pie charts of the normalized fatalities (NF) of the two buildings

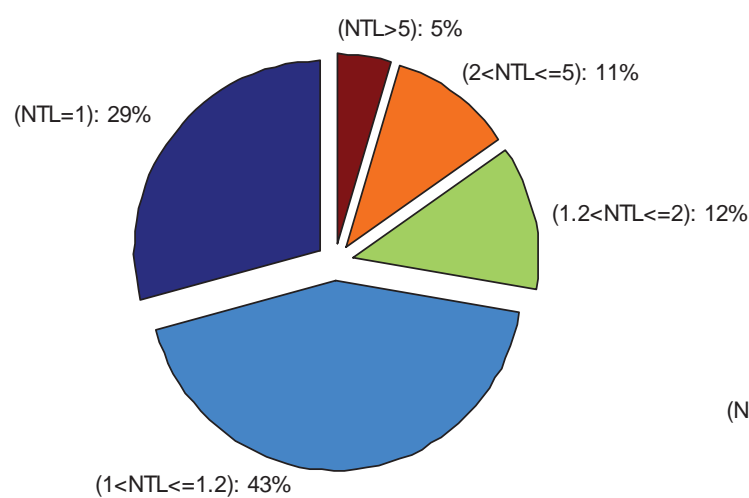

a. The three-story building

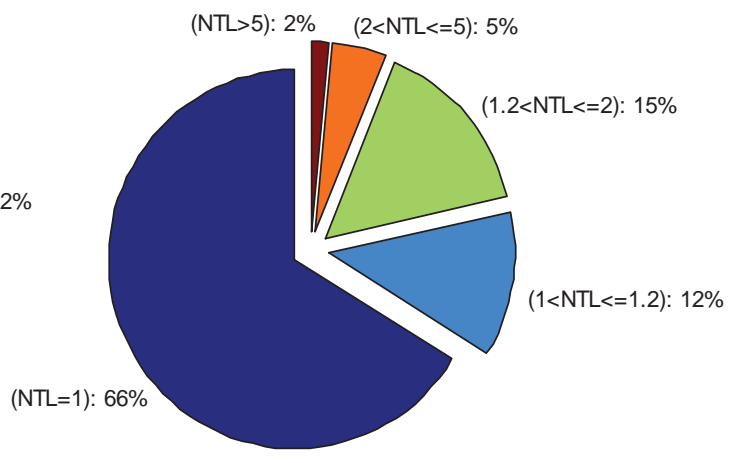

b. The six-story building

Figure 4.6 Pie charts of the normalized total loss (NTL) of the two buildings 
Figure 4.3 suggests that most of the MS-AS analyses results are not significantly different than the mainshock only analysis. Only about $30 \%$ of all the sequences cause more direct loss than the scenarios when only mainshocks are considered. The percentage of the MSAS which causes $20 \%$ or more direct loss than the mainshocks drops to approximately $10 \%$ for both buildings. As indicated by Figure 4.4, the underestimation in downtime due to neglecting aftershock hazard is more obvious than that in direct loss. Only slightly more than $30 \%$ of the mainshocks induce the same downtime as the MS-AS, although less than $50 \%$ of the mainshocks only cause slightly underestimation in the downtime. It is observed from the Figure 4.5 that the aftershock hazard can lead to significantly higher fatalities (sometimes more than 1000 times higher) than the mainshock hazard. The underestimation in the fatalities is more common for the three-story building, implying that the fatalities caused by aftershocks might be building sensitive. One possible reason may be that the three-story building has a shorter period than that of the six-story building and hence subject to larger spectral accelerations from the ground motions. Therefore, the three-story building tends to sustain higher damage during the mainshock, and therefore has higher collapse risk during the aftershocks, which causes higher fatality during the aftershocks. The different collapse risk of the two buildings also suggests that these building are not designed for a certain level of earthquake hazard, otherwise similar collapse risks should be expected. The total loss also demonstrated a similar trend, which is illustrated in Figure 4.6. For the three-story building, only $29 \%$ of the MS-AS do not yield higher total loss than that induced by the mainshock, whereas the percentage increases to $66 \%$ for the six-story building.

It is clear that the aftershock hazard has the potential to cause significant differences in the seismic performance metrics. However, it is not explicit which characteristics of the MS-AS sequence will contribute to such a difference. Therefore, a statistical correlation analysis is performed between the aforementioned normalized values and many characteristic parameters of the MS-AS sequences to indentify which characteristic parameters correlate with the differences between the MS-AS scenarios and the mainshock scenarios. The characteristics that are considered in this study are directly and strongly related to the MS-AS ground motions. Other parameters such as elastic and inelastic response of the buildings may also have substantial correlation with the difference in results, but they are not examined in this paper. The characteristic parameters include the $S_{a}\left(\mathrm{~T}_{1}\right)$ of the mainshock $\left(S_{a, \mathrm{M}}\right)$, maximum $S_{a}\left(\mathrm{~T}_{1}\right)$ of all the aftershocks $\left(S_{a, \mathrm{~A}}\right)$, the ratio of $S_{a, \mathrm{~A}}$ over $S_{a, \mathrm{M}}\left(S_{a, \mathrm{~A}} / S_{a, \mathrm{M}}\right)$, the number of total aftershocks $\left(N_{\mathrm{A}}\right)$, the number of aftershocks occurred before the first safety evaluation $\left(N_{\mathrm{AbE}}\right)$, the 
number of aftershocks occurred after the first safety evaluation and before the repair finished $\left(N_{\mathrm{AaE}}\right)$, and the number of aftershocks after the repair has finished $\left(N_{\mathrm{AaR}}\right)$. Since logarithmic relations are common in earthquake engineering, such as for seismic fragility (FEMA 2012a) and distribution of ground motion parameters (Haselton, et al. 2011), the correlation analysis is also performed between the normalized performance metrics and the parameters after taking natural logarithm (e.g. $\ln S_{a, \mathrm{M}}$ ) and taking exponential with base $e$ (e.g. $\left.e^{S a, M}\right)$, respectively. The Pearson's linear correlation coefficients and corresponding P-values are calculated. If a normalized performance metric is found to be correlated with a parameter in any of the three forms (original, logarithmic, and exponential) at the 0.95 significance level based on the corresponding P-value, this parameter would be considered as being strongly related to the difference caused by the aftershocks. Otherwise the parameter could only be considered as no evidence for correlation or in other words, weakly correlated with the performance. The parameters which are found to be strongly correlated to the normalized performance metrics are listed in Table 4.2.

Table 4.2 The parameters of MS-AS sequences that strongly related to the normalized performance metrics

\begin{tabular}{lllll}
\hline Building & $\begin{array}{l}\text { Normalized direct } \\
\text { loss }\end{array}$ & Normalized downtime & $\begin{array}{l}\text { Normalized } \\
\text { fatalities }\end{array}$ & Normalized total loss \\
\hline Three-story & $S_{a, \mathrm{~A}} / S_{a, \mathrm{M}}, S_{a, \mathrm{~A}}$ & $S_{a, \mathrm{~A}} / S_{a, \mathrm{M}}, S_{a, \mathrm{M}}, S_{a, \mathrm{~A}}$ & $N_{\mathrm{AaR}}$ & $\begin{array}{l}S_{a, \mathrm{~A}} / S_{a, \mathrm{M}}, S_{a, \mathrm{M}}, S_{a, \mathrm{~A}}, \\
\text { Six-story }\end{array}$ \\
$S_{a, \mathrm{~A}} / S_{a, \mathrm{M}}, S_{a, \mathrm{~A}}$ & $\begin{array}{l}S_{a, \mathrm{~A}} / S_{a, \mathrm{M}}, S_{a, \mathrm{M}}, S_{a, \mathrm{~A}}, \\
N_{\mathrm{AaR}}\end{array}$ & $S_{a, \mathrm{M}}$ & $N_{a, \mathrm{~A}} / S_{a, \mathrm{M}}, S_{a, \mathrm{M}}, S_{a, \mathrm{~A}}$ \\
\hline
\end{tabular}

It can be concluded from Table 4.2 that the difference in seismic performance are correlated with $S_{a, \mathrm{~A}} / S_{a, \mathrm{M}}, S_{a, \mathrm{M}}, S_{a, \mathrm{~A}}$, and $N_{\mathrm{AaR}}$. The related factors for the two buildings are not identical, which might be due to the different characteristics of the buildings and the limited sample size of the ground motions. The correlation coefficients between the normalized performance metrics and the $S_{a}$, M are negative whereas other correlation coefficients are positive, implying that the difference caused by aftershocks increases with the decrease of $S_{a, \text { M }}$ (mainshock intensity) and the increase of $S_{a \text {, A }} / S_{a \text {, M }}$ and $S_{a \text {, A }}$ (aftershock intensity). The positive coefficients between some normalized metrics and $N_{\text {AaR }}$ is also felt to be reasonable because the aftershocks occurring after the repair is finished can be treated as another MS-AS sequence applied on a new building. But the $N_{\text {AaR }}$ has coefficients smaller than others and was less common for the normalized metrics, suggesting that it is not the dominant factor compared with the intensities of the mainshock and aftershocks. This is reasonable as well since the intensities of aftershocks that occur after the repair is finished are generally quite smaller, and hence can only 
induce a limited level of additional consequences. But, if an intense aftershock occurred a long time after the mainshock, it can cause significant additional loss. Such a situation was observed in the Christchurch earthquake (Smyrou, et al. 2011). It is interesting that the number of total aftershocks does not have strong correlation with the seismic performances. This indicates when selecting the MS-AS sequences for performance assessment, it is more important to choose the aftershock with the highest intensity than choosing multiple of aftershocks. This finding can help engineers save time on selecting ground motions when performing NTHA.

\subsection{The uncertainties in decision-making and their influences}

As discussed previously, post-quake decisions highly depend on human factors, which may introduce substantial uncertainties into the actual decision process. Therefore, such uncertainties and their influences on the assessed performance metrics should be examined. Accordingly, the variance range of the criteria which trigger the decisions are defined and sensitivity study is performed herein.

The uncertainty in reparability can impact the decision whether the building can be repaired technically. It is assumed that the median of the repair fragility function is uncertain but the logarithmic standard deviation is deterministic. The lower-bound and upper-bound of the median RIDR of the repair fragility are taken as its $10^{\text {th }}$ and $90^{\text {th }}$ percentile, which are $0.68 \%$ and $1.47 \%$ respectively.

If the occupants are prudent, they would be likely to evacuate when relatively light damage is observed. If they are imprudent, they may decide to evacuate only after more serious damage occurs. Therefore, the extreme scenarios of being prudent and imprudent can be presumed to determine the corresponding criteria of decision of evacuation. For occupants who are very prudent, it is presumed that the evacuation would occur under any of these situations: 1). any beam or column reaches the light damage state (as shown in Table 3.1); 2). any story has visible RIDR; 3). any unit of drywall partition reaches the visible damage state; 4). any unit of the sprinklers fractures; 5). any ceiling unit collapses; and 6). any exterior glazing unit has crack or more serious damage. The scenario with prudent occupants is denoted as Eva-Prudent. For occupants who are imprudent, the criteria to evacuate are assumed to be any of the following conditions: 1). any beam or column reaches the severe damage state; 2). any story has serious RIDR; and 3). any unit of the sprinklers fractures. The scenario with imprudent occupants is denoted as Eva- 
Imprudent, whereas the criteria of evacuation which was described in the Section 4.4 and utilized in the previous analysis is denoted as Eva-Normal. The probability of visible RIDR and serious RIDR is assumed to be similar as the repair fragility, just with the median modified to $0.68 \%$ and $1.47 \%$ respectively.

Prudent inspectors are more likely to place tags with higher level on the buildings during safety evaluation, whereas imprudent inspectors have the opposite trend. However, the inspectors would follow the instructions in ATC-20 (ATC 2005), which provides explicit description for different tags and hence can reduce the uncertainty of the evaluation decision. Consequently, the tagging criteria of prudent inspectors, normal inspectors, and imprudent inspectors are supposed to be similar, except for the judgment of RIDR because there are no explicit definition of "significant out of plumb" required in ATC-20 (ATC 2005). The tagging criteria for prudent inspectors (denoted as Tag-Prudent) and imprudent inspectors (denoted as Tag-Impudent) are assumed to be similar to those of normal inspectors (denoted as Tag-Normal), which has been introduced in the previous section. But the medians of the RIDR fragility functions are assumed to be $0.68 \%$ and $1.47 \%$ for the Tag-Prudent and Tag-Imprudent respectively.

The values of threshold repair cost of owners are also uncertain. The low or high threshold may be related to the financial capacity of the owner, the use of the building, and the owner's expectation. The accurate distribution is complicated to simulate but a rough estimation is easier to achieve. Federal Emergency Management Agency (FEMA) uses a $50 \%$ of the replacement cost as the threshold value between the decision of repair and replacement (FEMA 2012a). The FEMA P-58 recommends the $40 \%$ of the replacement value as the threshold, which is adopted in this study as aforementioned (FEMA 2012a). Therefore, the 50\% of replacement value is assumed to be the high threshold, whereas a $30 \%$ of the replacement value is assumed to be the low threshold. The $40 \%$ of the replacement value which was used in the analyses introduced previously is assumed to be the middle threshold.

To compare the influence of the uncertainties in post-quake decisions with the influence of other uncertainty sources, the major influential uncertain parameters are also included in the sensitivity study. The most influential uncertainty source is the ground motions, which can even shadow the influence of other uncertainty source (Lamprou, et al. 2013; Porter, et al. 2002). Porter, et al. (2002) investigated the major uncertain variables in mainshock based loss estimation and found that the variations of assembly capacities also 
have dominant impact. Celik and Ellingwood (2010) and Chapter 3 revealed that the uncertainty in viscous damping have the most substantial influence on the structural responses of RC frame buildings. Therefore, the uncertainties in ground motions, assembly capacity, and viscous damping are also considered in the sensitivity study. Other uncertain parameters such as the unit cost, repair time, fatality ratio, material properties, and beam-column joint model parameters may also have significant impact on the results, but they are neither the most influential factors nor the factors of interest in this study, and thus are not examined here.

The uncertainties in ground motions actually lie in multiple parameters, such as the magnitude, site-to-source distance, spectral acceleration and shape (of either mainshock or aftershocks). Conventional mainshock based studies generally scale a set of ground motion records to different intensity levels according to the $S_{a}\left(\mathrm{~T}_{1}\right)$, and the difference in the results (swings) indicates the influence of uncertain $S_{a}\left(\mathrm{~T}_{1}\right)$. However, this method is questionable for scaling the MS-AS sequences. Since the increase of $S_{a}\left(\mathrm{~T}_{1}\right)$ of aftershocks may not linearly increase with the $S_{a}\left(\mathrm{~T}_{1}\right)$ of the mainshock, applying a uniform scale factor of a entire MS-AS sequence is not well grounded. Nevertheless, if the uniform scale factor is close to 1, the modification on the MS-AS sequence is limited, implying that the scaled ground motion is an acceptable approximation. For this purpose, the $60 \mathrm{MS}$-AS sequences are ranked based on the $S_{a, \mathrm{M}}$ of the two buildings respectively, and then they are divided into three groups with 20 sequences in each group to represent the small, moderate, and large earthquakes respectively. The two buildings have different $\mathrm{T}_{1}$, so the rank order and the inventory of each group are not identical. For each building, the MS-AS sequence in the group of small, moderate, and large earthquake are scaled to the intensity level of earthquakes with $90 \%, 50 \%$, and $10 \%$ of probability of exceedance in 50 years respectively, which are assumed to be the lower-bound, median, and upperbound earthquake intensities. The scale factor for each MS-AS were based on the $S_{a \text {, M }}$ of individual buildings, and are applied to scale both the mainshock and the aftershocks. The $S_{a}$, of different probability of exceedance for the two buildings are obtained from the hazard curve of U.S. Geological Survey (USGS) (USGS 2014), supposing the buildings are located at Los Angeles $\left(34.054^{\circ} \mathrm{N}, 118.243^{\circ} \mathrm{W}\right)$. The information about the $S_{a, \mathrm{M}}$ of different intensity level and the scale factors of different ground motion groups are presented in the Table 4.3. It can be seen that the scale factors are close to 1 , and hence ensures that the scaled MS-AS sequences are a reasonable approximation of the actual ground motions. It should be noted that the three scaled ground motion groups do not have common MS-AS sequences, which means the many uncertainty sources such as 
spectral shapes and aftershock intensities are not controlled explicitly between the groups of ground motions. This is because the uncertain parameters couple with each other, making it difficult to vary one parameter for sensitivity analysis while others remain unchanged. Therefore, the three groups of MS-AS sequences only represent the small, moderate, and large earthquakes in a general way and the ground motion uncertainties were included at the overall level.

Table 4.3 The target $S_{a, \mathrm{M}}$ of different earthquake groups and information of the scale factors

\begin{tabular}{llll}
\hline Parameters & & $\begin{array}{l}\text { The three-story } \\
\text { building }\end{array}$ & $\begin{array}{l}\text { The six-story } \\
\text { building }\end{array}$ \\
\hline Small & $S_{a, \mathrm{M}}$ of 90\% of PE in 50 Yr. & $0.085 \mathrm{~g}$ & $0.046 \mathrm{~g}$ \\
earthquakes & Mean of scale factors & 0.97 & 1.01 \\
& Standard deviation of scale factors & 0.42 & 0.31 \\
Moderate & $S_{a, \mathrm{M}}$ of 50\% of PE in 50 Yr. & $0.196 \mathrm{~g}$ & $0.109 \mathrm{~g}$ \\
earthquakes & Mean of scale factors & 0.79 & 0.95 \\
& Standard deviation of scale factors & 0.14 & 0.21 \\
Large & $S_{a, \mathrm{M} \text { of 10\% of PE in 50 Yr. }}$ & $0.562 \mathrm{~g}$ & $0.298 \mathrm{~g}$ \\
earthquakes & Mean of scale factors & 1.18 & 1.06 \\
& Standard deviation of scale factors & 0.33 & 0.29 \\
\hline
\end{tabular}

Note: PE=Probability of exceedance

The assembly capacities refer to the collapse fragilities and the fragility functions of different damage states of various fragility groups as shown in Table 3.1. It is assumed that the uncertainty only lies in the medians of the fragility functions and the dispersions are deterministic, so higher assembly capacity is equal to a higher median value. To examine the impact of uncertainty in assembly capacities on the seismic performance metrics, the lower-bound, median value, and upper-bound of the medians are assumed to be their $10^{\text {th }}, 50^{\text {th }}$, and $90^{\text {th }}$ percentiles respectively. Therefore, the median values of the median assembly capacities are the same as shown in Table 3.1. Consequently, the median value of the upper-bound and lower-bound were $\exp [\ln (C)-1.28 \beta]$ and $\exp [\ln (C)+1.28 \beta]$ respectively. $C$ and $\beta$ are the median and dispersion from the Table 3.1. The lower-bound and upper-bound of the median capacity of collapse is also computed in the same way. The story-based method which is used to compute the direct loss is adjusted according to the major assembly information shown in Table 3.1 and the repair cost data adopted in the method (Ramirez and Miranda 2009) to reflect the influence of different assembly capacities. The lower-bound, median, and upper-bound of the viscous damping are also taken as the $10^{\text {th }}, 50^{\text {th }}$, and $90^{\text {th }}$ percentiles of their distribution respectively, which are respectively $2.4 \%, 5.0 \%$, and $7.6 \%$ following the study of Porter, et al. (2002). 
The two-side bounds and median of all the uncertain parameters are all determined, and the summary of these parameters are presented in Table 4.4. Since it may be inappropriate to name the bounds of the post-quake decisions as lower-bound and upperbound because the influence of a specific bound on the seismic performance metrics are not necessarily the same, the left-bound and right-bound are utilized in Table 4.4 instead. It should be noted that no matter which bound is called left-bound or right-bound, the extreme results shown in the final tornado diagrams will be the same. The sensitivity study is performed with those data. For each ground motion group and each uncertain parameter, the two extreme results are recorded when the uncertain parameter is set to the left-bound and the right-bound respectively, while other parameters are set to their medians. The differences in the two results are typically called the swings, the value of which reflects the importance of the uncertain parameter. This procedure is repeated for each parameter and for each of the ground motion groups to examine the effect of different uncertain parameters under different earthquake intensity levels. Additionally, the parameters are all set to their medians to obtain the baseline results under each ground motion group. The differences of the baseline results of the scaled small earthquakes and the scaled large earthquakes can be considered as the swings caused by the uncertainty of ground motions.

Table 4.4 Parameters of the sensitivity study

\begin{tabular}{llll}
\hline Parameter & Left-bound & Median & Right-bound \\
\hline Ground motion & Scaled small earthquakes & $\begin{array}{l}\text { Scaled moderate } \\
\text { earthquakes }\end{array}$ & Scaled large earthquakes \\
Assembly capacity & $\exp [\ln (C)-1.28 \beta]$ & $C$ & $\exp [\ln (C)+1.28 \beta]$ \\
Damping ratio & $2.4 \%$ & $5.0 \%$ & $7.6 \%$ \\
Reparability & $0.68 \%$ & $1.00 \%$ & $1.47 \%$ \\
Evacuation & Eva-Prudent & Eva-Normal & Eva-Imprudent \\
Tagging & Tag-Prudent & Tag-Normal & Tag-Imprudent \\
Threshold repair & $30 \%$ of replacement & $40 \%$ of replacement value & $50 \%$ of replacement \\
cost & value & & value \\
\hline
\end{tabular}

The mean direct loss, downtime, fatalities, and total loss obtained for the sensitivity study are presented graphically as tornado diagrams in Figure 4.7 and 4.8 for the three-story and the six-story building respectively. The performance metrics are expressed as the fraction of their respective relevant loss over the replacement value of the building. The larger the swing is, the more important the uncertainty parameter would be. The trends of the influence due to the uncertainty parameters are the same for both buildings. The differences between the baselines of the MS-AS sequences with $10 \%$ and $90 \%$ of 
probability of exceedance in 50 years can be considered to be the swings caused by the uncertainty of ground motions, which is generally much larger than the swings of the other parameters. This suggests that the MS-AS ground motions are an important uncertainty source that requires consideration in analysis. It can also be found that assembly capacity is generally the dominant uncertainty parameter in the seismic performance metrics, including the direct loss on which Porter, et al. (2002) also found the uncertainty of assembly capacity is the most important. The damping ratio is generally less influential but still an important uncertain source as shown in the Figure 4.7 and 4.8. These observations are consistent with previous studies (Celik and Ellingwood 2010; Han, et al. 2014b; Lamprou, et al. 2013; Porter, et al. 2002).

Some uncertain post-quake decisions also have a substantial effect on the seismic performance metrics. The uncertainty of evacuation is important for the fatalities under small and moderate earthquakes, and hence it is also important for the total loss under same earthquake intensities. But its impact become less significant in large earthquakes, because the fatalities caused by large earthquakes mostly are induced by the mainshock, and evacuation after the mainshock will not influence the fatality very much. The influence of evacuation on the downtime loss is limited, although prudent evacuation will result in a few more days of downtime. This suggests that even if the earthquake is not intense, evacuating occupants after the mainshock would be a wise decision either from the perspective of humanity or the perspective of economics. The threshold repair cost is also found to be important for the direct loss and downtime under larger earthquakes, although it is not influential under less intense earthquakes because building repair cost seldom reaches the threshold. Therefore, the threshold value should be carefully treated in loss estimation and performance assessment. The uncertainty in reparability is insignificant, which is probably because the repair cost of these buildings reaches the threshold value before the building is technically not repairable. The uncertainty of tagging is also marginal, reflecting that the guide lines in ATC-20 can reduce the uncertainty of safety evaluation to some extent. 


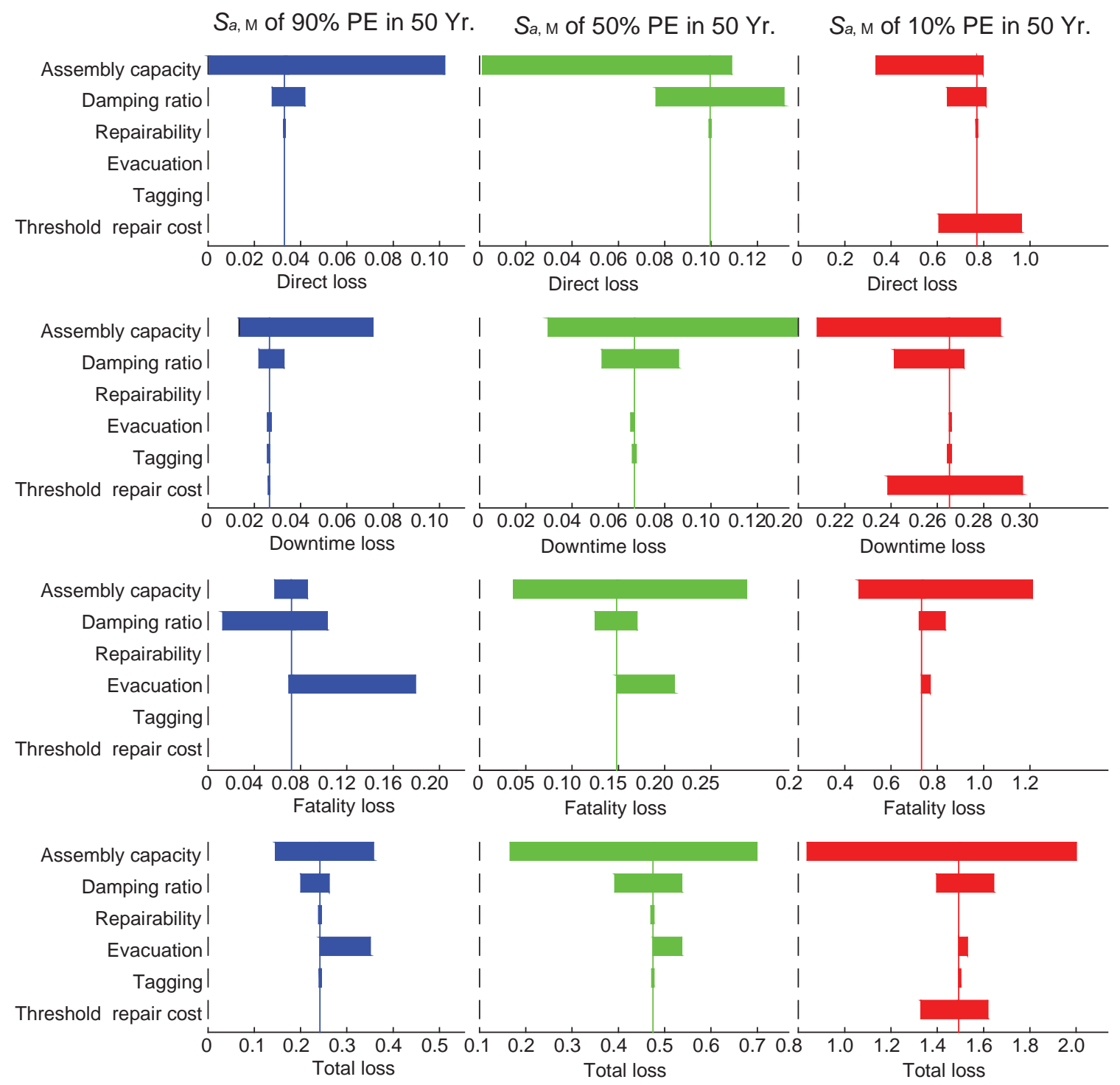

Figure 4.7 The results of sensitivity study on the three-story building 


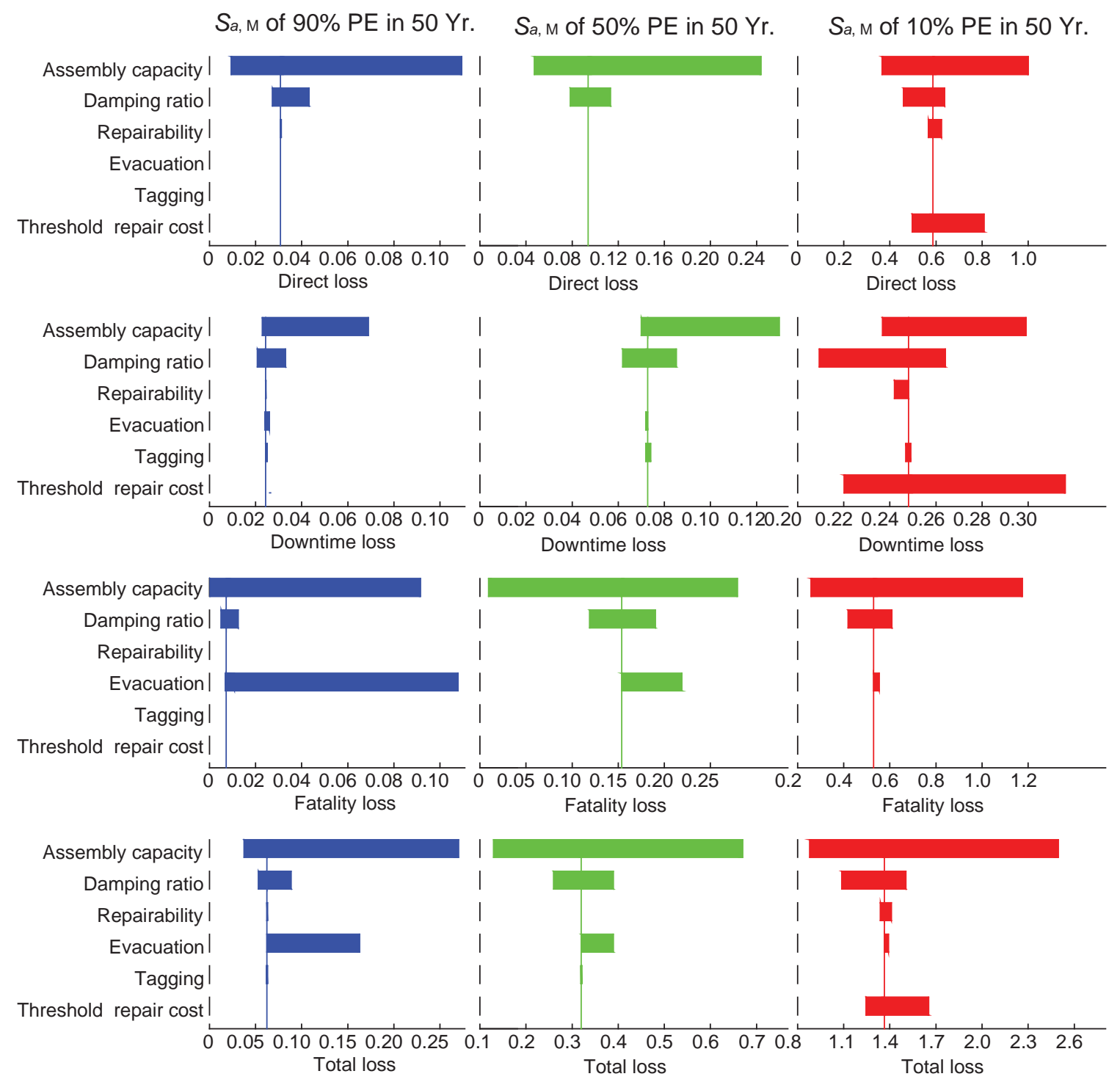

Figure 4.8 The results of sensitivity study on the six-story building

\subsection{Conclusions}

The seismic performance of two non-ductile RC frame buildings was investigated with the consideration of aftershocks and post-quake decisions using $60 \mathrm{MS}-\mathrm{AS}$ sequences. A procedure to incorporate them into the assessment was introduced. The direct loss, downtime, fatalities, and total loss of the buildings were examined. Through comparison between the results using this method and those obtained with the mainshock only, it was found that the aftershock hazard can cause significant additional loss to buildings and that amount of loss can now be quantified. The characteristics of aftershocks which may be relevant to their ability to cause more direct loss, downtime, and fatalities were identified 
through correlation analysis. The spectral acceleration of the mainshock, the maximum spectral acceleration of the aftershocks, and the number of aftershocks that occur after the building has been repaired were found to be strongly related to the potential of aftershocks to result in worse consequences.

The impact of different sources of uncertainty including the post-quake decisions was investigated through sensitivity analysis in this study. The uncertainties of tagging and reparability were found to be insignificant. However, the uncertainty related to evacuation was found to be important under small and moderate earthquakes. In comparison, the uncertain threshold repair cost was found to be influential under large earthquakes. Nevertheless, the impacts of the uncertain post-decisions are less significant than some traditional source of uncertainties, such as the ground motion and building resistant capacity (assembly capacity). It should be noted that the findings were obtained from investigation of non-ductile RC frame buildings, and therefore are not applicable to other building structures. However, the performance assessment methodology introduced in this study is independent of structure type, and could be applied to other building types. 



\section{Seismic Risk of Base Isolated Non-ductile Reinforced Concrete Buildings Considering Uncertainties and Mainshock-Aftershock Sequences ${ }^{4}$}

\subsection{Introduction}

The seismic design of reinforced concrete (RC) frame buildings has evolved to a sophisticated level over the last few decades, making them ductile in order to perform well in moderate to severe earthquakes. However, many buildings that were constructed prior to the implementation of modern building codes are vulnerable to earthquakes. The design deficiencies that make these structures vulnerable are minimal shear reinforcement, insufficient development length for longitudinal reinforcement and strong beam-weak column, essentially resulting in a lack of ductility capacity (Celik and Ellingwood 2009; Liel, et al. 2011). These buildings include typical RC frame buildings built in the Western United States (WUS) before the mid-1970s (Liel, et al. 2011) and the typical RC frames built in Central and Eastern United States (CEUS) prior to 2000 (Celik and Ellingwood 2009). Seismic rehabilitation for these non-ductile buildings is important in order to minimize extensive loss and casualties during earthquakes.

Among various seismic retrofit methods, base isolation is being increasingly used to "isolate" the superstructure from the earthquake ground motion, which has unique advantages in greatly reducing both the deformation and acceleration of the superstructure. When applied to retrofit an existing building, the parts connecting the superstructure and the footings are generally removed and replaced by a base isolation system, whereas the superstructure needs little structural retrofit work (De Luca, et al. 2001; Mokha, et al. 1996). This will induce minimal interruption for the superstructure occupancy and operation, which may also be an important advantage for stakeholders who must decide which retrofit method to select.

Many comparative studies have revealed that the responses of the isolated structures are significantly smaller than the fixed base structures (e.g. De Luca, et al. 2001; Erduran, et

\footnotetext{
${ }^{4}$ The material contained in this chapter was previously published in Structural Safety and is re-used herein with permission from Elsevier. The permission is presented in Appendix C
} 
al. 2011; Huang, et al. 2008; Karim and Yamazaki 2007; Sayani, et al. 2009; Zhang and Huo 2009). Most of these studies compared the seismic demands (e.g. inter story drift, floor acceleration and base shear) for the two types of building structures, but only a limited number of studies investigated the seismic risk of isolated structures based on probabilistic methods to incorporate the seismic demands, structural capacity, and seismic hazard. Karim and Yamazaki (2007) studied the seismic fragility of 30 isolated highway bridges that were designed to conform to Japanese seismic code. They found that when the pier height is low, the isolated highway bridges have a lower level of fragility than their fix-based counterparts; but when the pier height is high, the isolated highway bridges are more vulnerable than the fixed-base bridges. Zhang and Huo (2009) investigated which parameters are the most important for optimum design of isolated highway bridges to achieve a minimum fragility. Their research indicated that the design parameters of isolation devices affect the fragilities of highway bridges most, and the optimal parameters are functions of the structural properties and damage states. The results also suggested that well designed isolated highway bridges have a lower vulnerability than fixed base bridges. Huang, et al. (2008) evaluated the performance of both a conventional and a base isolated nuclear power plant under seismic and blast loading and found that the isolation system can effectively reduce the probability of unacceptable performance for nuclear power plants. However, little investigation has been conducted for the seismic risk of building structures, which have dissimilar characteristics to those of highway bridges and nuclear plants.

Performance based earthquake engineering (PBEE) is a design philosophy that allows building stakeholders to work with engineering teams and decide what level of performance best suits their needs and budget constraints. Thus, with the target performance level of rehabilitation for a building essentially decided by its stakeholders, there may be interest in seismic risk rather than a single response quantity, if properly informed. Therefore, it is necessary to evaluate the performance of the un-retrofitted and base isolated building using probabilistic seismic risk assessment. However, due to the inherent uncertainty of earthquakes ground motions and structural systems, all sources of uncertainties must be carefully identified and incorporated into the procedure. The two categories of uncertainties, namely aleatoric and epistemic uncertainties, are both considered in this paper.

In addition to conventional earthquake uncertainties, such as magnitude, epicenter, spectral content and amplitude (Porter, et al 2002; Yin and Li 2010), the fact that 
earthquake aftershocks also introduce uncertainty into the seismic demand has been a recent focus (Li and Ellingwood 2007; Nazari, et al. 2014; Ruiz-García and NegreteManriquez 2011; Yeo and Cornell 2005). The mainshock is usually followed by a number of aftershocks which may be severe and generally cause further damage to buildings (Huang, et al. 2008; Li, et al. 2014), and can increase the seismic demand (deformation or acceleration) for a structure. Therefore, 32 recorded mainshockaftershock (MS-AS) sequences are utilized in this paper to consider the effect of aftershocks. The traditional seismic risk evaluation using only mainshock records is also presented for comparison. Record-to-record uncertainty is also discussed.

Uncertainties in various fix-based structural systems have been extensively investigated. For example, Yin and Li (2010) examined the effect of ten hysteresis parameters on the dispersion of collapse capacity of light-frame wood buildings. Vamvatsikos and Fragiadakis (2010) conducted sensitivity research on steel structures to identify which parameters have the most significant impact on structural performance. Celik and Ellingwood (2010) studied the influence of uncertainties in material properties, damping and beam-column joint model parameters on the seismic fragility of RC frame buildings. Uncertainties of isolated bridges have also been studied. For instance, Padgett and DesRoches (2007) investigated the parameter sensitivity of structural response for a class of bridges with elastomeric isolators. Zhang and Huo (2009) examined the influence of design parameters on system fragility and developed an optimal design method.

Nonetheless, there is a dearth of insightful investigations related to the uncertainties of isolated building systems. There have been several research studies that have made progress. For example, Taflanidis and Jia (2011) proposed a framework for risk assessment and sensitivity analysis of base isolated buildings. However, the analysis was based on a simplified mathematical model to explain the framework, and the detailed structural properties and nonlinear behavior of the superstructure was not included in their procedure. In addition, factors such as temperature and ageing have considerable impact on the properties of isolation devices (elastomeric or slide bearing) (Constantinou, et al. 2007; Thompson, et al. 2000) and consequently need to be carefully treated in the assessment.

In this paper, a typical mid-rise non-ductile RC frame building in Los Angeles, CA is selected and hypothetically retrofitted using base isolation with lead rubber bearings (LRB). The un-retrofitted building and the base isolated building are then used in a 
comparative seismic risk analysis. Both aleatoric and epistemic uncertainties in demand and capacity are propagated through the full analyses. The differences in risk assessment from using MS-AS sequences and mainshocks alone are also discussed. The results found herein can provide insight into seismic risk assessment of base isolated buildings considering various sources of uncertainty, and offers risk-informed decision making tools for structural rehabilitation.

\subsection{Structural models}

\subsubsection{The un-retrofitted building}

The Van Nuys Holiday Inn (Krawinkler 2005; Park and Mosalam 2012) in Los Angeles, CA $\left(34.22^{\circ} \mathrm{N}, 118.47^{\circ} \mathrm{W}\right)$, which is a seven-story concrete moment frame building, is selected for investigation in this study. The building was designed in 1965 per Los Angeles Building Code 64 and constructed in 1966, with design details associated with typical non-ductile older-type RC frame buildings. The site condition is site class D. A three-bay frame in the transverse direction at the east end is extracted as a twodimensional structural model. The elevation, plan, and member cross-sectional views are presented in Figure 5.1.The thickness of the slabs are $10 \mathrm{in}$. $(254 \mathrm{~mm})$ at the $2^{\text {nd }}$ floor, 8.5 in. $(216 \mathrm{~mm})$ for the $3^{\text {rd }}$ to $7^{\text {th }}$ floor, and 8 in. $(203 \mathrm{~mm})$ for the roof. The cross-sectional dimensions of beams and columns are also presented in Figure 5.1. The design yield stress of reinforcements in columns and beams are $60 \mathrm{ksi}(414 \mathrm{MPa})$ and $40 \mathrm{ksi}$ (276 $\mathrm{MPa}$ ) respectively, whereas the nominal compressive strengths of concrete are $5 \mathrm{ksi}(34.5$ $\mathrm{MPa}$ ) for columns at the $1^{\text {st }}$ floor, $4 \mathrm{ksi}(27.6 \mathrm{MPa})$ for columns and beams at the $2^{\text {nd }}$ floor, and $3 \mathrm{ksi}(20.7 \mathrm{MPa})$ for all other members. Details of the reinforcement layout can be found in existing literature (Krawinkler 2005; Park and Mosalam 2012). 


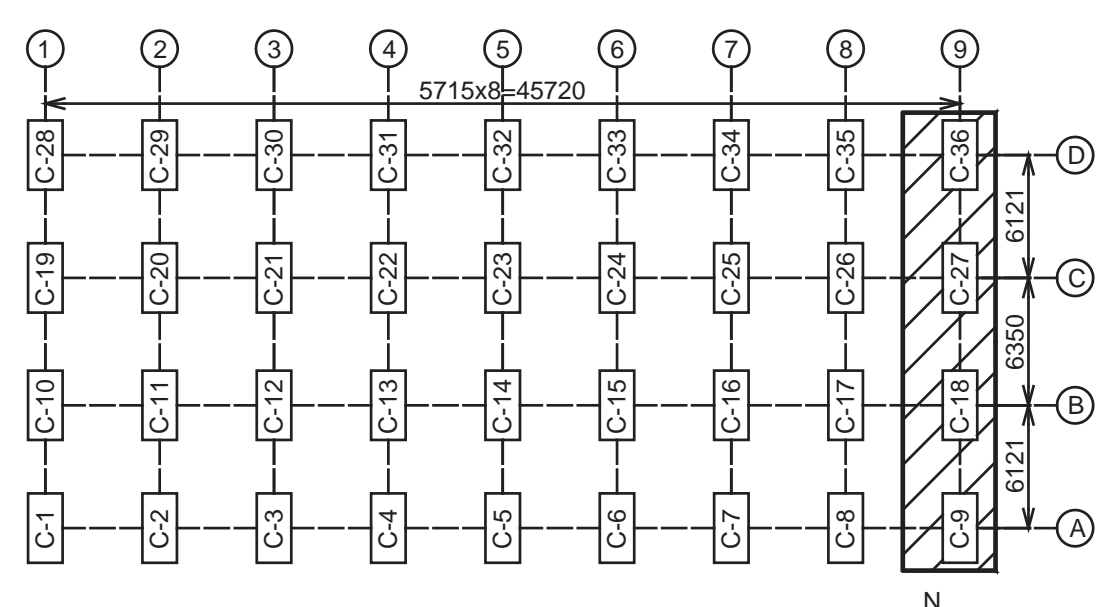

(a) Column plan

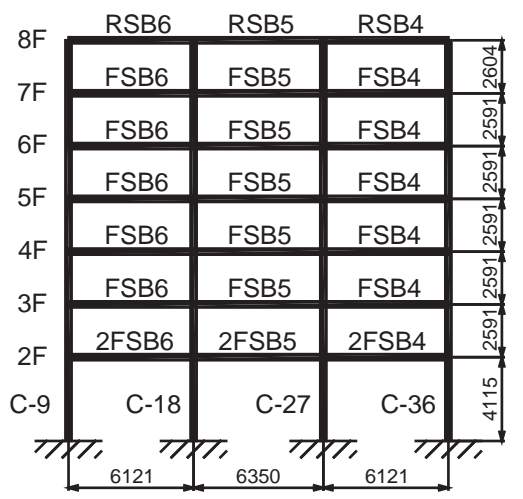

(b) Elevation
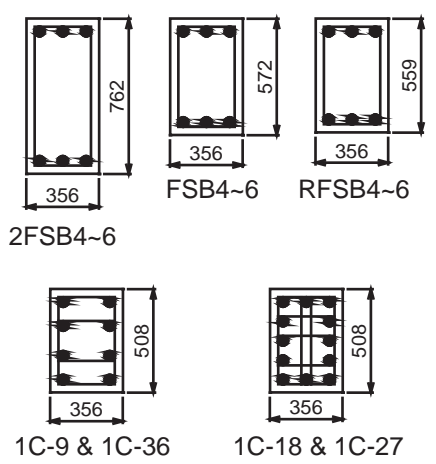

(c) Cross-sections of beams and columns

Figure 5.1 The layout of the un-retrofitted building (unit: $\mathrm{mm}$ )

A two-dimensional finite element model of the un-retrofitted frame is developed in OpenSees (Mazzoni, et al., 2006) which can consider the nonlinearities in both geometry and material. Using a two-dimensional model cannot account for out-of-plane behavior or torsional effects caused by earthquakes, but such a model is much less time consuming for analysis. In addition, for a regular RC frame building, adopting a two-dimensional model can yield sufficiently accurate results for both the un-retrofitted frame (Celik and Ellingwood 2009; Liel, et al. 2011) and the isolated frame (Sayani, et al. 2009; Yang, et al. 2010). Furthermore, results of a two-dimensional model can be used to draw conclusion without interference from torsional action or bi-axial interaction. The beamcolumn joint model is simulated using the joint model proposed by Park and Mosalam (2012) for seismically vulnerable beam-column joints, with rigid beams and columns end within the panel zone and a nonlinear rotational spring. Figure 5.2(a) shows the detailed joint model and the relationship between the normalized panel zone shear force 
(horizontal joint shear force over nominal joint shear strength $V_{j h} / V_{n}$ ) and the joint rotation. The beams and columns are modeled as Beam-With-Hinges elements (Scott and Fenves 2006), each of which consists of two fiber-sectioned plastic hinge zones at the ends of the element and a linear elastic zone in the middle of the element. The length of plastic hinge zone is estimated using the equation proposed by Panagiotakos and Fardis (2001). A stiffness reduction factor is applied on the elastic zones to account for the stiffness decrease due to cracking. The fundamental period of the model is estimated using the median values of the structural parameters and is $1.67 \mathrm{~s}$, the same as the fundamental period of the model adopted by Park and Mosalam (2012) for the same prototype building using the identical modeling method for beams, columns and joints.

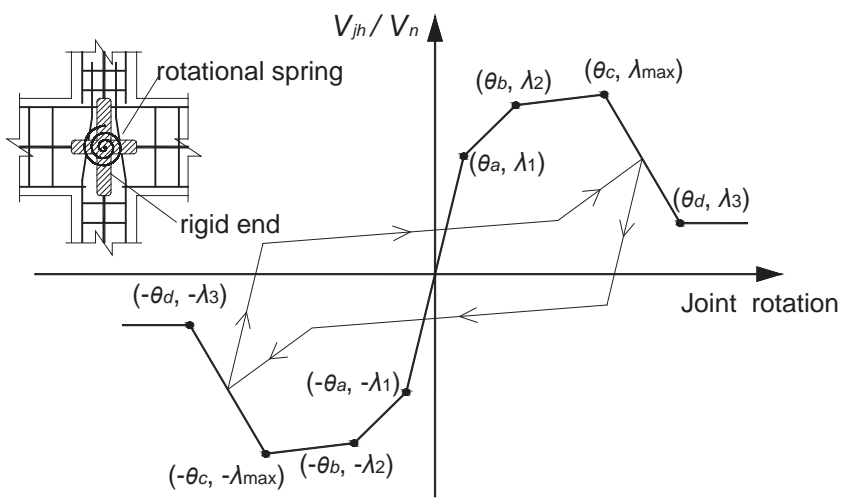

(a) Detail joint model and force-displacement relationship

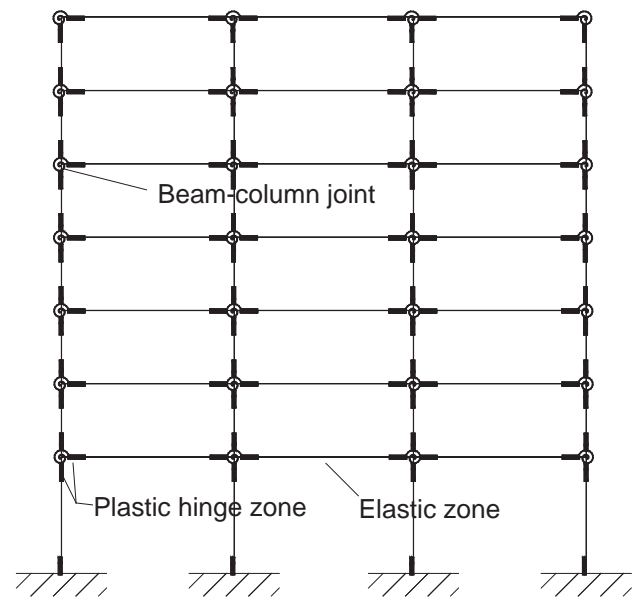

(b) Analytical model of the original building

Figure 5.2 The finite element model of the un-retrofitted building

At the fiber sections of the plastic hinge zones, the increase in compressive strength and ultimate strain of the confined concrete are calculated based on the results of the study by Saatcioglu and Razvi (1992).The nominal compressive strength of concrete and yield strength of steel were multiplied by 1.25 to obtain the mean value to account for the nominal value compared to the actual in-situ strength (bias) and the strength increase due to dynamic loading (Aslani and Miranda 2005b). The concrete constitutive model is simulated with modified Kent-Park model (Park, et al. 1982), whereas that of the reinforcements is modeled using the bilinear steel model with $0.5 \%$ strain hardening.

The effective seismic weight for each floor is calculated using 1.05 DL+0.25 LL (ASCE 2007), and is converted to lumped masses at each beam-column joint for dynamic analysis. The mean value of the Rayleigh damping for the first two modes is assumed to 
be 0.043 (Healey, et al. 1980). The building is assumed to be fixed on the rigid ground. The analytical model of the un-retrofitted building is validated through comparison with the aforementioned reference model (Park and Mosalam 2012). In addition to the same fundamental period which implies comparability for the linear behavior, the similarity in nonlinear behavior of the model in this paper and the reference model is also validated through comparison of incremental dynamic analysis (IDA) results using the same ground motion record, i.e. 1994 Northridge earthquake recorded at Tarzana station. The model used in this IDA utilizes median values for all structural parameters. As the IDA curve illustrates in Figure 5.3, the analytical model used herein is felt to adequately reproduce the seismic response of the reference model and of the prototype building.

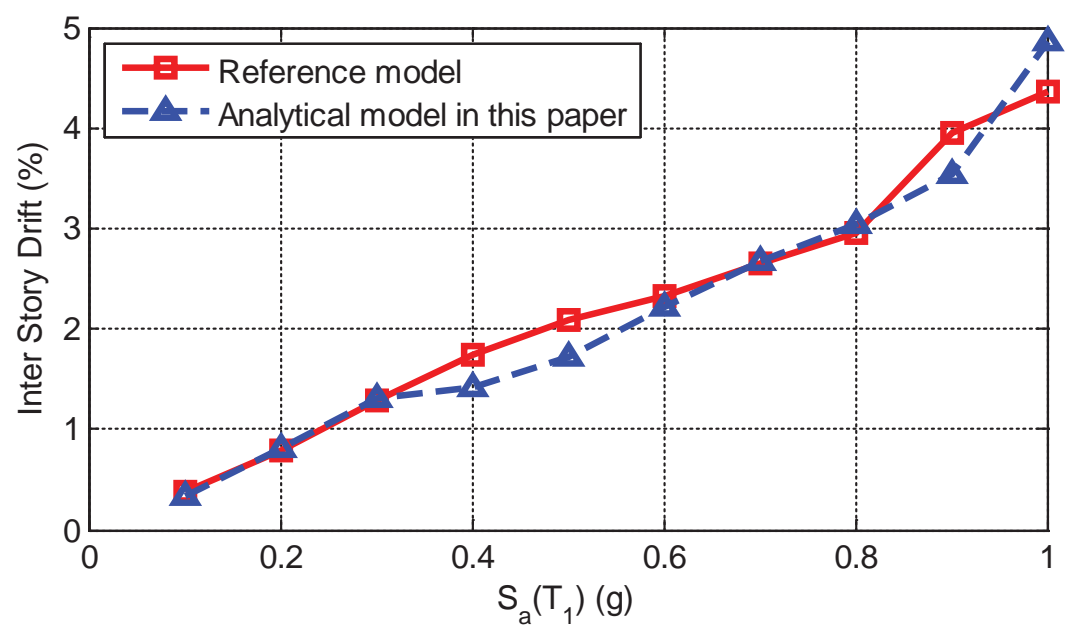

Figure 5.3 Comparison of the IDA curves of the model in this paper and the reference model using the same earthquake record

\subsubsection{The base isolated building}

The base isolation system is designed according to ASCE 41 (ASCE 2007), with rehabilitation objectives assigned as: (1) for the BSE-1 earthquake hazard level (10\%/50 years, also known as user-specified design earthquake level), the superstructure may be allowed to suffer certain damage but should be repairable after the earthquake; and (2) for the BSE-2 earthquake hazard level (2\%/50 years, also known as maximum considered earthquake), the damage of the superstructure shall not jeopardize life safety. These two rehabilitation objectives are basically equivalent to that for BSE-1 and BSE-2, the building shall not exceed the moderate damage (MD) and the extensive damage (ED) level as defined in HAZUS-MH (FEMA 2009a). By complying with these objectives, the 
rehabilitation eventually can achieve the enhanced rehabilitation objectives defined by ASCE 41 (ASCE 2007).

To use these two criteria in the design, the limit states are selected for the peak inter story drift ratio (denoted as PIDR hereafter). The PIDR at the MD and ED state are set to be $0.8 \%$ and $2.0 \%$ respectively, based on HAZUS-MH (FEMA 2009a). Structural capacities related to other damage states will be discussed later in this chapter.

Seismic isolation devices generally can be classified in two categories, namely, elastomeric bearings (e.g. high damping rubber bearings and lead rubber bearings) and sliding bearings (e.g. spherical sliding bearings and friction pendulum bearings). Despite the fact that the types of bearings can vary, their hysteretic behavior can be described using a bilinear model, as presented in Figure 5.4. For most base isolated buildings whose bearings yield quickly during earthquakes, $K_{p}$ and $Q_{d}$ were found to be key parameters that affect the hysteretic loops of the bearings and the system behavior (Constantinou, et al. 2007; Thompson, et al. 2000).

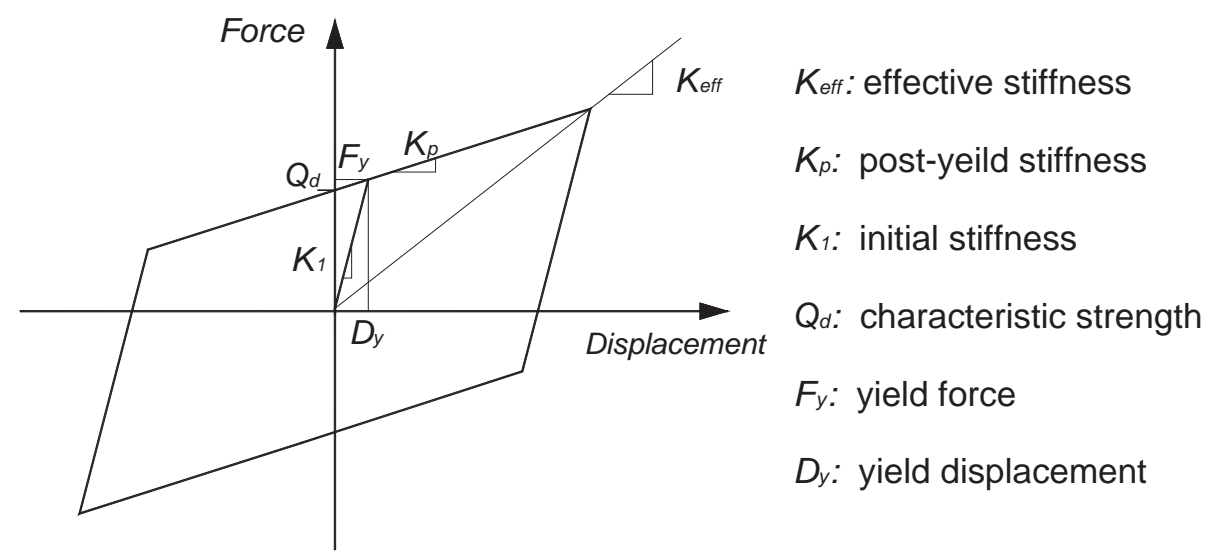

Figure 5.4 The bilinear force-displacement model for seismic isolation bearings

The nonlinear dynamic procedure per ASCE 41 (ASCE 2007) is employed for the rehabilitaion design. Four pairs of earthquake records from the PEER NGA database (PEER 2014) for Site Class D are selected and scaled to BSE-1 and BSE-2 levels for the analysis. The details for these records are presented in Table 5.1. The ground motions are scaled using the method proposed by Hancock, et al. (2006) so that the spectra in the period range from $0.2 \mathrm{~T}_{1}$ to $1.25 \mathrm{~T}_{1}$ ( $\mathrm{T}_{1}$ of the isolated building is the effective period of the isolated building, and is estimated to be $3 \sim 4 \mathrm{~s}$ ) best match the spectra of BSE-1 and 
BSE-2 for the Los Angeles area with Site Class D. The target spectra, the scaled records spectra and their mean spectra are presented in Figure 5.5.

Table 5.1 Ground motions used for design

\begin{tabular}{lll}
\hline Earthquake & Station & File Name \\
\hline Parkfield & CHOLAME \#8 & NGA_no_31_C08050.AT2 \\
$06 / 28 / 1966$ & & NGA_no_31_C08320.AT2 \\
San Fernando & LA HOLLYWOOD STOR LOT & NGA_no_68_PEL090.AT2 \\
$02 / 09 / 1971$ & & NGA_no_68_PEL180.AT2 \\
Loma Prieta & & NGA_no_738_NAS180.AT2 \\
$10 / 18 / 1989$ & ALAMEDA NAS HANGAR 23 & NGA_no_738_NAS270.AT2 \\
Northridge & & NGA_no_949_ARL090.AT2 \\
$01 / 17 / 1994$ & ARLETA & NGA_no_949_ARL360.AT2 \\
\hline
\end{tabular}
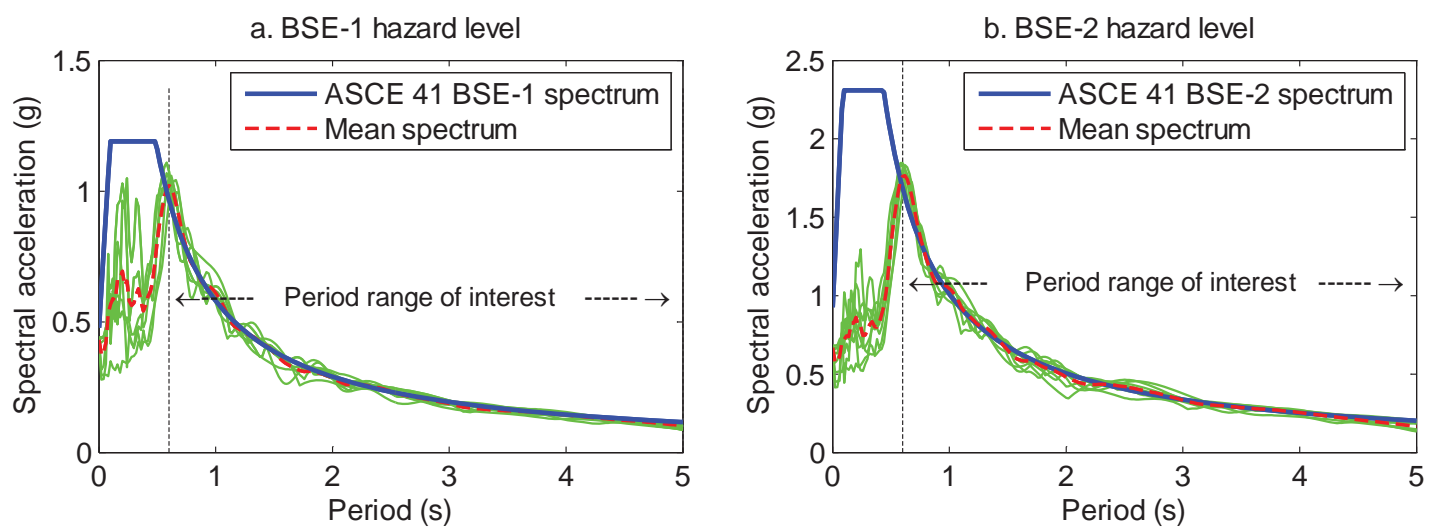

Figure 5.5 The target spectra and spectra of the scaled ground motions for BSE-1 and BSE-2 levels

In addition to the isolation bearings, the isolation system also contains a beam-slab system at the first floor. The beam-slab system should be strong enough to resist the gravity and seismic load as well as rigid enough to confine the bearings from out of plane rotation and keep them moving simultaneously. The slabs at the $1^{\text {st }}$ floor are identical to those of the $2^{\text {nd }}$ floor. Other details for the beam-slab system are shown in Figure 5.6.

Lead rubber bearings (LRB) are selected for this specific study, although other types of bearings may also be applied since the hysteretic behaviors are similar. A typical LRB is composed of alternate steel shims and laminated low damping rubber, with a lead core plug at its center. The viscous damping of the LRBs (less than 5\%) is close to the superstructure (Constantinou, et al. 2007), so their impact on the viscous damping of the entire building can be neglected. The layout of the bearings is shown in Figure 5.6. For 
the analytical model, the superstructure is identical to the un-retrofitted building, except the beam-slab and mass of the first floor are also accounted for. The LRBs are simulated using the zerolengthSection element with the Isolator2spring section, which was developed by Ryan, et al. (2005). This element is able to simulate the buckling failure of the LRBs under combined lateral deformation and vertical load from the superstructure. Also, this element can incorporate the effect of vertical load on the variation in the bearing properties, so that the effect of re-distribution of vertical load during the earthquakes can be considered (Ryan, et al. 2005). The $K_{p}$ and $Q_{d}$ are initially calculated using estimated maximum deformation of the bearings and the effective period of the building (period calculated with the effective stiffness at the maximum deformation). The results from nonlinear time history analysis (NTHA) are utilized to calculate actual LRB parameters, which are employed to adjust the design parameters. This trial procedure is repeated several times before stable solutions for design parameters are obtained, and $K_{p}$ and $Q_{d}$ are $401 \mathrm{kN} / \mathrm{m}$ and $40.8 \mathrm{kN}$ for each LRB, respectively. $K_{1}$ is set to $4,010 \mathrm{kN} / \mathrm{m}$, 10 times the value of $K_{p}$ (ASCE 2007; Yang, et al. 2010). Wind load is also checked for the isolated building to make sure the LRBs will not yield under wind action.

It should be noted that, unlike conventional structural elements, behavior of seismic bearings varies considerably under different service conditions. For sliding bearings, aging, contamination, cumulative movement and increase in temperature will increase the coefficient of friction. For elastomeric bearings, ageing and increase in temperature will cause an increase in $K_{p}$ and $Q_{d}$. Another important factor for rubber with relatively high shear modulus and damping is the scragging effect, which is a term used to define when the elastomeric bearings show higher $K_{p}$ and $Q_{d}$ during first few cycles (typically 3 cycles) of loading, and lower but stable $K_{p}$ and $Q_{d}$ during following cycles. The LRBs generally use natural rubber and the scragging of LRB can be neglected (Constantinou, et al. 2007; Thompson, et al. 2000). Therefore, in order to check whether the rehabilitation achieves the objectives, NTHA is also performed using the upper bound of $K_{p}$ and $Q_{d}$ for the LRB, which is calculated by incorporating system property modification factors for aging and temperature (Constantinou, et al. 2007). Mean results of the isolated building using both the upper and the lower bound properties of the LRB achieved the rehabilitation objectives. The detail of the system property modification factors will be discussed later. Using the upper and lower bound LRB parameters described previously, the maximum design PIDR of the superstructure at BSE- 1 and BSE-2 are $0.5 \%$ and $0.65 \%$ respectively. Hence the rehabilitation objectives are achieved. 
The LRBs are designed afterwards as shown in Figure 5.6. The shear modulus of rubber changes as the ingredient varies, and manufacturers can meet the demand of customers (Constantinou, et al. 2007). The shear modulus for rubber is $0.4 \mathrm{MPa}$, within the common range (Constantinou, et al. 2007) and the shear yield stress of lead is 9.2 MPa.

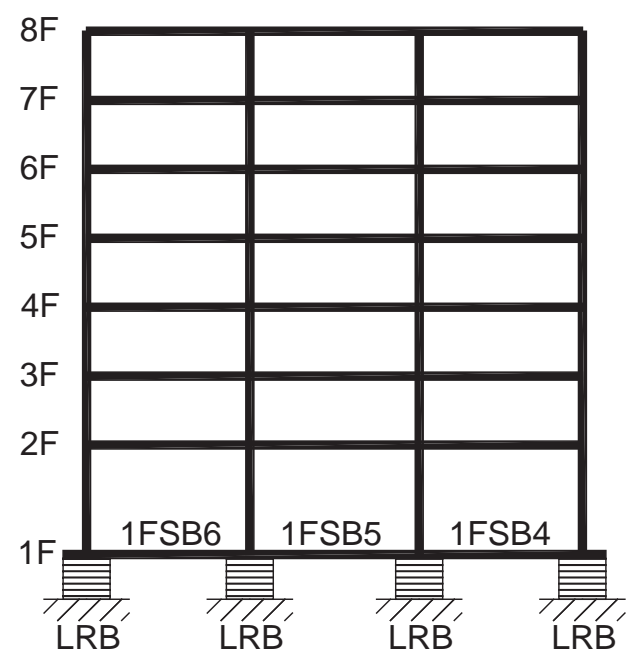

(a) Elevation

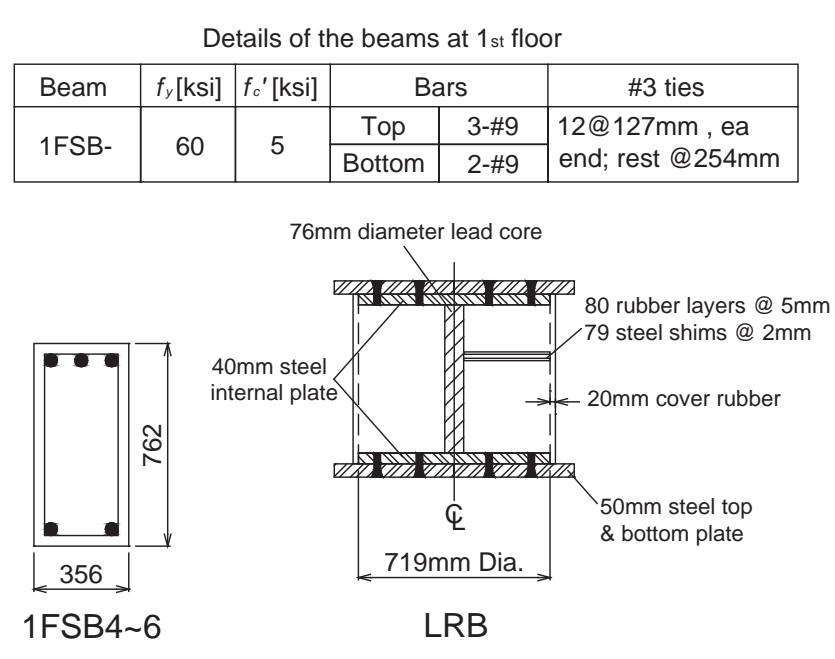

(b) Details of the base isolation system

Figure 5.6 The layout and details of the base isolated building

\subsection{Earthquake ground motions}

To incorporate the effect of aftershocks, MS-AS sequences need to be employed for the analysis. The mainshock is often followed by a series of aftershocks, particularly for larger earthquakes. Earthquake records containing multiple aftershocks of the same station and the same earthquake event are rare and the current methods to generate artificial aftershocks have been found to be inaccurate according to Ruiz-García and Negrete-Manriquez (2011). Accordingly, each of the MS-AS sequences used in this study contained one recorded mainshock and one recorded aftershock in a "back-to-back" way, with a 3-minute interval numerically placed between the mainshock analysis and the aftershock analysis to ensure the building returned to its static state before the aftershock.

The 32 as-recorded MS-AS sequences are acquired from the Center for Engineering Strong Motion Data (CESMD) (CESMD 2013) and the Pacific Earthquake Engineering NGA Database (PEER NGA) (PEER 2014). The aftershocks that are selected in this study mostly occurred within a week after the mainshock occurred, which means the building 
will not have been repaired before the aftershock occurs. All the sequences are far-field ground motions obtained from earthquakes that occurred in the Western United States (WUS) and are recorded at stations nearby. Those earthquakes include the 1979 Imperial Valley Earthquake, the 1980 Livermore Earthquake, the 1980 Mammoth Lakes Earthquake, the 1983 Coalinga Earthquake, the 1986 Chalfant Valley Earthquake, the 1987 Whittier Narrows Earthquake, the 1992 Petrolia Earthquake, and the 1994 Northridge Earthquake. The moment magnitudes of the mainshocks $\left(M_{\mathrm{m}}\right)$ range from M5.8 to 7.2, and the magnitudes of aftershocks $\left(M_{\mathrm{a}}\right)$ vary from M5.0 to 6.7. The average shear wave velocity in the upper 30 meters $\left(V_{\mathrm{S} 30}\right)$ of each station generally falls in between $183 \mathrm{~m} / \mathrm{s}$ and $367 \mathrm{~m} / \mathrm{s}$, which indicates their site conditions are equivalent to site class D (ASCE 2007). The details of these MS-AS sequences are presented in Table 2.1 in Chapter 2.

Two typical time histories of MS-AS sequences are shown in Fig 5.7 with the response spectra of the mainshocks and aftershocks also presented. Figure 5.7(a) shows the most common shape of MS-AS time history, for which the mainshock has larger amplitude. However, accelerograms such as the one shown in Figure 5.7(b) have also been observed, indicating the aftershocks may have larger amplitude than the mainshock. This may be caused by the uncertain differences between the mainshocks and the aftershocks in siteto-source distances, the rupture mechanisms, and other factors. Despite the unusual phenomenon, both the spectral envelopes and the median spectra suggest the mainshocks are stronger than the aftershocks, as presented in Figure 2.5(a) and (b) in Chapter 2.
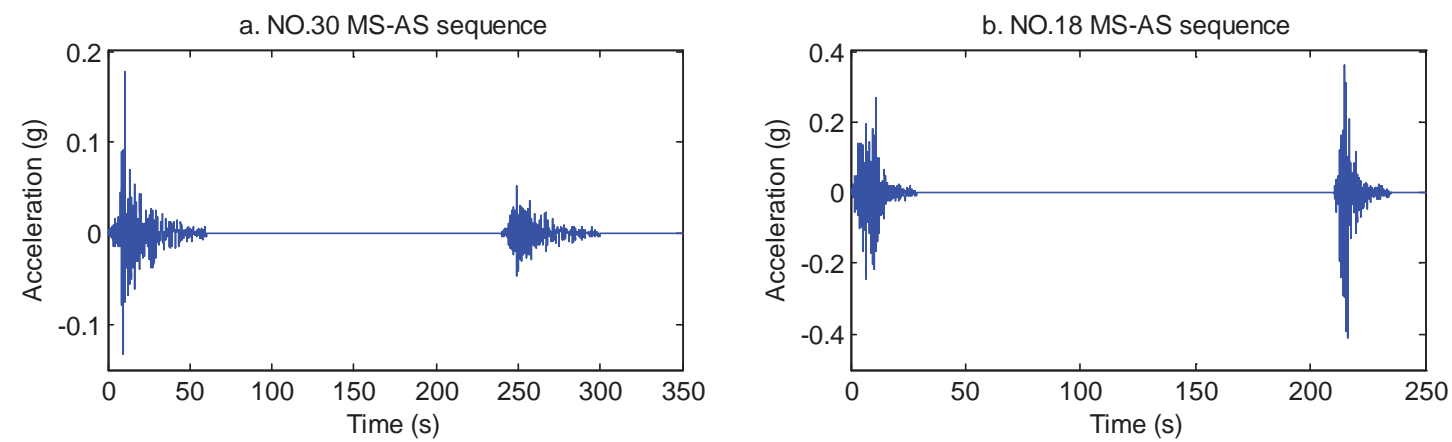

Figure 5.7 Acceleration time histories of some MS-AS sequences

\subsection{Seismic fragilities of building components}

\subsubsection{Basic function}


A seismic fragility describes the probability of structural or nonstructural elements reaching certain damage states given specific ground motion intensity. It is generally expressed as a lognormal cumulative distribution function, as shown in Eq. 2.6 in Chapter 2. The seismic intensity measure, SI, is the 5\% damped spectral acceleration at the building fundamental period, $S_{a}\left(\mathrm{~T}_{1}\right)$, in this study (for the isolated building, $\mathrm{T}_{1}$ is the effective period in this chapter). In Eq. 2.6, $\beta_{D \mid S I}$ and $\beta_{C}$ are the parameters describing uncertainties of seismic demand and structural capacity, respectively, whereas $\beta_{\mathrm{M}}$ is the parameter representing the modeling (epistemic) uncertainty.

The seismic demand $D$, which is calculated through NTHA with the suite of ground motions, is related to the seismic intensity SI via the widely used probabilistic model that is shown in Eq. 2.7. The dispersion of the regression, $\beta_{D \mid \mathrm{SI}}$, depicts the dependence of seismic demand on the seismic intensity, reflecting the record-to-record uncertainty.

\subsubsection{Structural capacities associated with building components and damage states}

The building systems include structural components ( $\mathrm{RC}$ frame and the isolation system) and nonstructural components which can be subcategorized as deformation sensitive nonstructural components (e.g. partitions and glass) and acceleration sensitive nonstructural components (e.g. mechanical equipments and contents). A previous study revealed that the nonstructural components account for more than $80 \%$ of the total cost of a building (Whittaker and Soong 2003), so the fragilities of both structural and nonstructural components are investigated. Three metrics are selected for deformation sensitive nonstructural components and RC frame, LRBs, and acceleration sensitive nonstructural components respectively, namely, the peak inter story drift ratio (PIDR), the peak shear strain (PSS) and the peak floor acceleration (PFA). Those metrics have been shown to be well correlated with key damage levels of the corresponding components (Celik and Ellingwood 2009; Krawinkler 2005; Zhang and Huo 2009). Four damage states were employed herein, namely, slight damage (SD), moderate damage (MD), extensive damage (ED) and collapse damage (CD). The structural capacities ( $C$ in Eq. 2.6) associated with the damage states facilitates the quantitative evaluation of seismic fragilities. 
The $C$ values of all the components at various damage states are shown in Table 5.2. For acceleration sensitive nonstructural components, uniform $C$ at a damage state is not feasible since the various acceleration sensitive nonstructural components behave quite differently. For an approximation, acceleration sensitive nonstructural components can be subcategorized into two types, namely mechanical, electronic and plumbing (MEP) systems and contents. PFA of MEP and contents at the four damage states are presented in Table 5.2 and are based on study of Elenas and Meskouris (2001).The nonstructural components are only considered for SD, MD and ED levels, since the damage of nonstructural components typically would not lead to the collapse of the entire building. The maximum shear strain that a LRB can accommodate varies based on the type of technology by the manufacturers, but the rubber should remain intact under maximum design deformation (Yang, et al. 2010). This was a shear strain of $110 \%$ according to the design described earlier in this paper. Consequently, the PSS of the LRBs at SD is assumed to be $120 \%$, slightly larger than the maximum design shear strain, and the PSS at $\mathrm{MD}$ is assumed to be $160 \%$. Although modern elastomeric bearings can withstand as much as $400 \%$ shear strain, previous tests showed that elastomeric rubber will have significant hardening at $200 \%$ shear strain, which will greatly change the material properties (Naeim and Kelly 1999). Thus, 200\% PSS is considered the ED level. Also, too high a shear strain can cause problems such as pounding and buckling, so the PSS at CD is set to $250 \%$, following the work of Zhang and Huo (2009). The PIDR of the frame at $\mathrm{SD}$, which was determined to be $0.5 \%$, is defined as the elastic limit of the analytical model with median parameters from nonlinear pushover analysis, and the PIDR at MD and ED are adopted from the widely used HAZUS-MH (FEMA 2009a). The deformation sensitive nonstructural components are assumed to have the same structural capacity as the RC frame, except they do not have the CD level.

The structural capacities of the RC frame at $\mathrm{CD}$ are calculated through IDA on the median-valued un-retrofitted building model using the $20 \%$ tangent slope criterion (FEMA 2000b), which defines the capacity point as the last IDA point with a tangent slope equal to $20 \%$ of the initial slope on the IDA curve. Both the entire MS-AS sequences and only the mainshocks are applied to determine the collapse structural capacities. The median PIDR at the $\mathrm{CD}$ (denoted as PIDR $\mathrm{CD}_{\mathrm{C}}$ hereafter) computed from the mainshocks and the MS-AS sequences are 5.99\% and 5.95\% respectively. The uncertainties of $\mathrm{PIDR}_{\mathrm{CD}}$ are 0.34 and 0.40 for mainshocks and MS-AS sequences respectively. All other $\beta_{C}$ are assumed to be 0.25 , and modeling uncertainty, $\beta_{\mathrm{M}}$ 
(epistemic uncertainty) is taken as 0.2 (Celik and Ellingwood 2010). The structural capacity at CD are also shown in Table 5.2.

Table 5.2 Structural capacity $C$ of each component at various damage states

\begin{tabular}{|c|c|c|c|c|c|}
\hline Damage state & & $\mathrm{DSNC}^{\mathrm{a} / \mathrm{RC}}$ frame & LRB & $\mathrm{MEP}^{\mathrm{b}}$ & Contents \\
\hline Slight damage (SD) & & $0.5 \%$ & $120 \%$ & $0.5 \mathrm{~g}$ & $0.2 \mathrm{~g}$ \\
\hline Moderate damage (MD) & & $0.8 \%$ & $160 \%$ & $1.2 \mathrm{~g}$ & $0.8 \mathrm{~g}$ \\
\hline Extensive damage (ED) & & $2.0 \%$ & $200 \%$ & $1.7 \mathrm{~g}$ & $1.25 \mathrm{~g}$ \\
\hline Collapse damage (CD) & $\begin{array}{l}\text { Mainshocks } \\
\text { MS-AS }\end{array}$ & $\begin{array}{l}5.99 \% \\
5.95 \%\end{array}$ & $250 \%$ & - & - \\
\hline
\end{tabular}

Note: ${ }^{\mathrm{a} D S N C}=$ deformation sensitive nonstructural components; ${ }^{\mathrm{b}} \mathrm{MEP}=$ mechanical, electronic and plumbing systems.

\subsubsection{Uncertain structural parameters and their modeling}

Important structural parameters must be treated as random variables so that the influence of structural uncertainties could be investigated. For the un-retrofitted building and the superstructure of the isolated buildings, these parameters included: concrete compressive strength, $f_{c}^{\prime}$, steel yield stress, $f_{y}$, viscous damping ratio, $\zeta$, and the beam-column joint model parameters $\left(\lambda_{1}, \lambda_{2}, \lambda_{\max }\right.$, and $\left.\lambda_{3}\right)$. For the isolation system, the uncertain parameters are initial post-yield stiffness, $K_{p i}$, initial characteristic strength, $Q_{d i}$, service time, $t_{\mathrm{s}}$, and temperature, $t_{\mathrm{emp}}$. Other structural parameters such as the gravitational loads are treated as constant due to their small coefficient of variation (COV) (Healey, et al. 1980; Ellingwood, et al. 1982).

The concrete compressive strength and steel yield stress are expressed using the normal and lognormal distribution, respectively (Celik and Ellingwood 2010; Healey, et al. 1980), with individual COV equal to 0.18 and 0.11 . The mean values for $f_{c}^{\prime}$ and $f_{y}$ are introduced earlier. A previous study showed the damping ratio $\zeta$ can be described using the lognormal distribution with a mean value of 0.043 and COV of 0.76 (Celik and Ellingwood 2010; Healey, et al. 1980). Since the information is insufficient to determine a suitable distribution, the beam-column joint model parameters are assumed to follow a uniform distribution which is the distribution with maximum uncertainty. The ranges of $\lambda_{1}$ and $\lambda_{2}$ are determined using the data provided in Park and Mosalam (2012), whereas the upper and lower bound of $\lambda_{\max }$ and $\lambda_{3}$ are assumed to be $\pm 5 \%$ and $\pm 10 \%$ of its nominal value respectively, due to insufficient available data and the fact that $\lambda_{\max }$ is larger than $\lambda_{2}$. 
The initial post-yield stiffness, $K_{p i}$, and initial characteristic strength, $Q_{d i}$, are defined herein as the post-yield stiffness and characteristic strength when just manufactured under normal temperature $\left(20^{\circ} \mathrm{C}\right) . K_{p i}$ and $Q_{d i}$ are close to the designed $K_{p}$ and $Q_{d}$, and the variation and distribution depends on different manufacturers. Therefore the $K_{p i}$ and $Q_{d i}$ are also assumed to be uniformly distributed within $\pm 5 \%$ of the design value, which is consistent with the range recommended by Constantinou, et al. (2011). The service time, $t_{\mathrm{s}}$, is used to account for the age hardening of the rubber due to continued vulcanization. The service time of the building after rehabilitation is assumed to be uniformly distributed between 0 and 50 years. The temperature, $t_{\mathrm{emp}}$, is utilized so that the bearing properties change caused by temperature can be incorporated. To investigate the influence of temperature on generic isolated buildings, the temperature range for the sensitivity study in this section is assumed to be $-15^{\circ} \mathrm{C} \sim 35^{\circ} \mathrm{C}$, with uniform distribution; whereas for the risk assessment of this specific building in Los Angeles, the range of the uniform distribution is set to be $0^{\circ} \mathrm{C} \sim 30^{\circ} \mathrm{C}<\mathrm{http} / / / \mathrm{www}$.weather.com>. The system property modification factor $\left(\lambda_{\mathrm{M}}\right)$ for $t_{\mathrm{s}}$ and $t_{\mathrm{emp}}$ are presented in Table 5.3 (Constantinou, et al. 2007).

Table 5.3 System property modification factor $\left(\lambda_{\mathrm{M}}\right)$ of aging and temperature

\begin{tabular}{lllllll}
\hline Parameter & Aging & \multicolumn{5}{c}{ Temperature } \\
& 0 Yr. & 50 Yr. $^{\mathrm{a}}$ & $20{ }^{\circ} \mathrm{C}$ & $0{ }^{\circ} \mathrm{C}$ & $-10^{\circ} \mathrm{C}$ & $-30^{\circ} \mathrm{C}$ \\
\hline post-yield stiffness, $K_{p}{ }^{\mathrm{b}}$ & 1.0 & 1.1 & 1.0 & 1.1 & 1.1 & 1.3 \\
characteristic strength, $Q_{d}{ }^{\mathrm{b}}$ & 1.0 & 1.1 & 1.0 & 1.2 & 1.4 & 1.8 \\
\hline Note: ${ }^{a}$ Estimated from data in Thompson, et al. $(2000) ;{ }^{\mathrm{b}} K_{p}=\lambda_{\mathrm{M}} \times K_{p i} ; Q_{d}=\lambda_{\mathrm{M}} \times Q_{d i .}$. & &
\end{tabular}

The uncertain parameters, along with their distributions and 10th, 50th, and 90th percentile values are listed in Table 5.4.

\subsubsection{Sensitivity of seismic demands (structural response) to structural uncertainties}

The suite of earthquake ground motion sequences is amplitude-scaled to the $S_{a}\left(\mathrm{~T}_{1}\right)$ at 3 different earthquake hazard levels for Los Angeles (50\%, 10\% and 2\% in 50 Yr.) so that the impact of the structural parameter uncertainties on the seismic demands under various ground motion intensities can be investigated. The $S_{a}\left(\mathrm{~T}_{1}\right)$ at each hazard level is obtained from the uniform hazard spectra constructed based on the USGS hazard map (USGS 2014), where $T_{1}$ is the fundamental period for the un-retrofitted building (1.67s) and median effective period of the isolated building (3.70s) obtained during the aforementioned design procedure. The two $\mathrm{T}_{1}$ are calculated when all the uncertain 
parameters are set to their median value. The $S_{a}\left(\mathrm{~T}_{1}\right)$ of the two buildings at the three hazard levels are presented in Table 5.5.

Table 5.4 Uncertain parameters and their distribution

\begin{tabular}{|c|c|c|c|c|c|c|}
\hline \multicolumn{2}{|c|}{ Parameters } & $\begin{array}{l}\text { Probability distribution } \\
\text { (N: normal; LN: } \\
\text { lognormal; U:uniform) }\end{array}$ & $\begin{array}{l}10^{\mathrm{th}} \\
\text { Percentil } \\
\mathrm{e}\end{array}$ & $\begin{array}{l}50^{\text {th }} \\
\text { Percentil } \\
\text { e }\end{array}$ & $\begin{array}{l}90^{\text {th }} \\
\text { Percentil } \\
\text { e }\end{array}$ & Source \\
\hline \multicolumn{7}{|c|}{ Un-retrofitted building\& superstructure } \\
\hline$f^{\prime}$ & $1^{\text {st }}$ Floor & $\mathrm{N}(\mu=43.1, \mathrm{COV}=18 \%)$ & 33.2 & 43.1 & 53.0 & \multirow{5}{*}{$\begin{array}{l}\text { Celik and } \\
\text { Ellingwood } \\
\text { 2010; Healey, } \\
\text { et al. } 1980\end{array}$} \\
\hline & $2^{\text {nd }}$ Floor & $\mathrm{N}(\mu=34.5, \mathrm{COV}=18 \%)$ & 26.5 & 34.5 & 42.5 & \\
\hline$(\mathrm{MPa})$ & Other Floors & $\mathrm{N}(\mu=25.9, \mathrm{COV}=18 \%)$ & 19.9 & 25.9 & 31.9 & \\
\hline \multirow[t]{2}{*}{$f_{y}(\mathrm{MPa})$} & $\begin{array}{l}\text { Columns \& } \\
\text { 1FSB- }\end{array}$ & $\mathrm{LN}(\mu=518, \mathrm{COV}=11 \%)$ & 447 & 515 & 593 & \\
\hline & $\begin{array}{l}\text { Other beams } \\
\text { and slabs }\end{array}$ & $\mathrm{LN}(\mu=345, \mathrm{COV}=11 \%)$ & 298 & 343 & 395 & \\
\hline$\zeta(\%)$ & & $\mathrm{LN}(\mu=4.26, \mathrm{COV}=76 \%)$ & 1.44 & 3.39 & 8.13 & \multirow{5}{*}{$\begin{array}{l}\text { Park ai } \\
\text { Mosalc } \\
2012\end{array}$} \\
\hline$\lambda_{1}$ & & $\mathrm{U}(0.54,0.78)$ & 0.56 & 0.66 & 0.76 & \\
\hline$\lambda_{2}$ & & $\mathrm{U}(0.80,0.95)$ & 0.82 & 0.88 & 0.94 & \\
\hline$\lambda_{\max }$ & & $\mathrm{U}(0.95,1.05)$ & 0.94 & 1.00 & 1.04 & \\
\hline$\lambda_{3}$ & & $\mathrm{U}(0.45,0.55)$ & 0.46 & 0.50 & 0.54 & \\
\hline \multicolumn{7}{|l|}{ LRB } \\
\hline $\begin{array}{l}K_{p i} \\
(\mathrm{kN} / \mathrm{m})\end{array}$ & & $\mathrm{U}(381,421)$ & 385 & 401 & 417 & \multirow[t]{2}{*}{$\begin{array}{l}\text { Constantinou, } \\
\text { et al. } 2011\end{array}$} \\
\hline$Q_{d i}(\mathrm{kN})$ & & $\mathrm{U}(38.8,42.8)$ & 39.2 & 40.8 & 42.4 & \\
\hline$t_{\mathrm{s}}(\mathrm{Yr})$. & & $\mathrm{U}(0,50)$ & 5 & 25 & 45 & $\begin{array}{l}\text { Thompson, et } \\
\text { al. } 2000\end{array}$ \\
\hline \multirow[t]{2}{*}{$t_{\mathrm{emp}}\left({ }^{\circ} \mathrm{C}\right)$} & $\begin{array}{l}\text { Generic } \\
\text { buildings }\end{array}$ & $\mathrm{U}(-15,35)$ & -10 & 10 & 30 & \multirow[t]{2}{*}{$\begin{array}{l}<\text { http://www. } \\
\text { weather.com> }\end{array}$} \\
\hline & $\begin{array}{l}\text { Buildings in } \\
\text { Los Angeles }\end{array}$ & $\mathrm{U}(0,30)$ & 3 & 15 & 27 & \\
\hline
\end{tabular}

Table 5.5 $S_{a}\left(\mathrm{~T}_{1}\right)$ of the two buildings at different hazard levels

\begin{tabular}{llll}
\hline Buildings & $50 \%$ in 50 Yr. & $10 \%$ in 50 Yr. & $2 \%$ in 50 Yr. \\
\hline The un-retrofitted building & $0.21 \mathrm{~g}$ & $0.34 \mathrm{~g}$ & $0.53 \mathrm{~g}$ \\
The isolated building & $0.09 \mathrm{~g}$ & $0.15 \mathrm{~g}$ & $0.24 \mathrm{~g}$ \\
\hline
\end{tabular}

The sensitivity of seismic demands to the structural uncertainty parameters is then investigated. All the parameters are set to their median values for the analytical models, and the seismic demands of each component are computed by NTHA using the ground motions scaled to each hazard level. The results of employing only mainshocks and the MS-AS sequences are also separated and compared. For each set of scaled ground motions, the results are fitted to a lognormal distribution, with the median ( $\mu$ PIDR, $\mu \mathrm{PFA}$ and $\left.\mu_{\mathrm{PSS}}\right)$ and logarithmic standard deviation $\left(\sigma_{\operatorname{Ln}(\mathrm{PIDR})}, \sigma_{\mathrm{Ln}(\mathrm{PFA})}\right.$ and $\left.\sigma_{\operatorname{Ln}(\mathrm{PSS})}\right)$ determined by maximum likelihood estimation. Then, the same procedure is repeated one parameter each time, setting the parameter equal to its $10^{\text {th }}$ or $90^{\text {th }}$ percentile and holding other 
parameters at their median values. For the analytical model of the un-retrofitted building, the NTHA failed to converge (implying the building has collapsed) for some ground motions scaled to higher hazard levels, in which cases, the likelihood function can be defined as follow.

$$
L\left(x_{1}, x_{2}, \ldots, x_{n} ; \mu, \sigma\right)=\prod_{i=1}^{m} f_{X}\left(x_{i} ; \mu, \sigma\right) \cdot \prod_{i=m+1}^{n}\left[1-F_{X}\left(x_{i} ; \mu, \sigma\right)\right]
$$

where the $f_{x}\left(x_{i} ; \mu, \sigma\right)$ and $F_{x}\left(x_{i} ; \mu, \sigma\right)$ are the probability density function (PDF) and cumulative distribution function (CDF) for the assumed lognormal distribution with parameter $\mu$ and $\sigma$, respectively. $x_{1}$ to $x_{n}(n=32)$ are the results from NTHA, among which the $x_{1}$ to $x_{m}$ are the converged results. For un-converged analyses, $x_{m+1}$ to $x_{n}$ of the PIDR

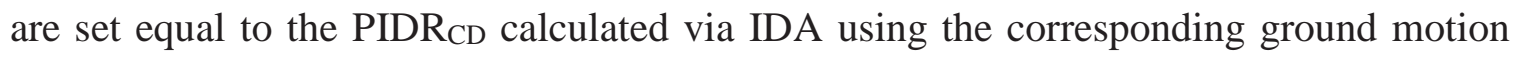
and the median-valued model, whereas $x_{m+1}$ to $x_{n}$ of the PFA are set to the PFA before the PIDR $_{C D}$ was reached during the NTHA. The variation in the median seismic demand and the logarithmic standard deviation of the demand are demonstrated in form of tornado diagrams, in which the differences between the extreme values suggest the sensitivity of seismic demand to the corresponding parameter. The tornado diagrams for the PIDR, PFA, and the PSS at various hazard levels are illustrated in Figure 5.8 5.10, respectively. 

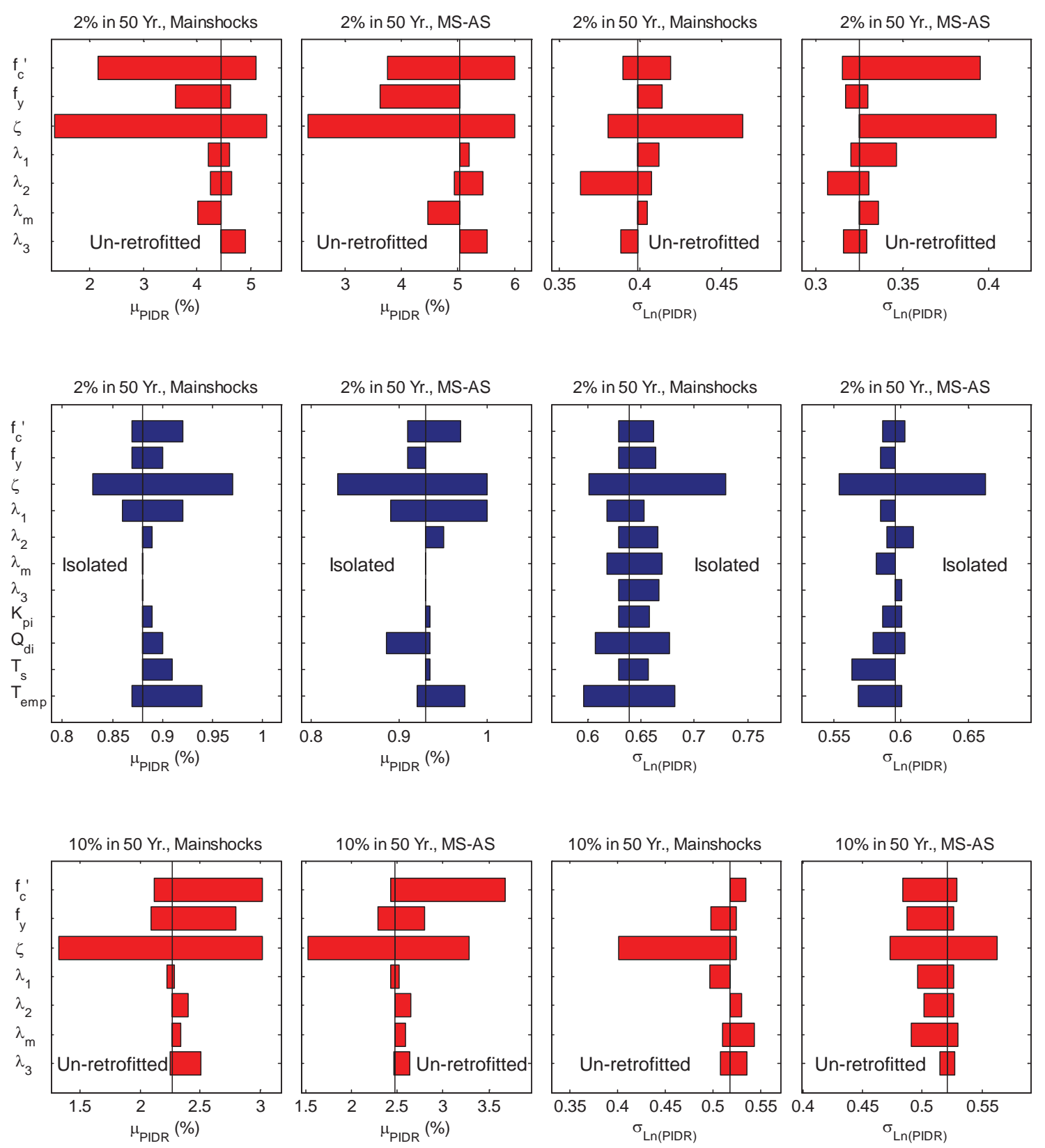

Figure 5.8 The parametric analysis for the peak inter story drift ratio (PIDR) of the two buildings 

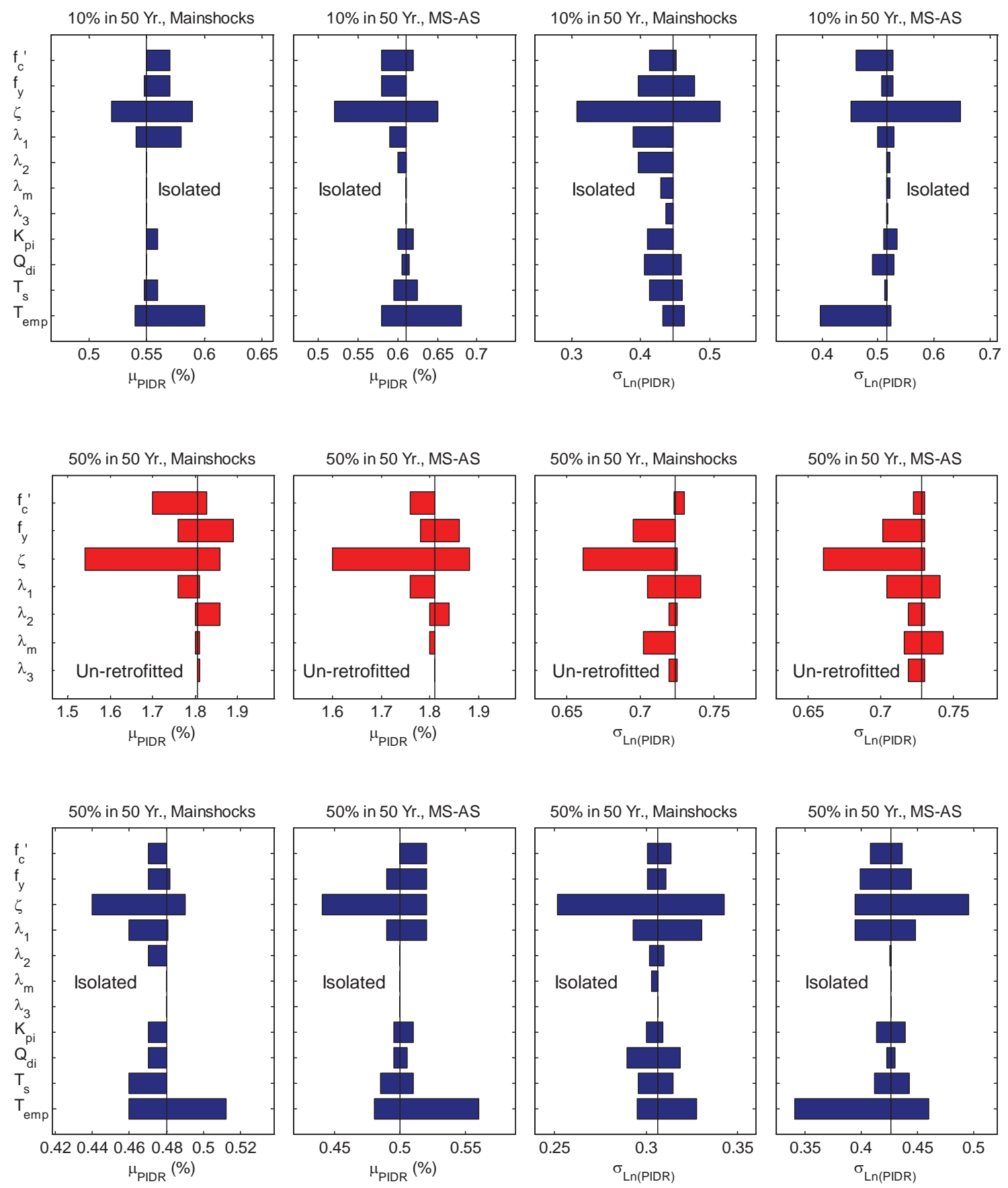

Figure 5.8 (continued)

It can be observed that, the viscous damping ratio, $\zeta$, the concrete compressive strength, $f_{c}^{\prime}$, and the steel yield stress, $f_{y}$, generally have the most significant effect on the PIDR of the un-retrofitted building. In comparison, Celik and Ellingwood (2010) found $\zeta, f_{c}^{\prime}$ and parameter for the joint cracking capacity have the greatest impact on PIDR of RC 
structures, but the $f_{y}$ was not important. This difference is because the beam-column joint model employed in the other study directly defined the joint capacity using the proposed parameter, whereas the joint capacity of the analytical model here is calculated with the Park and Mosalam joint model (2012), in which the joint capacity is greatly dependent on $f_{y}$. Therefore, both this study and the Celik and Ellingwood study found the most important factors for modeling RC frames are viscous damping, concrete strength, and beam-column joint capacity. Albeit the behavior of LRB has large uncertainty as previously discussed, the PIDR of the superstructure generally is dominated by $\zeta, f_{c}^{\prime}, f_{y}$ and $\lambda_{1}$, except that the temperature, $t_{\mathrm{emp}}$, and service time, $t_{\mathrm{s}}$, also have significant effect at low hazard levels.

The PIDRs of the isolated building are much smaller than that of the un-retrofitted building, indicating the isolation system effectively reduced the PIDR for superstructures. Comparison between the results obtained using only mainshocks and the MS-AS sequence clearly shows considering aftershock will increase the PIDR for the structures, especially when the mainshock has a high return period (e.g. $2 \%$ in 50 years) and significantly impaired the structural resistance. 

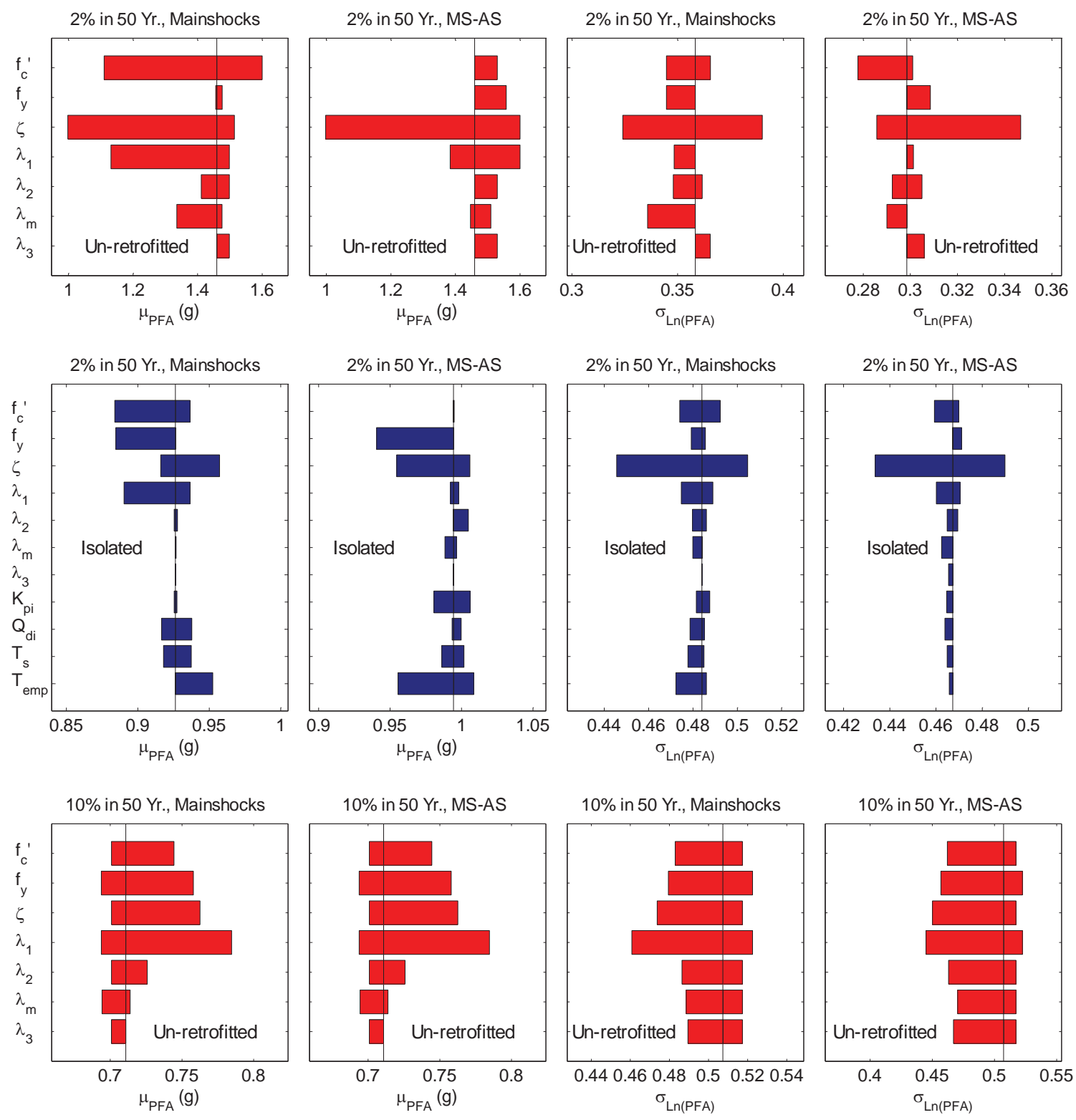

Figure 5.9 The parametric analysis for the peak floor acceleration (PFA) of the two buildings 

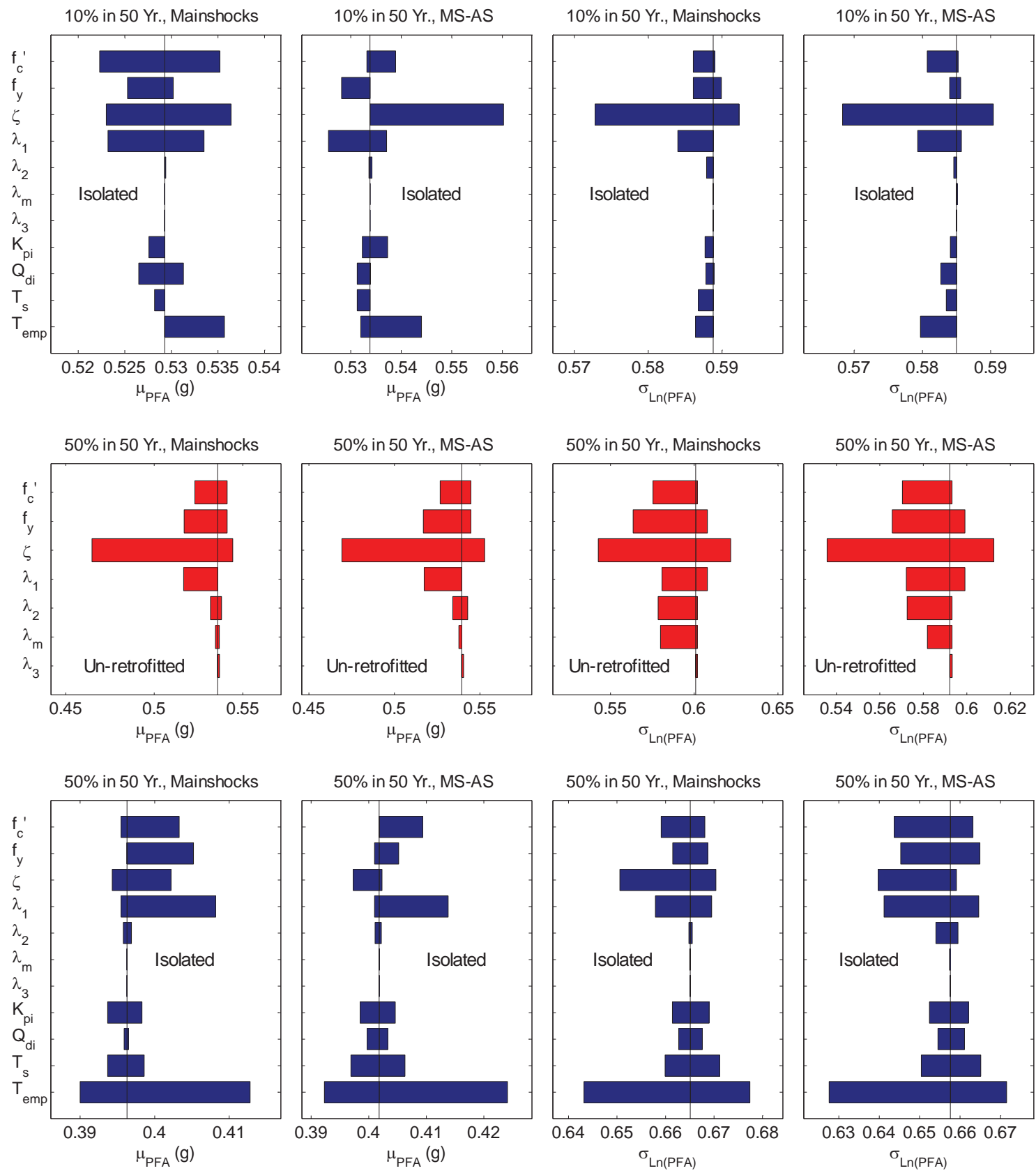

Figure 5.9 (continued)

The $\zeta, f_{c}^{\prime}, f_{y}$, and $\lambda_{1}$ have most significant influence on the PFA of the both buildings, and $t_{\mathrm{emp}}$ also have great impact on the PFA of the isolated building, especially at lower hazard levels. The PFAs of isolated building are all smaller than that of the un-retrofitted building when the hazard levels are identical, but the reduction in PFA is not as 
significant as the reduction in PIDR. It is also observed that considering MS-AS sequences leads to larger seismic demand than considering the mainshocks only.
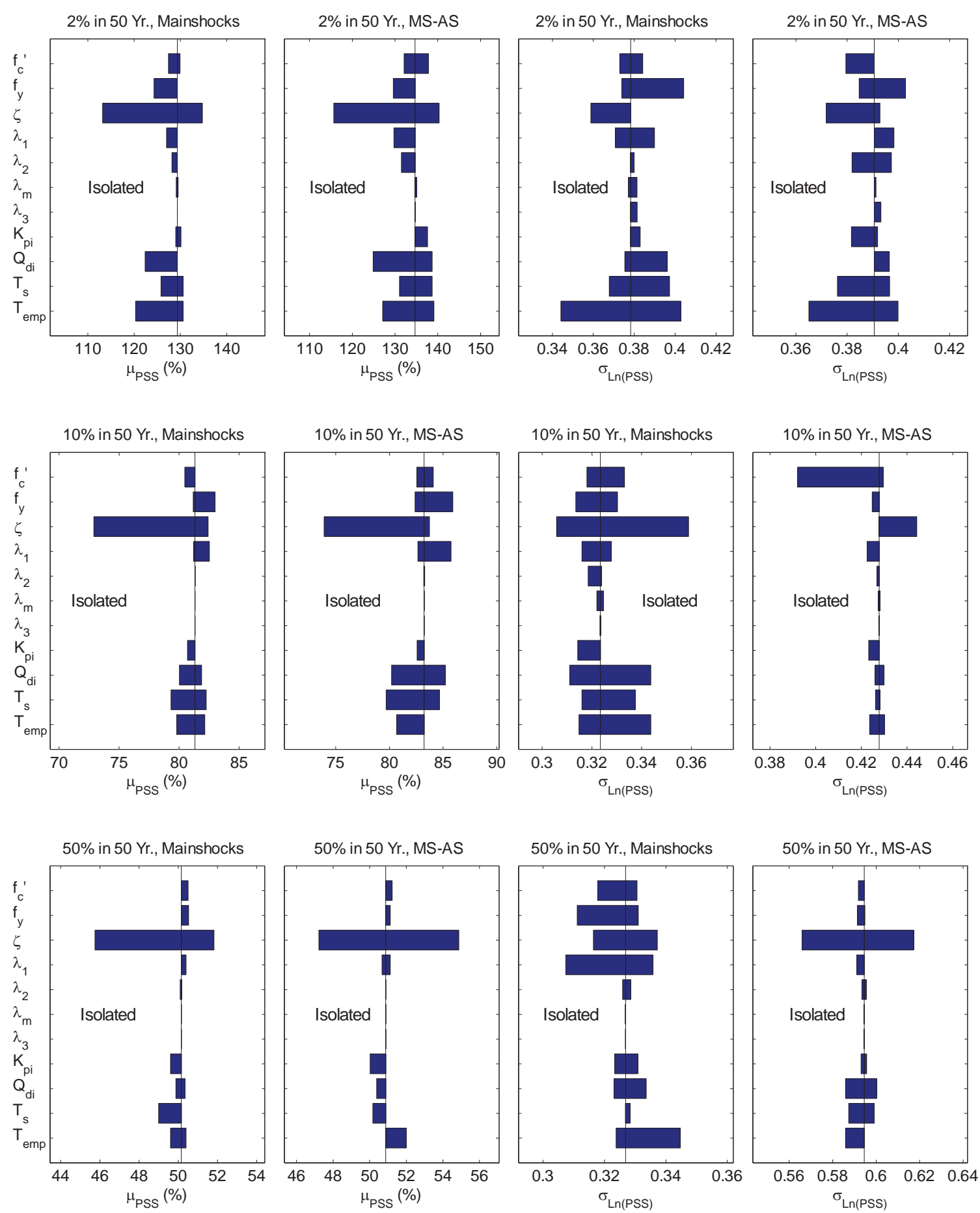

Figure 5.10 The parametric analysis for the peak shear strain (PSS) of the isolated building 
It is apparent that with regards to the deformation demand of the LRBs the dominating parameter is only $\zeta$. Therefore, considering the results of Figure 5.8 5.10, the $\zeta, f_{c}^{\prime}, f_{y}$, $\lambda_{1}$, and $t_{\mathrm{emp}}$ have the most significant effect on the various seismic demands of the isolated buildings with LRBs. Therefore, it is clear that the uncertainties in these parameters must be carefully treated during modeling and analysis. The effect of incorporating aftershocks can also be observed in Figure 5.10, but the differences are limited. By comparing the seismic demands for both buildings, it can be observed that the seismic demands of the isolated building are less variable, which can be caused by two reasons. First, the variation of the property of the isolation system is limited, although there are many factors that have impact on the properties of the isolation system. Second, the superstructure of the isolated building basic remains elastic during the analysis, while that of the un-retrofitted building is typically damaged, i.e. in the inelastic range, in which larger and more variable response are exhibited.

\subsubsection{Seismic fragility incorporating different source of uncertainties}

The sensitivity study above revealed the significant influence of structural parameter uncertainties on seismic demands. Thus, it is important to incorporate those uncertainties into fragility analyses. This aim can be achieved by constructing finite element models and applying Monte Carlo simulation (MCS) with the parameters distributed as listed in Table 5.4. To reduce the overwhelming workload required by a standard MCS, Latin Hypercube sampling (LHS) is adopted. The models of each building are randomly matched with the 32 ground motion sequences to perform NTHA. For each ground motion sequence, the corresponding un-retrofitted building model and the superstructure of isolated building model have the same structural parameter combinations from LHS, so that the results of the two models will be easier to compare. The results of NTHA are utilized for regression analyses with Eq. 2. The $\beta_{D \mid S I}$ for each component is calculated from the residuals of the regressions, and represents the record-to-record uncertainties of the ground motions. The ground motion uncertainties in spectral shapes is discussed earlier as well as the epistemic uncertainty, $\beta_{\mathrm{M}}$, and uncertainties in structural capacities, $\beta_{C}$. The seismic fragilities of the building components were then determined, as shown in Figure 5.11. The differences caused by the occurrence of aftershocks are also examined. 
As one would expect, the fragilities are generally higher (sometimes only slightly higher such as in part a of Figure 5.11) if aftershocks are also considered, which indicates the aftershocks will increase the probability that the components reach the damage states. However, this phenomenon cannot be observed for the structural components and DSNC when the building is isolated. This can be explained by considering that the frame is probably within the elastic range, and no significant cumulative damage occurred. Since the spectral accelerations are based on different fundamental periods, the fragilities of the components of the two buildings cannot be compared directly, although the component fragilities of the isolated building appear to be lower. But the annual probability of exceedance is lower for $S_{a}(\mathrm{~T}=3.70 \mathrm{~s})$ than for $S_{a}(\mathrm{~T}=1.67 \mathrm{~s})$ when the $S_{a}$ values are same. Therefore, the component fragilities of the superstructure for the isolated building are lower than those of the un-retrofitted building. Nevertheless, the LRBs of the isolated building demonstrate significantly higher fragility than the components of the superstructure, which means the overall fragility of the isolated building will not be that low. To directly compare the two buildings in a probabilistic manner, the annual and 50year probabilities of exceedance is examined. 
a. Frame \& DSNC of the un-retrofitted building

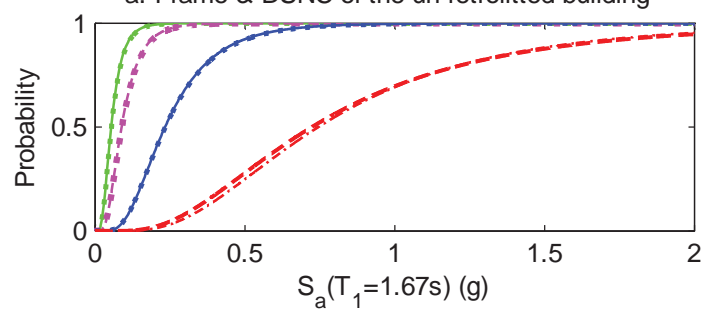

c. MEP of the un-retrofitted building
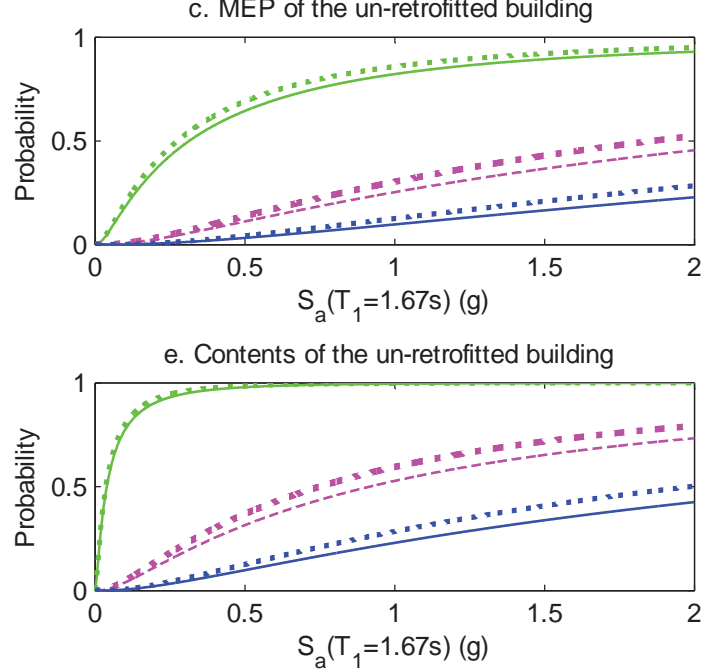

g. LRBs of the isolated building

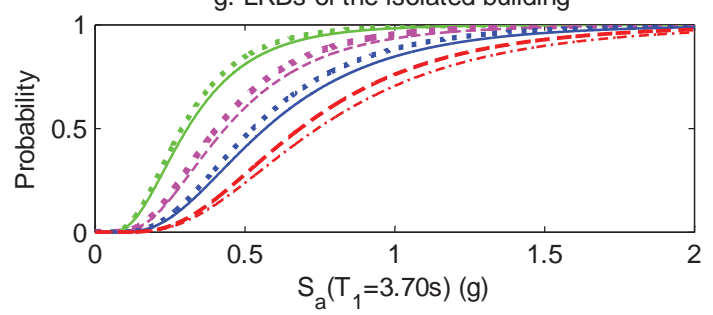

b. Frame \& DSNC of the isolated building

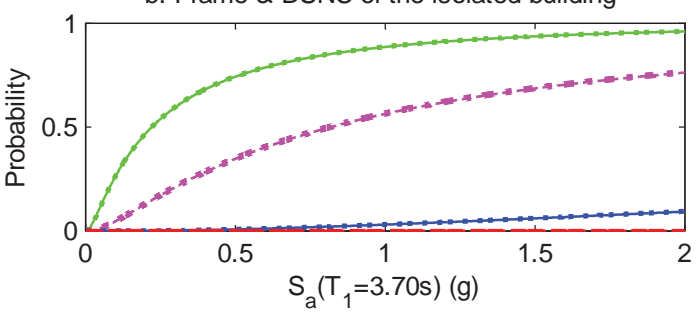

d. MEP of the isolated building
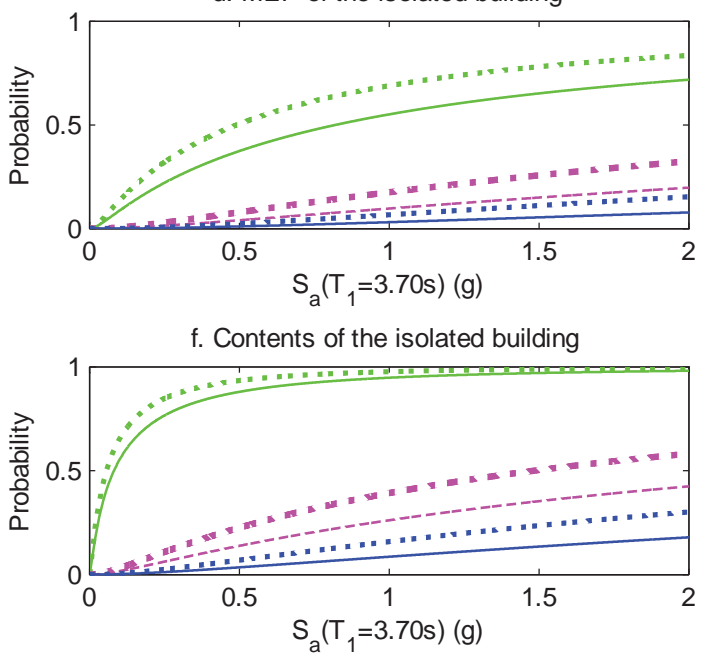

- Slight damage (SD), Mainshocks

" " " " " " Slight damage (SD), MS-AS

----- Moderate damage (MD), Mainshocks

". " Moderate damage (MD), MS-AS

_- Extensive damage (ED), Mainshocks

. . . . . Extensive damage (ED), MS-AS

-.-.-.- Collapse damage (CD), Mainshocks

- - - - Collapse damage (CD), MS-AS

Note: DSNC=deformation sensitive nonstructural components $\mathrm{MEP}=$ mechanical, electronic and plumbing systems.

Figure 5.11 The fragility curves of the building components under Mainshocks and MSAS sequences

\subsection{Seismic reliability}

Seismic risk, which is usually quantified annually or for a 50 year interval, convolves the seismic fragility with the seismic hazard curves. The seismic risk of a building exceeding prescribed damage states is expressed in the Eq. 2.8 to 2.11 in Chapter 2. Using the seismic fragility that is calculated previously, the annual probability that the seismic demand exceed the structural capacity, $\mathrm{P}(C<D)$, can be calculated with Eq. 2.8 to 2.11. After that, the equation below is used to calculate such probability of exceedance in 50 years (Ang and Tang 2007). 


$$
\mathrm{P}(C<D, 50 \text { Yr. })=1-[1-\mathrm{P}(C<D)]^{50}
$$

The $S_{a}\left(\mathrm{~T}_{1}\right)$ at different hazard levels for this specific building site from the USGS (USGS 2014) are listed in Table 5.5. For the un-retrofitted building $\left(\mathrm{T}_{1}=1.67 \mathrm{~s}\right)$, the constants in Eq. 2.9 are $k_{0}=3.425 \times 10^{-5}$ and $k=3.798$, and for the isolated building $\left(\mathrm{T}_{1}=3.70 \mathrm{~s}\right)$, $k_{0}=1.669 \times 10^{-6}$ and $k=3.798$. The annual and 50 year probability of the components for the two buildings exceeding the corresponding damage states (SD, MD, ED and CD) are calculated using the previous equations. Virtually all the components of the un-retrofitted building have annual and 50-year probabilities of exceedance of SD and MD close to 1.0, so they are not shown in figure format. The probabilities of exceedance of SD and MD for the components of the isolated building are somewhat lower, but for comparison purposes, only the results for ED and CD levels are presented in Figure 5.12. The results of the components at SD and MD levels are presented in Table 5.6.

Table 5.6 The annual and 50-year probabilities of exceedance (PE) oft SD and MD levels of the building components under Mainshocks and MS-AS sequences

\begin{tabular}{lllllllll}
\hline Parameters & \multicolumn{9}{c}{$\begin{array}{l}\text { Un-retrofitted Building } \\
\text { Frame\& }\end{array}$} & MEP & Contents & \multicolumn{2}{l}{$\begin{array}{l}\text { Isolated Building } \\
\text { Frame\& }\end{array}$} & LRBs & MEP & Contents \\
& & DSNC & & & DSNC & & & \\
\hline Annual PE & Mainshocks & 1.0 & 1.0 & 1.0 & 1.0 & $1.3 \times 10^{-3}$ & 1.0 & 1.0 \\
at SD & MS-AS & 1.0 & 1.0 & 1.0 & 1.0 & $1.5 \times 10^{-3}$ & 1.0 & 1.0 \\
50-year PE & Mainshocks & 1.0 & 1.0 & 1.0 & 1.0 & $6.4 \times 10^{-2}$ & 1.0 & 1.0 \\
at SD & MS-AS & 1.0 & 1.0 & 1.0 & 1.0 & $7.0 \times 10^{-2}$ & 1.0 & 1.0 \\
Annual PE & Mainshocks & 1.0 & 0.12 & 1.0 & 0.28 & $3.6 \times 10^{-4}$ & $2.4 \times 10^{-2}$ & 1.0 \\
at MD & MS-AS & 1.0 & 0.12 & 1.0 & 0.28 & $4.0 \times 10^{-4}$ & $3.3 \times 10^{-2}$ & 1.0 \\
50-year PE & Mainshocks & 1.0 & 0.99 & 1.0 & 1.0 & $1.8 \times 10^{-2}$ & 0.70 & 1.0 \\
at MD & MS-AS & 1.0 & 0.99 & 1.0 & 1.0 & $2.0 \times 10^{-2}$ & 0.81 & 1.0 \\
\hline
\end{tabular}



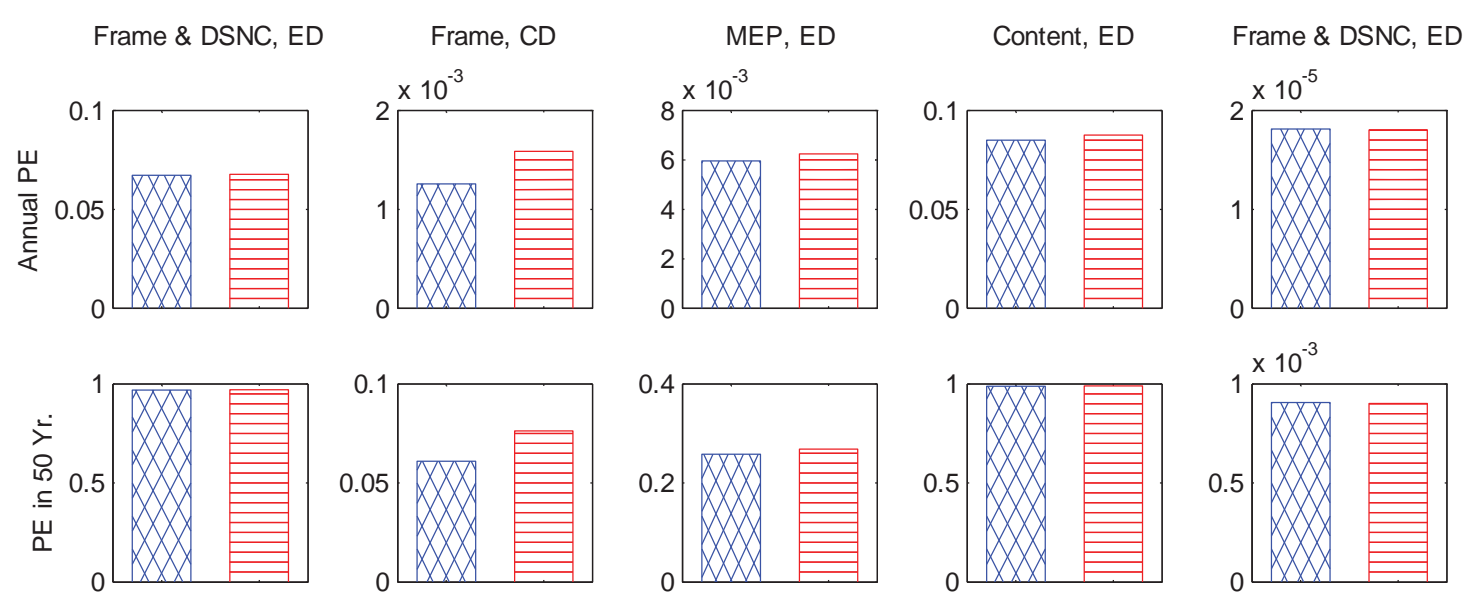

Un-retrofitted Building

Un-retrofitted Building

Un-retrofitted Building

Un-retrofitted Building

Isolated Building

\section{Mainshocks}
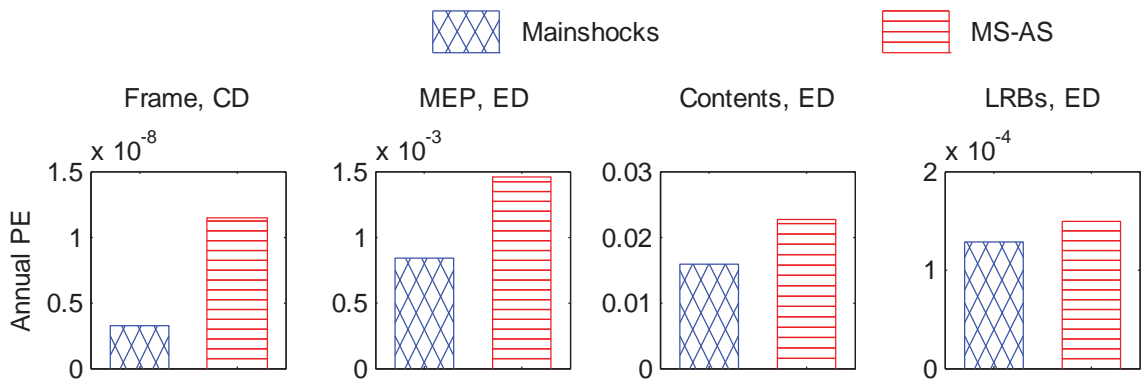

LRBs, CD
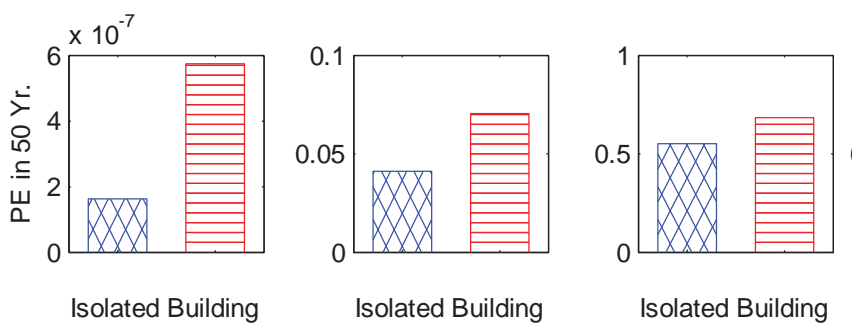

Note: $\mathrm{DSNC}=$ deformation sensitive nonstructural components; $\mathrm{MEP}=$ mechanical, electronic and plumbing systems.
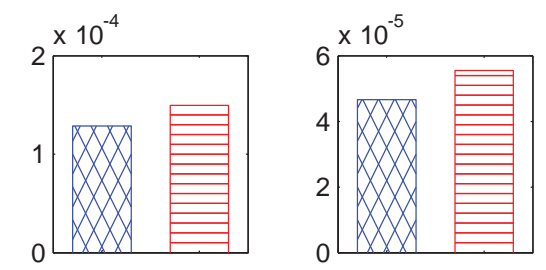

Figure 5.12 The annual and 50-year probabilities of exceedance (PE) at ED and CD levels of the building components under Mainshocks and MS-AS sequences

The components of the un-retrofitted building showed very high seismic variability. Notably, the high probabilities of exceedance at lower damage states, the annual and 50yearcollapse probability of the RC frame are as high as 0.0013 and 0.061 , respectively. However, this is on par with a recent report of PEER (Krawinkler 2005), where collapse probabilities of 0.0037 annually and 0.17 for 50-year are determined, respectively. Another investigation performed by Liel, et al. (2011) found the annual collapse probability of 12 non-ductile RC frame buildings ranged from 0.0016 to 0.0135 (Liel, et al. 2011). The high probabilities of exceedance indicates that the non-ductile RC frame 
buildings have much higher seismic vulnerability than code-conforming RC frames (Krawinkler 2005), as would be expected.

In contrast, the components of the isolated building show a much lower seismic vulnerability at $\mathrm{ED}$ and $\mathrm{CD}$ levels, especially for the structural components and deformation sensitive nonstructural components. The risk mitigation at SD and MD levels are not significant, which would likely be caused by the flexible superstructure, essentially reducing the effectiveness of the isolation (Zuniga-Cuevas and Teran-Gilmore 2013). It must be mentioned that, the probabilities of exceedance at the damage states for the superstructures and the LRBs cannot represent that of the entire isolated structural system, which means the annual and 50-year probabilities of exceedance of the isolated structural system must be determined to compare with those of the un-retrofitted building.

To obtain the systematic failure probability at each damage state, the following simplified procedures are applied. For the structural components (including the RC frame and the LRBs), the serial system is assumed to be able to capture its characteristics, which means the structural system will be considered to have reached a certain damage state once either the RC frame or the LRBs have reached their specific damage states. Although the exact probabilities of exceedance at the damage states for the structural system cannot be determined through any simplified method because of the complex statistical relationships between the components, the upper and lower bound probabilities of exceedance of such a system can be calculated by assuming the statistical relation between the RC frame and the LRBs are independent and fully dependent respectively (Choi, et al. 2004), and computed as:

$$
\max \left[\mathrm{P}\left(F_{1}\right), \ldots, \mathrm{P}\left(F_{n}\right)\right] \leq \mathrm{P}\left(F_{\text {system }}\right) \leq 1-\prod_{i=1}^{n}\left[1-\mathrm{P}\left(F_{i}\right)\right]
$$

where $\mathrm{P}\left(F_{\text {system }}\right)$ denotes the probabilities of exceedance at different damage states of the system, and $\mathrm{P}\left(F_{i}\right)$ means that of each component. The upper and lower bound annual and 50-year probabilities of exceedance at ED and CD levels for the structural system of the isolated building are then calculated and presented in Table 5.7. The upper and lower bound probabilities of exceedance for the structural system at SD and MD levels would be very close to those at the two damage states of the frame, which are much higher than 
the corresponding probabilities of exceedance of the LRBs and consequently dominate the system probability of failure.

Table 5.7 The upper and lower bound probabilities of exceedance (PE) at ED and CD levels for the structural system of the isolated building under Mainshocks and MS-AS

sequences

\begin{tabular}{llllll}
\hline Probability of & \multicolumn{2}{l}{ Structural system, ED } & \multicolumn{2}{l}{ Structural system, CD } \\
Exceedance & & Upper bound & Lower bound & Upper bound & Lower bound \\
\hline Annual PE & Mainshocks & $1.47 \times 10^{-4}$ & $1.29 \times 10^{-4}$ & $8.08 \times 10^{-5}$ & $8.08 \times 10^{-5}$ \\
& MS-AS & $1.68 \times 10^{-4}$ & $1.50 \times 10^{-4}$ & $1.16 \times 10^{-4}$ & $1.16 \times 10^{-4}$ \\
50 -year PE & Mainshocks & $7.32 \times 10^{-3}$ & $6.42 \times 10^{-3}$ & $4.03 \times 10^{-3}$ & $4.03 \times 10^{-3}$ \\
& MS-AS & $8.35 \times 10^{-3}$ & $7.46 \times 10^{-3}$ & $5.78 \times 10^{-3}$ & $5.78 \times 10^{-3}$ \\
\hline
\end{tabular}

The upper and lower bound probabilities of exceedance at ED and CD are both close to those of the LRBs at the same damage states, implying the system probability of failure is dominated by the LRBs at these damage states. The annual probabilities of exceedance of the structural system are approximately $1.5 \times 10^{-4}$ and $8 \times 10^{-5}$ for the ED and CD levels, respectively, whereas the 50-year probabilities of exceedance of the structural system are around 0.007 and 0.005 for the ED and CD levels, respectively. By comparing the seismic risk of the isolated and the un-retrofitted building, the effectiveness of the risk mitigation using base isolation is obvious at higher damage states. For the structural system and deformation sensitive nonstructural components, the seismic risk in 50 years has been reduced to $0.007 \sim 0.08$ times smaller; whereas the 50-year risk for acceleration sensitive nonstructural components has also been reduced to about $0.2 \sim 0.5$ times of the un-retrofitted building. For comparison, the modern code-conforming RC frame buildings have the annual collapse probability ranging from $1 \times 10^{-4}$ to $6 \times 10^{-4}$, according to the study by Liel, et al. (2011), which means the isolated building has the same (if not lower) collapse probability as a typical ductile RC frame building.

The underestimation of seismic risk when only mainshocks are considered is illustrated in Figure 5.12, Table 5.6 and Table 5.7. This phenomenon is more common for the isolated building. Although such underestimation in the seismic fragility (Figure 5.12) was found to be very small, it can reach as high as $25 \%$ and $43 \%$ for the 50 -year collapse risk of the un-retrofitted and isolated structural system, respectively. For the un-retrofitted building, the aftershock-considered seismic risk of acceleration sensitive nonstructural components is not significantly higher, but for the isolated building, such risk in 50 years is up to $75 \%$ higher than the risk calculated without incorporating the aftershocks. The seismic risks of some components at certain damage states are only slightly higher considering 
aftershocks, especially for the un-retrofitted building. The reason for this is that the fragility curves that consider aftershocks for these components are extremely close to their counterparts that consider only mainshocks.

\subsection{Conclusions}

Seismic risk analysis was performed for an old non-ductile RC frame building before and after hypothetical rehabilitation using base isolation with LRBs. The aleatoric and epistemic uncertainties were treated and incorporated in the entire process. A sensitivity study of the structural uncertainty showed that the viscous damping, concrete compressive strength, steel yield stress and the beam-column joint parameter that defining the elastic range of the joint have the most impact on the structural seismic demand for the un-retrofitted building; for the isolated buildings the temperature also have significant effects on the seismic demand.

Base isolation was found to be effective in reducing seismic risk for higher damage levels. For example, the 50-year probabilities of exceedance at ED and CD levels for structural systems are reduced significantly, even smaller than the modern ductile RC frame buildings. The risk mitigation is not significant for lower damage levels due to the extremely low vulnerability of the superstructure (the un-retrofitted frame).

A suite of recorded MS-AS sequences was used to investigate the influence if aftershocks are also incorporated in the analysis. Results reveal that the aftershocks increase the seismic demands and risk for the buildings. The underestimations in the seismic risk sometimes can be considerable if aftershocks are not considered. Such underestimations are more common for the components of the isolated building. 


\section{Seismic Performance Assessment and Cost-Benefit Analysis of Non-Ductile Reinforced Concrete Buildings Retrofitted with Base Isolation: Considering Mainshock-Aftershock Hazards}

\subsection{Introduction}

Older Reinforced Concrete (RC) frame buildings that were constructed prior to modern building codes tend to exhibit non-ductile behavior under seismic excitation, making them likely to result in casualties and significant economic loss during earthquake events (including mainshocks and aftershocks). This family of buildings includes typical RC moment frame buildings built before the mid-1970s in the Western United State (WUS) and those built before the late 1990s in Central and Eastern United States (CEUS) (Liel and Deierlein 2008; Celik and Ellingwood 2009). They also have higher expected repair cost for the damage induced by potential earthquakes than their counterparts built per modern codes (Liel and Deierlein 2008). Besides, it has been found that earthquakes aftershocks may cause more damage, higher seismic risks, and addition loss to these buildings (Han, et al. 2014a,b; Han, et al. 2015). Therefore, approaches to mitigate their seismic risk must be determined and applied. For example, the recently released 5-year mandatory retrofit plan in the city of Los Angeles included these non-ductile RC buildings (Totten 2014).

One technology that has been used to improve the seismic performance of a building is seismic base isolation, generally by adding an isolation layer which contains a number of isolators between the superstructure and the foundation. By designing proper lateral stiffness of the isolation layer, the fundamental period of the building can be elongated, shifting it to smaller spectral acceleration. This technique has been used in many countries, but is still not used in the United States except in very special cases. The primary reason is that many stakeholders hold the impression that the application of base isolation is expensive, and therefore base isolation was mainly utilized for the retrofit of some important historic buildings or infrastructures (e.g. De Luca, et al. 2001; Huang, et al. 2010; Mokha, et al. 1996). Some research has focused on improving the economical efficiency of base isolated buildings by reducing the costs for superstructures (Erduran, et al. 2011) or utilizing the crystallization property of the rubber bearings (Yang, et al. 
2010). However, a better way to evaluate the economy of utilizing base isolation as a retrofit method might be performing cost-benefit analysis under the framework of performance based earthquake engineering (PBEE).

The PBEE framework provides a mechanism for assessing a building's seismic performance by accounting for direct losses, downtime (non-operational time), and fatalities with explicit consideration of various uncertainty sources. The differences between the estimated direct loss, downtime, and fatalities of an un-retrofitted building and those of the building after retrofit indicate the benefit from the retrofit strategy. The benefit (avoided loss) can be compared with the cost due to implementing the retrofit strategy to determine whether the strategy is cost effective, which is also termed costbenefit analysis. State-of-the-art cost-benefit analysis for seismic building damage was developed in FEMA P-58 (FEMA 2012a), which consists of analysis of seismic hazard, structural response, damage, and loss. It also incorporates the impacts from collapse and repairability of buildings. Smyth, et al. (2004) examined the cost and benefit of retrofitting RC frame buildings in Turkey using additional braces or additional shear walls, and concluded that the benefit can outweigh the repair cost within the lifecycle even when only the direct loss was considered. Liel and Deierlein (2013) evaluated cost benefit of several common retrofit approaches for older RC frame buildings such as concrete jacket and carbon fiber warp. Their results showed that the cost-effectiveness can be achieved for these methods, and the cost-effectiveness became more significant when fatalities were also considered. Some effort has been make to investigate the costeffectiveness of using base isolation. Sayani (2009) utilized PBEE to compare the initial costs and the seismic repair costs of a fixed-based special moment resisting frame building and those of an isolated moment resisting frame building, and concluded that the isolated building is more cost effective when a life cycle longer than 250 years was considered. Only direct loss was considered in this study. Ryan, et al. (2010) performed life cycle analysis for two steel frame buildings with and without base isolation. Their result suggested that the benefit of base isolation would be more significant for buildings with stronger and stiffer superstructures. But they did not compare the cost with the benefit, thus whether the benefit can overweigh the cost was not discussed. Also, they only considered direct loss in the analysis. Goda, et al. (2010) combined simplified twodegree-of-freedom structural models with life cycle cost models to investigate the life cycle cost-benefit perspectives of base isolated buildings. They showed that the costeffectiveness of the base isolation can theoretically be achieved. However, the analysis procedure relied on highly simplified models, and the loss due to downtime and fatalities 
was not incorporated either. These studies revealed that base isolation can reduce the seismic direct loss effectively, but the base isolation is still not economically appealing because other than the result from simplified model, more detailed analysis shows a break-even time as long as 250 years. However, that body of research did not consider the indirect loss from downtime and fatalities, which could lead to underestimation in the benefit quantification of adopting base isolation. Moreover, none of these previous studies considered aftershock hazard which has been shown to be significant.

It should to be stressed that for most current loss estimation procedures, a basic assumption is that the buildings will be repaired to an undamaged state immediately after each earthquake, which means that aftershocks cannot be incorporated within the methodology. However, it has been recognized that the aftershocks following shortly after the mainshock may also have a relatively large magnitude, such as the 1999 Chi-chi earthquake (Kao and Chen 2010) and the 2011 Tohoku earthquake (Asano, et al. 2011), shorter site-to-source distance, and different energy content, which can give the aftershocks the potential to substantially damage buildings prior to any repair efforts. Some scholars have made an effort to incorporate aftershocks into PBEE (e.g. Yeo and Cornell 2005; Luco, et al, 2011; Yin and Li 2011; Li, et al. 2014; Raghunandan, et al. 2014). For example, Yeo and Cornell $(2005,2009 b)$ proposed a loss estimation model for life-cycle cost of buildings subjected to mainshocks and the subsequent aftershocks. They also introduced a general Markov and semi-Markov framework to simulate the mainshock occurrence with different building damage levels. Luco, et al. (2011) proposed a methodology which utilizes a risk integral for collapse risk assessment of mainshock damaged buildings. Aftershocks, damage of the structures caused by mainshock, and uncertainties in the extent of this damage were all incorporated. Yin and Li (2011) developed an object-oriented framework to estimate seismic loss of light-frame wood buildings subjected to mainshock-aftershock (MS-AS) sequences, and applied the framework on the loss assessment of a typical wood residential building. They found that the aftershocks contribute significantly to the total seismic loss estimation. Raghunandan, et al. (2014) investigated the aftershock vulnerability of four ductile RC frames by performing nonlinear dynamic analysis. They found that that collapse capacity of structures will not be reduced significantly in aftershocks unless the building has sustained extensive damage in the mainshock. They also examined different physical damage indicators to regarding the effectiveness for predicting reduction in collapse capacity of buildings in the aftershocks, and concluded that indicators related to drift is the best for quantifying red tagging criterion used in post-quake evaluation. Based on the 
current Pacific Earthquake Engineering Research (PEER) Center's PBEE methodology, Chapter 3 of this study developed a methodology to estimate the seismic direct loss, downtime, and fatalities with consideration of aftershock hazard and post-quake decisions.

This chapter presents the method and results of a study that aimed to quantify the costbenefit of base isolation as a retrofit strategy for non-ductile RC frame buildings with consideration of aftershock hazard and indirect loss. A low-rise and a mid-rise nonductile RC frame building are hypothetically retrofitted with base isolation. Then the direct loss, downtime, fatalities, and the total loss of the un-retrofitted and base isolated buildings are evaluated, assuming the scenarios that they are located at regions of lower and higher seismicity. Both the results with and without consideration of aftershock hazard are examined for comparison purposes. The estimated seismic performance metrics at different earthquake intensity levels are used in the cost-benefit analysis.

\subsection{Building models}

\subsubsection{The un-retrofitted buildings}

The low-rise and mid-rise non-ductile RC frame buildings in Chapter 2, 3, and 4 are still used in this chapter as the un-retrofitted building. To examine the difference between buildings in lower and higher seismic regions, the buildings are assumed to be located in St. Louis, MO (38.63 $\left.{ }^{\circ} \mathrm{N}, 90.20^{\circ} \mathrm{W}\right)$ and Los Angeles, CA (34.22 $\left.{ }^{\circ} \mathrm{N}, 118.47{ }^{\circ} \mathrm{W}\right)$, respectively. The site classifications of the two locations are both assumed to be site class D. Details about the prototype buildings, finite-element models, and the building performance models are presented in Chapter 2 or Chapter 3, and hence are not repeated herein.

\subsubsection{The isolated buildings}

The two buildings are numerically retrofitted with base isolation using similar design procedure as shown in Chapter 3. The design procedure is in accordance with the nonlinear dynamic procedure in ASCE 41-06 (ASCE 2007), with the rehabilitation objectives assigned as follows: (1) at BSE-1earthquake hazard level (10\%/50 years or 2/3 of the BSE-2 design spectra, whichever is smaller), the superstructure shall not exceed the Immediate Occupancy (IO) performance level; and (2) at the BSE-2 earthquake 
hazard level (2\%/50 years, also known as maximum considered earthquake), the superstructure shall not reach the Life Safety (LS) performance level. These two objectives are set equal to the peak inter story drift ratio (PIDR) limits of $1 \%$ and $2 \%$ at BSE-1 and BSE-2 earthquake level, respectively. Such objectives comply with the enhanced rehabilitation objectives defined by ASCE 41-06 (ASCE 2007). The design response spectra of BSE-1 and BSE-2 earthquake levels are constructed for St. Louis and Los Angeles, respectively. Following the requirements of ASCE 41-06 (ASCE 2007), four pairs of earthquake ground motion records from the PEER NGA database (PEER 2014) are matched with each design response spectra in the period range from $0.6 \mathrm{sec}$ to $5 \mathrm{sec}$, which is estimated to be the possible range of the isolated buildings' fundamental periods, utilizing the spectral match method developed by Hancock, et al. (2006). The ground motion records are listed in Table 3.1.

A beam-slab diaphragm system is added at the bottom of each un-retrofitted building, below which the isolators were placed. The slab is $150 \mathrm{~mm}$ in thickness, whereas the sections and the reinforcements of the beams are presented in Table 6.1. The isolators utilized in the retrofit are modeled as the lead rubber bearings (LRB), which are common in engineering practice (Thompson, et al. 2000; Constantinou, et al. 2007). The forcedisplacement relationship of LRB can be modeled using a bilinear model shown in Figure 3.4. As introduced in Chapter 3, the post-yield stiffness, $K_{\mathrm{p}}$ and the characteristic strength, $Q_{\mathrm{d}}$ are the key parameters for design (Thompson, et al. 2000; Constantinou, et al. 2007). In the two-dimensional finite element models, the LRBs are simulated using the zerolengthSection element with the Isolator2spring section, which is developed by Ryan, et al. (2005). Such a section is capable of simulating the buckling failure mode of LRBs under lateral deformation combined with vertical load. In addition, it can also incorporate the influence of vertical load on the variation of bearing properties, which means the re-distribution of vertical load during earthquakes can be considered (Ryan, et al. 2005). Nonlinear time history analysis is performed on the finite element models of the isolated buildings using the ground motions matched with the design spectra. The $K_{\mathrm{p}}$ and $Q_{\mathrm{d}}$ are determined via trial and error method until the average PIDR of each building under each ground motion set achieved the corresponding rehabilitation objectives. Since the $K_{\mathrm{p}}$ and $Q_{\mathrm{d}}$ of a LRB may vary when surrounding conditions changes, the upper bounds of the two parameters are calculated and the average PIDRs under such scenario are also checked to make sure the rehabilitation objectives are achieved, as required in ASCE 41-06 (2007). Figure 6.1 presents the PIDR of the designed three-story isolated building in Los Angeles under the eight ground motions at BSE-1 level and BSE-2 level, 
respectively. Since eight ground motions are used, the average of the responses obtained from the ground motions were utilized (ASCE 2007). The average PIDR under each group of the design ground motions are presented for all the buildings in Table 6.2. It can be seen that the rehabilitation objectives are met, and the buildings at Los Angeles and St. Louis are retrofitted to similar performance levels. More details about the ground motion matching and the design procedure are available in Chapter 3. The $K_{\mathrm{p}}$ and $Q_{\mathrm{d}}$ of each isolated building are listed in Table 6.1. Once the $K_{\mathrm{p}}$ and $Q_{\mathrm{d}}$ were determined, the details of the LRBs can be designed. The dimensions of the LRBs are shown in Table 6.1.

Table 6.1 Details about the LRBs and added beams

\begin{tabular}{|c|c|c|c|c|c|c|c|c|c|c|}
\hline \multirow[t]{2}{*}{ Location } & \multirow[t]{2}{*}{ Building } & \multirow[t]{2}{*}{$\begin{array}{l}K_{\mathrm{p}} \\
(\mathrm{kN} / \mathrm{m})\end{array}$} & \multirow[t]{2}{*}{$\begin{array}{l}Q_{\mathrm{d}} \\
(\mathrm{kN})\end{array}$} & \multicolumn{2}{|c|}{$\begin{array}{l}\text { Diameter } \\
(\mathrm{mm})\end{array}$} & \multirow{2}{*}{$\begin{array}{l}\text { Rubber } \\
\text { thickness } \\
(\mathrm{mm})\end{array}$} & \multirow{2}{*}{$\begin{array}{l}\text { Beam } \\
\text { height }^{1} \\
(\mathrm{~mm})\end{array}$} & \multicolumn{2}{|c|}{ Reinforcements } & \multirow[t]{2}{*}{ Ties } \\
\hline & & & & Outer & Inner & & & Top & Bottom & \\
\hline \multirow[t]{2}{*}{$\begin{array}{l}\text { St. } \\
\text { Louis }\end{array}$} & $\begin{array}{l}\text { Three- } \\
\text { story }\end{array}$ & 120.6 & 35.3 & 580 & 75 & 650 & 700 & $3-\# 8$ & $2-\# 9$ & \#3@127mm \\
\hline & $\begin{array}{l}\text { Six- } \\
\text { story }\end{array}$ & 153.7 & 40.2 & 690 & 80 & 720 & 1000 & $3-\# 8$ & $2-\# 9$ & \#3@127mm \\
\hline \multirow[t]{2}{*}{$\begin{array}{l}\text { Los } \\
\text { Angeles }\end{array}$} & $\begin{array}{l}\text { Three- } \\
\text { story }\end{array}$ & 92.3 & 21.13 & 580 & 58 & 850 & 700 & $3-\# 9$ & $2-\# 9$ & \#3@127mm \\
\hline & $\begin{array}{l}\text { Six- } \\
\text { story }\end{array}$ & 103.1 & 19.0 & 690 & 55 & 1080 & 1000 & $3-\# 9$ & $2-\# 9$ & \#3@127mm \\
\hline
\end{tabular}

Note: ${ }^{1}$. Widths of the beams are all $400 \mathrm{~mm}$.

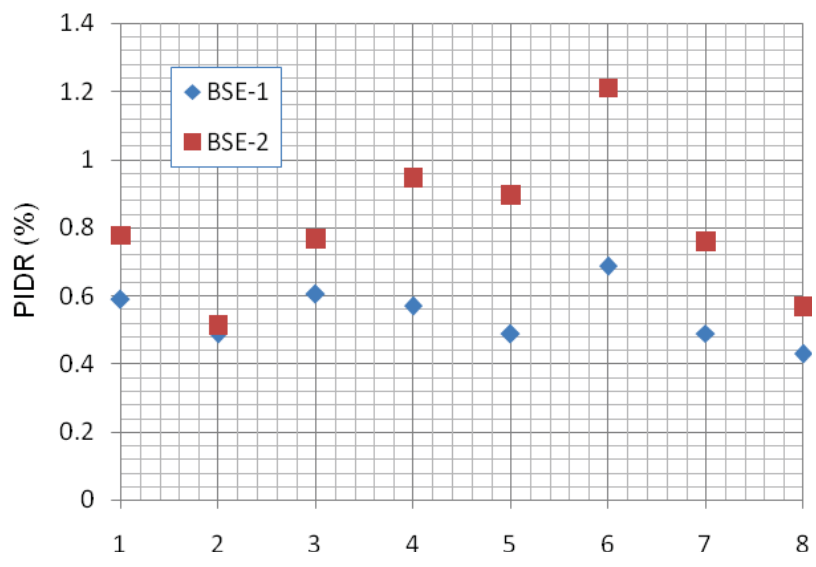

Figure 6.1 The PIDR of the three-story isolated building at Los Angeles under design ground motions

Table 6.2 The average PIDR of each building under the design ground motions

\begin{tabular}{lllll}
\hline Building & BSE-1 & & BSE-2 & \\
& Los Angeles & St. Louis & Los Angeles & St. Louis \\
\hline Three-story & 0.54 & 0.47 & 0.81 & 0.82 \\
Six-story & 0.47 & 0.48 & 0.88 & 0.81 \\
\hline
\end{tabular}


The total retrofit cost of a building includes: (1) adding the beam-slab system at the floor of the $1^{\text {st }}$ story; (2) cost related to installing isolation devices, such as the expenditure due to excavation, cutting columns, the isolators themselves, and constructing moats and isolation pedestals; (3) costs related to modification of nonstructural components, such as the expenditure caused by adding suspended elevator shafts and change the rigid pipelines for electronic and plumbing systems across the isolation layer to flexible pipelines. The cost of implementing base isolation is estimated based on available data (Sayani 2009; Cardone and Gesualdi 2013) with more details shown in Table 6.3. The total costs of retrofit for the three-story and six-story building are approximately US $\$ 197,300$ and US\$224,800 respectively, which is equal to $13.1 \%$ and $6.4 \%$ of the replacement cost of the un-retrofitted three-story and six-story building, respectively. These percentages are similar to the results of several previous case studies, which varied from 5\% to 12\% (Sayani 2009; Cardone and Gesualdi 2013). The difference between the retrofit cost of buildings located in St. Louis and Los Angeles are neglected since their isolation layers are quite similar. These retrofit costs only provide a reasonable estimation of the implementation of base isolation. It should be noted that the uncertainty in the retrofit costs may be substantial (Liel and Deierlein 2013; Sayani 2009), and the impact of this uncertainty needs further investigation. It has been shown that retrofitting a building with base isolation does not cause building occupant disruption because the construction only takes place at the basement level and therefore has a negligible impact on superstructure occupants (Cardone and Gesualdi 2013). This suggests that retrofitting with base isolation or repairing the isolators will not introduce any downtime or relevant downtime loss.

Table 6.3 Cost of retrofit with base isolation

\begin{tabular}{lllll}
\hline Building & $\begin{array}{l}\text { Cost due to adding } \\
\text { beam-slab system }\end{array}$ & $\begin{array}{l}\text { Cost related to installing } \\
\text { isolators }\end{array}$ & $\begin{array}{l}\text { Cost of modifying } \\
\text { nonstructural } \\
\text { components }\end{array}$ & $\begin{array}{l}\text { Total } \\
\text { cost }\end{array}$ \\
\hline Three-story & $\$ 24,900$ & $\$ 138,900$ & $\$ 33,600$ & $\$$ \\
Six-story & $\$ 35,500$ & $\$ 138,900$ & $\$ 50,400$ & $\begin{array}{l}\$ \\
224,400\end{array}$ \\
\hline
\end{tabular}

For the purpose of performance assessment, four damage states (DS1 DS4) of the LRBs are defined, with the median peak shear strain (PSS) equal to $100 \%, 150 \%, 200 \%$, and $250 \%$ respectively and the logarithmic standard deviation (structural uncertainty) all taken as 0.25 based on Zhang and Huo's study (Zhang and Huo 2009) on previous experimental tests. LRBs at DS1 and DS2 only required restoration to their original position which did not result in extra repair costs or downtime. LRBs at DS3 should be 
replaced with associated estimated repair cost of $\$ 8,680$ per isolator, but replacing the isolator will not introduce more downtime since the construction at isolation layers will not impact the occupants of the superstructure (Cardone and Gesualdi 2013). If a LRB reaches the DS4, the entire building will be considered collapsed and replacement will be required. This assumption is conservative but was still utilized because whether the building will collapse when a LRB fails needs to be further refined, but is not the focus of this study. The occupancy models, the fragility groups, and the associated parameters of superstructures are identical with their corresponding un-retrofitted buildings. The illustrative elevation of the isolated system is shown in Figure 6.2. It should be noted that the moats around the buildings are assumed to be wide enough to prevent pounding.

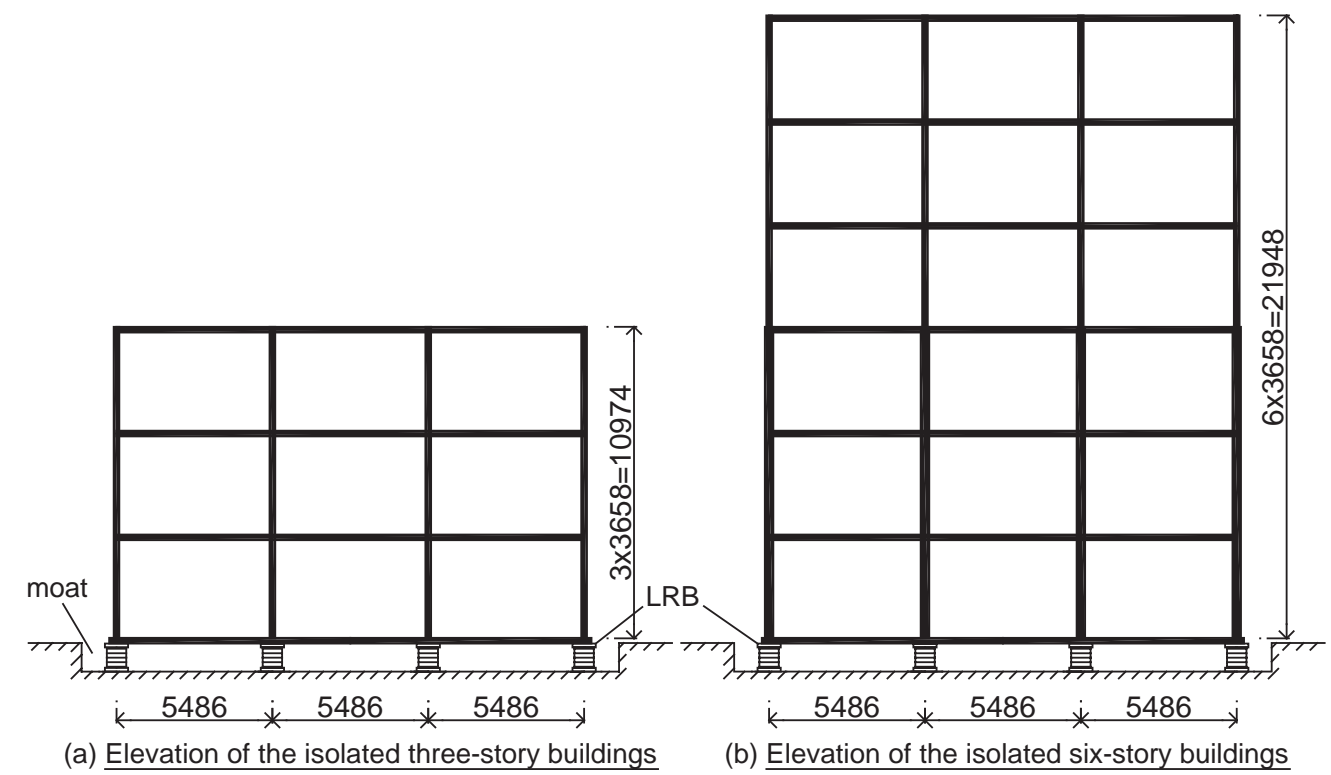

Figure 6.2 Elevation view of the isolated buildings

Previous studies shown in Chapter 4 and Chapter 5 suggest that the uncertainties in the mechanical behavior of isolators are less significant than the structural uncertainties of the superstructure, and the structural uncertainties are much less important than the ground motion uncertainties for performance assessment. The uncertainty of different fragility groups (e.g. beams, columns, partitions, isolators, etc.) is incorporated when defining the dispersion of the fragility functions. One part of the uncertainty is the structural uncertainty, which is typically represented by the logarithmic standard deviation of an engineering demand parameter of a component at a specific damage state. For example, the structural uncertainty of the columns at the slight damage state is taken as 0.33 (Mitrani-Reiser 2007). Structural uncertainty of all the fragility groups at different damage states are also explained in Chapter 3. These types of parameters are generally 
obtained through experiment (FEMA 2012a). The other part of the uncertainty is the modeling uncertainty, which is assumed to be 0.25 for each of the fragility groups at each damage state (FEMA 2012a). The dispersion of the fragility functions is calculated using square root of the sum of the squares of the structural uncertainty and the modeling uncertainty (Celik and Ellingwood 2009; FEMA 2012a). For example, the dispersion of the fragility function of the columns at slight damage state equal to $\sqrt{0.33^{2}+0.25^{2}}=0.41$. Therefore, each fragility group introduced some uncertainty into the building system. Since each isolated building had an additional fragility group of isolators compared to the corresponding un-retrofitted building, additional structural uncertainty is introduced into the total system.

\subsection{The mainshock-aftershock earthquake sequences}

In order to estimate the annual direct loss, downtime, fatalities, and total loss, the seismic performance of the buildings under earthquakes of a variety of hazard levels should be assessed. The considered seismic hazard levels should range from low intensity to very high intensity (FEMA 2012a). The spectral acceleration at the structural fundamental period is often used as the earthquake intensity measure (IM) for general buildings as they are well correlated with structural damage. However, since the effective periods of the isolated buildings are different when the deformations of the base isolators are different, it is difficult to use the spectral acceleration as the IM here for buildings under a variety of earthquake scenarios; this is also true for retrofit scenario comparisons. The IM employed here was the peak ground acceleration (PGA) of the mainshocks because of PGA's efficiency, practicality, sufficiency and hazard computability (Padgett, et al. 2008). PGA has also been used as the IM in many previous studies on seismic risk assessment of isolated structures (Ryan, et al. 2010; Zhang and Shu 2014; Perotti, et al. 2013). The hazard curves of the two locations obtained from U.S. Geological Survey (USGS 2014) are presented in Figure 6.3. For both locations, earthquakes with PGA from $0.005 \mathrm{~g}$ to the PGA of $1 \%$ probability of exceedance in 50 years are examined. The hazard curve within the PGA range of each location is divided into 9 intervals. For each interval, an intensity-based assessment is performed for the intensity at the mid-point of the interval. The estimated performance metrics are later weighted by the annual probability of exceedance of intensities with that interval. The annual direct loss, downtime, fatalities, and total loss could be obtained by summing up the weighted results of all the intervals, which will be introduced in the next section. More details about this method 
can be found in FEMA P-58 (FEMA 2012a). The PGAs at the mid-points of all intervals are listed in Table 6.4.

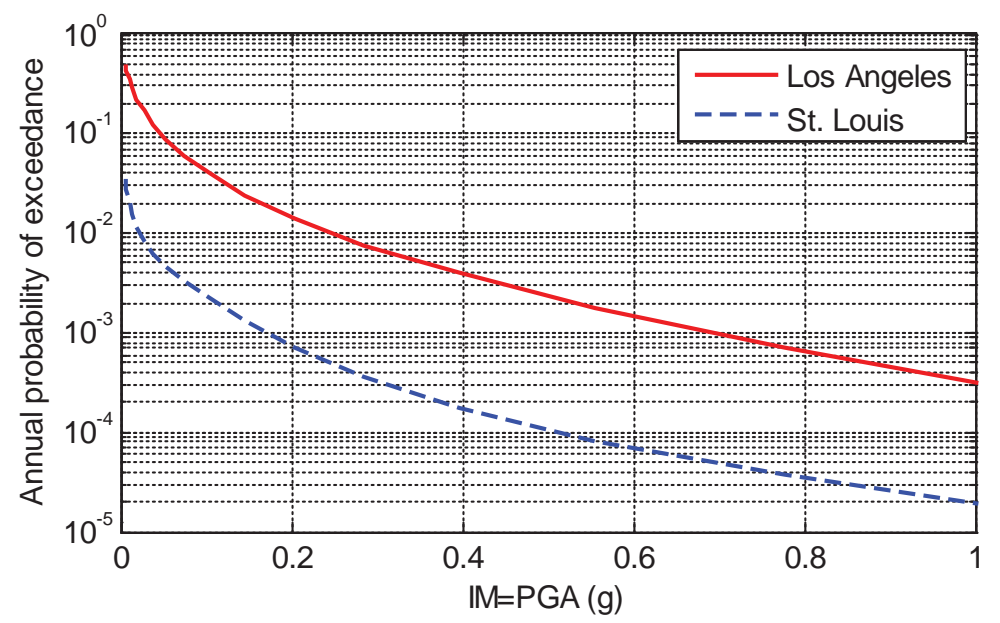

Figure 6.3 The seismic hazard curves of St. Louis and Los Angeles

Table 6.4 PGAs (g) at the mid-points of all intervals

\begin{tabular}{llllllllll}
\hline Locations & Interval & & & & & & & & \\
& 1 & 2 & 3 & 4 & 5 & 6 & 7 & 8 & 9 \\
\hline St. Louis & 0.020 & 0.050 & 0.080 & 0.109 & 0.139 & 0.169 & 0.199 & 0.229 & 0.258 \\
Los Angeles & 0.059 & 0.168 & 0.276 & 0.384 & 0.492 & 0.601 & 0.709 & 0.817 & 0.926 \\
\hline
\end{tabular}

The 44 mainshock records from the FEMA P695 far-field ground motion sets (FEMA 2009b) are utilized to simulate the mainshock ground motions. For each of 9 intervals at each location, the 44 mainshocks are multiplied by scale factors which ensure the PGA for all the mainshocks are equal to the PGA at the mid-point of the interval. Since previous seismic performance assessments in Chapter 3 indicates that considering multiple aftershocks would yield results very similar to the results obtained considering one aftershock with the largest magnitude, only one aftershock with the largest magnitude is considered for each mainshock-aftershock (MS-AS) sequence in this study. The aftershocks are stochastically synthesized based on the information of the corresponding mainshocks. The procedure of generating the aftershocks, which is presented in the flow chart in Figure 6.4, has been shown to be accurate in Chapter 2. 


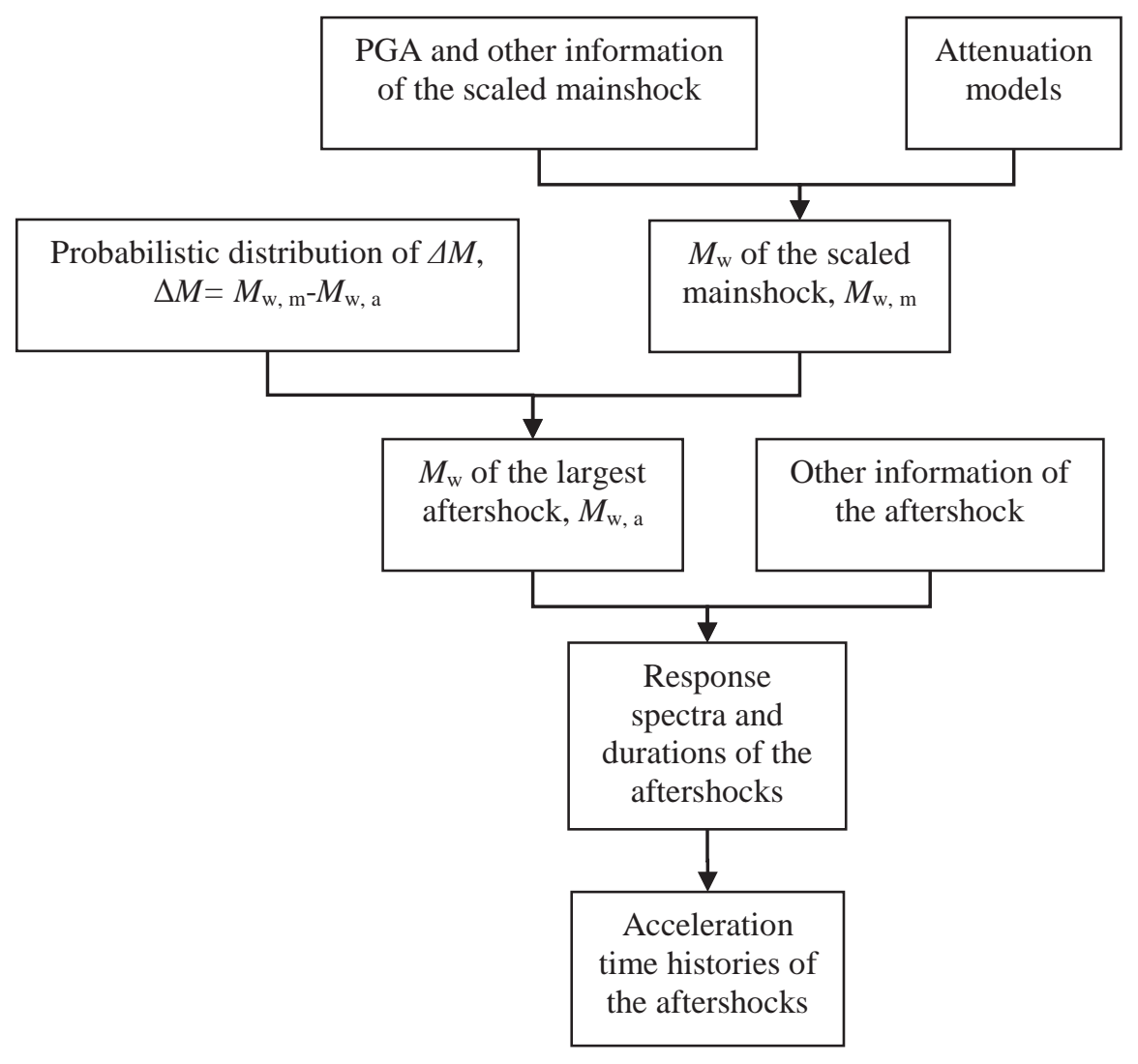

Figure 6.4 The basic procedure of synthesizing aftershock ground motions

The attenuation models developed by Abrahamson and Silva $(1996,1997)$ are adopted for predicting the PGA, response spectra, and durations as shown in Eq. 2.1 and 2.2. These models may cause some bias in predicting the ground motions in St. Louis. But they are still used here for their simplicity. Otherwise much work would be required to identify the probabilistic distribution of parameters that are used in other attenuation models, which is not the main focus of this study. The first three arrows in Figure 6.4 indicate Monte Carlo Simulation (MCS) processes with Latin Hypercube Sampling (LHS). The probabilistic distribution of the $\Delta M$, which is the difference between the moment magnitude of the mainshock and the largest aftershock, was found to be well represented by either a Gamma distribution or a Beta distribution (see Chapter 2 or Han, et al. 2014a). The largest aftershock in this study is measured in terms of magnitude, as the largest magnitude of aftershocks is more predictable than other intensity measures such as the largest acceleration of all aftershocks. In this study the Gamma distribution is preferred because the Beta distribution has an arbitrary upper limit for $\Delta M$. The probabilistic distribution function (PDF) of the Gamma distribution is presented as Eq. 6.1 , in which the $\Gamma(\cdot)$ indicate the gamma function. Other information required in the 
procedure, such as the PDFs of the site-to-source distance, hanging wall parameters, and the predicted values from the attenuation models, has been introduced in Chapter 2. An example of the median and the stochastically generated response spectrum of an aftershock obtained from attenuation models, as well as the actual response spectrum after synthesis, are presented in Figure 6.5(a). The shape of the stochastically generated spectrum (the dotted line) and the spectral shape of the actually synthesized ground motion (the solid line) may not look realistic, since the attenuation equations only provide prediction for spectral acceleration at some discrete periods. However, it has been validated that using the synthesized ground motions will still yield results that are similar to using the realistic ground motions (see Chapter 2 or Han, et al. 2014a).

$$
p(\Delta M)=\frac{3.3^{3.96}(\Delta M)^{2.96}}{\Gamma(3.96)} e^{-13.07} \quad \Delta M \geq 0
$$

Since it is still unclear whether an aftershock ground motion is linearly related to the corresponding mainshock ground motion, it may be inappropriate to scale the aftershocks to different intensity levels using the same scale factor as that of the corresponding mainshock. Therefore, ideally, for each of the 9 intensity levels at both locations, a group of aftershock ground motions should be generated, which is computationally intensive. Alternatively, aftershocks are generated for the mainshocks of intensity level 2, 5, and 8 for each location, and then scaled to their respective adjacent intensity levels based on the scale factors are determined by the mainshocks. Using such method, very large and very small scale factors can be avoided. The aftershock ground motions are combined with the corresponding mainshocks to perform back to back analysis, with a designated time between each record to allow the structure to come to rest. An example of a MS-AS sequence is shown in Figure 6.5(b).

(a) The response spectra of an aftershock

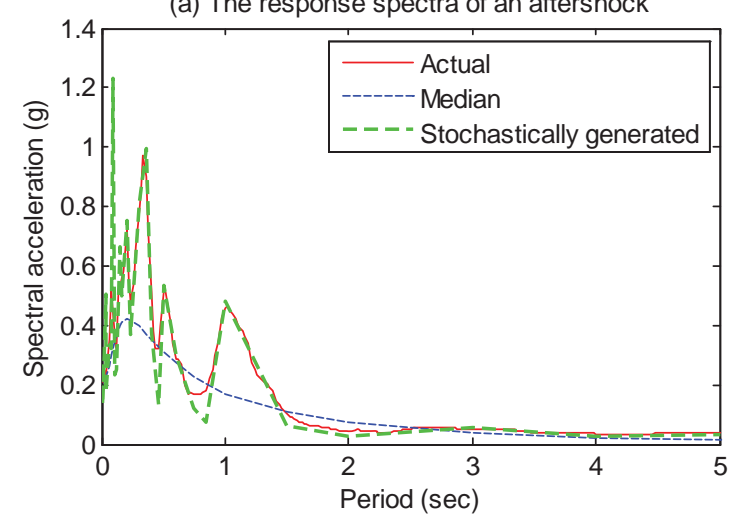

(b) The time history of a MS-AS sequence

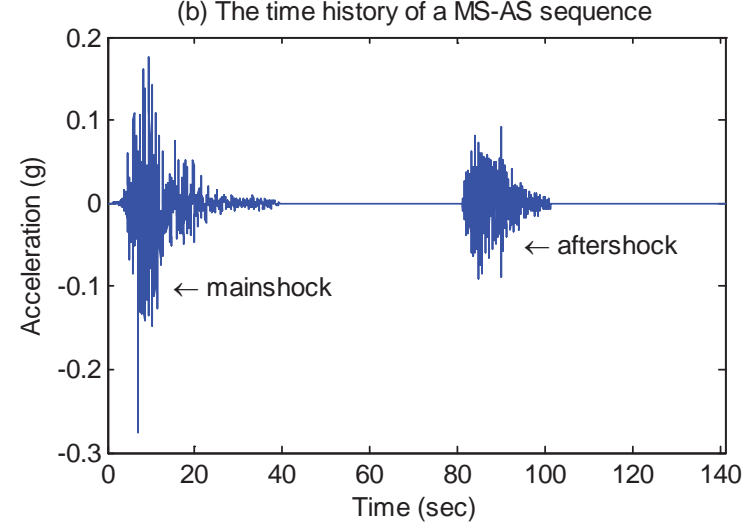

Figure 6.5 Examples of an aftershock response spectra set and a MS-AS sequence 
Investigation in Chapter 4 indicated that the occurrence time of major aftershocks may have influence on the estimated seismic performance metrics. If an aftershock occurs before the repair starts and before the occupants are evacuated, the probability of fatality and evacuation may increase. Earlier evacuation will also introduce more downtime to the building. Besides, if an aftershock occurs after the building has been repaired and is back to normal operation, there will be additional direct loss, downtime, and fatalities. Therefore, the probabilistic distribution of the occurrence time of the aftershock with the largest magnitude must be determined. Since to the best of the author's knowledge, there has not been any study on this issue, the occurrence time data of the aftershock with the largest magnitude are collected from 61 earthquake events recorded at USGS (2014). Common distributions such as lognormal, Poisson, exponential, Gamma, and Beta distribution were fitted and chi-square goodness-of-fit tests are performed to evaluate the fitted distributions. The fitted Poisson distribution, which is shown as Eq. 6.2, was found to be acceptable at the 5\% significance level. The $X_{T}$ in Eq. 6.2 denotes the occurrence time of the largest aftershock, in days. The occurrence time of each aftershock is generated using MCS with LHS. The histogram of the sample data and the fitted probability distribution function (PDF) of the Poisson distribution are shown in Figure 6.6 .

$$
p\left(X_{T}=x\right)=\frac{3.2^{x}}{x !} e^{-3.2} \quad x=0,1,2, \ldots
$$
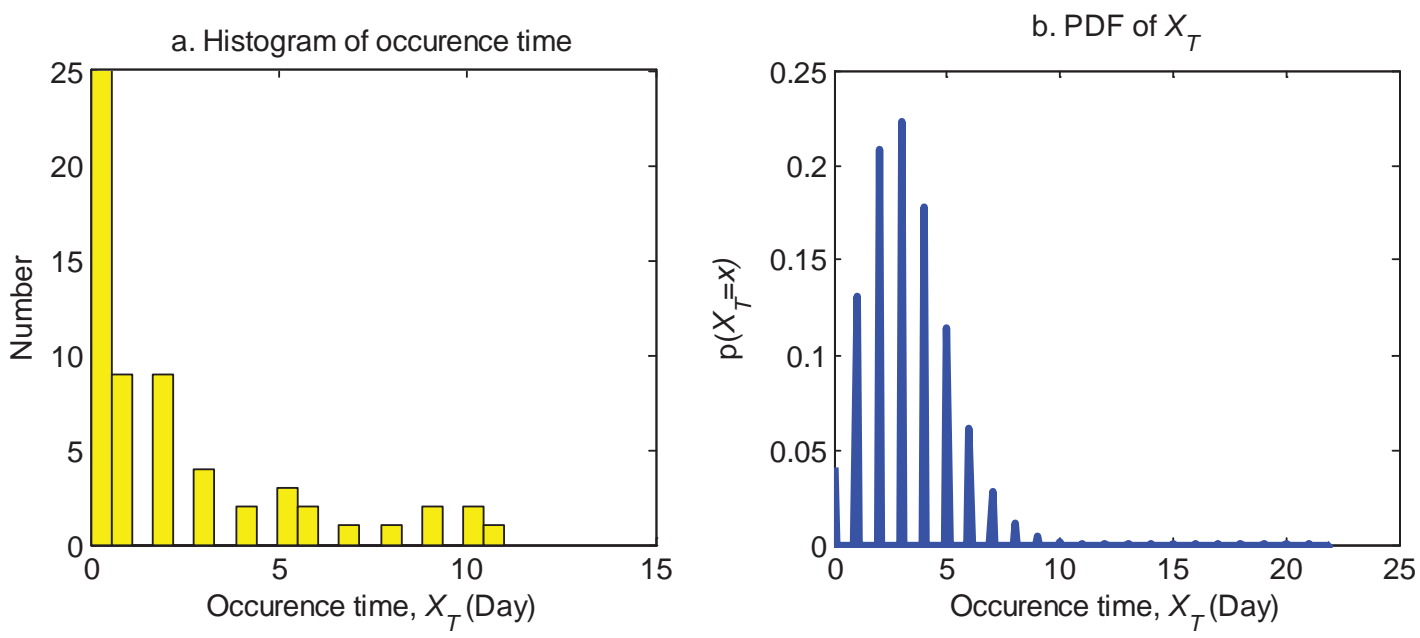

Figure 6.6 The histogram and the fitted PDF of the occurrence time of the largest aftershock 


\subsection{Seismic performance assessment and cost-benefit analysis}

\subsubsection{The annual seismic performance metrics of the buildings}

For each location and intensity level, there are $44 \mathrm{MS}-\mathrm{AS}$ ground motions. For each of the 44 MS-AS ground motions, NTHA is performed for each building model and seismic performance assessment is implemented with consideration of aftershocks. The performance assessment procedure is the same as that has been used in Chapter 3 and Chapter 4. For comparison, assessment considering only the mainshocks is also performed. The outcomes of the seismic performance assessment for an intensity level included the expected direct loss, downtime, fatalities, and total loss, each of which formed a distribution based on the 44 samples. Different distributions are fitted and evaluated through goodness-of-fit tests but no one distribution type is able to fit for all the sample distributions, likely a result of the limited sample sizes. However, percentile values of each sample distribution could be obtained from the sample cumulative distribution function (CDF) constructed using the rank ordered method (Rosowsky 2002). The total loss consisted of the direct loss and the indirect loss caused by downtime and fatalities. It is assumed that the daily loss due to downtime was $\$ 461$ for the three-story buildings and $\$ 921$ for the six-story buildings (Mitrani-Reiser 2007). Such downtime loss only considered the loss in rent revenue, and the daily loss is the average daily lease rate. This assumption will cause underestimation in the loss due to downtime, but it will yield more reliable results as the other part of loss due to non-operation greatly depends on the use of the building and has great uncertainty. The downtime loss calculated based on this assumption is conservative. Although it has been controversial to put a price tag on human life, for the purpose of this study the statistical value of life which is employed for estimation of the fatality-induce loss is assumed to be $\$ 4.16$ million per fatality (MitraniReiser 2007; Mrozek and Taylor 2007).

With the results of the seismic performance assessment for all the 9 earthquake intensity levels, the annual performance metrics can be calculated using the equation as follow:

$$
A P M=\sum_{i=1}^{9}\left(A P E_{i} \cdot P M_{i}\right)
$$

In Eq. 6.3, $A P M$ indicates an annual performance metric, which can be annual direct loss, annual downtime, annual fatalities, or annual total loss. $A P E_{i}$ denotes the annual probability of exceedance covered by the $i$ th interval of the hazard curve, which is calculated as the difference between the annual probabilities of exceedance at the two end 
points of the interval on hazard curve, as introduced previously. $P M_{i}$ denotes a performance metric obtained from the assessment under the ground motion at the $i$ th intensity level, which is the mid-point intensity of the $i$ th interval. As no uniform type of probabilistic distribution is found be able to fit the results, the rank ordered sample CDFs of the annual direct loss, downtime, fatalities, and total loss of all the buildings are constructed and are presented in Figure 6.7.
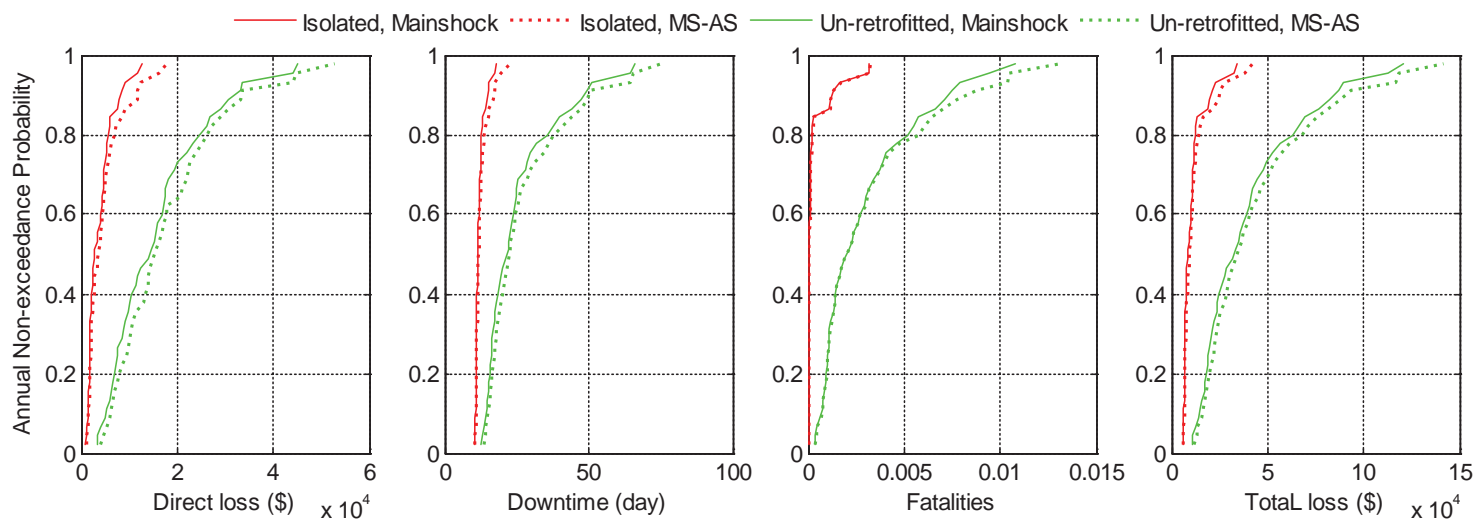

(a). The isolated and un-retrofitted three-story building in Los Angeles
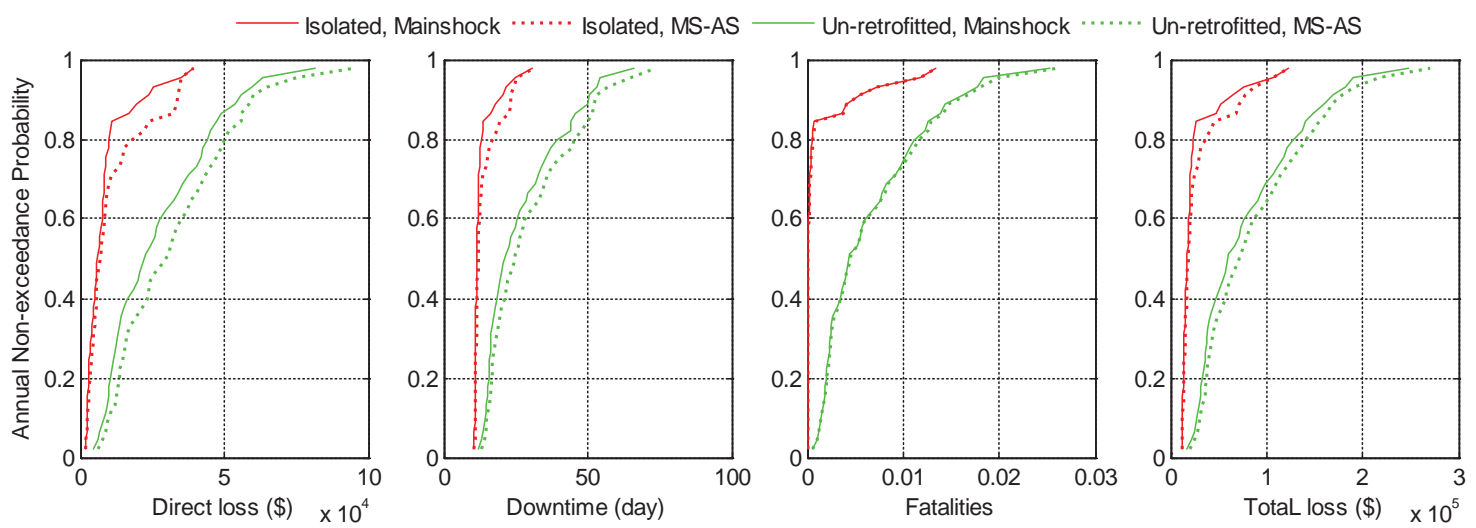

(b). The isolated and un-retrofitted six-story building in Los Angeles

Figure 6.7 The CDFs of the annual direct loss, downtime, fatalities, and total loss of all the buildings 

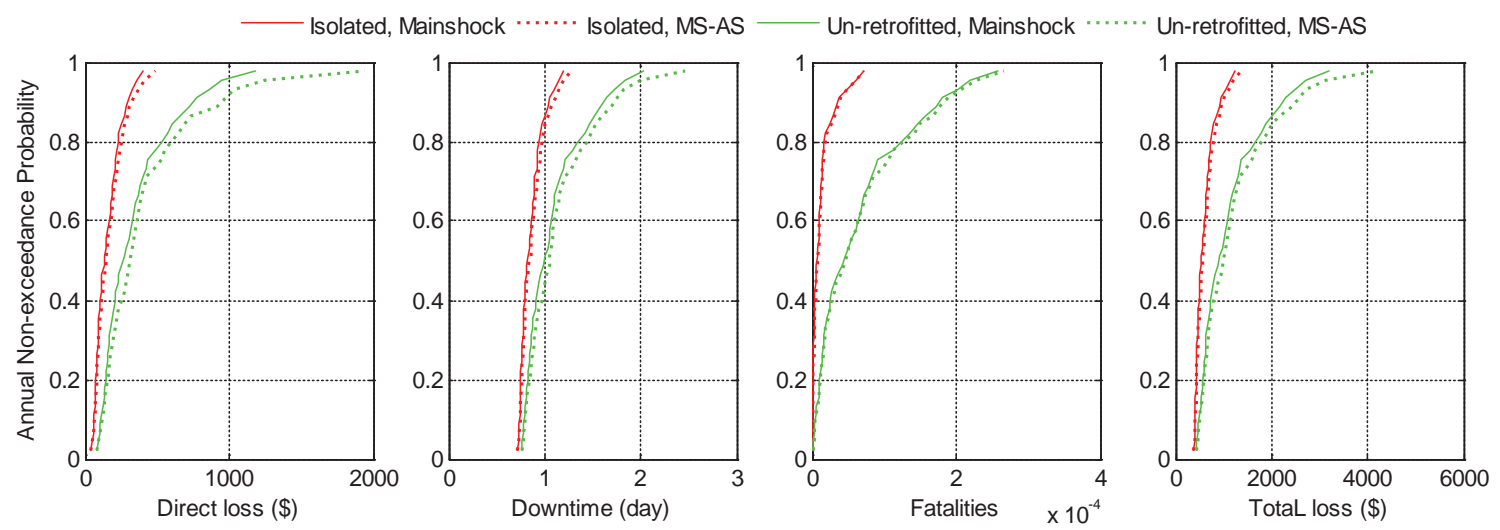

(c). The isolated and un-retrofitted three-story building in St. Louis
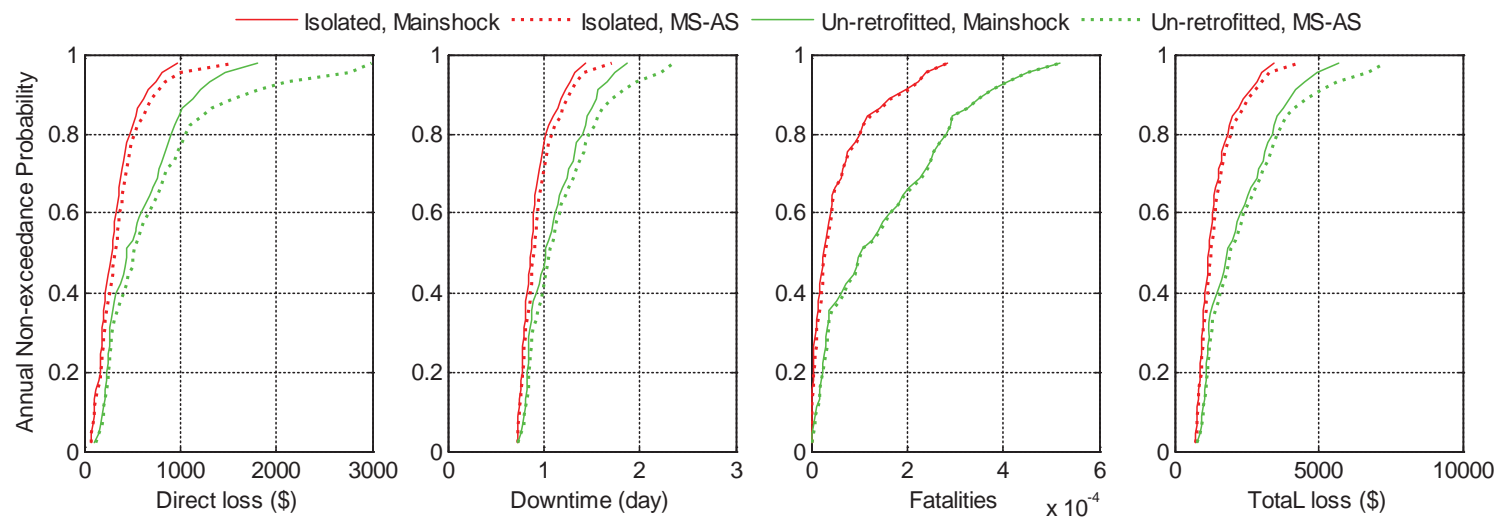

(d). The isolated and un-retrofitted six-story building in St. Louis

Figure 6.7 (continued)

As shown in Figure 6.7, the improvement in seismic performance metrics achieved by applying base isolation are significant, which is indicated by the obvious gaps between the CDFs of the isolated buildings and those of the corresponding un-retrofitted buildings. Comparison between the results of buildings sited in Los Angeles and in St. Louis shows very significant differences in the annual seismic loss, downtime, and fatalities. The annual direct loss, downtime, fatalities, and total loss of buildings in Los Angeles are generally one to two orders of magnitude greater than their counterparts in St. Louis, which demonstrates the substantial influence of seismicity, i.e. the building location. Another observation that can be made is that the total loss is substantially higher (up to 2 or 3 times higher) than the direct loss for each building, which means the indirect loss from downtime and fatalities is also very important. The gaps between the dotted lines and the solid lines imply the different outcomes with and without consideration of aftershock hazard. Such difference is obvious for annual direct loss, downtime, and total loss except for the fatalities. A possible explanation is that when significant fatalities are 
possible, the probability of evacuation after the mainshocks becomes very high, and consequently the expected additional fatalities caused by the aftershock becomes marginal. However, it is not easy to identify the exact difference between the outcomes with and without incorporating aftershock hazard from the figures. Therefore, the mean, $10^{\text {th }}$ percentile, and the $90^{\text {th }}$ percentile of the results considering aftershocks normalized by the respective results without consideration of aftershocks are presented in Table 6.5.

Table 6.5 The annual seismic performance metrics with consideration of aftershocks normalized by the corresponding results without consideration of aftershocks

\begin{tabular}{llllllllll}
\hline Parameters & & \multicolumn{2}{l}{ Los Angeles } & \multicolumn{3}{c}{ St. Louis } \\
& & \multicolumn{2}{l}{ Three-story } & \multicolumn{2}{l}{ Six-story } & \multicolumn{2}{l}{ Three-story } & \multicolumn{2}{l}{ Six-story } \\
& & $\mathrm{U}^{*}$ & $\mathrm{I}$ & $\mathrm{U}$ & $\mathrm{I}$ & $\mathrm{U}$ & $\mathrm{I}$ & $\mathrm{U}$ & $\mathrm{I}$ \\
\hline Direct & mean & 1.15 & 1.19 & 1.24 & 1.27 & 1.15 & 1.09 & 1.18 & 1.12 \\
Loss $(\$)$ & $10^{\text {th }}$ & 1.05 & 1.07 & 1.12 & 1.06 & 1.06 & 1.05 & 1.06 & 1.04 \\
& $90^{\text {th }}$ & 1.27 & 1.41 & 1.37 & 1.78 & 1.26 & 1.12 & 1.44 & 1.16 \\
Downtime & mean & 1.07 & 1.05 & 1.11 & 1.09 & 1.05 & 1.02 & 1.06 & 1.04 \\
(day) & $10^{\text {th }}$ & 1.03 & 1.01 & 1.06 & 1.01 & 1.01 & 1.01 & 1.01 & 1.01 \\
& $90^{\text {th }}$ & 1.13 & 1.13 & 1.16 & 1.29 & 1.08 & 1.05 & 1.14 & 1.06 \\
Fatalities & mean & 1.04 & 1.23 & 1.03 & 1.27 & 1.06 & 1.16 & 1.05 & 1.25 \\
& $10^{\text {th }}$ & 1.00 & 1.03 & 1.00 & 1.00 & 1.01 & 1.01 & 1.00 & 1.00 \\
Total Loss & $90^{\text {th }}$ & 1.11 & 1.45 & 1.07 & 1.45 & 1.15 & 1.33 & 1.11 & 1.68 \\
$(\$)$ & mean & 1.10 & 1.09 & 1.13 & 1.14 & 1.08 & 1.04 & 1.08 & 1.06 \\
& $10^{\text {th }}$ & 1.04 & 1.03 & 1.08 & 1.02 & 1.02 & 1.01 & 1.03 & 1.02 \\
& $90^{\text {th }}$ & 1.15 & 1.20 & 1.19 & 1.41 & 1.14 & 1.07 & 1.18 & 1.09 \\
\hline
\end{tabular}

${ }^{*}$ Note: $\mathrm{U}=$ Un-retrofitted building; I = Isolated building

From the results in Table 6.5 one can see the importance of considering aftershock hazard in seismic performance assessment. Considering aftershock hazard in the assessment results in a significant rise in direct loss, which ranges from $9 \%$ to $27 \%$ for mean values compared to the results obtained from the assessment considering only the mainshocks. Such rise decreases to around $5 \%$ for the $10^{\text {th }}$ percentile values and can increases up to $78 \%$ for the $90^{\text {th }}$ percentile values. The additional downtime caused by aftershocks is less significant, the mean values of which vary from $2 \%$ to $11 \%$ and are mostly around $5 \%$. The $10^{\text {th }}$ percentiles and $90^{\text {th }}$ percentiles of the additional downtime range from $1 \%$ to $29 \%$ of the mainshock-induced downtime, which are also smaller than those of additional direct loss. The differences in the percentage of the rise in annual direct loss and downtime between different buildings are not obvious.

However, the percentages of aftershock-induced additional fatalities are much higher for the isolated building than for the un-retrofitted buildings. The mean aftershock-induced additional fatalities are approximately $5 \%$ and $20 \%$ of the mainshock-induced fatalities for the un-retrofitted and the isolated buildings, respectively. The percentage of 
aftershock-induced additional fatalities over mainshock-induced fatalities have the $10^{\text {th }}$ percentiles and the $90^{\text {th }}$ percentiles around $0 \%$ and $10 \%$ respectively for the un-retrofitted buildings, whereas these two percentiles for the isolated buildings can be as high as $3 \%$ and $68 \%$, respectively. This phenomenon is likely because the superstructures of isolated buildings are protected so well that mainshocks do not result in evacuation. Thus occupants are highly possible to have stayed in the buildings during the aftershocks, and thereby caused additional fatalities during the aftershocks. In contrast, the un-retrofitted buildings had high probability to incur significant damage during the mainshocks which caused high probability of evacuation after the mainshocks. Consequently, the aftershock-induced additional fatalities are insignificant for the un-retrofitted buildings. However, it should be stressed that the fatalities of the isolated buildings are always much lower than those of the un-retrofitted buildings, as suggested in Figure 6.7. The results do not show significant difference between buildings in different locations or with different height.

When it comes to the annual total loss, the differences in results between different buildings are insignificant again, although obvious differences exist for normalized annual fatalities of the isolated and un-retrofitted buildings. This is because the annual fatalities of the isolated buildings were too low to make a significant contribution to the total loss. Considering aftershock hazard, the annual total loss will be $4 \%$ to $14 \%$ higher for mean values, $1 \%$ to $8 \%$ higher for the $10^{\text {th }}$ percentiles, and $7 \%$ to $41 \%$ higher for the $90^{\text {th }}$ percentiles. However, the differences caused by aftershocks in all the performance metrics are typically smaller than $20 \%$, suggesting the aftershock hazard is not the most important factor to be considered.

To quantitatively compare the seismic performance of the isolated and un-retrofitted buildings, the expected annual direct loss, downtime, fatalities, and total loss of all the buildings are presented in Table 6.6. Since Table 6.5 has already listed the differences in the outcomes with and without consideration of aftershocks, only the results obtained from assessments considering MS-AS are shown in Table 6.6. 
Table 6.6 The expected annual seismic performance metrics

\begin{tabular}{llllll}
\hline Parameters & & $\begin{array}{l}\text { Los Angeles } \\
\text { Three-story }\end{array}$ & Six-story & $\begin{array}{l}\text { St. Louis } \\
\text { Three-story }\end{array}$ & Six-story \\
\hline Direct Loss (\$) & U & 17,927 & 32,415 & 410 & 735 \\
& I & 4,777 & 11,204 & 169 & 378 \\
& U/I & 3.8 & 2.9 & 2.4 & 1.9 \\
Downtime & U & 27.6 & 29.9 & 1.1 & 1.2 \\
(day) & I & 12.6 & 14.2 & 0.9 & 1 \\
& U/I & 2.2 & 2.1 & 1.3 & 1.2 \\
Fatalities & U & $3.2 \times 10^{-3}$ & $6.8 \times 10^{-3}$ & $6.8 \times 10^{-5}$ & $1.5 \times 10^{-4}$ \\
& I & $3.4 \times 10^{-4}$ & $1.2 \times 10^{-3}$ & $1.3 \times 10^{-5}$ & $5.8 \times 10^{-5}$ \\
\multirow{5}{*}{ Total Loss $(\$)$} & U/I & 9.5 & 5.7 & 5.3 & 2.6 \\
& U & 43,983 & 88,215 & 1,219 & 2,452 \\
& I & 12,024 & 29,205 & 626 & 1,493 \\
& U/I & 3.7 & 3.0 & 1.9 & 1.6 \\
\hline
\end{tabular}

${ }^{*}$ Note: $\mathrm{U}=$ Un-retrofitted building; I = Isolated building

Results in Table 6.6 show that the base isolation can reduce the expected annual loss, downtime, and fatalities effectively. Those annual performance metrics of for the unretrofitted buildings are generally several times more than their counterparts of the corresponding isolated buildings. However, the values of these performance metrics are much smaller for buildings in St. Louis than for buildings in Los Angeles, because of the lower seismicity of St. Louis. Significant uncertainties can be observed from the results in Table 6.5 and 6.6, also it can be observed from the results shown afterwards. These uncertainties mainly came from the ground motions which have a variety of intensity, spectral shape, and MS-AS combination.

\subsubsection{Cost-benefit analysis}

Although the outcomes of performance assessment suggest retrofitting with base isolation can substantially reduce the annual direct loss, downtime, fatalities, and total loss of the non-ductile RC frame buildings as demonstrated in Figure 6.7 and Table 6.6, it is still unclear whether base isolation is economical considering its high initial cost. Therefore, cost-benefit analysis is performed based on the results obtained from the previous seismic assessment.

The Federal Emergency Management Agency (FEMA) P-58 guideline (FEMA 2012a) provided a method of cost-benefit analysis based on the net present value (NPV) of a stream of equal annual avoided loss, which is expressed as Eq. 6.4. 


$$
N P V=\frac{A}{i}\left[1-\frac{1}{(1+i)^{t}}\right]
$$

where $A$ is a stream of equal annual avoided loss, which is the difference between the loss (either direct loss or total loss) of an un-retrofitted building and the same type of loss of the corresponding isolated building calculated using the outcomes of the assessment, $t$ is the considered period in years, and $i$ is discount rate. The $N P V$ of $t$ years can be compared with the retrofit cost. If the former is higher, the benefit outweighs the cost in the period of $t$ years and vice versa.

There is some uncertainty in the discount rate, $i$. FEMA suggested a discount rate of $3 \%$ or $4 \%$ for public sector considerations and a discount rate of $4 \%$ to $6 \%$ is reasonable for private sector considerations (FEMA 1992). The Office of Management and Budget (OMB) of the U.S. recommended the discount rate of $3 \%$ and $7 \%$ should be both considered in cost-benefit analysis (OMB 2003). Therefore, three levels of discount rate are assumed here, which are 3\%,5\%, and 7\%, to account for the uncertainty in discount rate. The $N P V \mathrm{~s}$ of different years and under different discount rates are illustrated in Figure 6.8 for each building. It should be addressed that the NPVs shown in Figure 6.8 were calculated using the mean values of annual avoided direct loss and total loss. For example, the line with legend showing "Direct loss, Mainshock" shows the NPV calculated using the annual avoided direct loss with consideration of only the mainshock hazard. If a $N P V$ curve goes higher than the horizontal solid line indicating the repair cost, it means the benefit can outweigh the retrofit cost. The $\mathrm{X}$ coordinate of the intersection of a $N P V$ curve and the horizontal line indicate the corresponding break-even time in years. If a $N P V$ curve always goes below the horizontal solid line, it means the benefit cannot exceed the cost. 

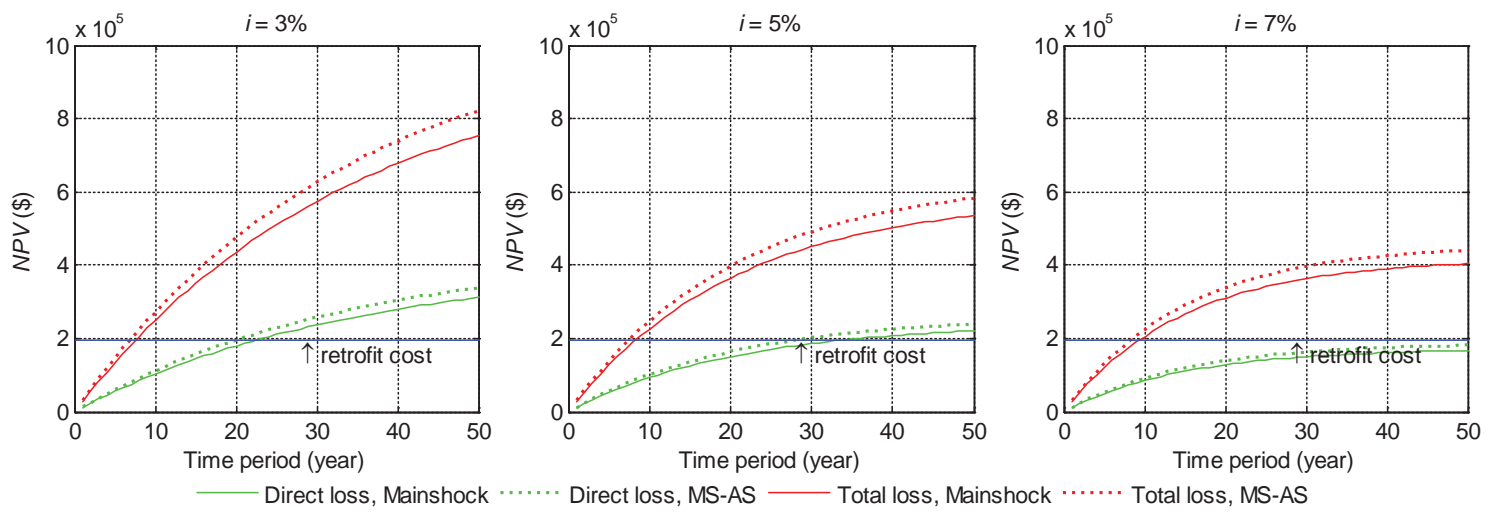

(a). The three-story building in Los Angeles
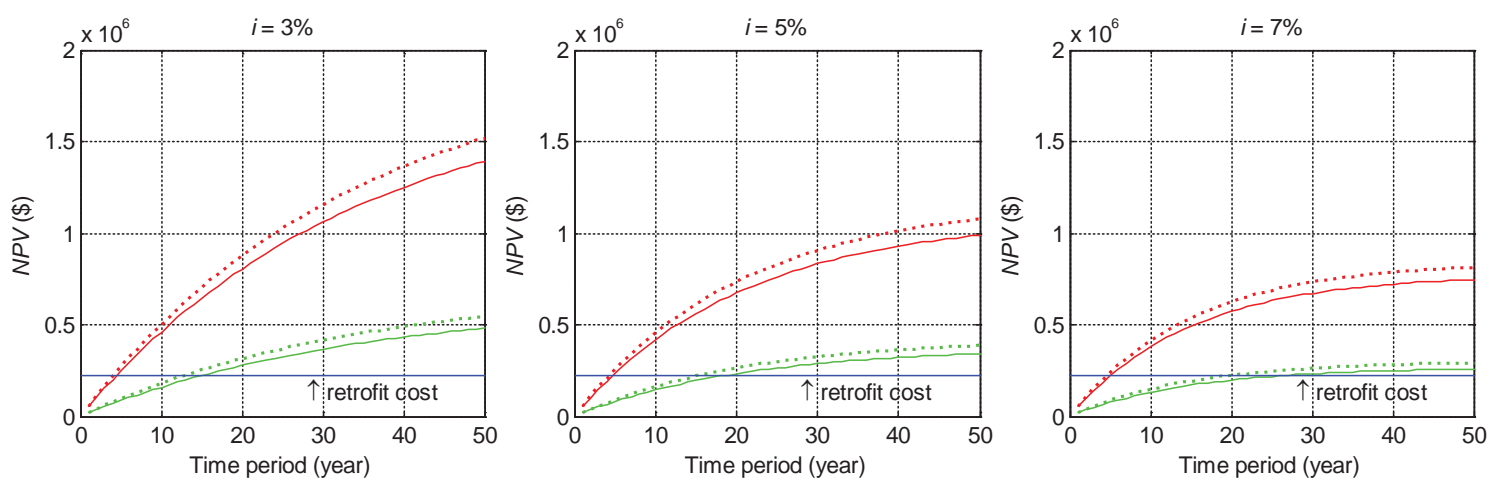

(b). The six-story building in Los Angeles

Figure 6.8 Comparison between retrofit costs and $N P V$ s of different years computed using mean annual avoided direct and total loss
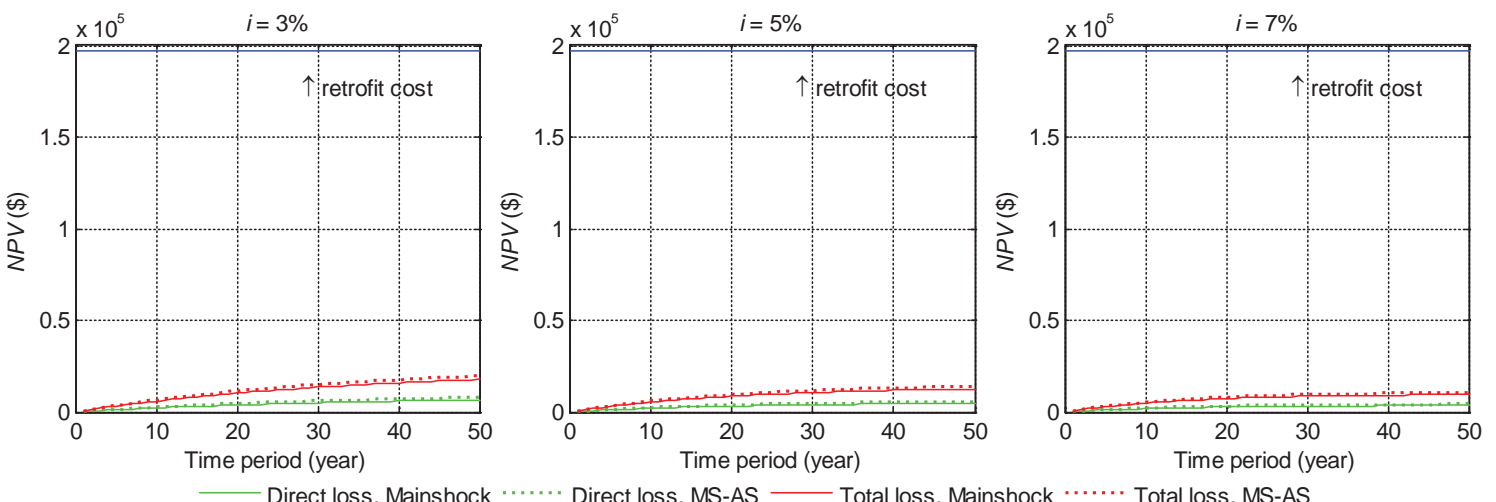

(c). The three-story building in St. Louis 

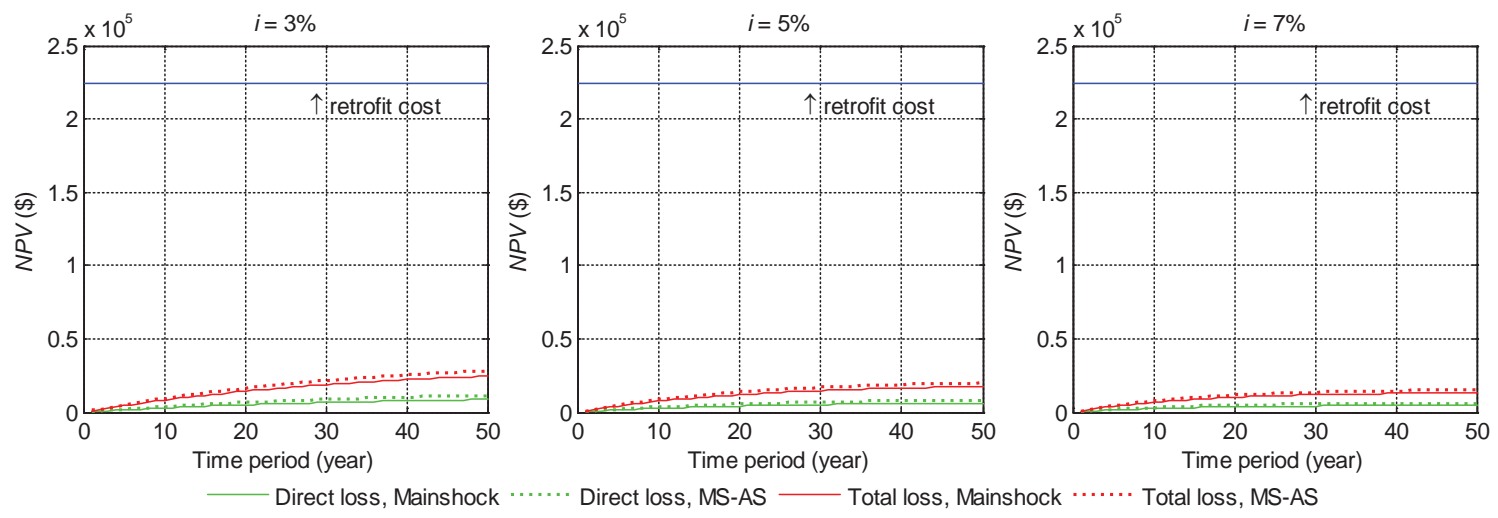

(d). The six-story building in St. Louis

Figure 6.8 (continued)

Figure 6.8 clearly suggests that the benefits from retrofit cannot outweigh the retrofit costs for the two buildings in St. Louis, which is due to the low annual avoided loss resulting from the lower seismicity of St. Louis. When only the direct losses are considered for the three-story building in Los Angeles, the benefits exceed the costs in 20 to 30 years if the $i=3 \%$ to $5 \%$, whereas the benefits cannot exceed the costs in 50 years if the $i$ rises to 7\%. However, if the total loss is considered for this building, the benefits will outweigh the costs in less than 10 years for all the discount rate levels, implying the importance of accounting for indirect loss in analysis. For the six-story building in Los Angeles, the benefits can exceed the costs in shorter time periods. This is because the avoided losses for the six-story building are higher than those for the three-story building, but the retrofit costs are not much different. The higher dotted lines compared with solid lines indicate that benefits are more significant when aftershock hazard is considered. The results shown in Figure 6.8 only imply the mean level of the benefits. To examine the influence of the uncertain benefits, the minimum time periods needed for benefits to outweigh costs, or the break-even time, are calculated using the mean, the $10^{\text {th }}$ percentile, and the $90^{\text {th }}$ percentile of the avoided annual direct and total loss, as listed in Table 6.7. The break-even time can help stakeholders decide on whether to adopt the retrofit based on the intended remaining service life of a building. The "N/A" shown in the table suggests the benefit cannot exceed the cost no matter how long the time period is. Since the analysis on the buildings in St. Louis found that the costs exceed the benefits for all the scenarios, only the results of buildings in Los Angeles are presented in Table 6.7. 
Table 6.7 The break-even time (in years) for the buildings in Los Angeles

\begin{tabular}{|c|c|c|c|c|c|c|c|c|c|c|c|}
\hline \multicolumn{3}{|c|}{ Parameters } & $\begin{array}{l}i=3 \% \\
\text { mean }\end{array}$ & $10^{\text {th }}$ & $90^{\text {th }}$ & \multicolumn{2}{|l|}{$i=5 \%$} & $90^{\text {th }}$ & \multicolumn{2}{|c|}{$i=7 \%$} & $90^{\text {th }}$ \\
\hline \multirow{4}{*}{$\begin{array}{l}\text { Three- } \\
\text { story }\end{array}$} & Direct & Mainshock & 23 & N/A & 9 & 35 & N/A & 10 & N/A & N/A & 12 \\
\hline & loss & MS-AS & 21 & N/A & 8 & 29 & N/A & 9 & N/A & N/A & 10 \\
\hline & Total & Mainshock & 8 & 63 & 4 & 9 & N/A & 4 & 10 & N/A & 4 \\
\hline & loss & MS-AS & 7 & 43 & 3 & 8 & N/A & 3 & 9 & N/A & 4 \\
\hline \multirow{4}{*}{$\begin{array}{l}\text { Six- } \\
\text { story }\end{array}$} & Direct & Mainshock & 16 & N/A & 7 & 19 & N/A & 8 & 28 & N/A & 8 \\
\hline & loss & MS-AS & 13 & 87 & 7 & 16 & N/A & 7 & 21 & N/A & 8 \\
\hline & Total & Mainshock & 5 & 21 & 2 & 5 & 29 & 3 & 6 & N/A & 3 \\
\hline & loss & MS-AS & 5 & 17 & 2 & 5 & 21 & 2 & 5 & 34 & 3 \\
\hline
\end{tabular}

Table 6.7 shows that considering the aftershocks can increase the avoided loss and thereby shorten the break-even time. Also, if other conditions are the same, the breakeven time for the six-story building will be shorter than that of the three-story building. These observations agree with the results shown in Figure 6.8. The discount rate also shows significant influence on the results. In some conditions, the benefits can outweigh the costs when $i=2 \%$, but cannot exceed the costs when $i=5 \%$ or $7 \%$. The uncertainty in the benefits is substantial, which lead to significant variation of the break-even time. For example, when $i=5 \%$ and total loss and MS-AS are considered, the break-even time can be as short as 3 years for the three-story building, but it is also possible that the benefits will never exceed the cost. Such a situation is not rare. Many results calculated using the $10^{\text {th }}$ percentiles of the avoided annual losses suggest the retrofit will not be economical, but the results calculated with the mean and the $90^{\text {th }}$ percentiles of the avoided annual losses lead to the opposite conclusion. However, if one looks into the results obtained when considering both aftershock hazard and total loss, which might be the most accurate result, it can be observed that the benefits can outweigh the costs mostly, except for the results of the three-story building calculated with the $10^{\text {th }}$ percentile of the benefits when discount rates are higher $(i=5 \%$ or $7 \%)$. It is worthwhile to mention that the discount rate will goes down as the time period increases. For a time period longer than 30 years, the discount rate will decrease to about 3\% (Bjarnadottir, et al. 2014), so the benefits might exceed the costs for these two conditions with $i=5 \%$ and $7 \%$, similar to the results of the condition with $i=3 \%$. Besides, judging from the breakeven time computed using the mean results, the investment of base isolation can be expected to be paid back in less than 10 years. Such results may make base isolation more appealing to stakeholders than the results of previous studies (e.g. Sayani 2009; Ryan, et al. 2010) which did not consider aftershock hazards or indirect loss and consequently needed much longer break-even time. 


\subsection{Conclusions}

Results of seismic performance assessment for the two non-ductile RC frame buildings before and after being retrofitted with base isolation suggest base isolation can effectively reduce the seismic direct loss, downtime, fatalities, and total loss, as one can expect. Further, cost-benefit analysis reveals that base isolation can be economical for buildings located in Los Angeles, representing high seismicity regions. The mean break-even time can be shorter than 10 years for these buildings. This is of note because traditionally base isolation is viewed as very expensive. The benefits from retrofitting with base isolation outweigh the retrofit costs more significantly for the six-story building than for the three story building. However, base isolation is not shown to be economically beneficial for buildings in St. Louis, representing a region with relatively low seismicity.

Indirect loss due to downtime and fatalities represent a substantial portion of the total loss, and thereby influence the results of the performance assessment and cost-benefit analysis. Therefore, they should not be neglected in an analysis. The results of costbenefit analysis can be significantly affected by uncertain sources, such as the uncertainties in the discount rate and the estimated seismic loss.

Aftershocks are found to be capable of causing significantly different outcomes for the seismic performance assessment and cost-benefit analysis. 


\section{Influence of Aftershocks and Base Isolation on the Robustness of Older Reinforced Concrete Buildings}

\subsection{Introduction}

Recent studies showed that the non-ductile reinforced concrete (RC) frame buildings that were constructed before the 1970's in the Western United States (WUS) (Liel and Deierlein 2008) and before the 2000's in the Central and Eastern United States (CEUS) (Celik and Ellingwood 2009) perform poorly under potential earthquakes, each of which consists of a mainshock and many aftershocks that can also be intensive, such as the 1994 Northridge Earthquake (Hauksson, et al. 1995), the 1999 Chi-Chi Earthquake (Kao and Chen 2000), and the 2011 Tohoku Earthquake (Asano, et al. 2011). The seismic risk and economic loss of these buildings are substantially higher than the ductile RC frame buildings (Celik and Ellingwood 2009; Liel, et al. 2010; Liel and Deierlein 2008). Additionally, their seismic risk and loss were found to be even greater when the aftershock hazard were considered (Han, et al.2014a,b; Han, et al.2015). Therefore, appropriate seismic retrofit strategies for these building are necessary.

Performance-based earthquake engineering (PBEE) provides researchers and engineers with approaches to quantity the seismic performance of buildings with consideration of the uncertainties in the seismic hazard, structural capacity, analysis procedure, and the seismic loss and other consequences. It has been applied to evaluate the seismic retrofit strategies of the non-ductile RC frame buildings. For example, Liel and Deierlein (2013) utilized PBEE to examine the retrofit cost and reduced seismic loss caused by applying several different retrofit methods, including carbon fiber wrapping, column jacketing, and adding additional wall piers. They concluded that the retrofit methods are cost effective when the loss due to fatalities was considered. Shoraka, et al. (2014) estimated the collapse risk of non-ductile RC frame buildings before and after retrofitted with different strategies. They found that using traditional retrofit approaches such as adding lateral force resistant systems, increasing ductility of columns, and weakening the beams can reduce the collapse risk of these buildings, but still cannot achieve the similar performance level as the ductile RC frame buildings. However, Chapter 5 investigated the seismic risk mitigation by retrofitting a non-ductile RC frame building with base isolation and found that utilizing base isolation can reduce the seismic risk of the non- 
ductile RC frame building to the similar level as the ductile RC frame buildings. Chapter 5 also included the aftershock hazard in the analysis procedure, and revealed that the aftershocks can increase the seismic risk of the building. Chapter 6 also investigated the cost and benefit of utilizing base isolation as a retrofit method for the non-ductile RC buildings, with consideration of aftershock hazard and the loss due to repair, downtime, and fatalities. The results in Chapter 6 show that the cost-effectiveness can be achieved for the buildings in WUS, but not for those in CEUS. The benefits from base isolation outweighed the retrofit cost more significantly when the aftershock hazard was incorporated.

Despite that these studies have examined the performance metrics such as seismic risk, loss, downtime, and fatalities of the non-ductile buildings, the robustness of non-ductile buildings have been rarely investigated. Robustness has become desirable because it suggests the building's capacity to withstand any unforeseen hazard without disproportionate consequences. However, there have been different approaches for quantifying the robustness. For example, Lind (1995) measured the robustness using a function of the failure probability for a damaged and the undamaged building. Baker, et al. (2008) defined the robustness as a function of direct and indirect risk of a building. Cavaco, et al. (2013) quantified the robustness using the ratios of structural properties between the undamaged and the damaged building. Robustness assessment has also been performed for many other buildings types under different damage scenarios. For example, Izzuddin, et al. (2008) developed a framework to assess the robustness of multistory buildings with sudden column loss. Xavier, et al. (2014) examined the influence of masonry infill on the robustness of multistory building under sudden column loss scenarios. Ribeiro, et al. (2014) performed reliability-based robustness assessment on steel frame buildings subject to mainshock and aftershocks. However, the influence of aftershocks and base isolation on the robustness of non-ductile building is still lacking in the literature.

In this study, robustness assessment is performed for two non-ductile buildings before and after retrofitting with base isolation. The influence of aftershock hazard is also investigated utilizing mainshock-aftershock ground motions. Robustness indices of the buildings are calculated based on their seismic loss under a variety of seismic intensity levels and their annual expected seismic loss, respectively.

\subsection{Robustness indices}


Structural robustness depicts a structure's ability to withstand any loading scenarios without a disproportionate consequence. There are mainly three types of robustness indices. The first type of robustness index (RI) is defined as the ratios of structural properties such as stiffness between the undamaged and damaged building (Cavaco, et al. 2013). This type of RI is easy to use in engineering practice, but is also known as incapable to explicitly describe the failure (Ribeiro, et al. 2014). The second type is defined as a function of the probability of failure of the undamaged and damaged building (Frangopol and Curley, 1987; Ribeiro, et al. 2014). However, this type of RI has been considered as a measure of structural redundancy rather than robustness (Starossek and Haberland 2008). The last type of RI is defined as a function of the direct consequences and the indirect consequences that are disproportional to the cause (Baker, et al. 2008). Although it requires detail assessment for all the consequences and thus can be compute-intensive, this RI is considered as a very powerful measure to quantify the robustness. Therefore, in this study, the RI proposed by Baker, et al. (2008) is adopted for assessment.

A brief explanation of the terminologies is presented here before this type of RI is introduced. When an event that may damage a structure occurs, different damage states (DS) may result and different consequences will be associated with each of these DS. Common consequences include repair/replacement cost, downtime (non-operational time), or fatalities, and these consequence types are utilized in this study. There is a possibility that the system failure, which causes disproportional consequences, occurs after the structure is damaged, and the consequence associated with the system failure is termed as indirect consequence. Similarly, the consequence associated with DS other than system failure is termed as direct consequences. Since the indirect consequences are due to system failure, they are disproportional consequences to the cause. Then the RI is expressed as a function of the risk of direct consequences and the risk of indirect consequences, as shown in Eq. 7.1.

$$
R I=\frac{R_{d i r}}{R_{d i r}+R_{\text {indir }}}
$$

where $R_{d i r}$ is the risk associated with direct consequences whereas the $R_{d i r}$ is the risk associated with indirect consequences. The two risk terms are generally represented using the mean values to incorporate both the consequences and the probability associated with 
each consequence. Therefore, it is clear that the RIranges from 0 to 1 , and the greater is the RI, the higher robustness is the structure under given damaging event.

For the robustness assessment considering seismic hazard, system failure is deemed when the building need to be replaced. The replacement sometimes is due to the collapse of a building, but it can also happen even if a building is not collapsed. For example, a building may be not repairable technically when excessive residual drift occurs, and thus has to be replaced (FEMA 2012a). Besides, building owners tend to decide to replace a building other than to repair it if the estimated repair cost is too high (FEMA 2012a). Details about the criteria to trigger building replacement are presented in the next section. Therefore, the indirect consequences are the repair cost, downtime, and fatalities associated with the scenarios that a building needs to be replaced, whereas the direct consequences are the repair cost, downtime, and fatalities associated with the scenarios that a building will be repaired. Since the three types of consequences are different in nature, it is necessary to combine them using a uniform unit. Although it is difficult and controversial to convert downtime and fatality to financial loss, it is common practice to evaluate them in monetary terms for comparison and decision making. Therefore, the Eq. 7.1 can be rewritten as follow, with $R_{\text {dir }}$ and $R_{\text {indir }}$ substituted by the respective financial losses:

$$
R I=\frac{L_{\text {repair }}}{L_{\text {repair }}+L_{\text {replace }}}
$$

where $L_{\text {repair }}$ is the mean financial loss due to repair, whereas the $L_{\text {replace }}$ is the mean financial loss due to replacement.

In some previous studies on seismic loss estimation (Aslani and Miranda 2005a; Ryan, et al. 2010; Ramirez, et al. 2012), seismic loss only included the cost directly related to repair/replacement, but ignored the loss due to downtime and fatalities. To determine the influence of including and excluding the loss due to downtime and fatalities on the RI, the $L_{\text {repair }}$ and $L_{\text {replace }}$ is calculated with and without consideration of downtime loss and fatality loss. More importantly, the RI is quantified with and without consideration of aftershock hazard to investigate the impact from aftershocks.

\subsection{Building models, mainshock-aftershock ground motions, and loss estimation}


The three-story and six-story RC frame building that has been used in Chapter 2, 3, 4, and 6 are still employed in this study. The location of the buildings is assumed to be Los Angeles, CA $\left(34.22^{\circ} \mathrm{N}, 118.47^{\circ} \mathrm{W}\right)$, with the site classified as category D. Information about these two un-retrofitted buildings is available in Chapter 3 and Chapter 4 . The two buildings are numerically retrofitted with base isolation. The design procedure and information about the isolated buildings are shown in Chapter 6 as the isolated buildings in Los Angeles.

MS-AS ground motions are essential for performing nonlinear time history analysis (NTHA), since the results of which will be used in loss estimation and robustness assessment. To examine the RI of the buildings under a variety of earthquake intensity levels, 9 seismic hazard levels ranging from low to very high intensity are considered. The intensity levels and the MS-AS ground motions are identical as those ground motions that are used for Los Angeles in Chapter 6.

The methodologies that developed in Chapter 3 and Chapter 4 are utilized for assessing the repair/replacement cost (termed as direct loss in Chapter 3, 4, and 6), downtime, and fatalities of buildings under mainshock-aftershock (MS-AS) sequences. The procedure and assumptions used in the assessment are presented in Chapter 3, 4, and 6. To calculate the RI, the loss due to downtime and fatalities has to be converted to monetary loss, as discussed earlier. The daily downtime loss and statistical value of life are discussed in Chapter 3, 4 and 6. The financial loss due to repair and replacement are extracted for robustness assessment.

\subsection{Seismic losses and robustness indices}

At each of the 9 intensity levels, for each of the 44 MS-AS ground motions, NTHA and seismic performance assessment are conducted for each building. For comparison, the results with and without consideration of aftershocks are both examined. The outcomes of the assessment under a MS-AS included the expected repair/replacement cost, downtime and fatalities. The downtime and fatalities are converted to monetary terms using the daily downtime loss and statistical value of lives that are discussed previously in Chapter 3, 4, and 6. For each intensity level, the mean repair/replacement cost, downtime, fatalities, and total loss that includes the financial loss due to downtime and fatalities are presented in the Figure 7.1. 

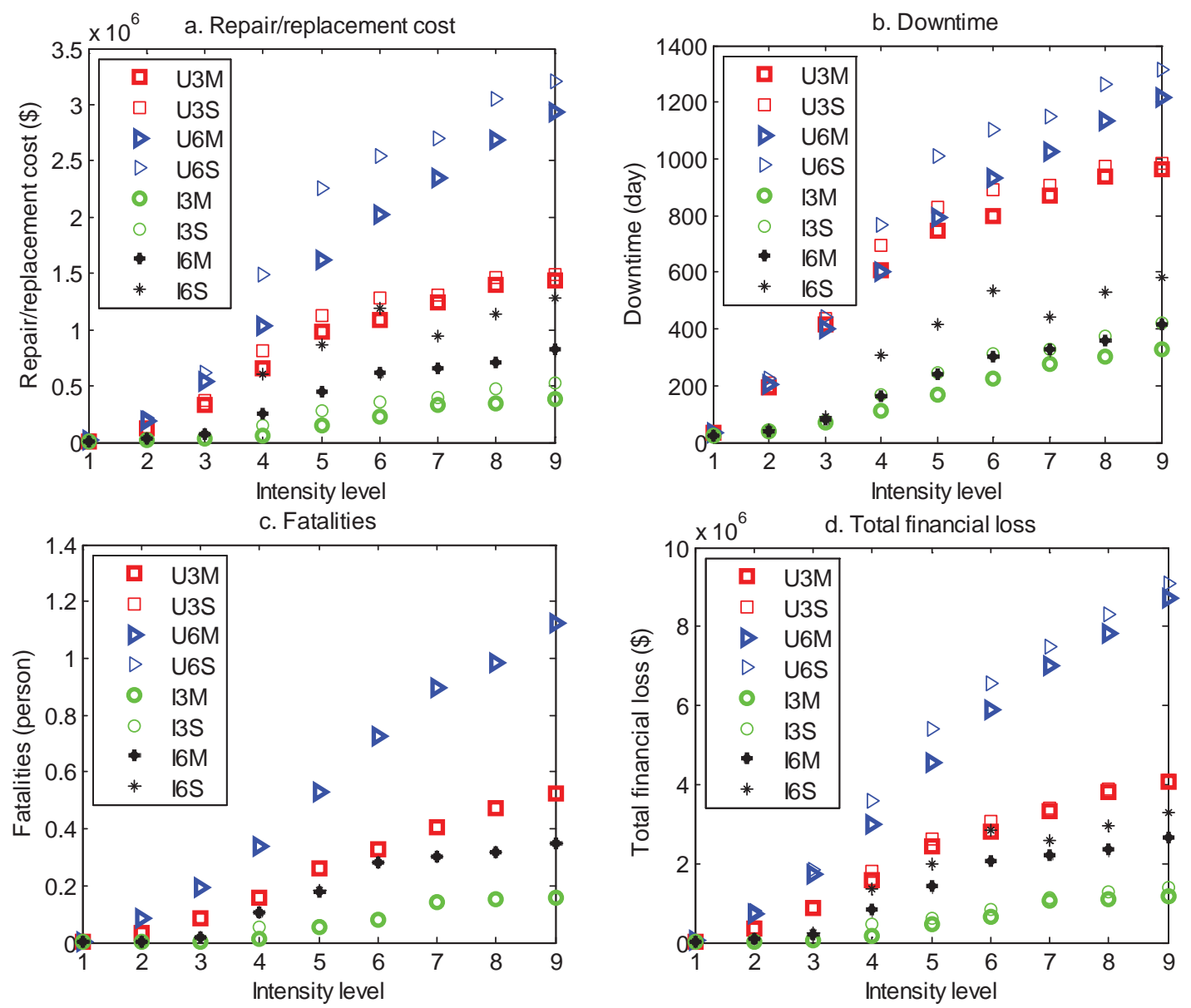

Figure 7.1 The mean results of the buildings at each intensity level (notation in the legend: $\mathrm{U}=$ an un-retrofitted building; $\mathrm{I}=$ an isolated building; $3=$ a three-story building; 6=a six-story building; $M=$ under mainshocks; $S=$ under MS-AS sequences)

Obviously, the isolated buildings can greatly mitigate the seismic consequences, especially for higher intensity levels, reflecting the effectiveness of retrofitting. As shown in the figures, all the consequences increase as the intensity level increases. One exception is the intensity level 6 for the isolated six-story building with consideration of aftershocks, which has higher consequence than the level 7 for the same building. The reason for this abnormal is that the isolated building collapsed under more aftershock ground motions at level 6, which is due to the uncertainty of aftershock ground motions. As previously introduced, the aftershocks at level 4 and 6 are scaled from the aftershocks at level 5, whereas the aftershocks at level 7 and 9 is scaled from the aftershocks at level 8. Therefore, the aftershocks at level 6 and 7 are totally different, which is why the 
aftershocks at level 6 can cause more collapse or non-repairable cases than those at level 7.

Another observation is that considering aftershocks can cause significantly higher repair/replacement cost, downtime, and total financial loss except for low intensity levels. The less significant differences due to aftershocks at low levels are because that the low intense mainshocks do not impair the structural capacity much, and also is because that the aftershocks also were not intense. For the un-retrofitted buildings at high intensity levels (e.g. level 8 and 9), the differences due to aftershocks are found to be less significant than the moderate intensity levels (e.g. level 4 7), which is due to the fact that more and more intense mainshock collapsed the building at high levels, causing the less importance of aftershocks. For the isolated buildings, building collapse is rare and hence such phenomenon cannot be seen in the Figure 7.1.

Despite the substantial difference caused be aftershocks in Figure 7.1(a), (b), and (d), the Figure 7.1(c) showing fatalities does not demonstrate such obvious differences. The reasons for this exception are that occupants were evacuated after the mainshock at higher levels since the building got damaged after the mainshock and thus no more fatalities for the aftershocks, and that the additional fatalities caused by aftershocks are low at lower levels since the structural damages from the mainshocks were slight and the aftershocks are not intense. Interestingly, in previous studies using recorded MS-AS sequences in Chapter 3 and 4, the additional fatalities caused by aftershocks are more common and significant. In those studies, more recorded MS-AS sequences have high intense aftershocks and low intense mainshock, which can cause additional fatalities in aftershocks without triggering evacuation. One possible explanation for the different characteristics of the MS-AS sequences is that the actual aftershock ground motions have greater uncertainty than those simulated using the aforementioned methods, allowing more intense aftershock ground motions occur. Another possible explanation is that the sampling method used in the previous studies or the available aftershocks in ground motion databases such as the Pacific Earthquake Engineering Research Center Ground Motion Database (PEER 2014) may have bias towards aftershock ground motions with higher intensity. Further investigation will be necessary to determine the actual reasons.

To better compare the repair/replacement cost and the total financial loss, the momentary results in Figure 7.1(a) and (d) are normalized by the replacement cost of each building, and are shown in Figure 7.2. It should be stressed again that the replacement cost of an 
isolated building is the replacement cost of a same un-retrofitted building plus the retrofit cost.
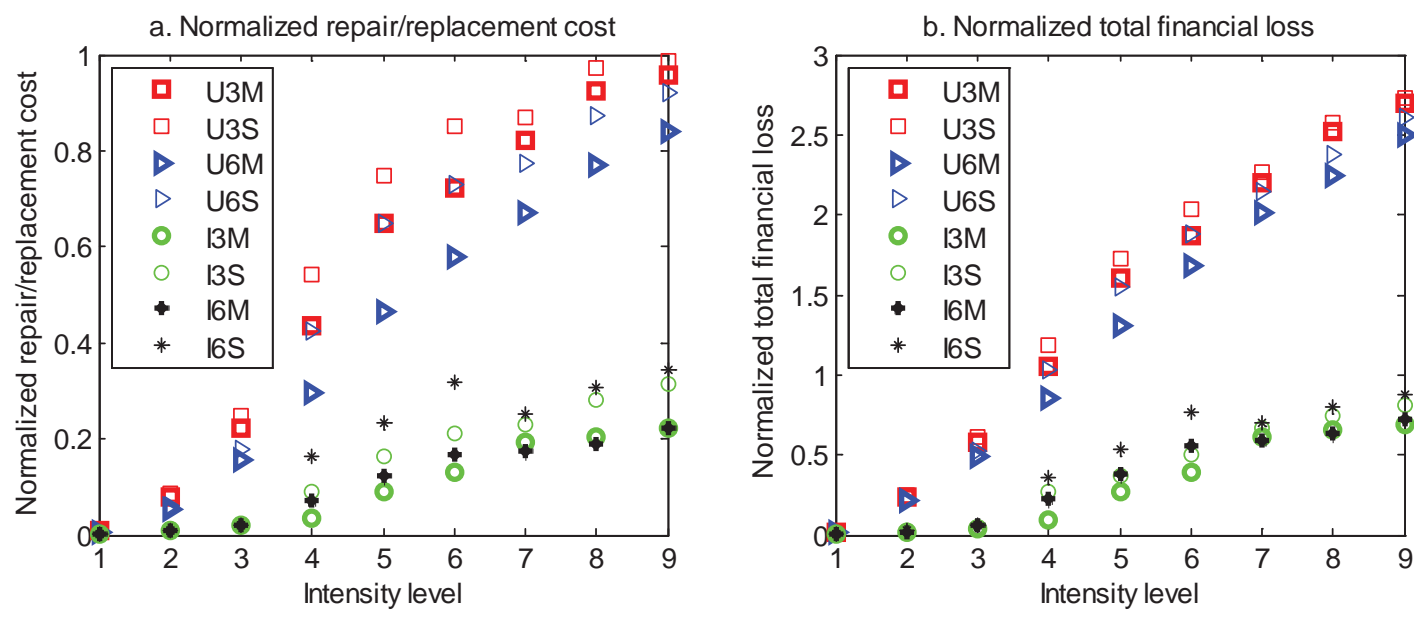

Figure 7.2 The normalized repair/replacement cost and total financial loss of the buildings at each intensity level (notation in the legend: $U=a n$ un-retrofitted building; $\mathrm{I}=\mathrm{an}$ isolated building; $3=\mathrm{a}$ three-story building; $6=\mathrm{a}$ six-story building; $\mathrm{M}=$ under mainshocks; $\mathrm{S}=$ under MS-AS sequences)

All the buildings have very low and similar normalized repair/replacement costs at intensity level 1, indicating the earthquakes of this intensity level barely damage the buildings. For un-retrofitted buildings, the repair/replacement costs at intensity level 9 are close to 1.0, showing that these buildings collapsed during most of the ground motions. Such variation in the normalized repair/replacement cost suggests that the 9 intervals have covered an intensity range that is adequate to simulate all the possible damage levels. Although the absolute repair/replacement costs and the total financial losses are different between any two of the four buildings, the normalized repair/replacement costs and the total financial losses are comparable between the two un-retrofitted buildings and the two isolated buildings, respectively, which indicates the consistence in design. When the normalized total financial loss is examined, one may find that the total financial loss can be more than two times higher than the repair/replacement cost or even the building's replacement cost. This suggests the substantial contribution to the financial loss from the downtime and fatalities. Therefore, despite many recent studies on seismic loss estimation mainly focused on the repair/replacement cost, it is important to include financial loss from other consequences such as downtime and fatalities. 
The results of loss estimation also provide data necessary for robustness assessment. Only the results considering total financial loss were examined because of the importance of the loss due to downtime and fatalities. As discussed in the second section, the indirect consequence is the loss due to replacement, $L_{\text {replace }}$, and the direct consequence is the loss due to repair, $L_{\text {repair }}$. These terms are obtained for each intensity level. It should be noted that the denominator, $L_{\text {replace }}+L_{\text {repair }}$ in Eq. 7.2 is actually the loss term that are shown in Figure 7.2. The $L_{\text {repair }}$ and $L_{\text {replace }}$ for the buildings at different intensity levels are presented in Figure 7.3.
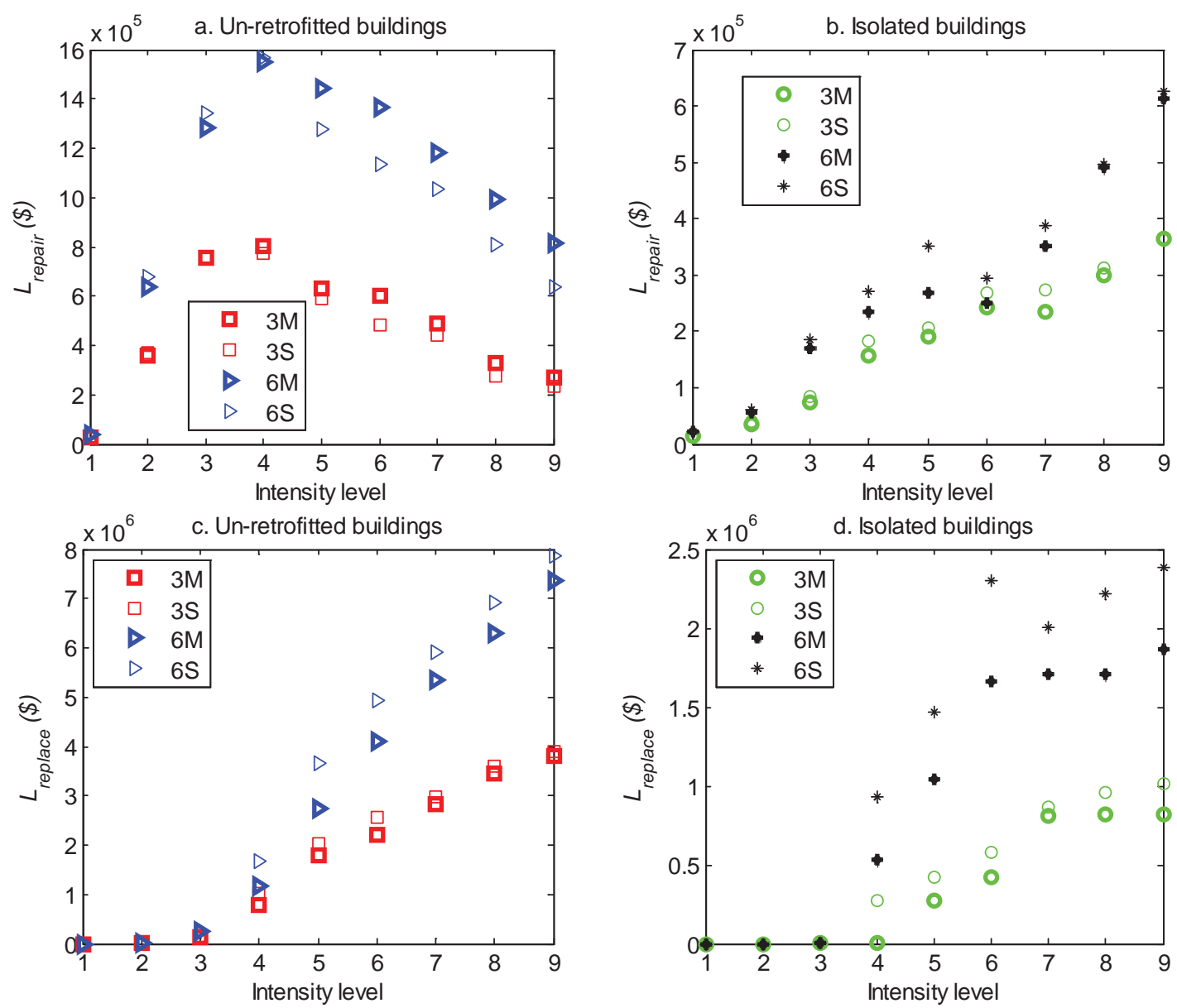

Figure 7.3 The $L_{\text {repair }}$ and $L_{\text {replace }}$ of the buildings at each intensity level (notation in the legend: $3=a$ three-story building; $6=$ a six-story building; $M=$ under mainshocks; $S=$ under MS-AS sequences)

Clearly, the $L_{\text {repair }}$ of the un-retrofitted and the isolated buildings show different trends as the intensity level increases. For the un-retrofitted buildings, $L_{\text {repair }}$ firstly increase from level 1 to 4 and then decrease from level 4 to 9 . The raising part is due to the fact that the 
increase in the ground motions intensity causes more serious damages, which however are still repairable for most ground motions. After the intensity level 4, as the intensity level keep going up, more serious damages that are not repairable or even building collapse become more and more common for all the ground motions. This is also the reason why the aftershocks cause increase in $L_{\text {repair }}$ for level 1 to 3 but cause decrease in for level 4 to 9 . The aftershocks always cause additional damage to buildings. When the buildings are repairable, aftershocks increase the $L_{\text {repair }}$, otherwise they increase the $L_{\text {replace }}$ as shown in Figure 7.3(c) and (d). For the isolated buildings, the $L_{\text {repair }}$ shown in the Figure 7.3(b) are actually similar as the raising parts in Figure 7.3(a). There are no descending parts for the isolated buildings because the earthquake intensity has not reach to a level that can cause common collapse or non-repairable damage of the isolated buildings. This also implies the structural capacity has been enhanced by retrofitting. Same as the raising parts for the un-retrofitted buildings, the aftershocks cause increase in the $L_{\text {repair }}$ for the isolated buildings. For the $L_{\text {replace }}$ of both un-retrofitted and isolated buildings, the basic trends are the same. The $L_{\text {replace }}$ just increases as the ground motions become more intense, except for the abnormal results for the isolated six-story building that is also observed in Figure 7.1 and has been explained. Aftershocks always cause additional $L_{\text {replace }}$. With the information about the $L_{\text {repair }}$ and $L_{\text {replace }}$, the RIs are obtained and are shown in Figure 7.4.
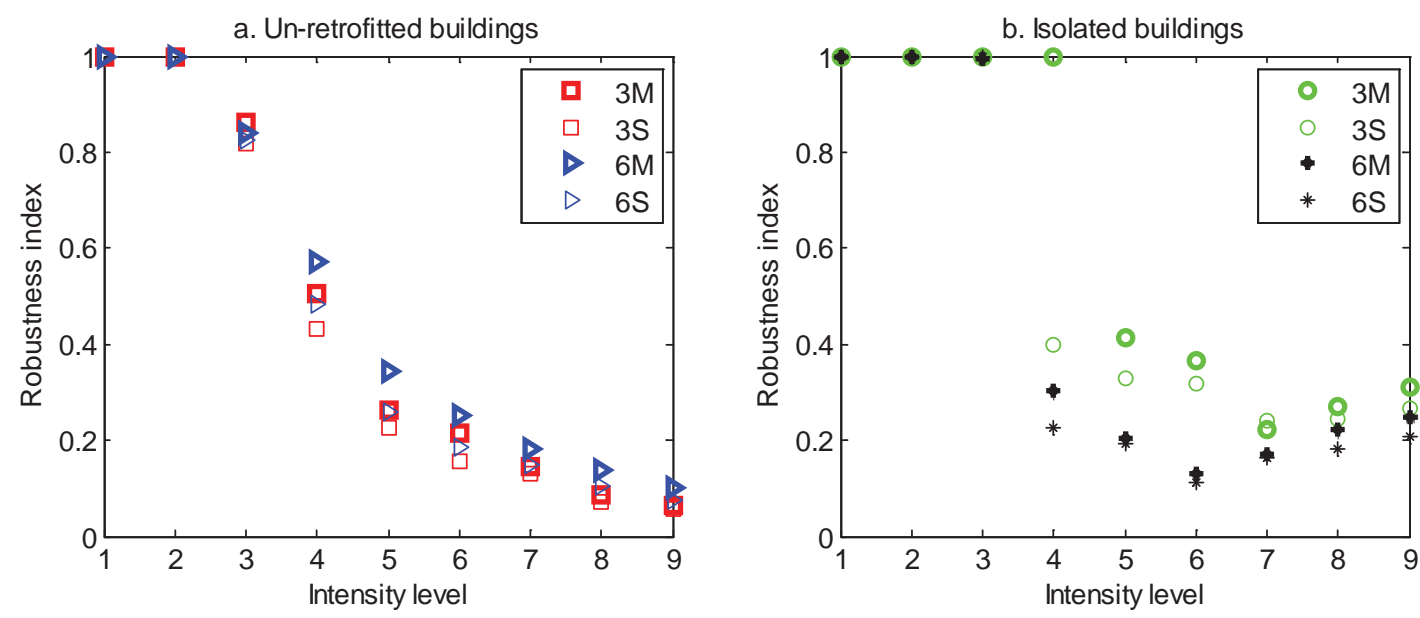

Figure 7.4 The RI of the buildings at each intensity level (notation in the legend: $3=a$ three-story building; $6=\mathrm{a}$ six-story building; $M=$ under mainshocks; $S=$ under MS-AS sequences)

In Figure 7.4(a), the RIs of the un-retrofitted buildings demonstrate a clear pattern, which is that the RIs decrease as the intensity level increases. However, the RIs for the isolated 
buildings are not monotonically decreasing, although for both types of buildings, the RIs at lower levels are close to 1 and the RIs at higher levels are close to 0. As previously discussed, the $L_{\text {repair }}$ and $L_{\text {replace }}$ both have some specific trends. However, since the RI used herein is a ratio of $L_{\text {repair }}$ to $L_{\text {repair }}+L_{\text {replace }}$ (see Eq. 7.2 ), the trend for RIs under a variety of ground motions is complicated. The trend for RI depends on the increasing rates of $L_{\text {repair }}$ and $L_{\text {replace, }}$ which can be affected by the uncertainty of ground motions and of structures. Take the isolated six-story building for example, the increase in $L_{\text {replace }}$ from level 7 to level 9 is insignificant compared with the increase in $L_{\text {repair, }}$ which caused the increase in the RI from level 7 to level 9. The fluctuation of RI for the isolated buildings suggests that this type of RI may have its limitation in describing the robustness under specific earthquake intense levels, as it only measures the relative value of direct consequence to the total consequence. As also admitted by the creator of this RI (Baker, et al. 2008), other decision making criterion should be judged before considering robustness. However, this limitation cannot undermine the importance of RI in decision making. It still provides an overall measure for the risk of a building. For two buildings with similar expected loss or other performance, the one with higher RI will still be preferable.

By far, all the loss estimation and robustness assessment is based on different intensity level. However, for decision making, the annual expected loss and the RI under the overall seismic hazard will be of more interest. FEMA P-58 (FEMA 2012a) suggests an approach to convert a building's loss under earthquakes with a variety of intensity levels to the annual expected loss by summing up the weighted losses of all the intervals. The equation, which is another form of Eq. 6.3, is presented below.

$$
A E L=\sum_{i=1}^{9}\left(A P E_{i} \cdot L_{i}\right)
$$

where the $A E L$ is the annual expected loss; $A P E_{i}$ is the annual probability of exceedance covered by the $i$ th interval; $L_{i}$ is the loss at the interval, which can be the total loss, $L_{\text {repair }}$ or $L_{\text {replace }}$. The annual total loss, annual $L_{\text {repair }}$, and annual $L_{\text {replace }}$ are calculated, and the RIs are then obtained. All the results are listed in the Table 7.1. Financial loss from downtime and fatalities are included, same as Figure 7.3 and 7.4. 
Table 7.1 The Annual loss and corresponding RI

\begin{tabular}{llccl}
\hline Parameters & Annual total loss $(\$)$ & Annual $L_{\text {repair }}(\$)$ & Annual $L_{\text {replace }}(\$)$ & RI \\
\hline U3M & 40,000 & 30,200 & 9,800 & 0.76 \\
U3S & 43,300 & 31,900 & 11,400 & 0.74 \\
I3M & 10,800 & 9,400 & 1,400 & 0.87 \\
I3S & 12,500 & 9,900 & 2,600 & 0.79 \\
U6M & 67,000 & 50,300 & 16,800 & 0.75 \\
U6S & 74,500 & 53,700 & 20,800 & 0.72 \\
I6M & 19,300 & 13,700 & 5,600 & 0.71 \\
I6S & 22,700 & 14,600 & 8,100 & 0.64 \\
\hline
\end{tabular}

As can be observed from Table 7.1, the isolated buildings can greatly reduce the annual total loss, annual $L_{\text {repair }}$, and annual $L_{\text {replace }}$ compared with the un-retrofitted buildings. For annual total loss and annual $L_{\text {repair }}$, retrofit can reduce the loss by approximately $70 \%$ for the two buildings. For the annual $L_{\text {replace }}$, the loss mitigation due to retrofit is from $78 \%$ to $86 \%$ for the three-story building and from $61 \%$ to $66 \%$ for the six-story building, respectively. Therefore, the effect of isolation on loss mitigation is substantial, although the isolated three-story building performs better in reducing the annual $L_{\text {replace. }}$ Aftershocks are also found to have substantial contribution to all the losses. For the annual total loss, the increases due to aftershocks are around $10 \%$ for the un-retrofitted buildings and about $17 \%$ for the isolated buildings, respectively. For the annual $L_{\text {repair }}$, the increases for all the buildings are around $6 \%$. For the annual $L_{\text {replace }}$, the increase for the un-retrofitted three-story building is $16 \%$ and that for the un-retrofitted six-story building is $24 \%$. However, this increase becomes $82 \%$ and $43 \%$ for the isolated three-story and six-story buildings, respectively. This suggests that aftershocks cause additional loss to buildings mainly by increasing the probability of collapse or serious damages that are not repairable. Additionally, the difference in the results between the isolated and unretrofitted building indicates that the influence of aftershocks on the seismic loss may vary from building to building. In this study, the aftershocks' impact on the isolated buildings is more significant than that on the un-retrofitted buildings.

The RIs are more complicated. For the three-story building, the RIs of the isolated building are higher than the un-retrofitted building, implying the retrofit has increased the structural robustness. However, for the six-story building, the RIs of the isolated building are lower than the un-retrofitted one, which makes the retrofit for the six-story building a bad design. However, if one considers the significant loss reduction due to the retrofit, the design may be acceptable. Again, this indicates that the robustness itself is not sufficient for decision making of strategy evaluation. Nevertheless, for buildings with similar conditions in other aspects, the RI can be used for evaluation. For example, the 
isolated three-story and six-story building has similar effectiveness in loss mitigation, but since the RI of the three-story building is higher, one may consider the retrofit for the three-story is better designed compared with the retrofit for the six-story building. As shown in Table 7.1, aftershocks reduced the RIs for all the buildings, as also observed in most cases in Figure 7.4. However, it is not necessarily that aftershocks will always reduce the RI. If the additional loss on the $L_{\text {repair }}$ and $L_{\text {replace }}$ due to considering aftershocks is expressed as $\Delta L_{\text {repair }}$ and $\Delta L_{\text {replace }}$, respectively, the difference of RIs with and without consideration of aftershocks will be as shown in Eq. 7.4.

$$
\begin{aligned}
R I_{M S-A S}-R I_{\text {Mainshock }} & =\frac{L_{\text {repair }}+\Delta L_{\text {repair }}}{L_{\text {repair }}+\Delta L_{\text {repair }}+L_{\text {replace }}+\Delta L_{\text {replace }}}-\frac{L_{\text {repair }}}{L_{\text {repair }}+L_{\text {replace }}} \\
& =\frac{\Delta L_{\text {repair }} \cdot L_{\text {replace }}-\Delta L_{\text {replace }} \cdot L_{\text {repair }}}{\left(L_{\text {repair }}+\Delta L_{\text {repair }}+L_{\text {replace }}+\Delta L_{\text {replace }}\right)\left(L_{\text {repair }}+L_{\text {replace }}\right)}
\end{aligned}
$$

where the $R I_{M S-A S}$ and $R I_{\text {Mainshock }}$ are the RIs with and without consideration of aftershocks, respectively. It can be observed that whether aftershocks can increase or decrease the RI depends on the multiplication of the $L_{\text {replace }}$ due to mainshocks and the additional $L_{\text {repair }}$ due to the aftershocks as well as the multiplication of the $L_{\text {repair }}$ due to mainshocks and the additional $L_{\text {replace }}$ due to the aftershocks. Therefore, the observation that the aftershocks can reduce the RI is based on the study for the selected buildings, and may not be true for other buildings.

\subsection{Conclusions}

Seismic loss estimation and robustness assessment was performed on two non-ductile RC frame buildings that were also hypothetically retrofitted with base isolation. Aftershocks were considered for multiple seismic hazard levels. Based on the results, some conclusions are drawn as follows. It should be addressed that these conclusions are based on the study of the selected building, which may not be applicable for other building types. But the methods that were proposed herein for loss estimation and robustness assessment may be used for other buildings.

1. Results of probabilistic analysis shows that base isolation can effectively reduce the seismic loss at various intensity levels and the annual seismic loss, no matter whether aftershocks are considered. 
2. Aftershocks can significantly increase the seismic loss of buildings, either at a specific hazard level or at an annual expected hazard basis. The significance of the additional loss due to aftershocks may vary from building to building.

3. The financial loss from seismic consequences such as downtime and fatalities can be even greater than the repair/replacement cost, and thus should be included in loss estimation.

4. The RI that was used in this study may not provide adequate information for decision making or strategy evaluation by itself. But it can be used along with other decision variables, such as the absolute financial loss, to make better informed decisions. However, when other decision variables are comparable for different strategies, the $\mathrm{RI}$ is a good reference for decision making.

5. The influence of aftershocks on the RI is uncertain and may depend on the ground motions as well as the building. 


\section{Summary, Conclusions, and Future Work}

\subsection{Summary and Conclusions}

Using probabilistic methods and present mainshock-based PBEE methodologies, aftershocks were incorporated into the PBEE framework for seismic risk and performance assessment. Seismic performance of older RC frame buildings and those buildings after retrofit with base isolation were also examined. The work and contributions are briefly summarized as follows.

1. A methodology for simulating aftershock ground motions that can yield statistically similar results as the recorded aftershock ground motions was proposed and validated through a case study.

2. The probabilities of exceedance at a variety of damage states were calculated for unretrofitted and isolated non-ductile RC frame buildings with consideration of aftershock hazards.

3. Influential uncertain structural properties of base isolated $\mathrm{RC}$ frame buildings were identified using a sensitivity study.

4. A methodology for assessing the seismic direct loss (repair/replacement cost), downtime, and fatalities of buildings subjected to mainshock and aftershock hazards was developed based on current seismic performance assessment methodologies.

5. The seismic direct loss (repair/replacement cost), downtime, and fatalities of two non-ductile RC frame buildings subjected to 78 recorded MS-AS sequences were estimated.

6. The characteristics of MS-AS sequences that are potentially related to the ability to caused additional consequences for older RC frame buildings during aftershocks were determined through a statistical analysis.

7. The influences of uncertainties of post-quake decisions on the seismic performance of older RC frame buildings were compared with other traditional uncertain sources under the MS-AS situations.

8. Life cycle cost-benefit analysis was performed to evaluate the cost effectiveness of base isolation that was used for retrofitting non-ductile RC frame buildings in regions with high and low seismicity. 
9. Robustness assessment was performed for two non-ductile RC frame buildings before and after base isolation. Robustness indices were examined for a variety of seismic levels and for an annual basis.

Major conclusions and findings in this study are summarized as follows.

1. Aftershocks have the potential to cause more serious damage, higher seismic risk, additional consequences (loss, downtime, and fatalities) to non-ductile RC frame buildings. Considering only mainshocks in seismic risk and performance assessment may cause significant underestimation.

2. Base isolation can greatly reduce seismic risk and mitigate seismic loss to nonductile RC frame buildings, no matter whether aftershock hazard is considered.

3. The uncertainty in the base isolation system is basically less significant than the major uncertainties of the superstructure for a non-ductile RC frame building. And the uncertainties in post-quake decisions are generally less important in performance assessment than the major uncertainties of structural capacity and ground motions.

4. The intensity of an aftershock relative to that of the mainshock, and the number of aftershocks that occurs after repair may be related to the aftershocks' ability to cause additional loss to non-ductile RC frame buildings, while other characteristics of MSAS sequences such as the total number of aftershocks is not important.

5. The loss due to downtime and fatalities can be more substantial than the repair/replacement cost for non-ductile RC frame buildings, and thus should be considered in decision making.

6. The cost of adopting base isolation for a non-ductile RC frame building in a high seismicity zone can be outweighed by the relevant benefit after a reasonable time length. However, cost-effectiveness is difficult to achieve for base isolation of a nonductile RC frame building in a low seismicity zone.

7. Aftershock hazard does not necessarily increase or decrease the robustness of nonductile RC frame buildings, same for base isolation. The robustness index employed in this study alone cannot provide sufficient information for decision making, but it can be useful when combined with other information.

\subsection{Future work}


Although this study provides insights to the performance and risk of un-retrofitted and base isolated non-ductile RC frame buildings under mainshock and aftershock hazards, further investigations are suggested for future studies as follows.

1. The current study employed one or two non-ductile RC frame buildings (Chapter 5 used one, and other chapters used two), which may not be sufficient to represent such type of buildings with variety of heights and structural configuration. Therefore, a portfolio of non-ductile RC frame buildings should be modeled and examined in the future. The buildings studied herein were all office buildings. Buildings with other occupancy such as school buildings and public commercial buildings may have dissimilar seismic loss, downtime, and fatalities compared with office buildings should also be investigated.

2. For the specific studies on the non-ductile RC buildings, some necessary assumptions were made to perform assessment. These assumptions, such as the probabilistic distribution of epicenters, the condition that triggers evacuation, the financial loss due to downtime, etc., although were reasonable, they may not be accurate and can consequently impact the accuracy of the result. Therefore, further investigation can be carried out to check whether these assumptions are justified, and how to improve these assumptions.

3. Only non-ductile RC frame buildings were investigated in this study. Therefore the findings about influences from aftershocks may be only applicable for this type of buildings. In the future, studies should be performed on other building types, such as ductile RC frame buildings, steel frame buildings, wood buildings, and so on.

4. The aftershock ground motions employed in this study were mostly far-field ground motions, whereas there was a lack of insight in the influence of aftershock hazard with consideration of near-fault ground motions. How to consider near-fault aftershocks and the consequent impact is still unknown. Future effort can be made on this topic.

5. The current study only focused on seismic risk and assessment. However, an ounce of prevention is worth a pound of cure. Therefore, it may be more important to develop approaches to incorporate aftershock hazard in the design process, which can be a promising direction for future endeavors.

6. Only the base isolation was evaluated as a retrofit strategy in this study for the nonductile RC frame buildings, while investigations on other retrofit methods are missing. Consequently, although this study revealed many appealing advantages of 
using base isolation for retrofit, there is no answer to the question that whether base isolation is better than other retrofit methods, such as adding additional truss, carbon fiber wrapping, and column jacking. A comprehensive study should be performed in the future to find out the most favorable retrofit strategy by comparing the results using a variety of retrofit methods with the consideration of aftershock hazard. 


\section{Bibliography}

Abrahamson, N.A. \& Silva, W.J. (1996). Empirical ground motion models. Report prepared for Brookhaven National Laboratory, New York, NY.

Abrahamson, N. A., \& Silva, W. J. (1997). Empirical response spectral attenuation relations for shallow crustal earthquakes. Seismological Research Letters, 68(1), 94127.

Abrahamson, N. A., \& Silva, W. J. (2008). Summary of the Abrahamson and Silva NGA ground-motion relations. Earthquake Spectra, 24(1), 67-97.

Amadio, C., Fragiacomo, M., \& Rajgelj, S. (2003). The effects of repeated earthquake ground motions on the non-linear response of SDOF systems. Earthquake Engineering \& Structural Dynamics, 32(2), 291-308.

Ang, A. H. S., \& Tang, W. H. (2007). Probability Concepts in Engineering: Emphasis on Applications to Civil and Environmental Engineering (v. 1). Wiley.

Asano, Y., Saito, T., Ito, Y., Shiomi, K., Hirose, H., Matsumoto, T., ... \& Sekiguchi, S. (2011). Spatial distribution and focal mechanisms of aftershocks of the 2011 off the Pacific coast of Tohoku earthquake. Earth, Planets and Space, 63(7), 669-673.

ASCE. (2007). Seismic rehabilitation of existing buildings, ASCE-41. American Society of Civil Engineers, Reston, VA.

ASCE. (2010). Minimum design loads for buildings and other structures. ASCE/SEI 7-10, American Society of Civil Engineers, Reston, VA.

Aschheim, M., \& Black, E. (1999). Effects of prior earthquake damage on response of simple stiffness-degrading structures. Earthquake Spectra,15(1), 1-24.

Aslani H. \& Miranda E. (2005a). Probabilistic earthquake loss estimation and loss disaggregation in buildings, Report No. 157, The John A. Blume Earthquake Engineering Center, Stanford University, Stanford, CA.

Aslani, H., \& Miranda, E. (2005b). Probability-based seismic response analysis. Engineering Structures, 27(8), 1151-1163.

ATC. (2005). Field Manual: Postearthquake Safety Evaluation of Building. ATC-20-1, Redwood City, CA.

ATC. (2008). Reducing the risks of nonstructural earthquake damage- state-of-the-art and practice report. ATC-69, Redwood City, CA. 
Baker, J.W., Schubert, M. \& Faber, M.H.. (2008). On the assessment of robustness. Structural Safety, 30 (3), 253-267.

Båth, M. (1965). Lateral inhomogeneities of the upper mantle. Tectonophysics, 2(6), 483514.

Bjarnadottir, S., Li, Y. \& Stewart, M.G.. (2014). Risk-based economic assessment of mitigation strategies for power distribution poles subjected to hurricanes. Structure and Infrastructure Engineering, 10 (6), 740-752.

Boore, D. M., Joyner, W. B., \& Fumal, T. E. (1997). Equations for Estimating Horizontal Response Spectra and Peak Acceleration from Western North American Earthquakes: A Summary of Recent Work. Seismological Research Letters, 68(1), 128-153.

Campbell, K. W., \& Bozorgnia, Y. (2003). Updated near-source ground-motion (attenuation) relations for the horizontal and vertical components of peak ground acceleration and acceleration response spectra. Bulletin of the Seismological Society of America, 93(1), 314-331.

Cardone, D. \& Gesualdi, G.. (2013). Seismic rehabilitation of existing RC buildings with seismic isolation: A case study. Earthquake Spectra. doi: 10.1193/ 110612EQS323M

Cavaco, E.S., Casas, J.R., Neves, L.A. \& Huespe, A.E.. (2013). Robustness of corroded reinforced concrete structures-a structural performance approach. Structure and Infrastructure Engineering, 9 (1), 42-58.

Celik, O. C., \& Ellingwood, B. R. (2008). Modeling beam-column joints in fragility assessment of gravity load designed reinforced concrete frames. Journal of Earthquake Engineering, 12(3), 357-381.

Celik O. C., \& Ellingwood B.R. (2009). Seismic risk assessment of gravity load designed reinforced concrete frames subjected to Mid-America ground motions, Journal of Structural Engineering. 135 (4), 414-424

Celik, O. C., \& Ellingwood, B. R. (2010). Seismic fragilities for non-ductile reinforced concrete frames-Role of aleatoric and epistemic uncertainties. Structural Safety, 32(1), 1-12.

Center for Engineering Strong Motion Data (CESMD).

(2013) <http://www.strongmotioncenter.org/> (Apr. 24, 2013).

Choi, E., DesRoches, R., \& Nielson, B. (2004). Seismic fragility of typical bridges in moderate seismic zones. Engineering Structures. 26(2), 187-199. 
Coburm A., Spence R. \& Pomonis A. (1992). Factors determining human casualty levels in earthquakes: mortality prediction in building collapse, Proceedings of the tenth world conference on earthquake engineering, 10, 5989-5994.

Comerio M.C. (2006). Estimating downtime in loss modeling. Earthquake Spectra. $22,349-365$

Comerio M.C. \& Blecher H.E. (2010). Estimating downtime from data on residential buildings after the Northridge and Loma Prieta Earthquakes. Earthquake Spectra. 26,951-965.

Constantinou, M. C., Kalpakidis, I., Filiatrault, A., \& Lay, R. E. (2011). LRFD-based analysis and design procedures for bridge bearings and seismic isolators. MCEER11-0004. Multidisciplinary Center for Earthquake Engineering Research, Buffalo, NY.

Constantinou, M. C., Whittaker, A. S., Kalpakidis, Y., Fenz, D. M., \& Warn, G. P.. (2007) Performance of seismic isolation hardware under service and seismic loading. MCEER-07-0012, Multidisciplinary Center for Earthquake Engineering Research, Buffalo, NY.

Cornell, C. A., Jalayer, F., Hamburger, R. O., \& Foutch, D. A. (2002). Probabilistic basis for 2000 SAC Federal Emergency Management Agency steel moment frame guidelines. Journal of Structural Engineering, 128(4), 526-533.

De Luca, A., Mele, E., Molina, J., Verzeletti, G., \& Pinto, A. V. (2001). Base isolation for retrofitting historic buildings: Evaluation of seismic performance through experimental investigation. Earthquake Engineering \& Structural Dynamics. 30(8), $1125-1145$.

Durkin M.E. \& Thiel C.C. (1992). Improving measures to reduce earthquake casualties. Earthquake Spectra. 8, 95-113.

Elenas, A., \& Meskouris, K. (2001). Correlation study between seismic acceleration parameters and damage indices of structures. Engineering Structures, 23(6), 698704.

Ellingwood, B., MacGregor, J. G., Galambos, T. V., \& Cornell, C. (1982). A. Probability based load criteria: load factors and load combinations. Journal of the Structural Division, 108(5), 978-997.

Erduran, E., Dao, N. D., \& Ryan, K. L. (2011). Comparative response assessment of minimally compliant low-rise conventional and base-isolated steel frames. Earthquake Engineering \& Structural Dynamics, 40(10), 1123-1141.

FEMA. (1992). A benefit-cost model for the seismic rehabilitation of buildings. FEMA 227, Washington, D.C. 
FEMA. (2000a). Prestandard and commentary for the seismic rehabilitation of the buildings. FEMA 356, Washington, D.C.

FEMA. (2000b). Recommended seismic design criteria for new steel moment-frame buildings. FEMA 350, Washington, D.C.

FEMA. (2009a). Multi-hazard Loss Estimation Methodology. Earthquake Model, HAZUS-MH MR4 Technical Manual. Washington, D.C.

FEMA. (2009b). Quantification of building seismic performance factors. FEMA P695, Washington, D.C.

FEMA. (2012a) Next-generation methodology for seismic performance assessment of buildings. FEMA P-58, Washington, D.C.

FEMA. (2012b). Reducing the risks of nonstructural earthquake damage. FEMA E-74. < http://www.fema.gov/earthquake-publications/fema-e-74-reducing-risksnonstructural-earthquake-damage.> (Feb. 22, 2013).

Frangopol, D.M. \& Curley, J.P.. (1987). Effects of damage and redundancy on structural reliability. Journal of Structural Engineering, 113 (7), 1533-1549.

Gasparini, D. \& Vanmarcke, E. H. (1976). Simulated earthquake motions compatible with prescribed response spectra. Department of Civil Engineering Research Report R76-4, No. 527. Massachusetts Institute of Technology, Cambridge, MA.

Goda, K., Lee, C. \& Hong, H. (2010). Lifecycle cost-benefit analysis of isolated buildings. Structural Safety, 32 (1), 52-63.

Goda, K. (2012). Nonlinear Response Potential of Mainshock-Aftershock Sequences from Japanese Earthquakes. Bulletin of the Seismological Society of America, 102(5), 2139-2156.

Goulet, C. A., Haselton, C. B., Mitrani-Reiser, J., Beck, J. L., Deierlein, G. G., Porter, K. A., \& Stewart, J. P. (2007). Evaluation of the seismic performance of a codeconforming reinforced-concrete frame building-from seismic hazard to collapse safety and economic losses. Earthquake Engineering \& Structural Dynamics, 36(13), 1973-1997.

Han, R., Li, Y. \& van de Lindt, J., (2014a). Assessment of seismic performance of buildings with incorporation of aftershocks. Journal of Performance of Constructed Facilities. doi: 10.1061/(ASCE)CF.1943-5509.0000596 .

Han, R., Li, Y. \& van de Lindt, J., (2014b). Seismic risk of base isolated non-ductile reinforced concrete buildings considering uncertainties and mainshock-aftershock sequences. Structural Safety, 50, 39-56. 
Han, R., Li, Y., \& van de Lindt, J. (2015) Loss estimation of reinforced concrete buildings considering aftershock hazards. Structures Congress 2015: pp. 2174-2185. doi: $10.1061 / 9780784479117.188$

Hancock J., Watson-Lamprey J., Abrahamson N.A., Bommer J.J., Markatis A., McCoy E., \& Mendis R. (2006) An improved method of matching response spectra of recorded earthquake ground motion using wavelets. Journal of Earthquake Engineering. 10(spec01), 67-89.

Haselton CB, Baker JW, Liel AB, \& Deierlein GG. (2011). Accounting for groundmotion spectral shape characteristics in structural collapse assessment through an adjustment for epsilon. Journal of Structural Engineering. 137:332-44.

Haselton, C. B., Liel, A. B., Deierlein, G. G., Dean, B. S., \& Chou, J. H. (2010). Seismic collapse safety of reinforced concrete buildings. I: Assessment of ductile moment frames. Journal of Structural Engineering,137(4), 481-491.

Haselton, C. B., Whittaker, A. S., Hortacsu, A., Baker, J. W., Bray, J., \& Grant, D. N. (2012). Selecting and Scaling Earthquake Ground Motions for Performing Response-History Analyses. 15th World Conference on Earthquake Engineering, Lisbon, Portugal.

Hatzigeorgiou, G. D., \& Liolios, A. A. (2010). Nonlinear behaviour of RC frames under repeated strong ground motions. Soil Dynamics \& Earthquake Engineering, 30(10), 1010-1025.

Hauksson, E., Jones, L. M., \& Hutton, K. (1995). The 1994 Northridge earthquake sequence in California: Seismological and tectonic aspects. Journal of Geophysical Research: Solid Earth (1978-2012), 100(B7), 12335-12355.

Healey, J. J., Wu, S. T., \& Murga, M. (1980). Seismic Safety Margins Research Program (Phase I). Project IV. Structural building response; Structural Building Response Review. No. UCRL-15185. Ebasco Services, Inc., NY.

Helmstetter, A., \& Sornette, D. (2003). Båth's law derived from the Gutenberg-Richter law and from aftershock properties. Geophysical research letters, 30(20), 2069.

Huang, Y., Wu, J., Zhang, T., \& Zhang, D. (2008). Relocation of the M8. 0 Wenchuan earthquake and its aftershock sequence. Science in China Series D: Earth Sciences, 51(12), 1703-1711.

Huang, Y. N., Whittaker, A. S., \& Luco, N. (2008). Performance Assessment of Conventional and Base-Isolated Nuclear Power Plants for Earthquake and Blast Loadings. MCEER-08-0019, Multidisciplinary Center for Earthquake Engineering Research, Buffalo, NY. 
Izzuddin, B., Vlassis, A., Elghazouli, A. \& Nethercot, D.. (2008). Progressive collapse of multi-storey buildings due to sudden column loss-part I: Simplified assessment framework. Engineering Structures, 30 (5), 1308-1318.

Jeon, J. S., DesRoches, R., Brilakis, I., \& Lowes, L. N. (2012). Aftershock Fragility Curves for Damaged Non-Ductile Reinforced Concrete Buildings. 15th World Conference on Earthquake Engineering, Lisbon, Portugal.

Kao, H., \& Chen, W. P. (2000). The Chi-Chi earthquake sequence: Active, out-ofsequence thrust faulting in Taiwan. Science. 288(5475), 2346-2349.

Kamiyama, M. (1984). Effects of subsoil conditions and other factors on the duration of earthquake ground shaking. Proceedings of 8th World Conference on Earthquake Engineering, San Francisco, CA.

Karim, K. R., \& Yamazaki, F. (2007). Effect of isolation on fragility curves of highway bridges based on simplified approach. Soil Dynamics \& Earthquake Engineering, 27(5), 414-426.

Kempton, J. J., \& Stewart, J. P. (2006). Prediction equations for significant duration of earthquake ground motions considering site and near-source effects. Earthquake Spectra, 22(4), 985-1013.

Krawinkler, H. (2005) Van Nuys hotel building testbed report: exercising seismic performance assessment. PEER 2005/11, Pacific Earthquake Engineering Research Center, Berkeley, CA.

Kumitani, S., \& Takada, T. (2008). Probabilistic assessment of buildings damage considering aftershocks of earthquakes. 14th World Conference on Earthquake Engineering, Beijing, China.

Kwon, O.S. \& Elnashai, A. (2006). The effect of material and ground motion uncertainty on the seismic vulnerability curves of RC structure. Engineering Structures, 28 (2), $289-303$.

Lamprou A, Jia G, \& Taflanidis AA. (2013). Life-cycle seismic loss estimation and global sensitivity analysis based on stochastic ground motion modeling. Engineering Structures. 54:192-206.

Lee, K., \& Foutch, D. A. (2004). Performance evaluation of damaged steel frame buildings subjected to seismic loads. Journal of Structural Engineering, 130(4), 588-599.

Lew M., Naeim F., Huang S.C., Lam H.K. \& Carpenter L.D. (2000). Geotechnical and geological effects of the 21 September 1999 Chi-Chi earthquake, Taiwan. The Structural Design of Tall Buildings. 9, 89-106. 
Li, Q., \& Ellingwood, B. R. (2007). Performance evaluation and damage assessment of steel frame buildings under main shock-aftershock earthquake sequences. Earthquake Engineering \& Structural Dynamics,36(3), 405-427.

Li Y. (2010). Assessment of damage risks to residential buildings and cost-benefit of mitigation strategies considering hurricane and earthquake hazards. Journal of Performance of Constructed Facilities. 26, 7-16.

Li, Y., Song, R., \& van de Lindt, J.W. (2014). Collapse fragility of steel structures subjected to earthquake mainshock-aftershock sequences, Journal of Structural Engineering, 140(12), 04014095.

Liel, A. B., \& Deierlein, G. G. (2008). Assessing the collapse risk of California's existing reinforced concrete frame structures: Metrics for seismic safety decisions. Report No. 166, The John A. Blume Earthquake Engineering Center, Stanford University, Stanford, CA.

Liel, A. B., \& Deierlein, G. G. (2013). Cost-benefit evaluation of seismic risk mitigation alternatives for older concrete frame buildings. Earthquake Spectra, 29(4), 13911411.

Liel, A. B., Haselton, C. B., \& Deierlein, G. G. (2011). Seismic collapse safety of reinforced concrete buildings: II. Comparative assessment of non-ductile and ductile moment frames, Journal of Structural Engineering, 137(4), 492-502.

Lind, N.C., (1995). A measure of vulnerability and damage tolerance. Reliability Engineering \& System Safety, 48 (1), 1-6.

Luco, N., Gerstenberger, M. C., Uma, S. R., Ryu, H., Liel, A. B., \& Raghunandan, M. (2011). A methodology for post-mainshock probabilistic assessment of building collapse risk. Ninth Pacific Conference on Earthquake Engineering, Auckland, New Zealand.

Mahin, S. A. (1980). Effects of duration and aftershocks on inelastic design earthquakes. Proceedings of the seventh world conference on earthquake engineering, Istanbul, Turkey.

Mavroeidis G.P. \& Papageorgiou A.S. (2003). A mathematical representation of nearfault ground motions. Bulletin of the Seismological Society of America. 93:1099131.

Mazzoni S., McKenna F., Scott M.H. \& Fenves G.L. (2006). OpenSees command language manual, Pacific Earthquake Engineering Research (PEER) Center. Berkeley, CA. 
McKay, M. D., Beckman, R. J., \& Conover, W. J. (2000). A comparison of three methods for selecting values of input variables in the analysis of output from a computer code. Technometrics, 42(1), 55-61.

Mitrani-Reiser J. (2007). An ounce of prevention: probabilistic loss estimation for performance-based earthquake engineering. Ph.D. thesis, Department of Mechanical and Civil Engineering, California Institute of Technology. Pasadena, CA.

Mokha, A. S., Amin, N., Constantinou, M. C., \& Zayas, V. (1996). Seismic isolation retrofit of large historic building. Journal of Structural Engineering, 122(3), 298308.

Mrozek J.R. \& Taylor L.O. (2002). What determines the value of life? a meta-analysis. Journal of Policy analysis and Management. 21, 253-270.

Naeim F, \& Kelly J M. (1999) Design of Seismic Isolated Structures: from Theory to Practice. John Wiley and Sons Inc. New York.

Nazari N., van de Lindt J. \& Li Y. (2013). Effect of Mainshock-Aftershock Sequences on Woodframe Building Damage Fragilities, Journal of Performance of Constructed Facilities. doi: 10.1061/(ASCE)CF.1943-5509.0000512

Office of Management and Budget (OMB). (2003). Circular A-4. Washington, DC: United States Office of Management and Budget.

Pacific Earthquake Engineering Research Center (PEER) Ground Motion Database. (2014). <http://peer.berkeley.edu/peer_ground_motion_database>.(Mar. 12, 2014).

Padgett, J. E., \& DesRoches, R. (2007). Sensitivity of seismic response and fragility to parameter uncertainty. Journal of Structural Engineering. 133(12), 1710-1718.

Padgett, J.E., Nielson, B.G. \& Desroches, R.. (2008). Selection of optimal intensity measures in probabilistic seismic demand models of highway bridge portfolios. Earthquake Engineering \& Structural Dynamics, 37 (5), 711-725.

Pagni C.A. \& Lowes L.N. (2006). Fragility functions for older reinforced concrete beamcolumn joints. Earthquake Spectra. 22: 215-238.

Panagiotakos, T. B. \& Fardis, M. N. (2001) Deformations of reinforced concrete members at yielding and ultimate. ACI Structural Journal. 98(2): 135-148.

Park, R., Priestley, M. J. N., \& Gill, W. D. (1982). Ductility of square confined concrete columns. Journal of Structural Division. 108 (4): 929-950.

Park, S. \& Mosalam, K. M.. (2012). Experimental and analytical studies on reinforced concrete buildings with seismically vulnerable beam-column joints. PEER 2012/03, Pacific Earthquake Engineering Research Center, Berkeley, CA. 
Perotti, F., Domaneschi, M., \& De Grandis, S.. (2013). The numerical computation of seismic fragility of base-isolated Nuclear Power Plants buildings. Nuclear Engineering and Design, 262, 189-200.

Porter, K.A. (2007). Fragility of hydraulic elevators for use in performance-based earthquake engineering. Earthquake Spectra. 23: 459-69.

Porter, K. A., Beck, J. L., \& Shaikhutdinov, R. V. (2002). Sensitivity of building loss estimates to major uncertain variables. Earthquake Spectra, 18(4), 719-743.

Porter K.A. \& Kiremidjian A.S. (2001). Assembly-based vulnerability of buildings and its uses in seismic performance evaluation and risk management decision-making. TR 139, The John A. Blume Earthquake Engineering Center, Stanford University. Stanford, CA.

Porter K.A., Kiremidjian A.S. \& LeGrue J.S. (2001). Assembly-based vulnerability of buildings and its use in performance evaluation. Earthquake Spectra. 17: 291-312.

Power, M., Chiou, B., Abrahamson, N., Bozorgnia, Y., Shantz, T., \& Roblee, C. (2008). An overview of the NGA project. Earthquake Spectra, 24(1), 3-21.

Raghunandan, M., Liel, A. B., \& Luco, N. (2014). Aftershock collapse vulnerability assessment of reinforced concrete frame structures. Earthquake Engineering \& Structural Dynamics. 44 (3), 419-439.

Ramirez, C.M., Liel, A.B., Mitrani-Reiser, J., Haselton, C.B., Spear, A.D., Steiner, J., Deierlein, G.G. \& Miranda, E., (2012). Expected earthquake damage and repair costs in reinforced concrete frame buildings. Earthquake Engineering \& Structural Dynamics, 41 (11), 1455-1475.

Ramirez C.M. \& Miranda E. (2009). Building-specific loss estimation methods \& tools for simplified performance-based earthquake engineering. TR 171, The John A. Blume Earthquake Engineering Center, Stanford University. Stanford, CA.

Rathje, E. M., Abrahamson, N. A., \& Bray, J. D. (1998). Simplified frequency content estimates of earthquake ground motions. Journal of Geotechnical and Geoenvironmental Engineering, 124(2), 150-159.

Ribeiro, F.L., Barbosa, A.R. \& Neves, L.C.. (2014). Application of reliability-based robustness assessment of steel moment resisting frame structures under postmainshock cascading events. Journal of Structural Engineering, 140 (8).

Rojahn C. \& Sharpe R.L. (1985). Earthquake damage evaluation data for California, Applied Technology Council. Redwood City, CA.

Rosenblueth, E., \& Meli, R. (1996). The 1985 Mexico earthquake: Causes and effects in Mexico City. Concrete International (ACI). 8(5):23-34. 
Rosowsky, D.V.. (2002). Reliability-based seismic design of wood shear walls. Journal of Structural Engineering, 128 (11), 1439-1453.

RS Means. (2014). Means square foot costs. 35th Edition, RS Means Company, Inc., Kingston, $M A$.

Ruiz-García, J., \& Negrete-Manriquez, J. C. (2011). Evaluation of drift demands in existing steel frames under as-recorded far-field and near-fault mainshockaftershock seismic sequences. Engineering Structures, 33(2), 621-634.

Ryan, K. L., Kelly, J. M., \& Chopra, A. K. (2005). Nonlinear model for lead-rubber bearings including axial-load effects. Journal of engineering mechanics. 131(12), 1270-1278.

Ryan, K., Sayani, P., Dao, N., Abraik, E. \& Baez, Y., (2010). Comparative life cycle analysis of conventional and base-isolated theme buildingsed. 9th US National \& 10th Canadian Conference on Earthquake Engineering, Toronto, Canada.

Saatcioglu, M., \& Razvi, S. R. (1992). Strength and ductility of confined concrete. Journal of Structural Engineering. 118(6), 1590-1607.

Sayani, P.J.. (2009). Relative performance comparison and loss estimation of seismically isolated and fixed-based buildings using PBEE approach. Graduate Theses and Dissertations, 482. Utah State University.

Sayani, P. J., \& Ryan, K. L. (2009). Comparative evaluation of base-isolated and fixedbase buildings using a comprehensive response index. Journal of Structural Engineering, 135(6), 698-707.

Scott, M.H. \& G.L. Fenves. (2006). Plastic hinge integration methods for force-based beam-column elements, Journal of Structural Engineering. 132(2):244-252.

Shcherbakov, R., Turcotte, D. L., \& Rundle, J. B. (2004). A generalized Omori's law for earthquake aftershock decay. Geophysical research letters, 31(11).

Shoraka, M.B., Elwood, K., Yang, T. \& Liel, A.. (2014). Collapse assessment of nonductile, retrofitted and ductile reinforced concrete frames. ACI Special Publication, 297.

Smyrou, E., Tasiopoulou, P., Bal, I. E., Gazetas, G., \& Vintzileou, E. (2011). Structural and geotechnical aspects of the Christchurch (2011) and Darfield (2010) earthquakes in N. Zealand. 7th National Conference on Earthquake Engineering. Istanbul, Turkey.

Smyth, A. W., Altay, G., Deodatis, G., Erdik, M., Franco, G., Gulkan, P., Kunreuther, H., Lus, H., Mete, E., Seeber, N., \& Yuzugullu, O.. (2004). Probabilistic benefit-cost analysis for earthquake damage mitigation: Evaluating measures for apartment houses in Turkey. Earthquake Spectra, 20(1), 171-203. 
Starossek, U. \& Haberland, M., (2008). Measures of structural robustness-requirements and applicationsed. ASCE SEI 2008 Structures Congress, Vancouver, Canada.

Sunasaka, Y. \& Kiremidjian, A. (1993). A method for structural safety evaluation under mainshock-aftershock earthquake sequences. Report No. 105. The John A. Blume Earthquake Engineering Center, Stanford University. Stanford, CA.

Strong-motion seismograph networks (K-NET). (2014). <http://www. kyoshin.bosai.go.jp/>. (Mar. 19, 2014).

Taflanidis, A. A., \& Jia, G. (2011) A simulation-based framework for risk assessment and probabilistic sensitivity analysis of base-isolated structures. Earthquake Engineering \& Structural Dynamics. 40(14), 1629-1651.

Thompson, A. C., Whittaker, A. S., Fenves, G. L., \& Mahin, S. A. (2000) Property modification factors for elastomeric seismic isolation bearings. Proceedings of the 12th World Conference on Earthquake Engineering. Auckand, New Zealand.

Totten, S.. (2014). LA unveils new earthquake preparedness plan. 89.3 KPCC. http://www.scpr.org/news/2014/12/08/48547/la-unveils-new-earthquakepreparedness-plan (8 Dec. 2014)

U.S. Geological Survey (USGS). (2000). USGS Circular 1193: Implications for earthquake risk reduction in the United States from the Kocaeli, Turkey, earthquake of August 17, 1999.,

USGS, (2014). http://www.usgs.gov/ (Oct. 20, 2014).

Utsu, T. (1961). A statistical study on the occurrence of aftershocks. Geophysics Magazine. 30: 521-605.

Vamvatsikos, D., \& Cornell, C. A. (2002). Incremental dynamic analysis. Earthquake Engineering \& Structural Dynamics, 31(3), 491-514.

Vamvatsikos, D., \& Fragiadakis, M. (2010). Incremental dynamic analysis for estimating seismic performance sensitivity and uncertainty. Earthquake Engineering \& Structural Dynamics. 39(2), 141-163.

Whittaker, A. S., \& Soong, T. T. (2003). An overview of nonstructural components research at three US Earthquake Engineering Research Centers. ATC Seminar on Seismic Design, Performance, and Retrofit of Nonstructural Components in Critical Facilities. Redwood City, CA.

Xavier, F., Macorini, L. \& Izzuddin, B., 2014. Robustness of multistory buildings with masonry infill. Journal of Performance of Constructed Facilities. doi: 10.1061/(ASCE)CF.1943-5509.0000684 
Yang, T. Y., Konstantinidis, D., \& Kelly, J. M. (2010). The influence of isolator hysteresis on equipment performance in seismic isolated buildings. Earthquake Spectra. 26(1), 275-293.

Yeo, G. L. \& Cornell C. A (2003). Building-specific seismic fatality estimation methodology. Proceedings of Ninth International Conference on Applications of Statistics and Probability in Civil Engineering (ICASP9).

Yeo, G. L., \& Cornell, C. A. (2005) Stochastic characterization and decision bases under time-dependent aftershock risk in performance-based earthquake engineering. PEER 2005/13, Pacific Earthquake Engineering Research Center, Berkeley, CA.

Yeo, G. L., \& Cornell, C. A. (2009a). A probabilistic framework for quantification of aftershock ground - motion hazard in California: Methodology and parametric study. Earthquake Engineering \& Structural Dynamics, 38(1), 45-60.

Yeo, G. L., \& Cornell, C. A. (2009b). Building life-cycle cost analysis due to mainshock and aftershock occurrences. Structural Safety. 2009; 31:396-408.

Yin, Y. J., \& Li, Y. (2010). Seismic Collapse Risk of Light-Frame Wood Construction Considering Aleatoric and Epistemic Uncertainties, Structural Safety, 32(4), 250261.

Yin, Y. J., \& Li, Y. (2011). Loss Estimation of Light-Frame Wood Construction Subjected to Mainshock-Aftershock Sequences. Journal of Performance of Constructed Facilities, 25(6), 504-513.

Yun, S. Y., \& Foutch, D. A. (2000). Performance prediction and evaluation of low ductility steel moment frames for seismic loads. SAC Background Rep. No. $S A C / B D-00 / 26$, SAC Joint Venture, Richmond, CA.

Zhang, J., \& Huo, Y. (2009). Evaluating effectiveness and optimum design of isolation devices for highway bridges using the fragility function method. Engineering Structures, 31(8), 1648-1660.

Zhang, J., \& Shu, Z.. (2014). Optimal design of isolation devices for buildings using performance based methodology, https://nees.org/resources/12704.

Zuniga-Cuevas, O., \& Teran-Gilmore, A. (2013). Parametric study on acceleration-based design of low-rise base isolated systems. Engineering Structures. 53, 25-37. 


\section{Appendix A: Permission to Publish Chapter 2}

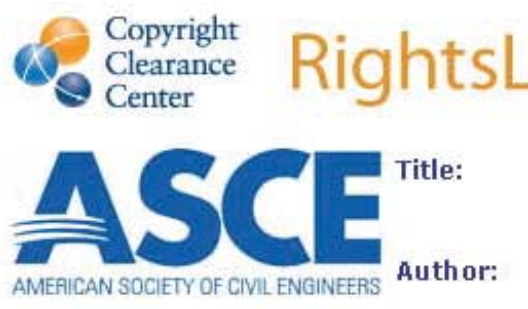

Assessment of Seisnic Performance of Buildings with Incorporation of Aftershocks

Publication: Journal of Performance of Constructed Facilities

Publisher: American Society of Civil Engineers

Date: 02/13/2014

Copyright 02014 , ASCE. All rights reserved.

Permissions Request

$A S$ an $A S C E$ author, you are permitted to reuse you own content for another $A S C E$ or non-ASCE publication.

Please add the full credit line "With permission from ASCE" to your source citation. Please print this page for your records.

Type of use: Dissertation/Thesis

Portion: full article

Form at: print and electronic

Use of this content will make up more than $25 \%$ of the new work: no

Author of this ASCE work or ASCE will publish the new work: yes

\section{BACK}

\section{CLOSE WINDOW}

Copyright (0) 2015 copvriaht Clearance Center. Inc. All Rights Reserved. Rrivacy statement. Ierms and Conditions.

Comments? We would like to hear from you. E-mail us at customercare@icopvright.com 



\section{Appendix B: Document showing that Figure 2.2 is in the public domain}

\section{I nformation Policies and I nstructions}

The USGS serves the Nation as an independent fact-finding agency that collects, monitors, analyzes, and provides scientific understanding about natural resource and natural hazard conditions, issues, and problems. The value of the USGS to the Nation rests on its ability to carry out studies on a national scale and to sustain long-term monitoring and assessment of natural resources and hazards. Because it has no regulatory or management mandate, the USGS provides impartial science that serves the needs of our changing world. It is the policy of the USGS to conduct its activities and to make the results of its scientific investigations available in a manner that will best serve the whole public, rather than the interest or benefit of any special group, corporation, or individual. The reputation of USGS science for excellence and objectivity is our most important asset. It brings authority to our data and findings and creates long-term credibility.

\subsubsection{Information Quality}

In Section 515(a) of the Treasury and General Government Appropriations Act for Fiscal Year 2001, Congress directed the Office of Management and Budget (OMB) to issue governmentwide guidelines that "provide policy and procedural guidance to Federal agencies for ensuring and maximizing the quality, objectivity, utility, and integrity of information (including statistical information) disseminated by Federal agencies."

The USGS guidelines and complaint process will apply to all information disseminated on or after October 1, 2002. Information disseminated prior to October 1, 2002, but not archived and still being used in a decisionmaking process is not exempt from these guidelines. Information records disseminated from studies completed and archived before October 1, 2002, are exempt from the guidelines.

Contact - If you have questions on USGS data and information accuracy, contact: 
USGS Information Quality Officer

Mail Stop 807

National Center

USGS

Reston, VA 20192

\subsubsection{Public Release of I nformation}

The USGS, as the science arm of the Department of the Interior and the earth and natural science agency for the Nation, has an ongoing obligation to keep the broadest spectrum of the public advised and engaged in its scientific research, investigations, and ongoing information releases. The USGS Home Page, its links to science information of the various programs and activities of the USGS, the resources of the USGS Newsroom, and the USGS search function all provide prompt and easy public access to the results of USGS scientific research and investigations.

Section 207 (f) (2) of the E-Government Act of 2002 requires Government agencies to develop an inventory of information to be published on their Web site. The purpose of Section 207 (f) (2) is to improve the methods by which Government information, including information on the Internet, is organized, preserved, and made accessible to the public. More information on this requirement can be found on the National Archives and Records Administration Web site at http://www.archives.gov/about_us/basic_laws_and_authorities/ego v_act_section_207.html.

Policy on Release of I nformation - As an integral part of its mission, the USGS has a continuing responsibility to keep the public informed of its various programs, activities, and research. It is the policy of the USGS to conduct its activities and to make the results of its scientific investigations available in a manner that will best serve the whole public, rather than the interest or benefit of any special group, corporation, or individual. The Internet affords the USGS a mechanism to achieve that broad distribution, impartially and simultaneously, in accordance with its mission and information dissemination policy.

Schedule and Priorities for Release of I nformation - The diversity of scientific expertise enables the USGS to carry out large-scale, multidisciplinary investigations that build the base of knowledge about the Earth. In turn, decisionmakers at all levels of government-and 
citizens in all walks of life-have the information tools they need to address pressing societal issues. As such, there is no set schedule on which the USGS releases its information; rather, the readiness of the science for release determines the schedule. Priority of release is consistent with the Department of the Interior Schedule of Content.

News releases are issued and information is posted on the USGS Home Page whenever a significant earthquake or other natural disaster occurs, a major personnel appointment is announced, budget information is available, or a science program has results to announce.

The USGS is a scientific publisher and regularly and routinely presents the results of its scientific research and investigations in printed and/or online format in publication series. Bibliographic citations and information on accessing and obtaining USGS information products are available in the USGS Publications Warehouse.

Contact - If you have questions concerning release of USGS information, contact the USGS Web.

\subsubsection{Copyrights and Credits}

USGS-authored or produced data and information are considered to be in the U.S. public domain. While the content of most USGS Web pages is in the U.S. public domain, not all information, illustrations, or photographs on our site are. Some non USGS photographs, images, and/or graphics that appear on USGS Web sites are used by the USGS with permission from the copyright holder. These materials are generally marked as being copyrighted. To use these copyrighted materials, you must obtain permission from the copyright holder under the copyright law.

When using information from USGS information products, publications, or Web sites, we ask that proper credit be given. Credit can be provided by including a citation such as the following:

Credit: U.S. Geological Survey

Department of the Interior/USGS

U.S. Geological Survey/photo by Jane Doe (if the photographer/artist is known)

Additional information on Acknowledging or Crediting USGS as Information Source is available. 
Policy - For relevant USGS policy on copyrights and trademarks, refer to the Survey Manual chapter entitled, "Use of Copyrighted Material in USGS I nformation Products."

Contact - If you have questions concerning the use of USGS information, contact the USGS Web.

\subsubsection{USGS Visual I dentity System}

To reinforce visually who we are and what we do, the USGS uses a visual identity system that provides planning and design solutions for USGS information products. A key component of the visual identity system is the USGS identifier. This identifier is trademarked and must be used in accordance with the rules outlined at Visual I dentity System. Information on who may use the USGS identifier and how to obtain a copy of it is available at Use of the Trademarked USGS Identifier by Non-USGS Organizations.

Policy - For relevant USGS policy on the Visual Identity System, refer to the Survey Manual chapter entitled, "USGS Visual I dentity System."

Contact - If you have questions on the USGS Visual I dentity System, contact the USGS Visual I dentity System Help Desk.

\subsubsection{Liability}

Neither the U.S. Government, the Department of the Interior, nor the USGS, nor any of their employees, contractors, or subcontractors, make any warranty, express or implied, nor assume any legal liability or responsibility for the accuracy, completeness, or usefulness of any information, apparatus, product, or process disclosed, nor represent that its use would not infringe on privately owned rights.

Links to non-USGS sites - Links and pointers to non-USGS sites are provided for information only and do not constitute endorsement by the USGS, U.S. Department of the Interior, or U.S. Government, of the referenced organizations, their suitability, content, products, or services, whether they are governmental, educational, or commercial. Some of the documents on this server may contain live references (or pointers) to information created and maintained by other organizations. Please note that the USGS does not control and cannot guarantee the relevance, timeliness, or accuracy of these outside materials. 


\section{Non-endorsement of non-USGS products and services -}

Hypertext links and other references to non-USGS products and services are provided for information only and do not constitute endorsement or warranty by the USGS, U.S. Department of the Interior, or U.S. Government, as to their suitability, content, usefulness, functioning, completeness, or accuracy.

Public domain software - Links are provided to public-domain software developed by or for the USGS. Although these programs have been used by the USGS, no warranty is made by the USGS as to the accuracy and functioning of the programs and related program material. Distribution of these materials also does not constitute any warranty, and no responsibility is assumed by the USGS in connection with any distribution activity.

Contact - If you have general questions about USGS Web sites, contact the USGS Web. 



\title{
Appendix C: Permission to Publish Chapter 5
}

\author{
ELSEVIER LI CENSE \\ TERMS AND CONDITIONS
}

May 14, 2015

This is a License Agreement between Ruilong Han ("You") and Elsevier ("Elsevier") provided by Copyright Clearance Center ("CCC"). The license consists of your order details, the terms and conditions provided by Elsevier, and the payment terms and conditions.

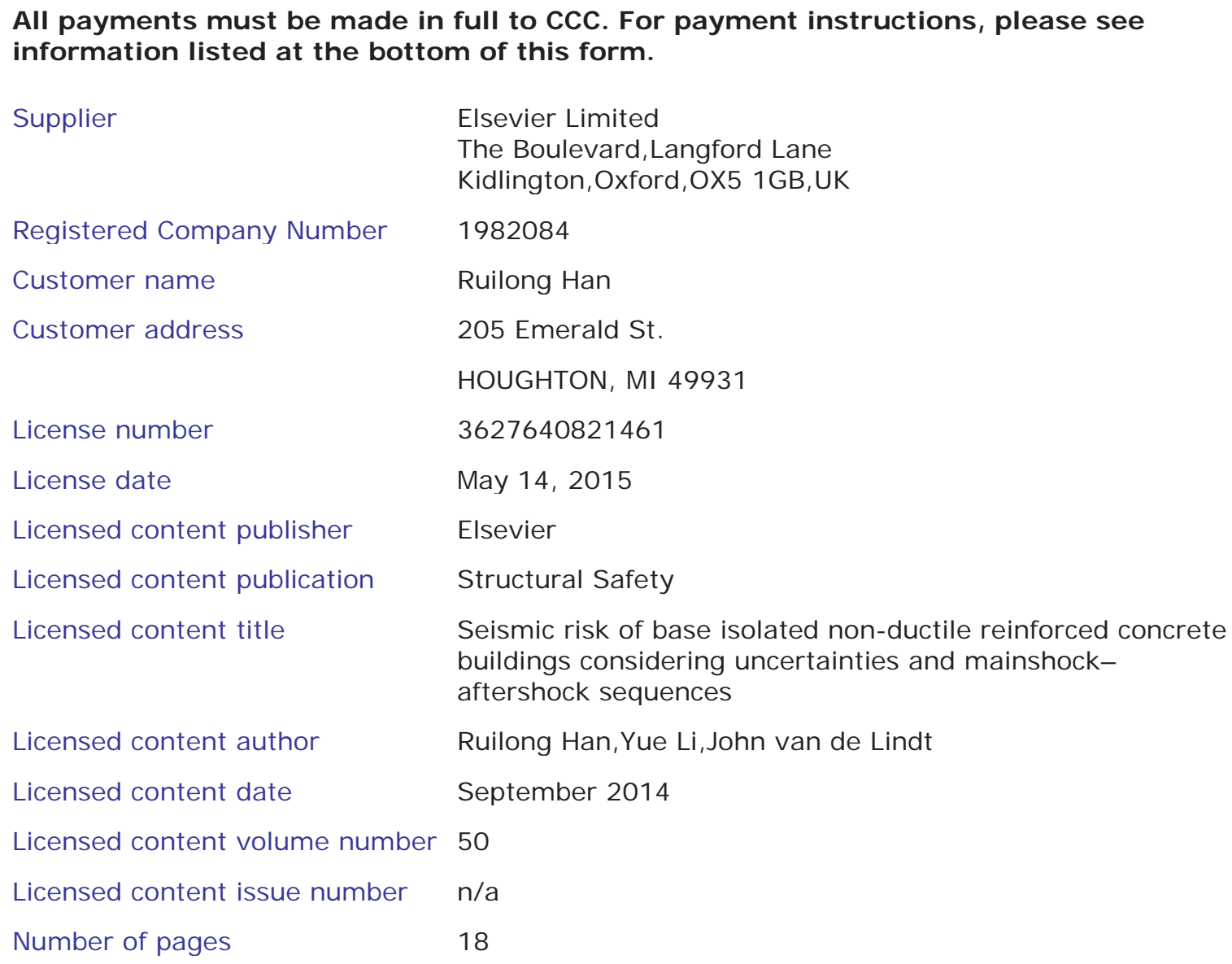

Supplier

Registered Company Number

Customer name

Customer address

License number

License date

Licensed content publisher

Licensed content publication

Licensed content title

Licensed content author

Licensed content date

Licensed content volume number

Licensed content issue number

Number of pages

Elsevier Limited

The Boulevard, Langford Lane

Kidlington, Oxford, OX5 1GB, UK

1982084

Ruilong Han

205 Emerald St.

HOUGHTON, MI 49931

3627640821461

May 14, 2015

Elsevier

Structural Safety

Seismic risk of base isolated non-ductile reinforced concrete buildings considering uncertainties and mainshockaftershock sequences

Ruilong Han,Yue Li,J ohn van de Lindt

September 2014

50

$\mathrm{n} / \mathrm{a}$

18 
Start Page

End Page

Type of Use

Portion

Format

Are you the author of this

Elsevier article?

Will you be translating?

Title of your thesis/dissertation

Expected completion date

Estimated size (number of pages)

Elsevier VAT number

Permissions price

VAT/Local Sales Tax

Total

Terms and Conditions
39

56

reuse in a thesis/dissertation

full article

both print and electronic

Yes

No

PERFORMANCE-BASED ENGINEERING FOR EVALUATION AND RETROFITTING OLDER REINFORCED CONCRETE BUILDINGS INCORPORATING AFTERSHOCK HAZARD

J un 2015

GB 494627212

0.00 USD

0.00 USD / 0.00 GBP

0.00 USD

\section{INTRODUCTION}

1. The publisher for this copyrighted material is Elsevier. By clicking "accept" in connection with completing this licensing transaction, you agree that the following terms and conditions apply to this transaction (along with the Billing and Payment terms and conditions established by Copyright Clearance Center, Inc. ("CCC"), at the time that you opened your Rightslink account and that are available at any time athttp://myaccount. copyright. com).

\section{GENERAL TERMS}

2. Elsevier hereby grants you permission to reproduce the aforementioned material subject to the terms and conditions indicated.

3. Acknowledgement: If any part of the material to be used (for example, figures) has appeared in our publication with credit or acknowledgement to another source, permission must also be sought from that source. If such permission is not obtained then that material may not be included in your publication/copies. Suitable acknowledgement to the source must be made, either as a footnote or in a reference list at the end of your 
publication, as follows:

"Reprinted from Publication title, Vol /edition number, Author(s), Title of article / title of chapter, Pages No., Copyright (Year), with permission from Elsevier [OR APPLICABLE SOCIETY COPYRIGHT OWNER]." Also Lancet special credit - "Reprinted from The Lancet, Vol. number, Author(s), Title of article, Pages No., Copyright (Year), with permission from Elsevier."

4. Reproduction of this material is confined to the purpose and/or media for which permission is hereby given.

5. Altering/Modifying Material: Not Permitted. However figures and illustrations may be altered/adapted minimally to serve your work. Any other abbreviations, additions, deletions and/or any other alterations shall be made only with prior written authorization of Elsevier Ltd. (Please contact Elsevier at permissions@elsevier.com)

6. If the permission fee for the requested use of our material is waived in this instance, please be advised that your future requests for Elsevier materials may attract a fee.

7. Reservation of Rights: Publisher reserves all rights not specifically granted in the combination of (i) the license details provided by you and accepted in the course of this licensing transaction, (ii) these terms and conditions and (iii) CCC's Billing and Payment terms and conditions.

8. License Contingent Upon Payment: While you may exercise the rights licensed immediately upon issuance of the license at the end of the licensing process for the transaction, provided that you have disclosed complete and accurate details of your proposed use, no license is finally effective unless and until full payment is received from you (either by publisher or by CCC) as provided in CCC' s Billing and Payment terms and conditions. If full payment is not received on a timely basis, then any license preliminarily granted shall be deemed automatically revoked and shall be void as if never granted. Further, in the event that you breach any of these terms and conditions or any of CCC's Billing and Payment terms and conditions, the license is automatically revoked and shall be void as if never granted. Use of 
materials as described in a revoked license, as well as any use of the materials beyond the scope of an unrevoked license, may constitute copyright infringement and publisher reserves the right to take any and all action to protect its copyright in the materials.

9. Warranties: Publisher makes no representations or warranties with respect to the licensed material.

10. Indemnity: You hereby indemnify and agree to hold harmless publisher and $\mathrm{CCC}$, and their respective officers, directors, employees and agents, from and against any and all claims arising out of your use of the licensed material other than as specifically authorized pursuant to this license.

11. No Transfer of License: This license is personal to you and may not be sublicensed, assigned, or transferred by you to any other person without publisher's written permission.

12. No Amendment Except in Writing: This license may not be amended except in a writing signed by both parties (or, in the case of publisher, by CCC on publisher's behalf).

13. Objection to Contrary Terms: Publisher hereby objects to any terms contained in any purchase order, acknowledgment, check endorsement or other writing prepared by you, which terms are inconsistent with these terms and conditions or CCC's Billing and Payment terms and conditions. These terms and conditions, together with CCC's Billing and Payment terms and conditions (which are incorporated herein), comprise the entire agreement between you and publisher (and CCC) concerning this licensing transaction. In the event of any conflict between your obligations established by these terms and conditions and those established by CCC's Billing and Payment terms and conditions, these terms and conditions shall control.

14. Revocation: Elsevier or Copyright Clearance Center may deny the permissions described in this License at their sole discretion, for any reason or no reason, with a full refund payable to you. Notice of such denial will be made using the contact information provided by you. Failure to receive such notice will not alter or invalidate the denial. In no event will Elsevier or Copyright Clearance Center be 
responsible or liable for any costs, expenses or damage incurred by you as a result of a denial of your permission request, other than a refund of the amount(s) paid by you to Elsevier and/or Copyright Clearance Center for denied permissions.

\section{LIMITED LICENSE}

The following terms and conditions apply only to specific license types:

15. Translation: This permission is granted for non-exclusive worldEnglish rights only unless your license was granted for translation rights. If you licensed translation rights you may only translate this content into the languages you requested. A professional translator must perform all translations and reproduce the content word for word preserving the integrity of the article. If this license is to re-use 1 or 2 figures then permission is granted for non-exclusive world rights in all languages.

16. Posting licensed content on any Website: The following terms and conditions apply as follows: Licensing material from an Elsevier journal: All content posted to the web site must maintain the copyright information line on the bottom of each image; A hyper-text must be included to the Homepage of the journal from which you are licensing athttp://www. sciencedirect.com/science/journal/xxxxx or the Elsevier homepage for books at http://www. elsevier.com; Central Storage: This license does not include permission for a scanned version of the material to be stored in a central repository such as that provided by Heron/XanEdu.

Licensing material from an Elsevier book: A hyper-text link must be included to the Elsevier homepage at http://www. elsevier.com . All content posted to the web site must maintain the copyright information line on the bottom of each image.

Posting licensed content on Electronic reserve: In addition to the above the following clauses are applicable: The web site must be passwordprotected and made available only to bona fide students registered on a relevant course. This permission is granted for 1 year only. You may obtain a new license for future website posting. 
17. For journal authors: the following clauses are applicable in addition to the above:

\section{Preprints :}

A preprint is an author's own write-up of research results and analysis, it has not been peer-reviewed, nor has it had any other value added to it by a publisher (such as formatting, copyright, technical enhancement etc.).

Authors can share their preprints anywhere at any time. Preprints should not be added to or enhanced in any way in order to appear more like, or to substitute for, the final versions of articles however authors can update their preprints on arXiv or RePEc with their Accepted Author Manuscript (see below).

If accepted for publication, we encourage authors to link from the preprint to their formal publication via its D0I. Millions of researchers have access to the formal publications on ScienceDirect, and so links will help users to find, access, cite and use the best available version. Please note that Cell Press, The Lancet and some society-owned have different preprint policies. Information on these policies is available on the journal homepage.

Accepted Author Manuscripts: An accepted author manuscript is the manuscript of an article that has been accepted for publication and which typically includes author-incorporated changes suggested during submission, peer review and editor-author communications.

Authors can share their accepted author manuscript:

- $\quad$ immediately

- via their non-commercial person homepage or blog

- by updating a preprint in arXiv or RePEc with the accepted manuscript

- via their research institute or institutional repository for internal institutional uses or as part of an invitation-only research collaboration workgroup

- directly by providing copies to their students or to research collaborators for their personal use 
- for private scholarly sharing as part of an invitation-only work group on commercial sites with which Elsevier has an agreement

- - after the embargo period

- via non-commercial hosting platforms such as their institutional repository

- via commercial sites with which Elsevier has an agreement

In all cases accepted manuscripts should:

- - link to the formal publication via its DOI

- - bear a CC-BY-NC-ND license - this is easy to do

- - if aggregated with other manuscripts, for example in a repository or other site, be shared in alignment with our hosting policy not be added to or enhanced in any way to appear more like, or to substitute for, the published journal article.

Published journal article (JPA): A published journal article (PJA) is the definitive final record of published research that appears or will appear in the journal and embodies all value-adding publishing activities including peer review co-ordination, copy-editing, formatting, (if relevant) pagination and online enrichment.

Policies for sharing publishing journal articles differ for subscription and gold open access articles:

Subscription Articles: If you are an author, please share a link to your article rather than the full-text. Millions of researchers have access to the formal publications on ScienceDirect, and so links will help your users to find, access, cite, and use the best available version.

Theses and dissertations which contain embedded PJAs as part of the formal submission can be posted publicly by the awarding institution with DOI links back to the formal publications on ScienceDirect.

If you are affiliated with a library that subscribes to ScienceDirect you have additional private sharing rights for others' research accessed under that agreement. This includes use for classroom teaching and internal training at the institution (including use in course packs and 
courseware programs), and inclusion of the article for grant funding purposes.

Gold Open Access Articles: May be shared according to the authorselected end-user license and should contain a CrossMark logo, the end user license, and a DOI link to the formal publication on ScienceDirect.

Please refer to Elsevier's posting policy for further information.

18. For book authors the following clauses are applicable in addition to the above: Authors are permitted to place a brief summary of their work online only. You are not allowed to download and post the published electronic version of your chapter, nor may you scan the printed edition to create an electronic version. Posting to a repository: Authors are permitted to post a summary of their chapter only in their institution's repository.

19. Thesis/Dissertation: If your license is for use in a thesis/dissertation your thesis may be submitted to your institution in either print or electronic form. Should your thesis be published commercially, please reapply for permission. These requirements include permission for the Library and Archives of Canada to supply single copies, on demand, of the complete thesis and include permission for Proquest/UMI to supply single copies, on demand, of the complete thesis. Should your thesis be published commercially, please reapply for permission. Theses and dissertations which contain embedded PJAs as part of the formal submission can be posted publicly by the awarding institution with DOI links back to the formal publications on ScienceDirect.

\section{Elsevier 0pen Access Terms and Conditions}

You can publish open access with Elsevier in hundreds of open access journals or in nearly 2000 established subscription journals that support open access publishing. Permitted third party re-use of these open access articles is defined by the author's choice of Creative Commons user license. See our open access license policy for more information. 


\section{Terms \& Conditions applicable to all Open Access articles published with Elsevier:}

Any reuse of the article must not represent the author as endorsing the adaptation of the article nor should the article be modified in such a way as to damage the author's honour or reputation. If any changes have been made, such changes must be clearly indicated.

The author(s) must be appropriately credited and we ask that you include the end user license and a DOI link to the formal publication on ScienceDirect.

If any part of the material to be used (for example, figures) has appeared in our publication with credit or acknowledgement to another source it is the responsibility of the user to ensure their reuse complies with the terms and conditions determined by the rights holder.

\section{Additional Terms \& Conditions applicable to each Creative Commons user license:}

CC BY: The CC-BY license allows users to copy, to create extracts, abstracts and new works from the Article, to alter and revise the Article and to make commercial use of the Article (including reuse and/or resale of the Article by commercial entities), provided the user gives appropriate credit (with a link to the formal publication through the relevant D0I), provides a link to the license, indicates if changes were made and the licensor is not represented as endorsing the use made of the work. The full details of the license are available athttp://creativecommons. org/licenses/by/4. 0.

CC BY NC SA: The CC BY-NC-SA license allows users to copy, to create extracts, abstracts and new works from the Article, to alter and revise the Article, provided this is not done for commercial purposes, and that the user gives appropriate credit (with a link to the formal publication through the relevant DOI), provides a link to the license, indicates if changes were made and the licensor is not represented as endorsing the use made of the work. Further, any new works must be made available on the same conditions. The full details of the license are available athttp://creativecommons. org/licenses/by-nc-sa/4. 0 .

CC BY NC ND: The CC BY-NC-ND license allows users to copy and 
distribute the Article, provided this is not done for commercial purposes and further does not permit distribution of the Article if it is changed or edited in any way, and provided the user gives appropriate credit (with a link to the formal publication through the relevant D0I), provides a link to the license, and that the licensor is not represented as endorsing the use made of the work. The full details of the license are available athttp://creativecommons.org/licenses/by-nc-nd/4. 0. Any commercial reuse of Open Access articles published with a CC BY NC SA or CC BY NC ND license requires permission from Elsevier and will be subject to a fee.

Commercial reuse includes:

- - Associating advertising with the full text of the Article

- - Charging fees for document delivery or access

- - Article aggregation

- - Systematic distribution via e-mail lists or share buttons

Posting or linking by commercial companies for use by customers of those companies.

20. 0ther Conditions:

v1. 7

Questions? customercare@copyright.com or +1-855-239-3415 (toll free in the US) or +1-978-646-2777.

Gratis licenses (referencing $\$ 0$ in the Total field) are free. Please retain this printable license for your reference. No payment is required. 